\title{
Modeling the processes affecting larval haddock (Melanogrammus aeglefinus) survival on Georges Bank
}

\author{
by \\ Colleen Mary Petrik \\ B.S., Marine Science and Biology \\ University of Miami, 2005 \\ Submitted in partial fulfillment of the requirements for the degree of \\ Doctor of Philosophy in Biological Oceanography \\ at the \\ MASSACHUSETTS INSTITUTE OF TECHNOLOGY \\ and the \\ WOODS HOLE OCEANOGRAPHIC INSTITUTION
}

February 2011

(C) 2011 Colleen Mary Petrik. All rights reserved.

The author hereby grants to MIT and WHOI permission to reproduce and to distribute publicly paper and electronic copies of this thesis document in whole or in part in any medium now known or hereafter created.

Signature of Author

Joint Program in Oceanography/Applied Ocean Science and Engineering Massachusetts Institute of Technology and Woods Hole Oceanographic Institution

17 December 2010

Certified by

Cabell S. Davis

Thesis Supervisor

Accepted by

Simon Thorrold

Chair, Joint Committee for Biological Oceanography

Massachusetts Institute of Technology and Woods Hole Oceanographic Institution 


\title{
Modeling the processes affecting larval haddock (Melanogrammus aeglefinus) survival on Georges Bank
}

\author{
by \\ Colleen Mary Petrik \\ Submitted to the Department of Biology on 17 December 2010, \\ in Partial Fulfillment of the Requirements for the Degree of \\ Doctor of Philosophy in Biological Oceanography
}

\begin{abstract}
The ultimate goal of early life studies of fish over the past century has been to better understand recruitment variability. Recruitment is the single most important natural event controlling year-class strength and biomass in fish populations. As evident in Georges Bank haddock, Melanogrammus aeglefinus, there is a strong relationship between recruitment success and processes occurring during the planktonic larval stage. Spatially explicit coupled biological-physical individual-based models are ideal for studying the processes of feeding, growth, and predation during the larval stage. This thesis sought new insights into the mechanisms controlling the recruitment process in fish populations by using recent advances in biological-physical modeling methods together with laboratory and field data sets. Interactions between feeding, metabolism and growth, vertical behavior, advection, predation, and the oceanic environment of larval haddock were quantitatively investigated using individual-based models. A mechanistic feeding model illustrated that species-specific behavioral characteristics of copepod prey are critically important in determining food availability to the haddock larvae. Experiments conducted with a one-dimensional vertical behavior model suggested that larval haddock should focus on avoiding visual predation when they are small and vulnerable and food is readily available. Coupled hydrodynamics, concentration-based copepod species, and individual-based larval haddock models demonstrated that the increased egg hatching rates and lower predation rates on larvae in 1998 contributed to its larger year-class. Additionally, results from these coupled models imply that losses to predation may be responsible for interannual variability in recruitment and larval survival. The findings of this thesis can be used to better manage the haddock population on Georges Bank by providing insights into how changes in the physical and biological environment of haddock affect their survival and recruitment, and more generally about the processes significant for larval fish survival.
\end{abstract}

Thesis supervisor: Cabell S. Davis

Title: Senior Scientist, WHOI 


\section{Acknowledgements}

First and foremost, I thank Cabell Davis for being an insightful, encouraging, fun, and flexible thesis advisor. He presented me with many great opportunities, such as visiting the Liquid Jungle Lab in Panama, participating in two research cruises in the Caribbean, and presenting my work at multiple conferences in Europe. Cabell also allowed me the freedom to choose my own research topics and work remotely at times. His unwavering enthusiasm and genuine curiosity renewed my interest in oceanography whenever I was discouraged with my research and continues to motivate me.

I would like to extend appreciation to my other thesis committee members. Rubao Ji and all his lab members were so patient and helpful while I learned Linux, FORTRAN, and FVCOM. I have little experience with the live versions of the organisms I study, and I thank Greg Lough for supplying this knowledge of haddock and cod. I thank Andy Solow for his statistical assistance and Glenn Flierl for physical and mathematical considerations, and both of them for helping me see the big picture.

Furthermore, I have benefitted from the work of and interactions with many colleagues. Trond Kristiansen supplied me with a larval fish model and numerous potential research questions to answer with it. I have the utmost respect for David Mountain, Larry Buckley, Betsy Broughton, and everyone involved in the collection and analysis of GLOBEC data, if not for all the information it has provided, then simply because I did not have to venture out onto Georges Bank in the winter. I am grateful for my involvement with the ICES Working Group on Physical Biological Interactions. This group involved me in their workshops and meetings, gave me a venue to present my work and a place to submit it for publication, offered advice on research, introduced me to potential collaborators, and inspired me to produce science as admirable as theirs.

I was fortunate to start the MIT-WHOI Joint Program with a great cohort of Biology students, Kelton McMahon, Christine Mingione Thompson, Louie Wurch, and Whitney Krey, who have been there for academic concerns and social entertainment. Many other friends at WHOI and MIT kept me sane, including Paul Craddock, Taylor Crockford, Jimmy Elsenbeck, Matt Mazloff, Caleb Mills, Melissa Patrician, and Meredith White. I appreciate my family and David Fortunato for their love and support, even if they did not always understand what I was studying. My mom's advice and sentiments were always uplifting, while David gave me the confidence to reach this goal.

Last but not least, I am thankful for the Academic Programs Office, who have helped me in a number of ways. They make the graduate experience bearable, if not pleasant, and I attribute much of the success of the Joint Program to them.

Financial support was provided by a WHOI Watson Fellowship, a WHOI Coastal Ocean Institute Student Research Proposal Award, and GLOBEC grants NA17RJ1223 (NOAA) and OCE0815838 (NSF). 


\section{Contents}

1. Fisheries recruitment variability: a case study using larval haddock on Georges Bank 11

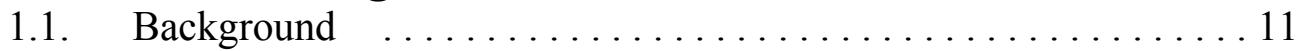

1.1.1. Recruitment variability $\quad \ldots \ldots \ldots \ldots \ldots \ldots \ldots 11$

1.1.2. Haddock ............................ 14

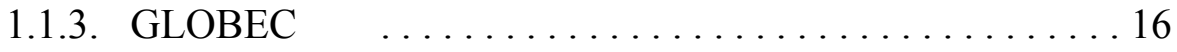

1.1.4. Georges Bank ......................... 17

1.1.5. Individual-based modeling $\ldots \ldots \ldots \ldots \ldots \ldots \ldots 21$

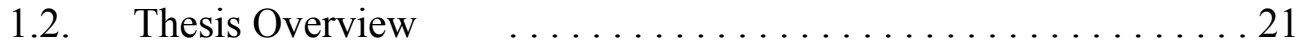

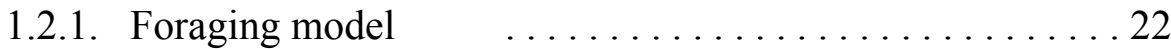

1.2.2. Vertical behavior model $\quad \ldots \ldots \ldots \ldots \ldots \ldots 23$

1.2.3. Three-dimensional coupled biological-physical model 25

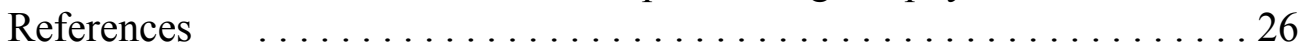

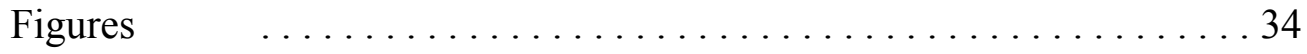

2. Prey selection by larval haddock and cod on copepods with species-specific behavior: an individual-based model analysis

3. Modeling the vertical behavior of larval haddock on Georges Bank with respect to starvation and predation mortality 61

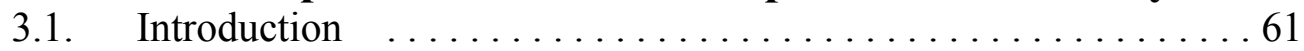

3.2. Model ............................... 64

3.2.1. Environment .......................664

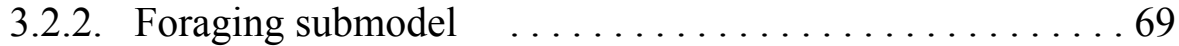

3.2.3. Bioenergetics submodel $\quad \ldots \ldots \ldots \ldots \ldots \ldots \ldots 70$

3.2.4. Vertical behavior models $\quad \ldots \ldots \ldots \ldots \ldots \ldots \ldots 70$

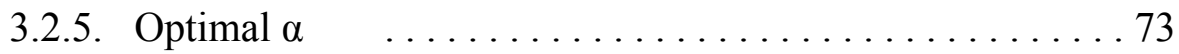

3.2.6. Fitness .............................. 75

3.2.7. Simulations ..........................76

3.3. Results................................ 76

3.3.1. Case A - Diffusion $\ldots . \ldots \ldots \ldots \ldots \ldots . \ldots 76$

3.3.2. Case $\mathrm{B}-$ Prey concentration and light with random direction $\quad$. . . . . . . . . . . . . . . . 77

3.3.3. Case $\mathrm{C}-$ Prey concentration and light with directed

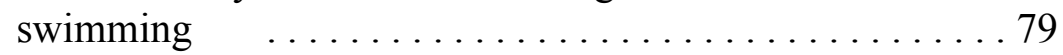

3.3.4. All cases $\ldots \ldots \ldots \ldots \ldots \ldots \ldots \ldots \ldots \ldots \ldots . \ldots . \ldots . \ldots 1$

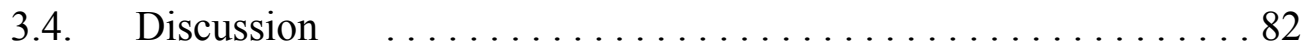

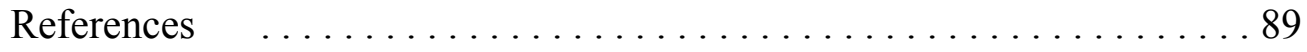


Tables ....................................... 97

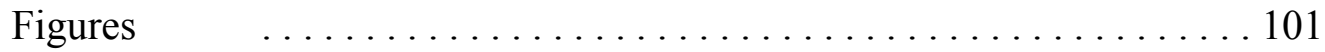

4. Interannual differences in larval haddock survival: hypothesis testing with a coupled biophysical model of Georges Bank 115

4.1. Introduction .............................. 115

4.2. Model ................................. 118

4.2.1. Physical environment ...................... 118

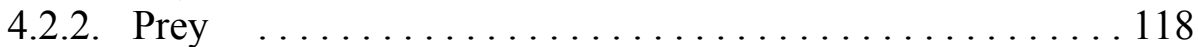

4.2.3. Foraging submodel .......................... 119

4.2.4. Bioenergetics submodel $\quad \ldots \ldots \ldots \ldots \ldots \ldots \ldots 120$

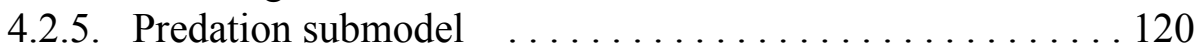

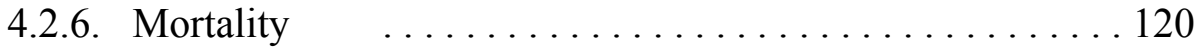

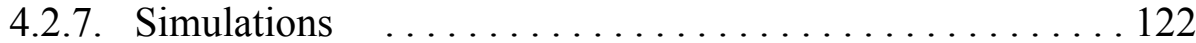

4.3. Results................................ 128

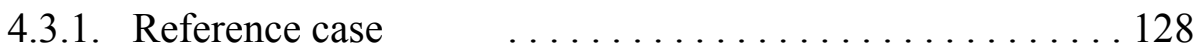

4.3.2. Hatch distribution effect on survival and sources of mortality ............................ 129

4.3.3. Mean depth of cases with behavior $\ldots \ldots \ldots \ldots \ldots 130$

4.3.4. Alternate hypotheses $\ldots \ldots \ldots \ldots \ldots \ldots \ldots \ldots \ldots \ldots 131$

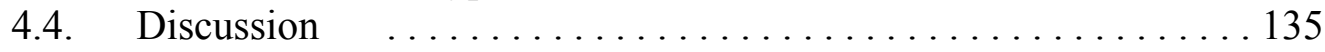

4.4.1. Advection ........................... 136

4.4.2. Starvation and growth........................ 138

4.4.3. Swimming behavior ......................... 139

4.4.4. Hatch date of survivors $\quad \ldots \ldots \ldots \ldots \ldots \ldots \ldots 141$

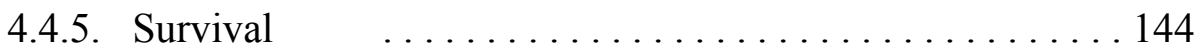

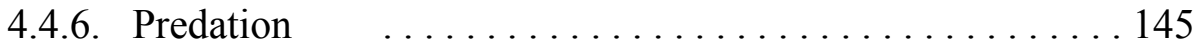

4.4.7. Conclusions ............................... 149

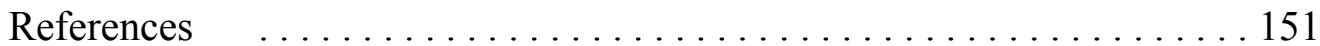

Tables ....................................... 160

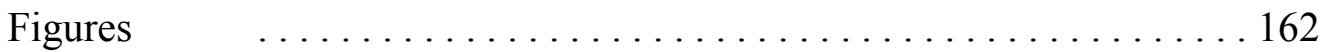

5. Conclusions from individual-based modeling of larval haddock on

Georges Bank 175

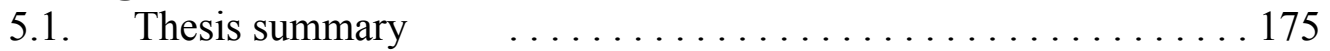

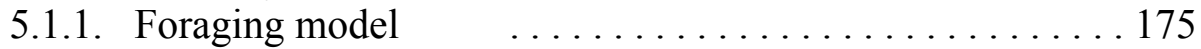

5.1.2. Vertical behavior model $\quad \ldots \ldots \ldots \ldots \ldots \ldots . \ldots 176$

5.1.3. Three-dimensional coupled biological-physical model 177

5.2. Significance ............................. 178

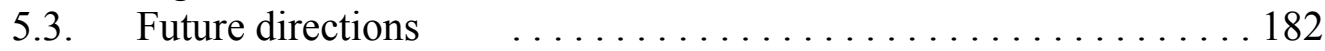

5.3.1. Larval fish vertical behavior . . . . . . . . . . . . 182

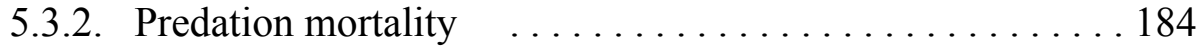

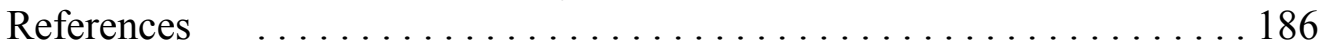




\section{List of Figures}

1.1 Georges Bank haddock biomass by age

1.2 Haddock larva

1.3 Map of Georges Bank subregions and circulation

1.4 Schematic of thesis models

3.1 Vertical profiles of model turbulence, prey density, and predation rate

3.2 Example vertical profiles of swimming speed using Cases B and C

3.3 Vertical distributions of larvae using Case A in fixed environment

3.4 Mean depths of larvae using Case $\mathrm{A}$ in fixed environment

3.5 Vertical distributions of larvae using Case B in high turbulent, fixed environment

3.6 Mean depths of larvae using Case B in high turbulent, fixed environment

3.7 Vertical distributions of larvae using Case B in low turbulent, fixed environment

3.8 Mean depths of larvae using Case B in low turbulent, fixed environment

3.9 Vertical distributions of larvae using Case $\mathrm{C}$ in high turbulent, fixed environment

3.10 Vertical distributions of larvae using Case $\mathrm{C}$ in low turbulent, fixed environment

3.11 Mean depths of larvae using Case $\mathrm{C}$ in low turbulent, fixed environment

3.12 Mean fitness vs. $\alpha$ for all cases and environments

3.13 Mean predation rate of larvae using Case A in high turbulent, fixed environment

4.1 Map of Georges Bank subregions

4.2 Reference case trajectories from hatch until $12 \mathrm{~mm}$ for each cohort and year

4.3 Percent contribution of each cohort to hatch and survival in the reference case

4.4 Fate of all individuals as percent of total number hatched

4.5 Mean depth of passive individuals and those using the four different behaviors

4.6 Total number of surviving individuals hatched in 1995 and 1998 for all 14 cases

4.7 1998:1995 ratio of the number of survivors per hatched larva for all 14 cases

4.8 Percentage of individuals lost to advection, predation, and starvation

4.9 Fraction of total surviving larvae from each cohort and year for all 14 cases

4.10 Mean specific growth rate of larvae from hatch until mean time to $12 \mathrm{~mm}$

4.11 Comparison of model growth rates and prey concentrations to Buckley \& Durbin (2006) derived curves

4.12 Comparison of mean log abundance of the potential predators on Georges Bank 


\section{List of Tables}

3.1 Model coefficients, variables, and equations

3.2 Minimum and maximum prey concentrations

3.3 Case A statistics

3.4 Case B statistics

3.5 Case C statistics

3.6 Mean time to $12 \mathrm{~mm}$ in the fixed environment with high and low turbulence

4.1 Multiplication factor used to adjust copepod population model concentrations

4.2 Total number of larvae hatched by cohort

4.3 Mean time to $12 \mathrm{~mm}$ and mean specific growth rate of the reference case

4.4 Mean temperature experienced by larvae in the reference case

4.5 Mean Pseudocalanus spp. concentrations in the reference case

4.6 Total number of surviving larvae by cohort in the reference case 


\section{Chapter 1}

\section{Fisheries recruitment variability: a case study using larval haddock on Georges Bank}

\subsection{Background}

\subsubsection{Recruitment variability}

The annual variation in year-class size of a fish population is an important determinant of the fishable biomass of the stock (Trippel \& Chambers 1997). The wellknown lack of correlation between spawning stock size and number of age-1 fish recruited to the adult population led Hjort (1914) to hypothesize that the size of a yearclass is determined during the early life stage of fish. Over the past century, much emphasis has been placed on understanding the survival from the egg to the early juvenile stage. There are several classic hypotheses on the sources of mortality during this time period. Cushing (1984) postulated the "match-mismatch theory" suggesting that mortality occurs when the seasonal timing of the appearance of feeding fish larvae does not match that of the zooplankton bloom. The "member vagrant hypothesis" presented by Iles \& Sinclair (1982) speculates that the physical conditions in a region might not retain larval fish in nursery habitats, thus leading to losses. Certain turbulent mixing 
levels can cause mortality according to two hypotheses, either by breaking up patches of prey necessary for high feeding rates (“ocean-stability"; Lasker 1975, Davis et al. 1991) or by decreasing the likelihood of capturing prey ("downside of turbulence"; MacKenzie \& Kiørboe 2000). Strong wind forcing may affect larval feeding seasonally by causing the "washout" of copepod prey populations from the nursery area prior to larval hatching such that prey concentrations are low for first-feeding larvae (Davis 1984, Lewis et al. 1994, 2001). A final hypothesis is that predation causes the bulk of larval fish mortality (Bailey \& Houde 1989).

Each of these hypotheses has been supported for larval cod (Gadus morhua) and/or haddock (Melanogrammus aeglefinus), members of the Gadidae family. In the North Sea, cod recruitment was greater when its dominant copepod prey Calanus finmarchicus was produced later in the season than average (Cushing 1984). There was a strong correlation between cod recruitment and C. finmarchicus abundance for the years 1962-1977 and no correlation when the years 1949-1961 were included, suggesting that cod larvae and C. finmarchicus production was matched during the years with correlation and mismatched the previous years (Cushing 1984). A coupled biological-physical model by Werner et al. (1993) demonstrated the importance of the member-vagrant hypothesis for larval cod and haddock. In their simulations only individual larvae that remained below $25 \mathrm{~m}$ and shoalward of the $70 \mathrm{~m}$ isobath were retained in their habitat on Georges Bank (Werner et al. 1993, 1996). Likewise, Chase (1955) found a relationship between wind forcing and haddock recruitment on Georges Bank. The ocean-stability hypothesis was supported by Buckley and Lough (1987) who found increased prey 
concentrations and growth of larval haddock at a stratified site compared to a well-mixed site on Georges Bank. However, when prey is not concentrated in a layer or patch, a certain amount of turbulence is needed to increase encounters with prey as suggested by Werner et al. (1996), who were only able to model survival and realistic growth rates of larval cod using observed mean prey concentrations in turbulent conditions. Without turbulence, both larval cod and haddock starved in the first 2-3 days of the simulation (Werner et al. 1996). Field and modeling studies have shown that winter storms cause advective loss (washout) of copepod populations on Georges Bank thus reducing food available to larval fish, and that the strong 1975 haddock year-class was associated with a low-wind winter (Davis 1984, Lewis et al. 1994). Finally, mesocosm studies of cod larvae reported fast growth rates and high survival at natural prey concentrations but in the absence of predators (Øiestad 1985, Bailey \& Houde 1989), implying that the lower survival rates observed in the field were the result of predation. Further strength for the predation hypothesis comes from the observation that mortality is the highest for eggs and yolk-sac larvae, which are non-feeding stages (Bailey \& Houde 1989).

Despite the evidence supporting the match-mismatch hypothesis in the North Sea, it appears that the haddock population on Georges Bank has greater survival when mismatched (phase-shifted) to the copepod populations (Buckley \& Durbin 2006). By hatching before the spring bloom, haddock are maximizing their size at time of year rather than size at age (Lapolla \& Buckley 2005, Buckley \& Durbin 2006, Buckley et al. 2010). Hatching early results in slower growth from less food, less light needed for visual feeding, and lower temperatures compared to later in the year, but larvae benefit 
from lower predation rates during this time (Lapolla \& Buckley 2005, Buckley \& Durbin 2006, Buckley et al. 2010). These findings contradict the larval fish paradigms about size and survival, namely the "bigger is better," "growth rate," and "stage duration" hypotheses (Legget \& Deblois 1994), which are based on the assumptions that mortality of larvae decreases with size and that larvae experience greater mortality than juveniles. Thus individuals with higher growth rates will spend less time as vulnerable larvae, particularly small larvae, with high mortality rates. From these studies it is apparent that many factors, such as seasonal changes in prey availability, predation risk, and the physical environment, are important in regulating the recruitment of cod and haddock. Thus to understand recruitment, we need to disentangle these factors, determine their relative importance, and reveal how they are affected by environmental variability.

\subsubsection{Haddock}

In an attempt to study processes controlling recruitment in fish populations, haddock was chosen as the model species because it represents a classic case of a recruitment-dominated fish stock, with relatively infrequent large year-classes dominating the population and fishable biomass at any given time (Figure 1.1). Haddock spawning is more restricted in time and space than cod, such that interactions with environmental conditions are more likely to yield boom or bust years. Haddock is also a commercially important fish species that has been exploited since the $19^{\text {th }}$ century and has experienced stock collapses over the past four decades (Fogarty et al. 2001, Brodziak \& Traver 2006). Haddock live on both coasts of the North Atlantic, including a 
population on Georges Bank (Fogarty et al. 2001). The haddock life cycle consists of pelagic stages of eggs, larvae (Figure 1.2), and juveniles, followed by demersal stages of juveniles and adults. Development through the pelagic stages coincides with drift around the bank (Figure 1.3). Larvae hatch with a yolk sac and must begin feeding before its depletion (4-7 days post hatch; Auditore et al. 1994). Growth of both haddock and cod larvae on Georges Bank is food-limited and strongly dependent on availability of copepod prey (Buckley \& Durbin 2006). On Georges Bank the four main copepod prey species of larval haddock and cod are C. finmarchicus, Pseudocalanus spp., Oithona similis, and Centropages typicus (Kane 1984).

Haddock recruitment is more variable than cod in many regions including Georges Bank, the North Sea, the Barents Sea, the Eastern Scotian Shelf, Browns Bank, the Faroe Islands, and Iceland (Fogarty et al. 2001). The haddock population on Georges Bank has had a few outstanding year-classes over the past half century (Figure 1.1). With 789 million age-1 recruits, the 2003 haddock year-class on Georges Bank was exceptionally large, replacing the extraordinary 1963 year-class as the largest ever recorded (Brodziak \& Traver 2006). Other moderately strong year-classes occurred in 1975, 1978, 1998, and 2000 (Figure 1.1). Although both cod and haddock are similar demersal fishes with overlapping ranges and prey, haddock spawning is more restricted both seasonally and spatially. On Georges Bank cod spawn between November and June with the peak in March (Incze et al. 1996), while haddock have a shorter spawning duration from January through April with the peak in early April (Auditore et al. 1994, Lough et al. 2006). Likewise, cod spawning occurs over a broader area of Georges Bank, 
while haddock spawning is primarily restricted to the northeast peak of the bank. In addition, field observations have shown that haddock larvae are more food-limited than cod larvae. The guts of cod larvae collected from Georges Bank typically contained later stages of copepods, larger prey, and more biomass than the guts of haddock larvae (Kane 1984). Furthermore, laboratory experiments show that larval haddock have a lower tolerance to variation in temperature and salinity than cod (Laurence \& Rogers 1976). The combination of shorter spawning duration, restricted spawning area, weaker feeding abilities, and lower tolerance to environmental changes may explain why haddock recruitment is more punctuated than that of cod, though the underlying mechanisms are not understood. This combination of restricted spawning, sensitivity to environmental conditions, and dominant year-classes make haddock well suited as a model fish species for unraveling the factors controlling recruitment in fish populations.

\subsubsection{GLOBEC}

The U.S. GLOBal ocean ECosystem dynamics (GLOBEC) program is a multidisciplinary collaboration between oceanographers and fisheries scientists in order to study the effects of climate change on marine ecosystems. The U.S. GLOBEC Northwest Atlantic/Georges Bank (GLOBEC GB) program focuses on the population dynamics of dominant copepod species and fishes Atlantic cod and haddock, with respect to physical and biological changes of their habitat (Wiebe et al. 2002). The GLOBEC GB program collected data on monthly broadscale and process-oriented surveys during the years 1995-1999. One of the aims of GLOBEC GB Phase 4b is synthesis of the data 
to better understand the recruitment of cod and haddock. The approaches include the creation of biophysical models of fish larvae and full life cycle models of cod and haddock. Previous modeling studies of larval cod and haddock (Werner et al. 1996, Leising \& Franks 1999) used a bioenergetics model based on Laurence (1985), which contained errors (Buckley et al. 2000). Alternative metabolic data was available for cod, and modeling was able to continue, resulting in many models of larval cod developed for specific regions such as Georges Bank, the Norwegian shelf, and the North Sea (e.g. Lough et al. 2005, Kristiansen et al. 2009c). An individual-based biophysical model for haddock that includes food-dependent growth and mechanistic feeding has not been constructed and implemented for any region since finding errors in the metabolism formulation. Recently, Lankin et al. (2008) have studied the metabolism of larval haddock, so that a model that includes temperature- and food-dependent growth and mechanistic feeding can be created. This thesis will develop a model to examine the underlying mechanisms controlling survival during the larval stage, focusing on larval haddock on Georges Bank as a model system.

\subsubsection{Georges Bank}

The study site is Georges Bank, a submerged plateau $300 \mathrm{~km}$ long by $150 \mathrm{~km}$ wide off the coast of New England (Figure 1.3). The majority of the bank is in the Exclusive Economic Zone of the United States, with part of the northeast peak governed by Canada. The general circulation of Georges Bank features a clockwise gyre around the bank forced by the density field, tidal rectification, and wind stress (Butman \& 
Beardsley 1987). Water enters the Gulf of Maine (GOM) from the Scotian Shelf and Northeast Channel and flows counterclockwise around the gulf, with a portion of the flow exiting through the western Great South Channel (GSC). A significant portion of the GOM flow moves onto Georges Bank along the northwestern edge and continues clockwise around the bank (Butman et al. 1982). In winter and spring, most of the Georges Bank flow exits the bank across the southern GSC, continuing along the shelf south of New England (Butman \& Beardsley 1987). During summer, seasonal heating enhances the geostrophic flow around the bank with most of the flow recirculated on the bank (Butman \& Beardsley 1987). The relatively fresh GOM water above $100 \mathrm{~m}$ is from the Scotian Shelf while the deeper GOM water is derived either from Labrador Slope Water (LSW) or Warm Slope Water (WSW; Pershing et al. 2001). The bulk of the Georges Bank water is from the fresher surface waters of the GOM, with smaller amounts of deep water being upwelled via tidal pumping along the northern edge, potentially impacting nutrient input to the bank (Chen \& Beardsley 1998, Townsend et al. 2004). Loss of water and plankton also can occur by the passage of storms (Lewis et al, 1994, 2001) and Gulf Stream rings at the edge of the bank (Butman et al. 1982, Flierl \& Wroblewski 1985).

The bathymetry of Georges Bank is characterized by a steep incline on the northern edge from $220 \mathrm{~m}$ to less than $60 \mathrm{~m}$ at the central plateau, while the southern flank deepens gradually from 60 to $100 \mathrm{~m}$ and then falls sharply to $>2000 \mathrm{~m}$ at the edge of the continental shelf. The water on the shallow plateau $(<60 \mathrm{~m})$ is tidally mixed while the deeper water on the flanks $(>60 \mathrm{~m})$ is seasonally stratified, with a front where the 
mixed and stratified water meet (Butman et al. 1982). Georges Bank is a very productive habitat from the continued upwelling and resuspension of nutrients by tidal forcing (Chen $\&$ Beardsley 1998). The high levels of nutrients, phytoplankton, and zooplankton on the bank support many fisheries, including cod and haddock.

The LSW and WSW described above form a coupled system that responds to basin-scale changes in climate on interannual to millennial time scales (Pershing et al. 2001). The LSW has lower nutrient concentrations (nitrate and silicate) than the WSW (Townsend et al. 2004) and therefore can potentially impact the productivity of the GOM/Georges Bank ecosystem. The latitudinal position of LSW and WSW along the coast is under North Atlantic Oscillation (NAO) influence (Pershing et al. 2001, Townsend et al. 2004). During NAO lows there is enhanced volume transport of the Labrador Current and the LSW advances further downstream, displacing WSW further offshore (Pershing et al. 2001, Townsend et al. 2004). It is during these years that the deep water in the GOM is of LSW origin. Throughout NAO highs the Labrador Current and LSW transport are reduced, the frontal boundary retreats upstream, and WSW moves onshore towards the shelf (Pershing et al. 2001, Townsend et al. 2004) resulting in WSW-formed GOM deep water. With one exception, the GLOBEC study years took place during NAO highs. The NAO low of 1996 resulted in LSW entering Georges Bank during the spring of 1998 (Townsend et al. 2004). The C. finmarchicus population on Georges Bank originates in the GOM (Durbin et al. 1997). Abundance of $C$. finmarchicus in the GOM is correlated to the coupled slope system mode and the NAO, 
and other copepod species may be as well (Pershing et al. 2001), which would have effects on the availability of prey for larval fish on Georges Bank.

The surface water of Georges Bank is derived from Scotian Shelf water and also has interannual variations. In the late 1990s there was a low sea surface salinity anomaly in the Northwest Atlantic (Häkkinen 2002, Belkin 2004). The input of fresher Scotian Shelf water into the GOM and Georges Bank could cause an earlier spring bloom (Ji et al. 2007) and result in a greater overlap of larval haddock with their food, resulting in increased survival (Platt et al. 2003). Potential support for this hypothesis comes from a negative correlation of salinity with growth and survival of larval cod and haddock found over the course of the GLOBEC GB study period (Buckley et al. 2006).

The 1998 haddock year-class was large on Georges Bank (Buckley \& Durbin 2006). The 1998 haddock spawning period was broader than other years and egg production was low, but the egg and larval survival rates were the highest of the study period (Buckley \& Durbin 2006, Mountain et al. 2008). Prey biomass and larval growth rates were high in 1997, 1998, and 1999, but these conditions alone did not result in large haddock year-classes in 1997 and 1999 (Buckley \& Durbin 2006). On the other hand, 1995 was a year of low recruitment. Of the 5 study years, 1995 had the highest salinity (Buckley et al. 2006) and low prey biomass (Buckley \& Durbin 2006). Both larval abundance at 15 days post hatch (Mountain et al. 2008) and recruitment per hatched egg (Mountain \& Kane 2010) were higher in 1998 than 1995. 


\subsubsection{Individual-based modeling}

Individual-based models (IBMs) have been widely used to study larval fish biology and transport. The inherent sparsity of larval fish in the environment precludes the use of concentration-based models, but IBMs are ideal for modeling larval fish. Using IBMs also allows individuals to be adaptive, such that they make choices depending on internal states and external environments in ways that increase fitness (Grimm \& Railsback 2005). With an IBM, growth and death are the outcomes of adaptive behavior, and behavioral strategies may differ between individuals. An IBM makes it possible to answer questions related to individual variability of size and growth rate, which are important in many of the larval mortality hypotheses. Another benefit of these models of individual behavior is the emergence of properties of the population, such as recruitment.

\subsection{Thesis Overview}

The goal of this thesis is to study the processes that affect larval survival and thus recruitment success in the Georges Bank haddock population. Focus is placed on the feeding and vertical behavior of larval haddock because these factors affect starvation, growth, predation, and horizontal transport. 


\subsubsection{Foraging model}

Until recently, most models of larval cod and haddock feeding have assigned stages of copepod species to different larval size classes as possible prey targets based on the mouth gape of the larvae and width of the copepods. A recent trophodynamic model of larval cod included a mechanistic feeding component where encounter rate, pursuit success, and capture success determined larval feeding success (Kristiansen et al. 2009b). Prey encounter rates were a function of prey characteristics, larval size, ambient light (since haddock and cod are visual foragers), turbulence, and prey density. Pursuit and capture success depended on the predation abilities of the larval fish and the escape behaviors of the copepod prey. It included copepod species-specific size information, but escape behaviors were parameterized for the copepod Acartia tonsa. The prey preferences predicted by this model (Kristiansen et al. 2009b) did not match observations; specifically it did not replicate the negative selection of C. typicus (Heath \& Lough 2007). Prey preference of fish larvae depends on copepod species, even when they are the same length (Munk 1997) because escape behaviors differ between copepod species (Viitasalo et al. 1998, Titelman 2001, Titelman \& Kiørboe 2003). I hypothesized that adding species-specific characteristics of the copepod prey to the mechanistic feeding model for larval fish would resolve the discrepancies between simulations and observations, as accurate prey preferences are important to studies of survival because they affect growth.

In Chapter 2, I parameterize the mechanistic foraging model, as well as a growth model, for haddock and cod, based upon their differences in morphology and 
bioenergetics. I also add species- and stage-specific parameters for the four main copepod prey species C. finmarchicus, Pseudocalanus spp., O. similis., and C. typicus gathered from the literature on larval fish foraging behavior and copepod escape behavior. The goal of this second chapter is to answer the question: Which copepod species and stages are available as prey for larval haddock and cod, and why?

\subsubsection{Vertical behavior model}

It is not always clear how or why animals make behavioral decisions, such as habitat (depth) choice of larval fish in the water column. The vertical position of larval fish is important because it affects immediate growth and predation, and long-term drift and dispersal. Using imposed behaviors in a model does not always produce sound results because they are only valid for a particular environment and internal state (usually measured in a laboratory), both of which change in situ. It would be better to use a dynamic strategy where larvae can respond behaviorally to changes in the environment.

Habitat choice theory suggests that there is a trade-off between feeding/growth and predation (Gilliam \& Fraser 1987). One formulation of this trade-off is the maximization of instantaneous ingestion or growth minus predation mortality. Kristiansen et al. (2009b) explored this behavioral strategy, with the addition of a risk sensitivity parameter that changed how the individual weighed the importance of feeding/growth and mortality as a function of gut fullness. The different forms of this equation resulted in very similar survival probabilities (0.001-0.005\% difference) and 
vertical distributions that did not match observations (Kristiansen et al. 2009a), both suggesting that a better solution exits.

There are a number of theoretical and practical concerns for implementing feeding/growth and mortality trade-off behaviors in IBMs (Railsback et al. 1999). One of the theoretical concerns is that the larval fish has perfect knowledge of its growth and mortality rates in the entire water column. Obviously, perfect knowledge is an unrealistic assumption, but larval fish may not even be able to sense gradients, at least in prey and predators that they sense one at a time in their small perception area. Fortunately, these types of information are not necessary and models with individuals that respond to local conditions can produce observed or optimal distributions (e.g. Davis et al. 1991).

In Chapter 3, I develop a one-dimensional model to test different swimming behaviors that affect the vertical distribution of haddock larvae, as well as their survival. The one-dimensional environment is representative of the southern flank of Georges Bank during the spring, with varying levels of prey, predators, and turbulence that larvae may experience. The behaviors are functions of ambient prey and light conditions and are meant to resolve the importance of starvation and visual predation mortality in the behavioral decisions governing larval haddock vertical distribution. The objective of this third chapter was to answer the questions: (1) How do different behaviors affect the depth distribution and mortality of haddock larvae?, and (2) Which behavior(s) produce(s) vertical distributions most similar to observations? 


\subsubsection{Three-dimensional coupled biological-physical model}

In Chapter 4, I create the first biophysical IBM of larval haddock for Georges Bank using mechanistic feeding, and temperature- and food-dependent growth that incorporates recent metabolic data. In addition to the feeding and bioenergetics models, the IBM also includes models of predation and vertical behavior. The haddock IBM is coupled to a hydrodynamics model that moves the larvae in three-dimensions on Georges Bank and provides the light, temperature, and turbulence data. The IBM is also coupled to a concentration-based copepod population model, which receives input from the same hydrodynamics model and a lower trophic level nutrients-phytoplankton-zooplanktondetritus (NPZD) model. The copepod model supplies the prey fields for haddock feeding in the IBM (Figure 1.4).

This three-dimensional (3D) biophysical IBM is an excellent tool for testing questions related to larval haddock survival. The years 1995 and 1998 had different levels of wind, salinity, temperature, prey, haddock spawning, and egg hatching. These important physical and biological factors are manipulated in Chapter 4 to answer the question: Why were the levels of larval haddock survival on Georges Bank different in the years 1995 and $1998 ?$

In addition to answering this question, the 3D model also provides some insights on interannual variability of the Georges Bank haddock population and the importance of certain sources of mortality. 


\section{References}

Auditore PJ, Lough RG, Broughton EA (1994) A review of the comparative development of Atlantic cod (Gadus morhua L.) and haddock (Melanogrammus aeglefinus L.) based on an illustrated series of larvae and juveniles from Georges Bank. NAFO Sci Counc Studies 20:7-18

Bailey KM, Houde ED (1989) Predation on eggs and larvae of marine fishes and the recruitment problem. Adv Mar Biol 25:1-83

Belkin IM (2004) Propagation of the "Great Salinity Anomaly" of the 1990s around the northern North Atlantic. Geophys Res Lett 31:L08306 doi:10.1029/2003GL019334

Brodziak J, Traver M (2006) Status of fishery resources off the Northeastern US: haddock. http://www.nefsc.noaa.gov/sos/spsyn/pg/haddock/. 8/20/10

Buckley LJ, Durbin EG (2006) Seasonal and inter-annual trends in the zooplankton prey and growth rate of Atlantic cod (Gadus morhua) and haddock (Melanogrammus aeglefinus) larvae on Georges Bank. Deep-Sea Res II 53:2758-2770

Buckley LJ, Lough RG (1987) Recent growth, biochemical composition, and prey field of larval haddock (Melanogrammus aeglefinus) and Atlantic cod (Gadus morhua) on Georges Bank. Can J Fish Aquat Sci 44:14-25

Buckley LJ, Caldarone EM, Lough RG, St. Onge-Burns JM (2006) Ontogenetic and seasonal trends in recent growth rates of Atlantic cod and haddock larvae on Georges Bank: effects of photoperiod and temperature. Mar Ecol Prog Ser 325: $205-226$ 
Buckley LJ, Lough RG, Mountain D (2010) Seasonal trends in mortality and growth of cod and haddock larvae result in an optimal window for survival. Mar Ecol Prog Ser 405:57-69

Buckley LJ, Lough RG, Peck MA, Werner FE (2000) Comment: Larval Atlantic cod and haddock growth models, metabolism, ingestion, and temperature effects. Can J Fish Aquat Sci 57:1957-1960

Butman B, Beardsley RC (1987) Long-term observations on the southern flank of Georges Bank. Part I: A description of the seasonal cycle of currents, temperature, stratification, and winds stress. J Phys Oceanogr 17:367-384

Butman B, Beardsley RC, Magnell B, Frye D, Vermersch JA, Schlitz R, Limeburner R, Wright WR, Noble MA (1982) Recent observations of the mean circulation on Georges Bank. J Phys Oceanogr 12:569-591

Chase J (1955) Winds and temperature in relation to the brood-strength of Georges Bank haddock. J Cons Int Explor Mer 21:17-24

Chen C, Beardsley RC (1998) Tidal mixing over finite-amplitude banks: a model study with application to Georges Bank. J Mar Res 56:1163-1203

Cushing DH (1984) The gadoid outburst in the North Sea. J Cons Int Explor Mer 41:159-166

Davis CS (1984) Interaction of a copepod population with the mean circulation on Georges Bank. J Mar Res 42:573-590

Davis CS, Flierl GR, Wiebe PH, Franks PJS (1991) Micropatchiness, turbulence and recruitment in plankton. J Mar Res 49:109-151 
Durbin EG, Runge JA, Campbell RG, Garrahan PR, Casas MC, Plourde S (1997) Late fall-early winter recruitment of Calanus finmarchicus on Georges Bank. Mar Ecol Prog Ser 151:103-114

Flierl GR, Wroblewski, JS (1985) The possible influence of warm core Gulf Stream rings upon shelf water larval fish distributions. Fish Bull 83:313-330

Fogarty MJ, Myers RA, Bowen KG (2001) Recruitment of cod and haddock in the North Atlantic: a comparative analysis. ICES J Mar Sci 58:952-961

Gilliam JF, Fraser DF (1987) Habitat selection under predation hazard: test of a model with foraging minnows. Ecology 68:1856-1862

Grimm V, Railsback SF (eds) (2005) Individual based modeling and ecology. Princeton University Press, Princeton, 428p

Häkkinen S (2002) Freshening of the Labrador Sea surface waters in the 1990s: another great salinity anomaly? Geophys Res Lett 29:2232 doi:10.1029/2002GL015243

Heath MR, Lough RG (2007) A synthesis of large-scale patterns in the planktonic prey of larval and juvenile cod (Gadus morhua). Fish Oceanogr 16:169-185

Hjort J (1914) Fluctuations in the great fisheries of Northern Europe viewed in the light of biological research. Rapp P-v Réun Cons Int Explor Mer 20:1-228

Iles TD, Sinclair M (1982) Atlantic herring: stock discreteness and abundance. Science 215:627-633

Incze LS, Aas P, Ainaire T (1996) Distributions of copepod nauplii and turbulence on the southern flank of Georges Bank: implications for feeding by larval cod (Gadus morhua). Deep-Sea Res II 43:1855-1873 
Ji R, Davis CS, Chen C, Townsend DW, Mountain DG, Beardsley RC (2007) Influence of ocean freshening on shelf phytoplankton dynamics. Geophys Res Lett 34:L24607 doi:10.1029/2007GL032010

Kane J (1984) The feeding habits of co-occurring cod and haddock larvae from Georges Bank. Mar Ecol Prog Ser 16:9-20

Kristiansen T, Jørgensen C, Lough RG, Vikebø F, Fiksen Ø (2009a) Modeling rule-based behavior: habitat selection and the growth-survival trade-off in larval cod. Behav Ecol 20:490-500

Kristiansen T, Lough RG, Werner FE, Broughton E, Buckley LJ (2009b) Individualbased modeling of feeding ecology and prey selection of larval cod on Georges Bank. Mar Ecol Prog Ser 376:227-243

Kristiansen T, Vikebø F, Sundby S, Huse G, Fiksen Ø (2009c) Modeling growth of larval cod (Gadus morhua) in large-scale seasonal and latitudinal environmental gradients. Deep-Sea Res II 56:2001-20011

Lankin KF, Peck MA, Buckley LJ, Bengtson DA (2008) The effects of temperature, body size and growth rate on energy losses due to metabolism in early life stages of haddock (Melanogrammus aeglefinus). Mar Biol 155:461-472

Lapolla A, Buckley LJ (2005) Hatch date distributions of young-of-year haddock Melanogrammus aeglefinus in the Gulf of Maine/Georges Bank region: implications for recruitment. Mar Ecol Prog Ser 290:239-249 
Lasker R (1975) Field criteria for survival of anchovy larvae: the relation between inshore chlorophyll maximum layers and successful first feeding. Fish Bull $73: 453-462$

Laurence GC (1985) A report on the development of stochastic models of food limited growth and survival of cod and haddock larvae. In: Laurence GC, Lough RG (eds) Growth and survival of larval fishes in relation to the trophodynamics of Georges Bank cod and haddock. NOAA Tech Memo NMFS-F/NEC-36, p 83-150

Laurence GC, Rogers CA (1976) Effects of temperature and salinity on comparative embryo development and mortality of Atlantic cod (Gadus morhua L.) and haddock (Melanogrammus aeglefinus L.). J Cons Int Explor Mer 36:220-228

Legget WC, Deblois E (1994) Recruitment in marine fishes: is it regulated by starvation and predation in the egg and larval stages? Netherlands J Sea Res 32:119-134

Leising AW, Franks PJS (1999) Larval Atlantic cod (Gadus morhua) and haddock (Melanogrammus aeglefinus) growth on Georges Bank: a model with temperature, prey size, and turbulence forcing. Can J Fish Aquat Sci 56:25-36

Lewis CVW, Chen C, Davis CS (2001) Variability in wind forcing and its effect on circulation and plankton transport over Georges Bank. Deep-Sea Res II 48:137158

Lewis CVW, Davis CS, Gawarkiewcz G (1994) Wind-forced biological-physical dynamics on an isolated off-shore bank. Deep-Sea Res II 41:51-73 
Lough RG, Buckley LJ, Werner FE, Quinlan JA, Pehrson Edwards K (2005) A general biophysical model of larval cod (Gadus morhua) growth applied to populations on Georges Bank. Fish Oceanogr 14:241-262

Lough RG, Hannah CG, Berrien P, Brickman D, Loder JW, Quinlan JA (2006) Spawning pattern variability and its effect on retention, larval growth and recruitment in Georges Bank cod and haddock. Mar Ecol Prog Ser 310:193-212

MacKenzie BR, Kiørboe T (2000) Larval fish feeding and turbulence: a case for the downside. Limnol Oceanogr 45:1-10

Mountain DG, Kane J (2010) Major changes in the Georges Bank ecosystem, 1980s to the 1990s. Mar Ecol Prog Ser 398:81-91

Mountain D, Green J, Sibunka J, Johnson D (2008) Growth and mortality of Atlantic cod Gadus morhua and haddock Melanogrammus aeglefinus eggs and larvae on Georges Bank, 1995 to 1999. Mar Ecol Prog Ser 353:225-242

Munk P (1997) Prey size spectra and prey availability of larval and small juvenile cod. J Fish Biol 51:340-351

Øiestad V (1985) Predation on fish larvae as a regulatory force, illustrated in mesocosm studies with large groups of larvae. N Atl Fish Org Counc Studies 8:25-32

Pershing AJ, Greene CH, Hannah C, Sameoto D, Head E, Mountain DG, Jossi JW, Benfield MC, Reid PC, Durbin EG (2001) Oceanographic responses to climate in the northwest Atlantic. Oceanogr 14:76-82

Platt T, Fuentes-Yaco C, Frank KT (2003) Spring algal bloom and larval fish survival. Nature 423:398-399 
Railsback SF, Lamberson RH, Harvey BC, Duffy WE (1999) Movement rules for individual-based models of stream fish. Ecol Model 123:73-89

Titelman J (2001) Swimming and escape behavior of copepod nauplii: implications for predator-prey interactions among copepods. Mar Ecol Prog Ser 213:203-213

Titelman J, Kiørboe T (2003) Predator avoidance by nauplii. Mar Ecol Prog Ser $247: 137-149$

Townsend DW, Thomas AC, Mayer LM, Quinlan Jr TM (2004) Oceanography of the Northwest Atlantic continental shelf. In: Robinson AR, Brink KH (eds) The Sea: The Global Coastal Ocean: Interdisciplinary Regional Studies and Syntheses, Volume 14. Harvard University Press, Cambridge, p 119-168

Trippel EA, Chambers RC (1997) Introduction. In: Chambers RC, Trippel EA (eds) Early life history and recruitment in fish populations. Chapman and Hall, London, p xxi-xxxii

Viitasalo M, Kiørboe T, Flinkman J, Pedersen LW, Visser AW (1998) Predation vulnerability of planktonic copepods: consequences of predator foraging strategies and prey sensory abilities. Mar Ecol Prog Ser 175:129-142

Werner FE, Page FH, Lynch DR, Loder JW, Lough RG, Perry RI, Greenberg DA, Sinclair M (1993) Influences of mean advection and simple behavior on the distribution of cod and haddock early life stages on Georges Bank. Fish Oceanogr 2:43-64 
Werner FE, Perry RI, Lough RG, Naimie CE (1996) Trophodynamic and advective influences on Georges Bank larval cod and haddock. Deep-Sea Res II 43:17931822

Wiebe P, Beardsley R, Mountain D, Bucklin A (2002) U.S. GLOBEC Northwest Atlantic/Georges Bank Program. Oceanogr 15:13-29 


\section{Figures}

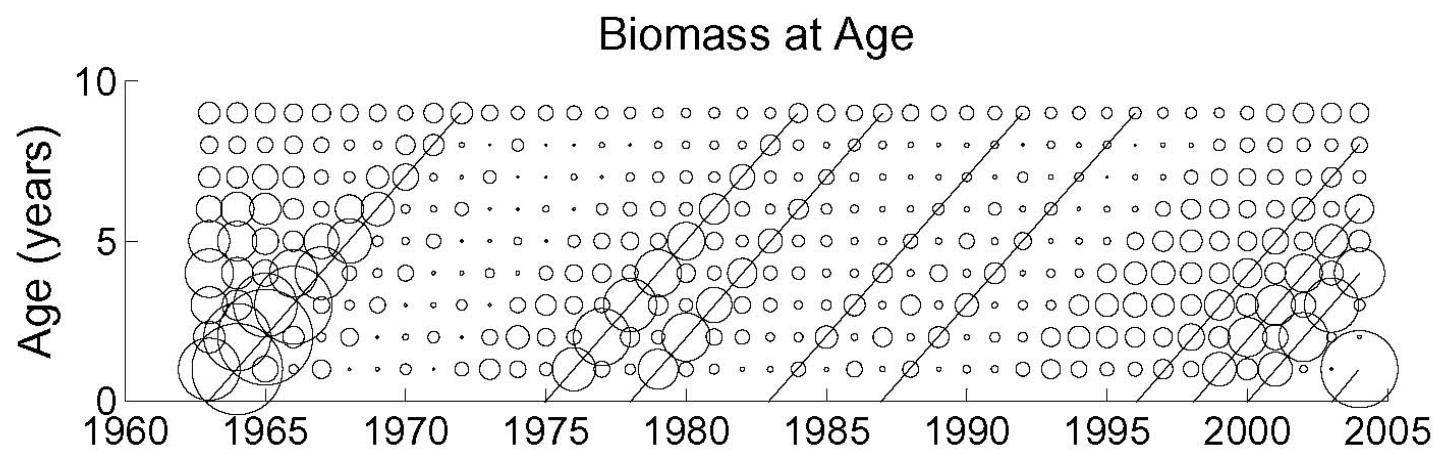

Figure 1.1. Georges Bank haddock biomass by age. Size of bubbles indicates relative amount. Biomass from strong year-classes $(1963,1975,2003)$ propagates through the population for years (adapted from Brodziak \& Traver 2006). 


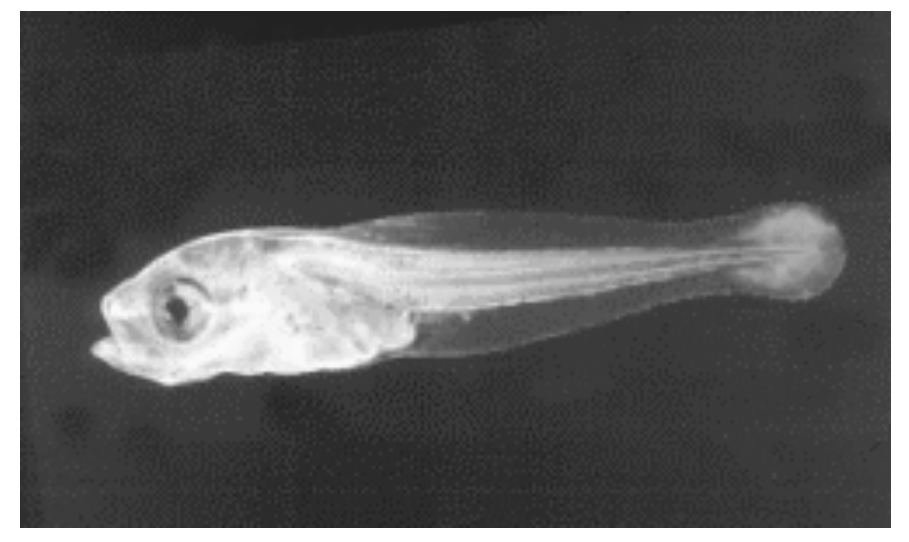

Figure 1.2. Haddock larva (Wes Pratt, http://www.usglobec.org). 


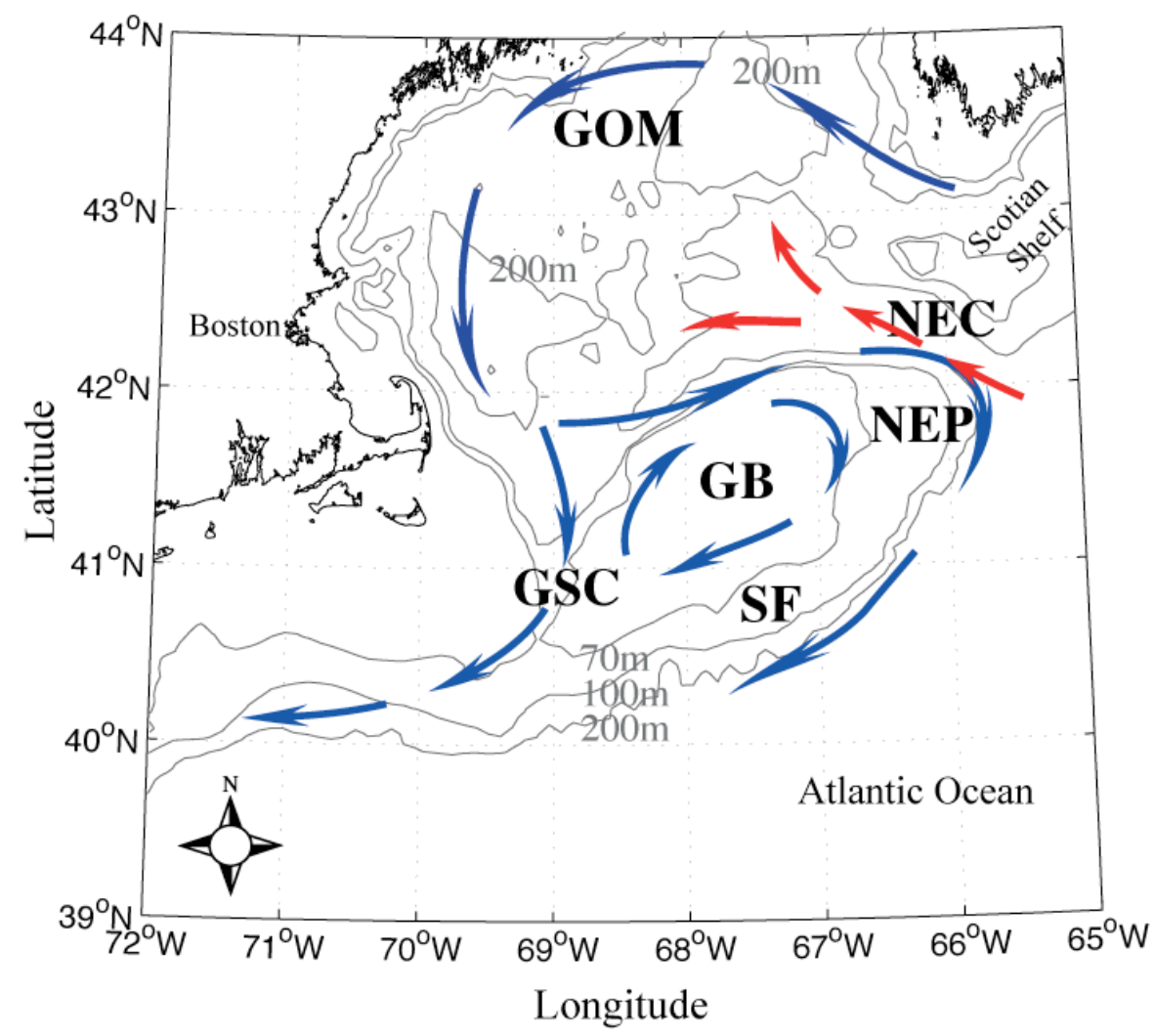

Figure 1.3. Map of the Gulf of Maine (GOM) and Georges Bank (GB) with the subregions: Northeast Channel (NEC), Northeast Peak (NEP), Southern Flank (SF), Great South Channel (GSC). The $70 \mathrm{~m}, 100 \mathrm{~m}$, and $200 \mathrm{~m}$ isobaths are labeled. Blue arrows denote the general surface circulation and red arrows are deep waters. 


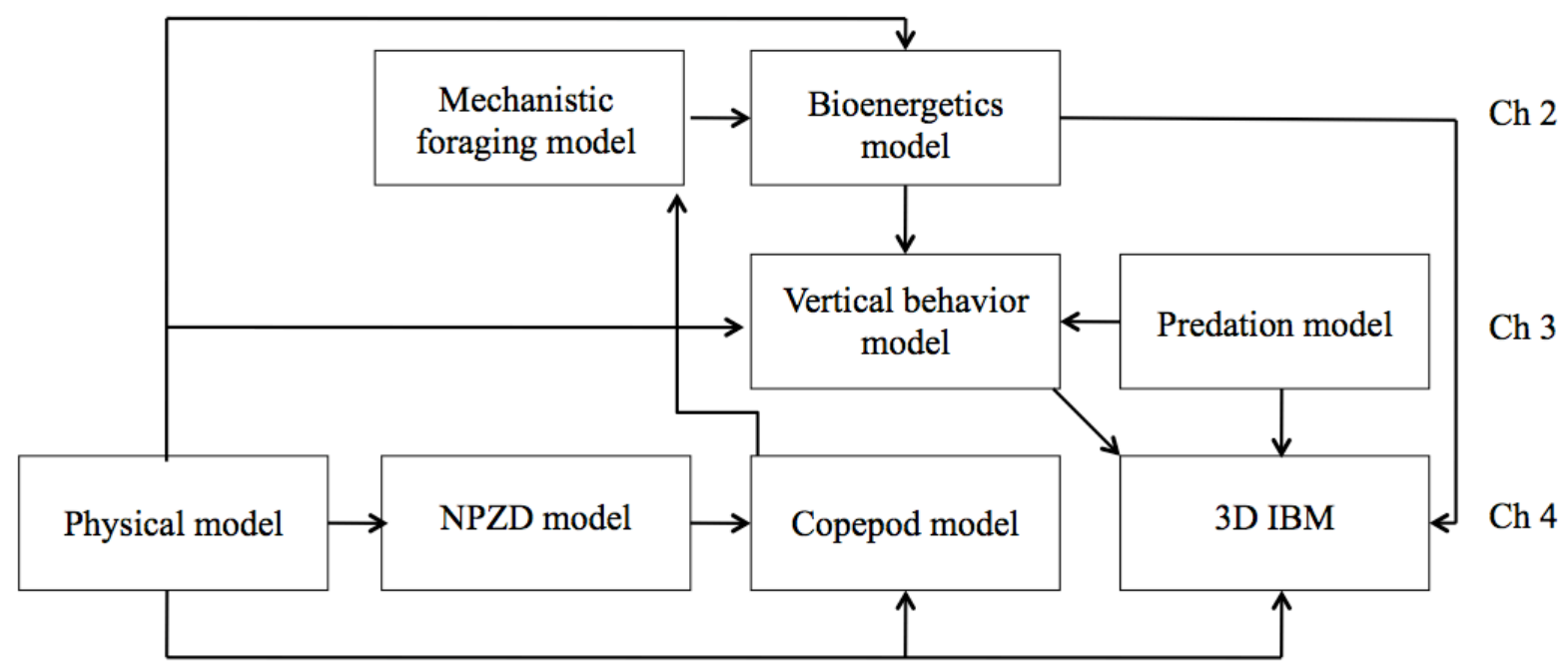

Figure 1.4. Flow chart of thesis models. The models used in each chapter are on the same line as the chapter number and above. NPZD - Nutrients-Phytoplankton-ZooplanktonDetritus, 3D IBM - Three-Dimensional Individual-Based Model. 


\section{Chapter 2}

\section{Prey selection by larval haddock and cod on}

copepods with species-specific behavior: an individual-based model analysis

by Colleen M. Petrik, Trond Kristiansen, R. Gregory Lough, and Cabell S. Davis

Reprinted from Marine Ecology Progress Series 396:123-143 


\title{
Prey selection by larval haddock and cod on copepods with species-specific behavior: an individual-based model analysis
}

\author{
Colleen M. Petrik ${ }^{1, *}$, Trond Kristiansen ${ }^{2}$, R. Gregory Lough ${ }^{3}$, Cabell S. Davis ${ }^{1}$ \\ ${ }^{1}$ Biology Department, Woods Hole Oceanographic Institution, Woods Hole, Massachusetts 02543, USA \\ ${ }^{2}$ Institute of Marine Research, PO Box 1870 Nordnes, 5817 Bergen, Norway \\ ${ }^{3}$ Northeast Fisheries Science Center, NMFS, NOAA, Woods Hole, Massachusetts 02543, USA
}

\begin{abstract}
Coupled biological-physical models of larval fish have become a widely used tool for studying recruitment variability. Within these models, foraging components include prey selection as a determinant of food availability but have not yet considered species-specific escape behaviors of prey, which can be important in determining capture success. Furthermore, there has been extensive work on some species (e.g. cod Gadus morhua), but less on others (e.g. haddock Melanogrammus aeglefinus). We collected information from the literature on the escape behaviors of the copepods Calanus finmarchicus, Pseudocalanus spp., Oithona similis, and Centropages typicus, the dominant prey of larval haddock and cod on Georges Bank (NW Atlantic), for use in a mechanistic foraging model. The foraging model was coupled to a bioenergetics model to simulate larval haddock and cod feeding and growth. Larval haddock and cod demonstrated positive selection of Pseudocalanus spp. and negative selection of $C$. finmarchicus based on modeled Chesson's preference index. Speciesspecific differences in escape abilities affected selection more than encounter rate. Prey escape behavior explained why larval cod rarely feed on C. typicus, although these prey items are numerous in the water column. Disparities between larval haddock and cod in their simulated prey selection and growth rates were the result of different mouth sizes and metabolisms. Simulated haddock foraging agreed with gut content observations of the size and species composition of ingested prey. These models are the first to describe haddock foraging and to include species-specific prey behaviors.
\end{abstract}

KEY WORDS: Individual-based model · Foraging · Escape behavior $\cdot$ Haddock $\cdot$ Cod $\cdot$ Copepods . Larval fish · Georges Bank

\section{INTRODUCTION}

Survival and thereby recruitment of fish is largely determined during the first 6 mo after hatch (Houde 1987, Sundby et al. 1989). During this period, survival is affected by biological and physical conditions controlling the ability of larvae to find food in the water column. To study these processes, foraging models have been used in coupled biological-physical individual-based models (IBMs) of larval fish. Incorporating mechanistic feeding components into IBMs makes it possible to examine the foraging process in relation to key environmental conditions such as stratification, turbulence, and prey patchiness.

The foraging process itself is quite complex. For any predator, consumption rate is the product of encounter rate and capture success (Bailey \& Houde 1989). Larval fish foraging follows a particular behavioral sequence: (1) encounter, (2) pursuit, (3) attack/capture, and (4) ingestion (MacKenzie \& Kiørboe 2000). Encounter is defined as the detection of the prey and is a function of prey density, the relative velocities of predator and 
prey, and the visibility of the prey (Rothschild \& Osborn 1988, Bailey \& Houde 1989, MacKenzie \& Kiørboe 2000, Fiksen \& MacKenzie 2002). Capture success is influenced by the predator's swimming speed and mouth size, the turbulent velocity, and the prey's ability to detect and respond to a predator during the pursuit or attack (Bailey \& Houde 1989, MacKenzie \& Kiørboe 2000). During the pursuit the larva swims towards the prey until: (1) the larva attacks the prey, (2) the prey escapes and the larva does not follow it, or (3) the prey is advected away and the larva does not follow it (MacKenzie \& Kiørboe 2000). An attack occurs when the fish larva opens its mouth to capture and ingest the prey (MacKenzie \& Kiørboe 2000). For cod Gadus morhua, this involves sucking in a volume of water and the prey within it (MacKenzie \& Kiørboe 1995). Capture has occurred once the prey is in the mouth of the larva, and it is followed by ingestion (MacKenzie et al. 1994). The process of larval fish feeding on copepods has been mechanistically modeled by Caparroy et al. (2000) and adapted for larval cod by Fiksen \& MacKenzie (2002).

The ability of a fish larva to capture copepod prey depends on the copepod species, even when the copepods are the same size (Munk 1997), because escape behaviors vary between copepod species (Tiselius \& Jonsson 1990, Viitasalo et al. 1998, Titelman 2001, Titelman \& Kiørboe 2003). Copepods possess adaptations to reduce their vulnerability to predation, including mechanoreceptors on their setae that detect the hydrodynamic signals produced by predators (Haury et al. 1980, Yen et al. 1992). The signal that copepods perceive is the deformation rate of the fluid (Kiørboe \& Visser 1999). A deformation rate above a certain threshold will elicit an escape 'jump' (Kiørboe \& Visser 1999), where a copepod orients itself away from the predator and jumps at a speed 50 to 200 times greater than its average swimming speed (Mauchline 1998, Titelman \& Kiørboe 2003, Waggett \& Buskey 2007). The deformation rate threshold, escape jump angle, and escape jump speed are all species- and stage-specific (Tiselius \& Jonsson 1990, Viitasalo et al. 1998, Titelman 2001, Titelman \& Kiørboe 2003).

On Georges Bank (NW Atlantic) the 4 main copepod prey items of the larval gadids cod and haddock are Calanus finmarchicus, Pseudocalanus spp., Oithona similis, and Centropages typicus (Kane 1984). From gut observations of both cod and haddock, it is evident that not all potential prey species are found in the larval gut. Larval cod and haddock prefer Pseudocalanus spp., while Centropages typicus and O. similis are ingested less than in proportion to their abundance in the water column, and Calanus finmarchicus is rarely selected because of its large size (Kane 1984, Heath \& Lough 2007, Broughton \& Lough in press).
Until recently, most models of larval cod and haddock feeding have assigned stages of copepod species to different larval size classes as possible prey targets based on gut contents or the mouth gape of the larvae and width of the copepods. Current trophodynamic models of larval cod (Kristiansen et al. 2007, 2009b) include a mechanistic foraging component where encounter rate, pursuit success, and capture success determine ingestion. Kristiansen et al. (2009b) used an IBM with a mechanistic feeding component that included species-specific size information, but escape behaviors were limited to escape speed that was parameterized for the copepod Acartia tonsa. These model experiments were unable to explain why Centropages typicus is not a preferred prey item for larval cod. The authors suggested this disparity could be caused by a different behavioral strategy between Pseudocalanus spp. and $C$. typicus (which are similar in size). We expand on the Kristiansen et al. (2009b) model by including species- and stage-specific escape behaviors to determine which species and life stages of copepods larval haddock and cod can capture, and how this influences energy gained, growth, and thereby chances of survival.

An accurate understanding of foraging in haddock and cod larvae is important, since growth of both species is strongly dependent on the availability of copepod prey (Buckley \& Durbin 2006). The larval diets of these closely related species overlap significantly on Georges Bank (Kane 1984, Broughton \& Lough in press). However, the guts of haddock larvae typically contain earlier stages of copepods, smaller prey, and less biomass than the guts of cod larvae of the same size (Kane 1984, Lough \& Mountain 1996, Rowlands et al. 2008). The fin development of larvae 8 to $9 \mathrm{~mm}$ is more advanced in haddock than cod. Auditore et al. (1994) suggest that the advanced fin development may give haddock more maneuverability for setting up precise feeding strikes and selecting smaller prey. The feeding behavior of larval cod has been well characterized (MacKenzie \& Kiørboe 1995, Munk 1995, Fiksen et al. 1998, Hunt von Herbing \& Gallager 2000, Ruzicka 2004, Ruzicka \& Gallager 2006a, 2006b), but mechanistic feeding studies of larval haddock are lacking. Here we explore the differences between larval haddock and cod prey selection by modeling foraging behavior in both species.

Our objectives are to (1) use information on the morphology and physiology of larval haddock to create the first coupled mechanistic foraging and bioenergetics model for this species, (2) use speciesspecific prey behaviors in foraging models of both larval haddock and cod, and (3) examine why certain copepod species are positively or negatively selected as prey. 


\section{MATERIALS AND METHODS}

The model. The model description follows the overview, design, details (ODD) protocol for describing individual- and agent-based models (Grimm \& Railsback 2005, Grimm et al. 2006) and consists of 7 elements. The first 3 elements provide an overview, the 4 th element explains general concepts underlying the model's design, and the remaining 3 elements provide details.

Purpose. The purpose of our IBM was to improve our understanding of the complex feeding ecology of larval haddock and cod on Georges Bank. This included the interaction between copepod size/escape behavior, larval fish feeding behavior, and the abiotic environment. Analysis of the feeding ecology was made possible using a mechanistic feeding component that accounted for the processes of prey encounter, pursuit, and capture. Species-specific copepod behaviors were included in the foraging component to improve on previous work of larval cod prey selection (Kristiansen et al. 2009b). Additionally, the IBM was parameterized for larval haddock to investigate whether the model could capture the differences between larval haddock and cod diets. A bioenergetics component of the IBM was used to examine the effects of feeding on growth. In these short numerical experiments larvae did not die. They were not preyed upon, nor did they die from starvation, so the potential effects of only the fittest larvae surviving were not examined here.

State variables and scales. The model environment was a 1-dimensional water column $70 \mathrm{~m}$ deep and divided into discrete $1 \mathrm{~m}$ depth intervals. Each depth layer was characterized by temperature, light, turbulence, and prey abundance, all of which varied with time. The IBM simulated individual larval fish that were described by the state variables: species, length, weight, depth, gut size, stomach fullness, and growth rate. Prey items were identified by species (4 total: Calanus finmarchicus, Pseudocalanus spp., Oithona similis, and Centropages typicus), stage (13 total: 6 naupliar stages, NI to NVI; 5 copepodite stages, CI to $\mathrm{CV}_{\text {; }}$ and 1 adult stage separated into females and males, CVIf and CVIm), length, width, weight, and concentration. The model was run for $108 \mathrm{~h}(4.5 \mathrm{~d})$ with a time step of $1 \mathrm{~h}$.

Process overview and scheduling. For each time step, the environmental variables were updated, and then the foraging and bioenergetics components were run sequentially. Within a component, individuals were called one at a time by depth, starting at $1 \mathrm{~m}$ and ending at $70 \mathrm{~m}$. Within the foraging component, the steps of encounter, pursuit, and capture were simulated in that order, for each individual and for each species and stage of copepod. The capture process was repeated 1000 times for each individual larva and prey type to calculate a probability of successful capture. Total biomass captured by each individual for each time step was stored in the stomach, and used in the bioenergetics component to calculate energy needed to sustain metabolism. The remaining energy in the stomach was then used to calculate growth.

Design concepts. Emergence: Prey preference, a measure of what prey types an individual ingests compared to the prey types available in its environment, emerged from the mechanistically modeled foraging process of each individual fish. Additionally, the average growth rate arose from the foraging activities of all individuals.

Sensing: Visual detection of prey was light-dependent. Though larvae could not sense the deformation threshold of each copepod prey type, the approach speed was modeled to be less than that which would elicit an escape response.

Interaction: Individual larvae were assumed not to interact with each other due to their observed sparseness in nature and lack of grazing pressure on their prey populations (Pepin \& Penney 2000), thus there were no density-dependent responses and larvae were assumed not to reduce the prey density by feeding. Based on laboratory observations, we assumed that each species and stage of copepod prey was encountered and pursued, and potentially captured and ingested, one at a time. Encounter was a function of prey concentration, among other variables; it was not determined by explicitly modeling the position of each copepod relative to each larval fish.

Stochasticity: Within the foraging subroutine, probabilities of encounter, successful approach, and successful capture were used to compute the total prey ingested. The probabilities of encounter and successful approach were calculated from theoretical equations (Caparroy et al. 2000, Fiksen \& MacKenzie 2002, Kristiansen et al. 2007, 2009b). The probability of successful capture was determined from 1000 attempts of capturing each copepod species and stage. During each capture attempt, the escape jump angle of a copepod was drawn from a normal distribution with mean specific to that species and an $\mathrm{SD}$ of $30^{\circ}$, where $0^{\circ}$ was directly away from the mouth of the larval fish.

Observation: Every hour, for each individual, observations were made of all the larval state variables, the probability of successful capture of each prey item, the total number of each species and stage of prey ingested, the length and width of each prey item ingested, the total biomass ingested, and the larval growth rate.

Initialization. The model was initialized with 1 larval fish fixed at each $1 \mathrm{~m}$ depth position from surface to bottom for a total of 70 . All model simulations were repeated for 5 initial larval standard lengths: 5, 7, 9, 11, 
or $15 \mathrm{~mm}$, spanning the range of larval/early juvenile sizes measured on Georges Bank. Stomach fullness was initialized at $10 \%$ to ensure hunger, but avoid effects of immediate starvation. Model simulations were run from 13:00 h local time on 22 May to 24:00 h on 27 May for both 1993 and 1994. This period was chosen to take advantage of an existing field data set used to force the model and compared with model results (Lough et al. 2005). Several simulations were conducted to examine differences between years, differences between cod and haddock, and sensitivity to parameterization of foraging behaviors. Because the effects of stochasticity (escape jump angle) on prey ingested and growth rate were so small, the results of 1 simulation run are presented here.

Input. In situ temperature and prey concentration and modeled light and turbulence served as model input. Temperature and prey concentration were measured on the seasonally stratified southern flank of Georges Bank in May of 1993 and 1994 in a study that tracked a cohort of larvae with a drifter at $13 \mathrm{~m}$ depth (Lough et al. 2005). Temperature from conductivity, temperature, depth (CTD) observations and prey concentration from Multiple Opening/Closing Net and Environmental Sampling System (MOCNESS) collections were interpolated in space and time to produce values for each depth and each hour over the $4.5 \mathrm{~d}$. Surface light was modeled as a function of the day of the year and latitude (Skartveit et al. 1998), which was used with a constant attenuation coefficient $(k=0.18)$ to calculate exponentially decaying light at depth. Turbulence was calculated from a 1-dimensional model for Georges Bank forced by winds, hydrographic conditions, and the $\mathrm{M}_{2}$ tide (Naimie 1996).

Submodels. Foraging: The mechanistic feeding component of the IBM was built on previous work by Caparroy et al. (2000) and Fiksen \& MacKenzie (2002), and is described in detail in Kristiansen et al. (2007, $2009 b)$. The foraging submodel sequentially simulated the encounter, pursuit, and capture of prey by larval fish. Encounter occurs in front of the larva's head in a hemisphere volume with radius equal to the perception distance. The visual perception of a prey item is determined by larval size, light level, water quality between the prey and the larva (beam attenuation coefficient), prey contrast, and prey image area. Haddock and cod larvae move in a 'pause-travel' pattern (Evans \& O'Brien 1988). During the pause, the larva encounters a prey item that resides in the hemisphere in front of its head. Encounter between prey and predator is also achieved if the prey swims, or is advected by turbulence into the larval visual hemisphere during pause. These methods of encounter depend on the prey density, larval visual abilities (size and light-level dependent), prey swimming speed, and turbulent velocity. The larva will try to pursue all prey encountered. To avoid being detected by the prey, the larva always pursues at a speed that ensures that the resulting shear is below the sensitivity threshold of the prey. A copepod escapes during pursuit if the larva takes too long to reach it. The larva must travel at the undetectable speed and reach the copepod in $<10 \mathrm{~s}$, the average pursuit time measured in laboratory experiments (see Fiksen \& MacKenzie 2002). Thus, successful pursuit is controlled by the sensitivity threshold of that prey type, and the encounter distance between prey and predator. Also during pursuit, the prey can be advected by turbulence out of the perception volume of the larva (MacKenzie \& Kiørboe 2000). If the larva reaches the prey without detection or without loss by turbulent advection it reaches the attack position a short distance from the prey. During larval attack, the copepod has one last chance to escape by jumping, with its specific speed and angle, out of the volume of water that will be engulfed by the larva. If the prey remains within visual detection of the larva, the larva will try again to capture it, up to 3 times.

The mechanistic feeding component of the IBM is the same as described in Kristiansen et al. (2009b), with the exception that we included species-specific swimming and escape behaviors (swimming speed, detection threshold, escape jump angle, escape jump speed) for the dominant prey items Calanus finmarchicus, Pseudocalanus spp., Oithona similis, and Centropages typicus (see 'Copepod parameterization' below). Furthermore, the mouth gape parameter, $m$ $(\mathrm{mm})$, differed between simulations of $\operatorname{cod}\left(m_{c}\right)$ and haddock $\left(m_{h}\right)$ as follows:

$$
\begin{gathered}
m_{C}=\exp \left(-3.720+1.818 \times \ln (L)-0.1219 \times \ln (L)^{2}\right) \\
m_{h}=0.128 \times L^{0.923}
\end{gathered}
$$

where $L$ is standard length in $\mathrm{mm}$. The mouth gape sizes were empirically derived by Otterå \& Folkvord (1993) for cod and Rowlands et al. (2006) for haddock.

Bioenergetics: After the ingested prey items have been stored in the stomach from the feeding component, the IBM uses a bioenergetics component to calculate growth and metabolism. The details of this model can be found in Kristiansen et al. (2007) with the only difference being the respiration rate. Rather than using the respiration rate of Finn et al. (2002), we modeled the routine respiration rate as described in Lough et al. (2005), which was measured on larval cod from the Georges Bank population. The routine respiration rate applied in the larval haddock simulations was from a laboratory study by Lankin et al. (2008), and, like cod, was measured on fish from Georges Bank at temperatures of 4,7 , and $10^{\circ} \mathrm{C}$. The routine respiration rates $\left(\mu \mathrm{l} \mathrm{O}_{2} \mathrm{fish}^{-1} \mathrm{~h}^{-1}\right)$ of $\operatorname{cod}\left(R_{c}\right)$ and haddock $\left(R_{h}\right)$ are 


$$
\begin{gathered}
R_{C}=0.00114 \times W^{(1.029-0.00774 \times \ln (W))} \times \exp (T \times \\
(0.10720-0.00320 \times \ln (W))) \\
R_{h}=1.021 \times(W \times 1000)^{0.979} \times \exp (0.092 \times T)
\end{gathered}
$$

where $W$ is dry weight in $\mu g$, and $T$ is temperature in ${ }^{\circ} \mathrm{C}$. When light was below the threshold value of $0.01 \mu \mathrm{mol} \mathrm{s} \mathrm{s}^{-1} \mathrm{~m}^{-2}$ it was regarded as too dark to feed and the routine respiration was used in the bioenergetic calculations. Above this threshold we invoked an active metabolism of $1.4 \times R$ for larvae $<5.5 \mathrm{~mm}$ and $2.5 \times R$ for larvae $>5.5 \mathrm{~mm}$ (Lough et al. 2005). Growth was either temperature- and food-dependent or just temperature-dependent determined by the amount of biomass stored in the stomach. The amount of biomass ingested in the foraging subroutine was stored in the gut, and not allowed to exceed the capacity of the gut. If this amount of biomass was enough for maximum growth, as determined by weight, respiration rate and assimilation rate, then growth was the maximum temperature-dependent rate. If the biomass in the gut was below this amount, it was converted into body mass and growth was food-limited.

Copepod parameterization. The copepod parameters necessary for use in the mechanistic foraging model were image area, contrast, swimming speed, deformation rate threshold, escape jump speed, and escape jump angle. The image area of all species and stages was calculated for elongate prey as a function of copepod length and width (area $=0.75 \times$ length $\times$ width). Information on species-specific contrast was lacking, thus all species and stages were assumed to have the same value (0.3; Utne-Palm 1999) used to represent moderately transparent prey $0.1=$ transparent, 1.0 = black; Fiksen et al. 1998). Species- and stagespecific information on swimming speed, deformation rate threshold, escape jump speed, and escape jump angle of Calanus finmarchicus, Pseudocalanus spp., Oithona similis, and Centropages typicus was gathered from the literature. The literature comprised laboratory experiments of moving tanks with obstacles (Haury et al. 1980), stationary tanks with siphons (Fields \& Yen 1997, Viitasalo et al. 1998, 2001, Kiørboe et al. 1999, Titelman 2001, Titelman \& Kiørboe 2003), and tanks with predators (Greene et al. 1986, Tiselius \& Jonsson 1990, Viitasalo et al. 1998, Svensen \& Kiørboe 2000, Titelman 2001). The experiments recorded behaviors with video and then measured the behaviors by digital analysis.

We were not able to find data for each stage of each species for every behavior, nor was there enough data to individually fit equations to determine the behaviors as functions of stage or size. To solve this problem we assumed that mean escape jump angle was constant for a given species and that deformation rate threshold, swimming speed, and escape jump speed were proportional to length. Justification for this assumption comes from Kiørboe \& Visser (1999) who showed that the deformation rate threshold scales inversely with size, while swimming speed and escape speed are often reported in body lengths (BL) $\mathrm{s}^{-1}$ because they increase with prey size (Mauchline 1998, Caparroy et al. 2000). Some copepods have a hop-sink motility (Mauchline 1998, Titelman 2001, Titelman \& Kiørboe 2003) with 2 associated speeds. This motility was represented as 1 swimming speed by averaging the hop speed and sinking speed by the proportion of time spent performing each behavior.

Values for the behaviors were often listed in the literature for 1 developmental stage only or for a group of stages. Linear regressions of escape behavior as a function of length were created by assigning the average prosome length (Davis 1984, 1987) to each developmental stage. If 1 value of a behavior was given for a group of stages (e.g. NI to NIII) that value was used for each stage within that group. Because for certain behaviors there was only 1 value reported for 1 stage of a species, all regressions were assumed to intercept the origin.

Information on certain behaviors was lacking altogether for some species. The genus Pseudocalanus on Georges Bank comprises P. moultoni and P. newmani (McGillicuddy \& Bucklin 2002), which we parameterized using data for the closely related $P$. elongatus. Swimming speeds of a related species, Calanus pacificus, were used to fit a linear regression to the $C$. finmarchicus lengths. This method resulted in a swimming speed of $1.97 \mathrm{BL} \mathrm{s}^{-1}$, which is equivalent to the $2 \mathrm{BL} \mathrm{s}^{-1}$ found by Hardy \& Bainbridge (1954 in Mauchline 1998) for $C$. finmarchicus nauplii. It is a conservative estimate for copepodites and adults that have been reported to swim up to $5 \mathrm{BL} \mathrm{s}^{-1}$ (Mauchline 1998). The literature on Oithona similis escape speed provided the average velocities of initial escape attempts (47.2 $\left.\mathrm{BL} \mathrm{s}^{-1}\right)$ and the final escape attempt (77.0 BL s${ }^{-1}$ ) that freed the individual from siphon flow (Fields 2000). The average of escape speed of the other 3 copepod species in $\mathrm{BL} \mathrm{s} \mathrm{s}^{-1}\left(74.1 \mathrm{BL} \mathrm{s}^{-1}\right)$ was closer to the final escape attempt speed of $O$. similis, and this average was used in the simulations. Finally, there was no information on $O$. similis or Pseudocalanus spp. escape angle. Escape angles for $O$. similis and Pseudocalanus spp. were assumed to be $30^{\circ}$ (0.524 radians), the value used by Fiksen \& MacKenzie (2002) that they adapted from results in Titelman (2001). The equations for copepod escape behavior and their sources are given in Table 1. We recognize that copepod behavior is more complex than what is represented by these functions; however, they are a first attempt at incorporating species-specific copepod behavior into larval fish foraging models. 
Larval haddock parameterization. Like cod, haddock is a saltatory (pause-travel) forager (Auditore et al. 1994). Saltatory foraging is distinguished by a swimming burst used to move to a new search location, a glide while the larva slows down, and a pause, during which the larva searches for prey (Evans \& O'Brien 1988). Behavioral characteristics of the saltatory foraging strategy include burst speed, burst duration (BD), pause duration (PD), and pause frequency $(\mathrm{PF})$. These characteristics have been measured for cod (MacKenzie \& Kiørboe 1995, Munk 1995, Fiksen et al. 1998, Hunt von Herbing \& Gallager 2000, Ruzicka \& Gallager 2006b), but not for haddock. Therefore, larval haddock foraging behavior must be inferred from unpublished studies of haddock and published information about number, type, and biomass of prey ingested.

Laurence (1985) defines search capacity as the product of the larval swimming speed and the crosssectional area of its perception volume, and reports that larval haddock has a lower search capacity as a function of weight in comparison to cod larvae. However, in studies of larval haddock and cod (Werner et al. 1996, Lough et al. 2005), length is used as a measure of age rather than weight because their mean length at age is equivalent (Bolz \& Lough 1988). At a given length, a larval haddock weighs more than cod (Fig. 1a). Thus, the search capacities of haddock and cod as a function of length, a proxy for age, are relatively equal (Fig. 1b). The search volume geometry of cod has been approximated as a hemisphere (Hunt von Herbing \& Gallager 2000, Fiksen \& MacKenzie 2002). In contrast, unpublished laboratory observations (H. Browman unpubl. data) led Galbraith et al. (2004) to conclude that the search volume geometry of a $6 \mathrm{~mm}$ cod larva is a wedge. However, the different perception distances used with each search volume geometry result in equivalent volumes of water searched (Ruzicka \& Gallager 2006a). Additionally, Mariani et al. (2007) found that model results using hemisphere geometry were more consistent with laboratory and field observations of larval cod. Taking into account the equivalent search capacities of cod and haddock, we assumed that the swimming speed and perception distance of haddock and cod could be treated as equal for a given length, and that their search geometry was hemispherical. If larval haddock eat significantly smaller prey than cod then that must be attributed to differences in metabolism, mouth size, and other aspects of foraging behavior such as PD and PF.

To understand the sensitivity of haddock gut contents to changes in foraging behavior, 3 different simulations were completed using different sets of parameters, but forced by the same environmental conditions from May 1993. All 3 used mouth size as a function of length from Rowlands et al. (2006; our Eq. 2) and a length-weight re-

Table 1. Calanus finmarchicus, Pseudocalanus spp., Oithona similis, and Centropages typicus. Functions for copepod escape behavior. L: body length (mm), NI to NVI: 6 naupliar stages, CI to CV: 5 copepodite stages, CVI: adult stage

\begin{tabular}{|c|c|c|c|c|}
\hline Species & Parameter & Function & Species: stages & Source \\
\hline \multicolumn{5}{|c|}{ C. finmarchicus } \\
\hline & Swimming speed $\left(\mathrm{mm} \mathrm{s}^{-1}\right)$ & $1.97 \times \mathrm{L}$ & C. pacificus: NII-NIII, NV-CVI & Greene et al. (1986) \\
\hline & Escape speed $\left(\mathrm{mm} \mathrm{s}^{-1}\right)$ & $74.5 \times \mathrm{L}$ & C. finmarchicus: CIV-CV & Haury et al. (1980) \\
\hline & Sensitivity threshold $\left(\mathrm{s}^{-1}\right)$ & $1.00 \times \mathrm{L}^{-1}$ & C. finmarchicus: CV & Kiørboe et al. (1999) \\
\hline & Escape jump angle (rad) & 1.13 & C. finmarchicus: CIV-CV & Haury et al. (1980) \\
\hline \multicolumn{5}{|c|}{ Pseudocalanus spp. } \\
\hline & Swimming speed $\left(\mathrm{mm} \mathrm{s}^{-1}\right)$ & $0.859 \times \mathrm{L}$ & P. elongatus: CII-CIV, CVI & Tiselius \& Jonsson (1990) \\
\hline & & & Pseudocalanus spp.: NIII-CI & Landry \& Fagerness (1988) \\
\hline & Escape speed $\left(\mathrm{mm} \mathrm{s}^{-1}\right)$ & $57.3 \times \mathrm{L}$ & P. elongatus: CI-CVI & Viitasalo et al. (2001) \\
\hline & Sensitivity threshold $\left(\mathrm{s}^{-1}\right)$ & $2.78 \times \mathrm{L}^{-1}$ & P. elongatus ${ }^{\mathrm{a}}$ : CI-CVI & Viitasalo et al. (2001) \\
\hline & Escape jump angle (rad) & 0.524 & - & - \\
\hline \multicolumn{5}{|l|}{ O. similis } \\
\hline & $\begin{array}{l}\text { Swimming speed }\left(\mathrm{mm} \mathrm{s}^{-1}\right) \\
\text { Escape speed }\left(\mathrm{mm} \mathrm{s}^{-1}\right)\end{array}$ & $\begin{array}{l}0.708 \times \mathrm{L} \\
74.1 \times \mathrm{L}\end{array}$ & $\begin{array}{c}\text { Oithona sp.: CVI } \\
\text { - }\end{array}$ & $\begin{array}{l}\text { Svensen \& Kiørboe (2000) } \\
\qquad-\end{array}$ \\
\hline & Sensitivity threshold $\left(\mathrm{s}^{-1}\right)$ & $2.66 \times \mathrm{L}^{-1}$ & Oithona sp.: CVI & Kiørboe et al. (1999) \\
\hline & Escape jump angle (rad) & 0.524 & - & - \\
\hline \multirow{5}{*}{ C. typicus } & Surimminc snond $\left(\mathrm{mm}^{-1} \mathrm{~s}^{-1}\right.$ & & & \\
\hline & Swimming speed (mm s ${ }^{1}$ ) & $1.301 \times \mathrm{L}$ & $\begin{array}{l}\text { C. typicus: CIV-CVi } \\
\text { C. typicus: NI-NII, NIV-NV, CVI }\end{array}$ & $\begin{array}{l}\text { Tiselius \& Jonsson (1990) } \\
\text { Titelman \& Kiørboe (2003) }\end{array}$ \\
\hline & Escape speed $\left(\mathrm{mm} \mathrm{s}^{-1}\right)$ & $90.6 \times \mathrm{L}$ & C. typicus: NI-NII, NIV-NV, CVI & Titelman \& Kiørboe (2003) \\
\hline & Sensitivity threshold $\left(\mathrm{s}^{-1}\right)$ & $0.396 \times \mathrm{L}^{-1}$ & C. typicus: NI-NII, NIV-NV, CVI & Titelman \& Kiørboe (2003) \\
\hline & Escape jump angle (rad) & 0.421 & C. typicus: NI-NII, NIV-NV, CVI & Titelman \& Kiørboe (2003) \\
\hline
\end{tabular}



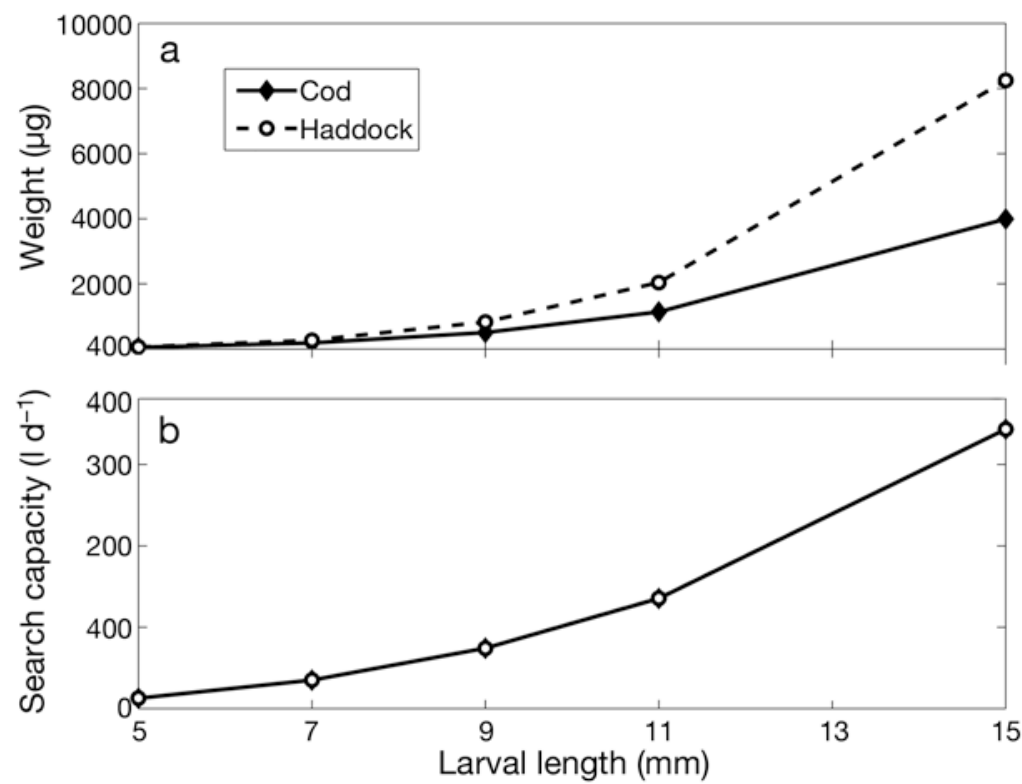

Fig. 1. Melanogrammus aeglefinus and Gadus morhua. (a) Dry body mass of larvae as a function of length as determined by the species-specific equations in Laurence (1985). (b) Search capacity of larvae as a function of length. Note that the lines in (b) are overlapping. Weight for both species was calculated from length (a), and then search capacity was calculated from weight. Both calculations used the species-specific equations of Laurence (1985)

ment (Ivlev 1961). Active prey selection occurs when a predator actively selects and rejects prey, possibly for taste or nutritional value, while fixed prey selection occurs because some prey types are more vulnerable than others (Greene et al. 1986). Chesson's preference index, $\alpha_{i}$ detects prey selection by measuring preference for a specific prey type relative to its abundance and the abundance of the other prey types (Chesson 1978). It is calculated as

$$
\alpha_{i}=\frac{\left(r_{i} / n_{i}\right)}{\sum_{i=1}^{m}\left(r_{i} / n_{i}\right)}
$$

where $r_{i}$ is the number of prey type $i$ in the diet, $n_{i}$ is the abundance of prey type $i$ in the environment, and $m$ is the total number of prey types. Neutral selection occurs when prey types are eaten in amounts proportional to their abundance in the environment $(1 / m)$. A preference value above neutral indicates positive selection, whereas a value below specifies negative selection (Chesson 1978). Chesson's preference index was also used to calculate

lationship derived for haddock and a routine respiration rate as a function of weight and temperature calculated for haddock by Lankin et al. (2008; our Eq. 4). PF and PD were the only behavioral characteristics varied between simulations (Table 2). The first baseline simulation used $\mathrm{PF}$ and $\mathrm{PD}$ values employed for larval cod $>5.5 \mathrm{~mm}$ by Lough et al. (2005), PF $=0.53 \mathrm{~s}^{-1}$ and $\mathrm{PD}=1.4 \mathrm{~s}$. The second and third simulations respectively used PF values $200 \%$ and $50 \%$ of those for cod. According to Ruzicka \& Gallager (2006b) the BD of larval cod is relatively constant across different environmental conditions, but PF and PD are plastic. PF and PD are inversely related, such that if one is increased the other must decrease so that $\mathrm{BD}+\mathrm{PD}=\mathrm{PF}^{-1}$ (Ruzicka 2004). This formulation was used to calculate the PD for the second and third simulations assuming that BD for haddock is equal to that of cod. PF was chosen as the behavior to alter because it has a greater effect in the encounter rate model. We looked at the effects of foraging behavior parameters on average biomass and prey length ingested and Chesson's preference index. Percent error was calculated between observations and each simulation (model-data misfit). Percent difference of the 200\% and $50 \%$ simulations from the baseline haddock model were also calculated.

Prey preference index. Prey selection is defined as a difference between the composition of a predator's diet and the availability of prey types in the environ- ratios of preferred prey length to larval length, and preferred prey width to larval length.

Simulation experiments. A total of 40 simulations were run: 5 initial larval lengths $(5,7,9,11$, and 15 mm), 2 yr (1993, 1994), 2 species (cod, haddock), and 3 different parameterizations for haddock (50, 100 , and $200 \%$ PF). The larvae were initialized at different lengths to compare their foraging and growth results to observations of 3 to $5 \mathrm{~mm}, 6$ to $8 \mathrm{~mm}$, and 9 to $13 \mathrm{~mm}$ larvae (Lough et al. 2005, Broughton \& Lough in press). Both haddock and cod were simulated in order to compare and contrast their prey preferences. Due to the uncertainty of haddock foraging behavior, 3 different parameterizations of PF and PD were completed to examine their effect on prey preference and growth.

Table 2. Melanogrammus aeglefinus. Saltatory foraging behavior parameters and values used for haddock simulations. PF: pause frequency; PD: pause duration

\begin{tabular}{|lcc|}
\hline \multirow{2}{*}{ Parameter } & \multicolumn{2}{c|}{ Value used for simulation } \\
& PF $\left(\mathrm{s}^{-1}\right)$ & PD (s) \\
\hline Baseline $^{\mathrm{a}}$ & 0.53 & 1.40 \\
$200 \%$ of baseline PF value & 1.06 & 0.457 \\
$50 \%$ of baseline PF value & 0.265 & 3.287 \\
a From Lough et al. (2005) & & \\
\hline
\end{tabular}




\section{RESULTS}

\section{Copepod escape parameters}

The accuracy of the copepod behavior functions was assessed by comparing them to observations. Viitasalo et al. (2001) observed that adult Pseudocalanus spp. had a lower deformation rate threshold compared to adult Temora longicornis. From our equations, the detection threshold of an adult Pseudocalanus is $2.8 \mathrm{~s}^{-1}$, which is less than the $6.5 \mathrm{~s}^{-1}$ calculated for an adult $T$. longicornis (Kiørboe et al. 1999). Other sources of agreement between the equations and observations include the Calanus finmarchicus deformation threshold being much less than that of Oithona similis (Kiørboe et al. 1999), and that nauplii of any particular species need larger deformation rates than copepodites of that same species (Titelman 2001). Titelman \& Kiørboe (2003) used a model to calculate which type of swimming style would result in the greatest encounter rates with larval cod. When all else was held constant, encounter rate decreased in the order of the following styles: high-frequency hopsink, medium-frequency hop-sink, continuously cruising in straight lines, continuously cruising in loops, and low-frequency hopsink. By using our equations for swimming speed to estimate encounter rate for hypothetical copepods of the same size, encounter would be greatest for C. finmarchicus, followed by Centropages typicus, then Pseudocalanus spp., and lastly $O$. similis. Since the motility of $C$. finmarchicus and C. typicus is medium-frequency hopsink, Pseudocalanus spp. is a continuous swimmer, and $O$. similis has a low-frequency hop-sink motility (Mauchline 1998, Titelman \& Kiørboe 2003), our results agree with those of Titelman \& Kiørboe (2003).

Escape angle (where $0 \% 180^{\circ}$ is directly away from/towards the predator) increased with Centropages typicus, Pseudocalanus spp. and Oithona similis, and lastly, Calanus finmarchicus (Fig. 2a). O. similis had the slowest swimming speed, followed by Pseudocalanus spp., C. typicus, and C. finmarchicus (Fig. 2b). C. finmarchicus was the fastest at escape jumping, with C. typicus, Pseudocalanus spp., and $O$. similis slower (Fig. 2c). Of the 4 main prey targets, the most sensitive (lowest deformation rate threshold) was $C$. typicus, then $C$. finmarchicus, with the much less sensitive Pseudocalanus spp. and $O$. similis following (Fig. 2d).

\section{Modeled haddock feeding on observed prey densities}

At prey densities observed in May of 1993 and 1994 on Georges Bank, larval haddock had the greatest probability of capturing Oithona similis, followed by Pseudocalanus spp., Centropages typicus, and Calanus finmarchicus in decreasing order (e.g. see 5 and 9 mm cases for 1993 in Fig. 3a,b). The probabil-

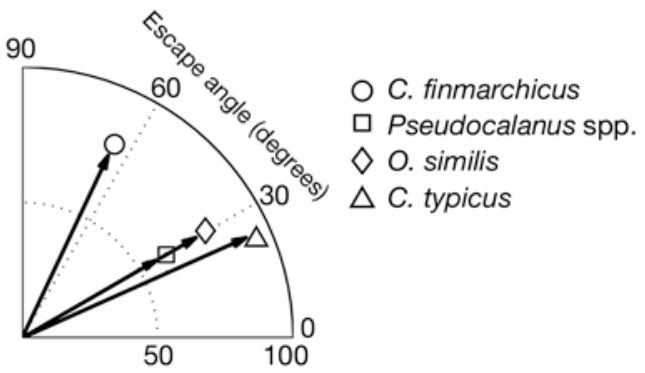

a
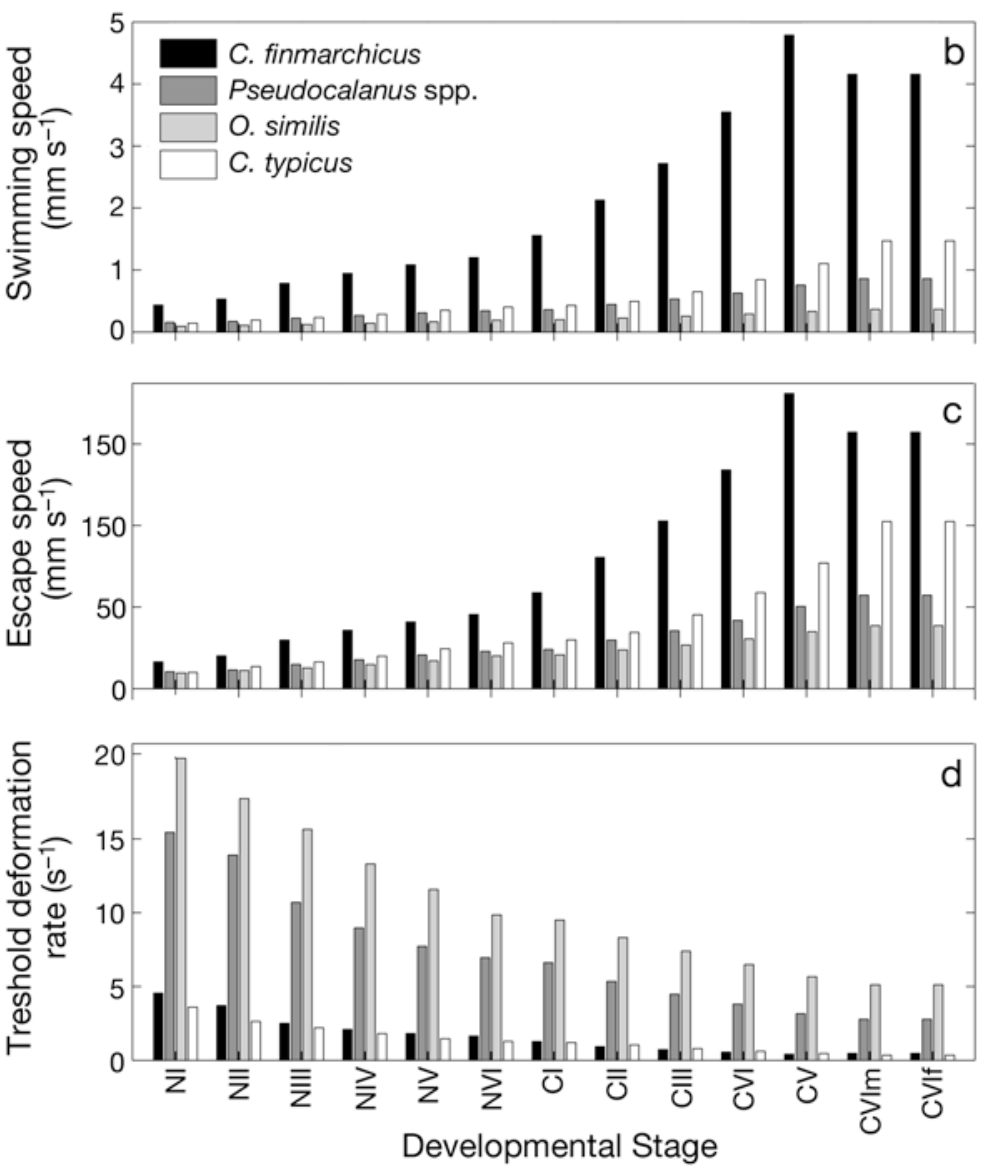

Fig. 2. Calanus finmarchicus, Pseudocalanus spp., Oithona similis, and Centropages typicus. Parameterized (a) escape jump angle and speed for each species, (b) swimming speed, (c) escape jump speed, and (d) deformation rate threshold of each developmental stage. BL: body length, NI to NVI: 6 naupliar stages, CI to CV: 5 copepodite stages, CVIf: adult female, CVIm: adult male 
ity of capturing a given copepod stage increased with larval size (cf. Fig. 3a,b). Chesson's preference index for all sizes in both years revealed a strong preference for Pseudocalanus spp. (e.g. 1993, Fig. 3c,d). Some stages of $O$. similis and $C$. typicus were positively selected, while others negatively (cf. Fig. 3c,d). Larval haddock under $15 \mathrm{~mm}$ in length had a negative selection for all stages of C. finmarchicus (Fig. 3c,d). In both years, haddock increasingly preferred larger, later stages as the larva grew (e.g. 1993, Fig. 3c,d). As larval size increased, preference for $C$. finmarchicus and
C. typicus increased, $O$. similis preference decreased, and preference for Pseudocalanus spp. varied little with haddock length (Table 3 ). On average, modeled larval haddock preferred in decreasing order: Pseudocalanus spp., C. typicus, O. similis, and C. finmarchicus (Table 3). Using prey densities from 1994 resulted in a decrease in preference for Pseudocalanus spp. and C. typicus, and an increase in preference for C. finmarchicus and O. similis (Table 3) compared to 1993.

The ratio of preferred prey length to larval length was between 0.03 and 0.13 for both 5 and $9 \mathrm{~mm}$ larval
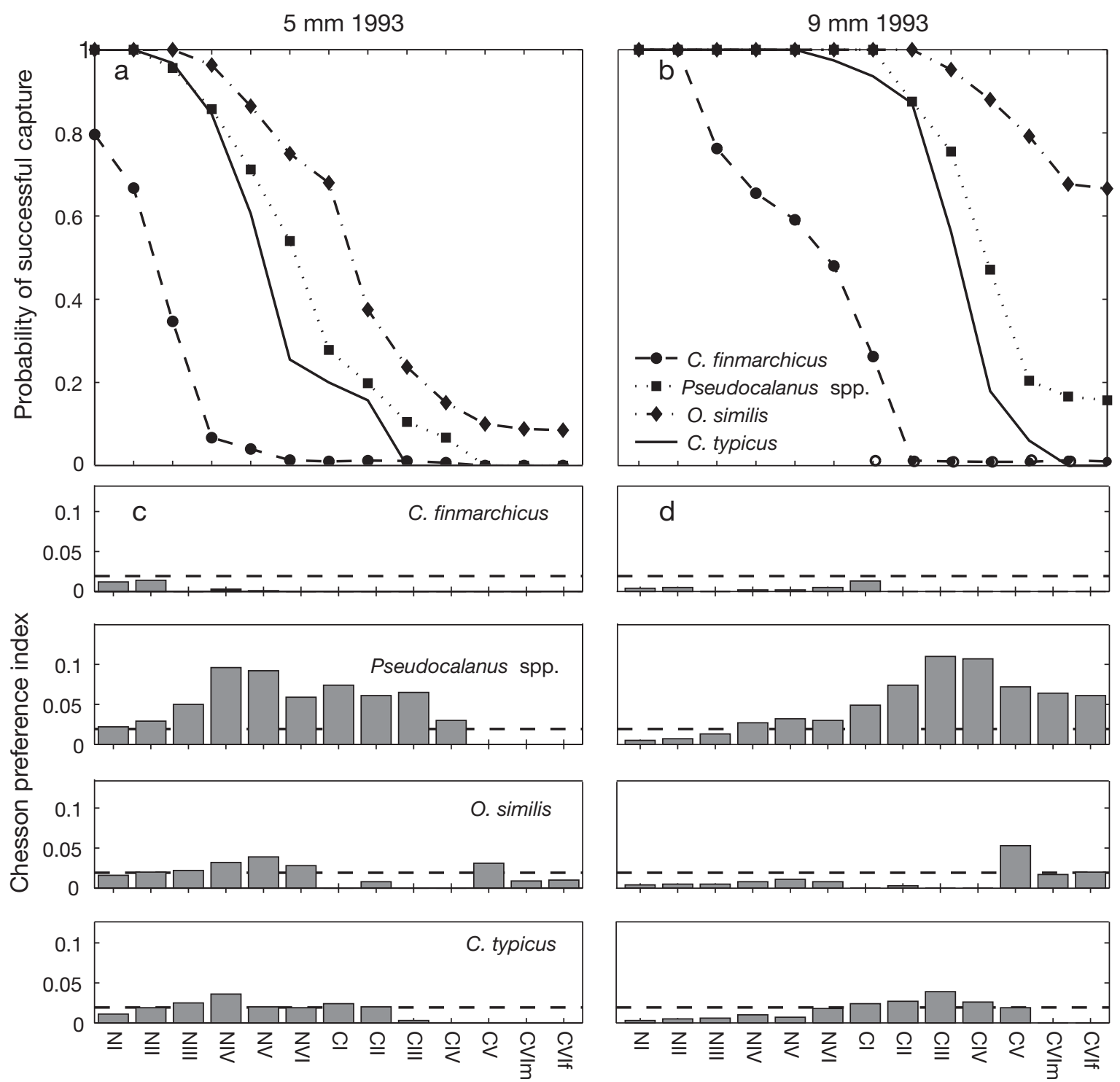

\section{Developmental stage}

Fig. 3. Melanogrammus aeglefinus. Modeled probability of successful capture for (a) $5 \mathrm{~mm}$ and (b) 9 mm larvae. Modeled Chesson's preference index for each developmental stage of Calanus finmarchicus, Pseudocalanus spp., Oithona similis, and Centropages typicus feeding on observed copepod densities from 1993 for (c) $5 \mathrm{~mm}$ and (d) $9 \mathrm{~mm}$ larvae. The dashed line indicates neutral selection, $\alpha=0.019$. NI to NVI: 6 naupliar stages, CI to CV: 5 copepodite stages, CVIf: adult female, CVIm: adult male 
Table 3. Melanogrammus aeglefinus. Sum of modeled larval haddock Chesson's preference index $(\times 100)$ of all developmental stages of each copepod species. Neutral selection $\alpha=25$

\begin{tabular}{|lcccccc|}
\hline & \multicolumn{7}{c|}{ Chesson's preference index $(\times 100)$} & \\
\cline { 2 - 7 } Copepod species & 5 & 7 & 9 & 11 & 15 & Mean \\
\cline { 2 - 7 } & & & & & & \\
\hline $\mathbf{1 9 9 3}$ & 3.0 & 2.8 & 3.1 & 4.4 & 8.2 & 4.3 \\
Calanus finmarchicus & 57.8 & 65.8 & 65.1 & 65.1 & 60.9 & 62.9 \\
Pseudocalanus spp. & 21.5 & 12.9 & 13.4 & 11.0 & 7.0 & 13.2 \\
Oithona similis & 17.7 & 18.4 & 18.4 & 19.5 & 24.0 & 19.6 \\
Centropages typicus & & & & & & \\
1994 & 2.9 & 5.4 & 4.9 & 5.1 & 8.7 & 5.4 \\
Calanus finmarchicus & 57.0 & 59.6 & 59.1 & 60.2 & 59.1 & 59.0 \\
Pseudocalanus spp. & 23.0 & 18.5 & 19.1 & 16.3 & 11.0 & 17.6 \\
Oithoma similis & 17.1 & 16.6 & 16.8 & 18.5 & 21.4 & 18.1 \\
Centropages typicus & 17.6 & \\
\hline
\end{tabular}

haddock (Fig. 4a,b). The ratio of preferred prey width to larval length was wider for $5 \mathrm{~mm}$ larvae $(0.02$ to 0.08; Fig. 4c) than for $9 \mathrm{~mm}$ larvae $(0.015$ to 0.045 ; Fig. 4d). However, the strength of preference for all copepod stages of the same length and/or width was not the same, with Pseudocalanus spp. being the highest (Fig. 4). The same results were obtained for the 1994 runs (data not shown), thus, simulated haddock larvae preferred prey with the same length to larval length ratio in both years. The average prey length eaten in 1994, however, was greater than in 1993 for the 7, 9, and $11 \mathrm{~mm}$ size classes (Fig. 5a). The average biomass ingested increased with larval size and was greater in 1994 than 1993 for all sizes (Fig. 5b). The average growth rate $\left(\% \mathrm{~d}^{-1}\right)$ increased until $11 \mathrm{~mm}$ and then declined for $15 \mathrm{~mm}$ haddock larvae (Fig. 5c). Growth rates were also higher in 1994 than 1993 for all sizes of larval haddock (Fig. 5c) and all depths above $65 \mathrm{~m}$ (Fig. 5d). Growth was negative at depths below $55 \mathrm{~m}$ (Fig. 5d).

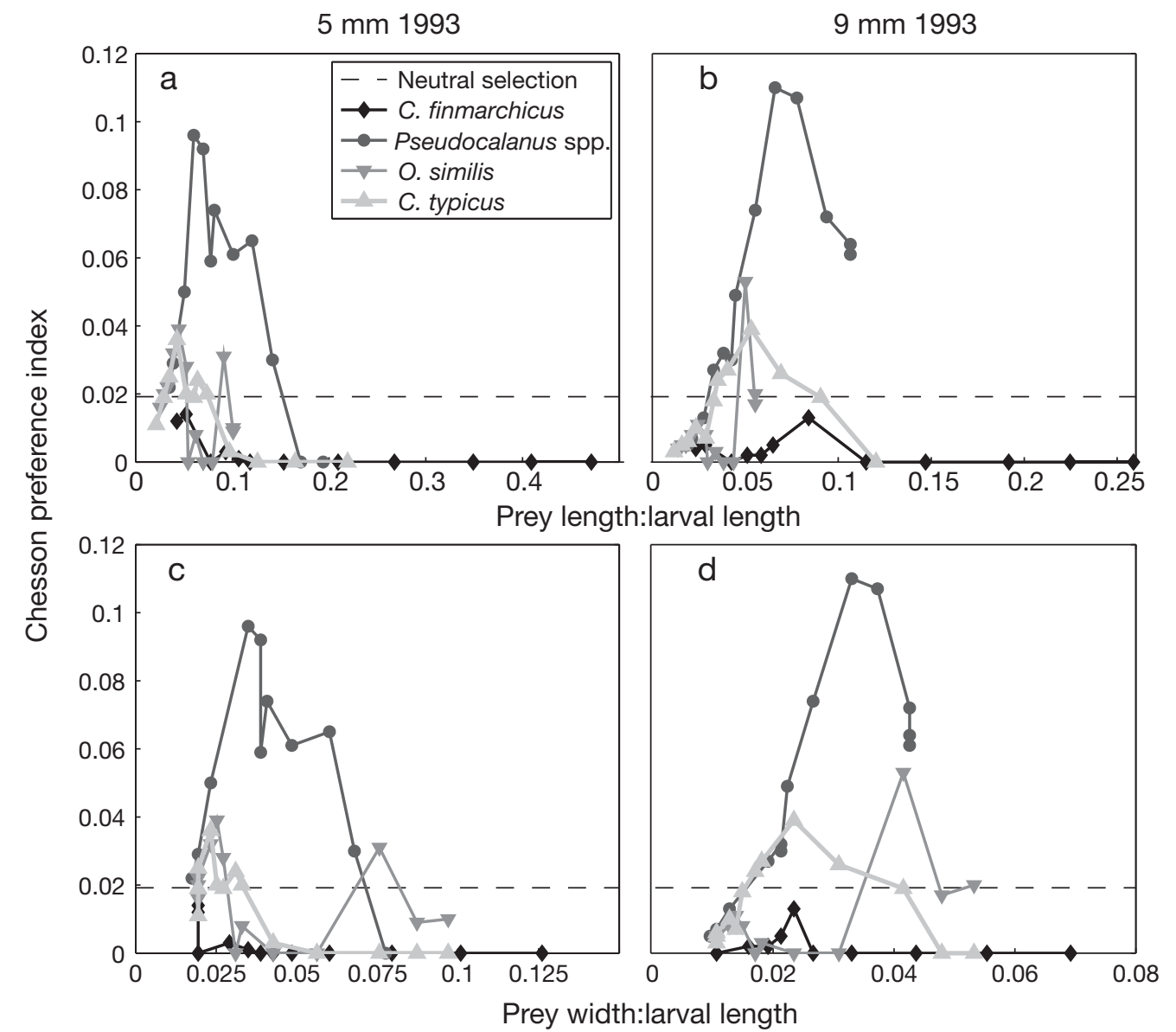

Fig. 4. Melanogrammus aeglefinus. Modeled preference as a function of prey length:larval length ratio (a,b) and prey width: larval length ratio (c,d) for Calanus finmarchicus, Pseudocalanus spp., Oithona similis, and Centropages typicus with prey densities observed in 1993 for $(\mathrm{a}, \mathrm{c}) 5 \mathrm{~mm}$ and $(\mathrm{b}, \mathrm{d}) 9 \mathrm{~mm}$ larvae 


\section{Comparisons between modeled haddock and cod}

The qualitative differences between simulations for cod using observed prey distributions from 1993 and 1994 were the same as those for haddock. The probability of cod capturing a given copepod species followed the same decreasing order as found for haddock: Oithona similis, Pseudocalanus spp., Centropages typicus, and Calanus finmarchicus. At $5 \mathrm{~mm}$, the probability of capturing each stage was greater for haddock (Fig. 6a). At $7 \mathrm{~mm}$ the probabilities of capture were very similar, with cod slightly greater than haddock for the stages where they differed (data not shown). Larger cod (9 to $15 \mathrm{~mm}$ ) had a greater probability of successful capture of all copepod species and stages (Fig. 6b-d).

Under observed prey conditions, the differences in Chesson's preference index between haddock and cod appeared small under both 1993 and 1994 conditions (cf. 1993 in Fig. 7), with nearly identical preferences in both years. Nonetheless, for prey densities observed in 1993 and 1994, $5 \mathrm{~mm}$ haddock ate on average larger prey than cod, while cod in the 9 to $15 \mathrm{~mm}$ length classes ate larger prey than haddock (Fig. 8a,b). On average, haddock larvae consumed a greater biomass of copepods than cod for all sizes and years (Fig. 8c,d). Average daily growth rates were greater for $5 \mathrm{~mm}$ haddock larvae, equivalent for $7 \mathrm{~mm}$ larvae, and greater for 9 to $15 \mathrm{~mm}$ cod larvae as modeled for both years (Fig. 8e,f). By depth, the growth rates were similar in 1993 (Fig. 8g), with cod growth rates greater in the surface and deep waters. In 1994, cod growth exceeded that of haddock at all depths (Fig. 8h).

\section{Comparisons to observations}

Observations of larval haddock and cod gut contents as well as measurements of RNA:DNA ratios were made on the same cruise that measured the prey distribution used to force the model (Lough et al. 2005). Modeled foraging results were compared to observed gut contents and the resulting Chesson's preference index (Broughton \& Lough in press), while growth rates were compared to those calculated from the RNA:DNA ratios and reported by Lough et al. $(1997,2005)$.

The observed prey composition in the gut did not differ between each corresponding size class (3 to $5 \mathrm{~mm}$, 6 to $8 \mathrm{~mm}$, and 9 to $13 \mathrm{~mm}$ ) of larval haddock and cod for both 1993 and 1994 ( $\chi^{2}$ test, $p>0.05$ ). The absence of statistically significant differences in gut contents, as well as significant niche overlap (Broughton \& Lough in press), are reflected in the nearly identical modeled preferences of haddock and cod (Fig. 7). The model was able to capture some qualitative differences, such as haddock eating smaller prey than cod (Fig. 8a,b) and haddock eating younger stages of copepods for longer than cod. Broughton \& Lough (in press) found that in 1994 cod larvae shifted to larger, later-stage copepods sooner than haddock larvae. A similar trend can be seen in the modeled Chesson's preference index grouped by stage, where 7 and $9 \mathrm{~mm}$ cod had greater preference for Pseudocalanus spp. adults and the larger copepodite stages of all species, while haddock showed stronger preference for the smaller
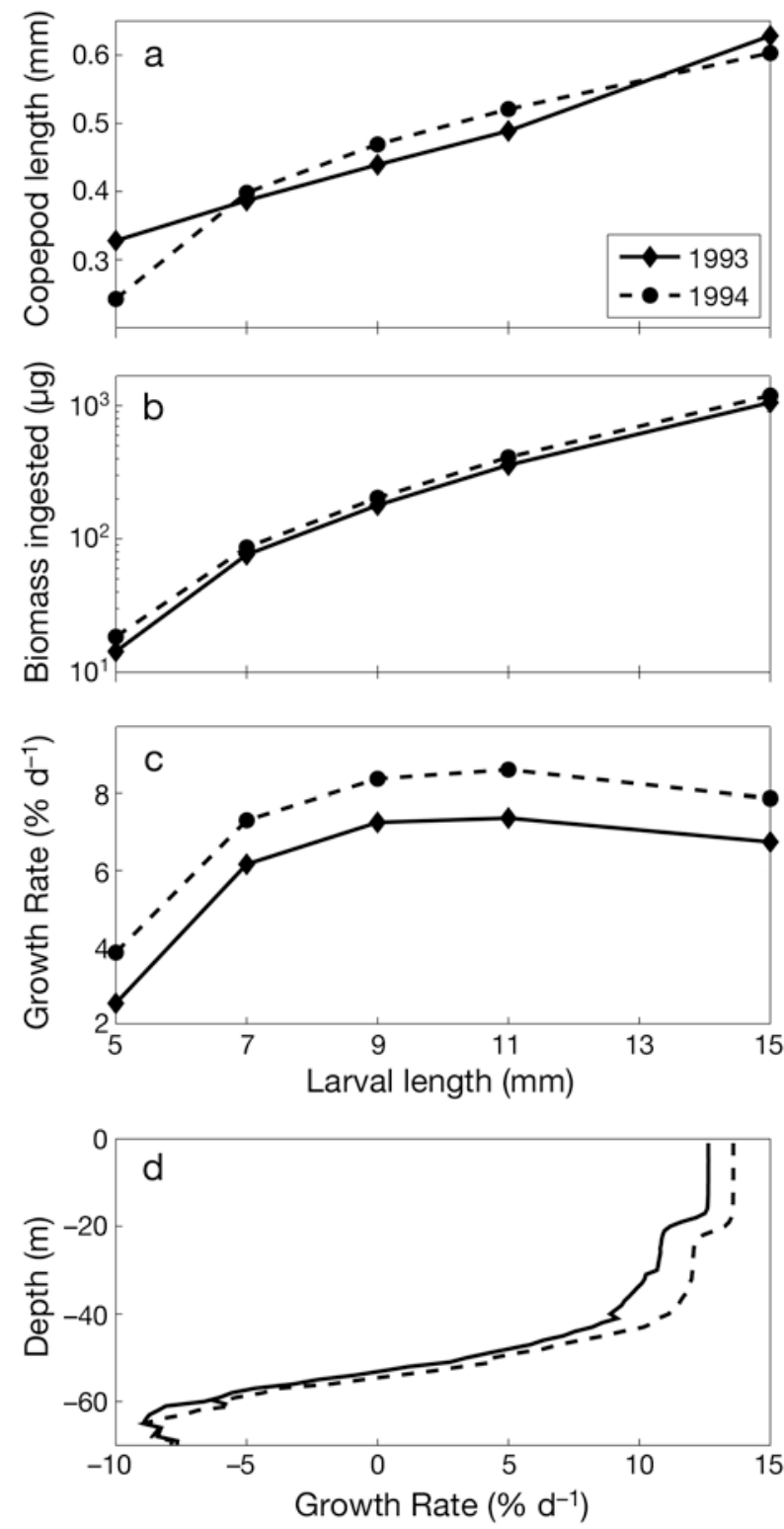

Fig. 5. Melanogrammus aeglefinus. Modeled (a) average length of prey eaten by each size class, (b) average copepod biomass (dry wt) ingested daily by each size class, and average daily growth rate by (c) size and (d) depth, for simulations under observed prey conditions from 1993 (solid line) and 1994 (dashed line) 
Oithona similis, Pseudocalanus spp., and Centropages typicus nauplii (Fig. 9).

Broughton \& Lough (in press) established that Chesson's preference indices of haddock and cod demonstrate positive selection for all life stages of Pseudocalanus spp. and varying life stages of Oithona similis, which agrees with model results. To perform a statistical comparison, Chesson's preference index was calculated from the modeled individuals in the 10 observed MOCNESS depth bins (midpoints of surface, $5,15,25,30,35,45,50,55$, and $60 \mathrm{~m}$ ). The index for each depth bin was then weighted by the number of individual larvae observed in that depth bin. These values were averaged to produce an index weighted by depth for each of the 52 prey types. The observed Chesson's preference index was given for a group of stages (Calanus finmarchicus: NI to NIII, NIV to NVI, CI to CII, CIII to CIV, CV to CVI; Pseudocalanus spp., Oithoma similis, and Centropages typicus: NI to NIII, NIV to NVI, CI to CIII, CIV to CV, CVI), thus modeled indices for the stages within a group were added together to create 1 index for each group. This was done for each of the $5,7,9$, and $11 \mathrm{~mm}$ size classes.

A Kendall rank correlation analysis was performed to assess agreement between the observed and depthweighted modeled preference indices. The correlation coefficients demonstrate weak to moderate agreement (Table 4). Independence was rejected in 7 out of 16 cases with $\mathrm{p}<0.05$ and 12 cases with $\mathrm{p}<0.1$ (Table 5), suggesting that the model was capturing aspects of the observations.

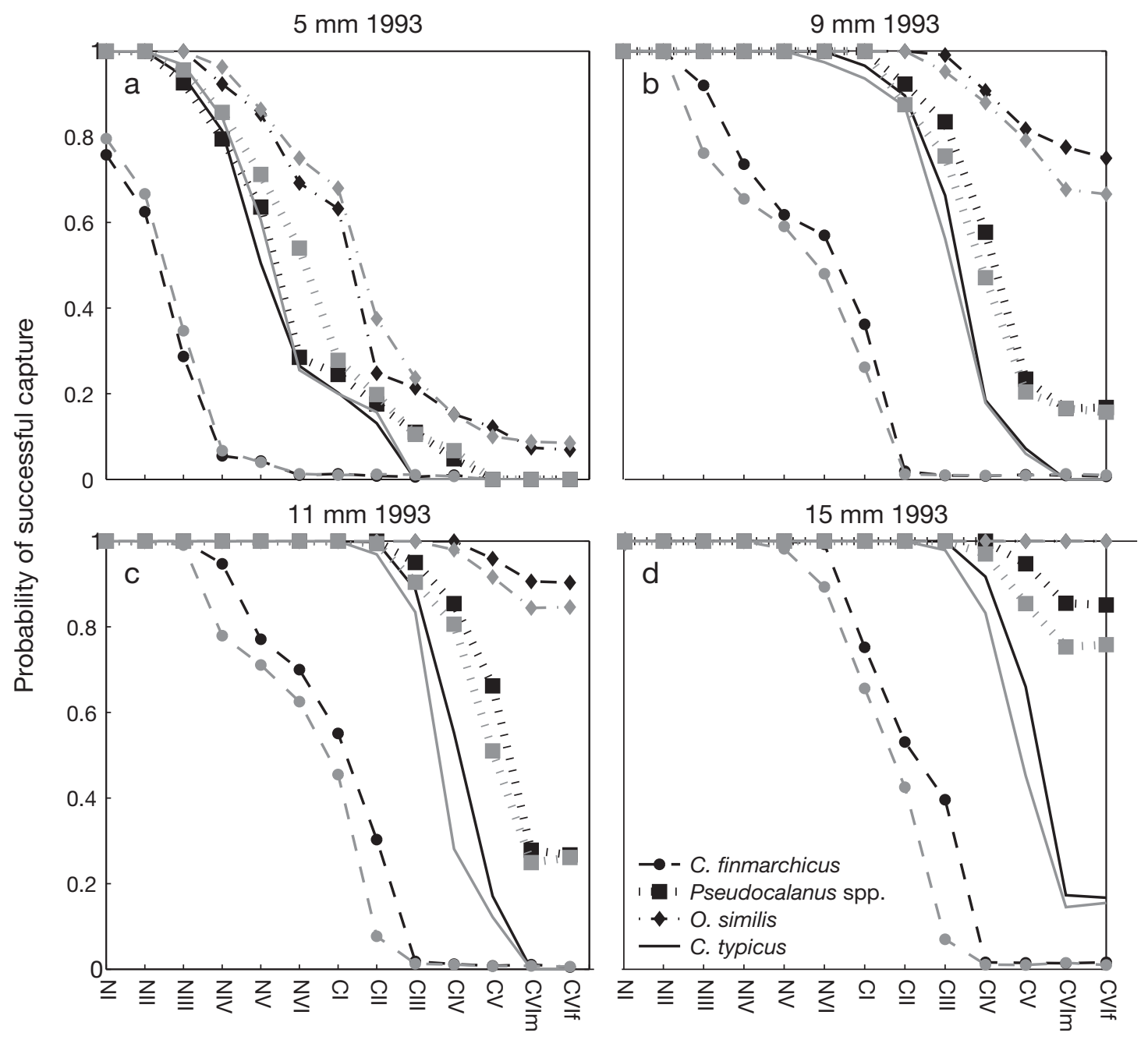

Developmental stage

Fig. 6. Melanogrammus aeglefinus (gray) and Gadus morhua (black). Differences in modeled probability of successful capture for each developmental stage of Calanus finmarchicus, Pseudocalanus spp., Oithona similis, and Centropages typicus under 1993 observed prey conditions for larvae of size (a) $5 \mathrm{~mm}$, (b) $9 \mathrm{~mm}$, (c) $11 \mathrm{~mm}$, and (d) $15 \mathrm{~mm}$. NI to NVI: 6 naupliar stages, CI to CV: 5 copepodite stages, CVIf: adult female, CVIm: adult male 
The lengths of copepods eaten by larval haddock and cod do not differ significantly (Wilcoxon rank-sum test, $\mathrm{p}>0.05$ ) with the exception of the $5 \mathrm{~mm}$ length class in 1994 (Wilcoxon rank-sum test, p = 0.02). Contrary to model results (Fig. 8b), field-caught cod larvae of 3 to $5 \mathrm{~mm}$ ate larger prey than haddock larvae in 1994. From observations of 5 to $11 \mathrm{~mm}$ haddock and cod, the average length of copepods eaten predicted by the model fell within $1 \mathrm{SD}$ for haddock 5 to $9 \mathrm{~mm}$ in 1993 and 5 to $11 \mathrm{~mm}$ in 1994, and for cod 5 to $11 \mathrm{~mm}$ in 1993 and 5 to $9 \mathrm{~mm}$ in 1994 (Fig. 10). The model had a tendency to underestimate the average length eaten by the larger larvae.

There was no statistical difference between the observed amount of biomass ingested by haddock and cod larvae (Wilcoxon rank-sum test, p > 0.05), again with the exception of the $5 \mathrm{~mm}$ size class in 1994, where cod ate significantly more biomass than haddock (Wilcoxon rank-sum test, $\mathrm{p}=0.02$ ). This one difference is not reflected in the model; $5 \mathrm{~mm}$ haddock and cod ate roughly the same amount of biomass in 1994 (0.75 and $0.73 \mu \mathrm{g}$ respectively; Fig. 8d). The amount of biomass found in the guts of field-caught larvae was greater than that simulated by the models for haddock and cod of all sizes and years. With the exception of $11 \mathrm{~mm}$ haddock in 1993, biomass estimates were within $1 \mathrm{SD}$ of observed values (Fig. 11a-d). Haddock and cod ingested more biomass in 1994 than 1993 for all sizes of larvae in simulations (Figs. 5b \& 8c,d), whereas observed $11 \mathrm{~mm}$ haddock and $9 \mathrm{~mm}$ cod larvae did not (Fig. 11e,f).

Finally, model growth rates were compared to those measured from field-collected larval haddock (Lough et al. 1997) and cod (Lough et al. 2005) from the May 1993

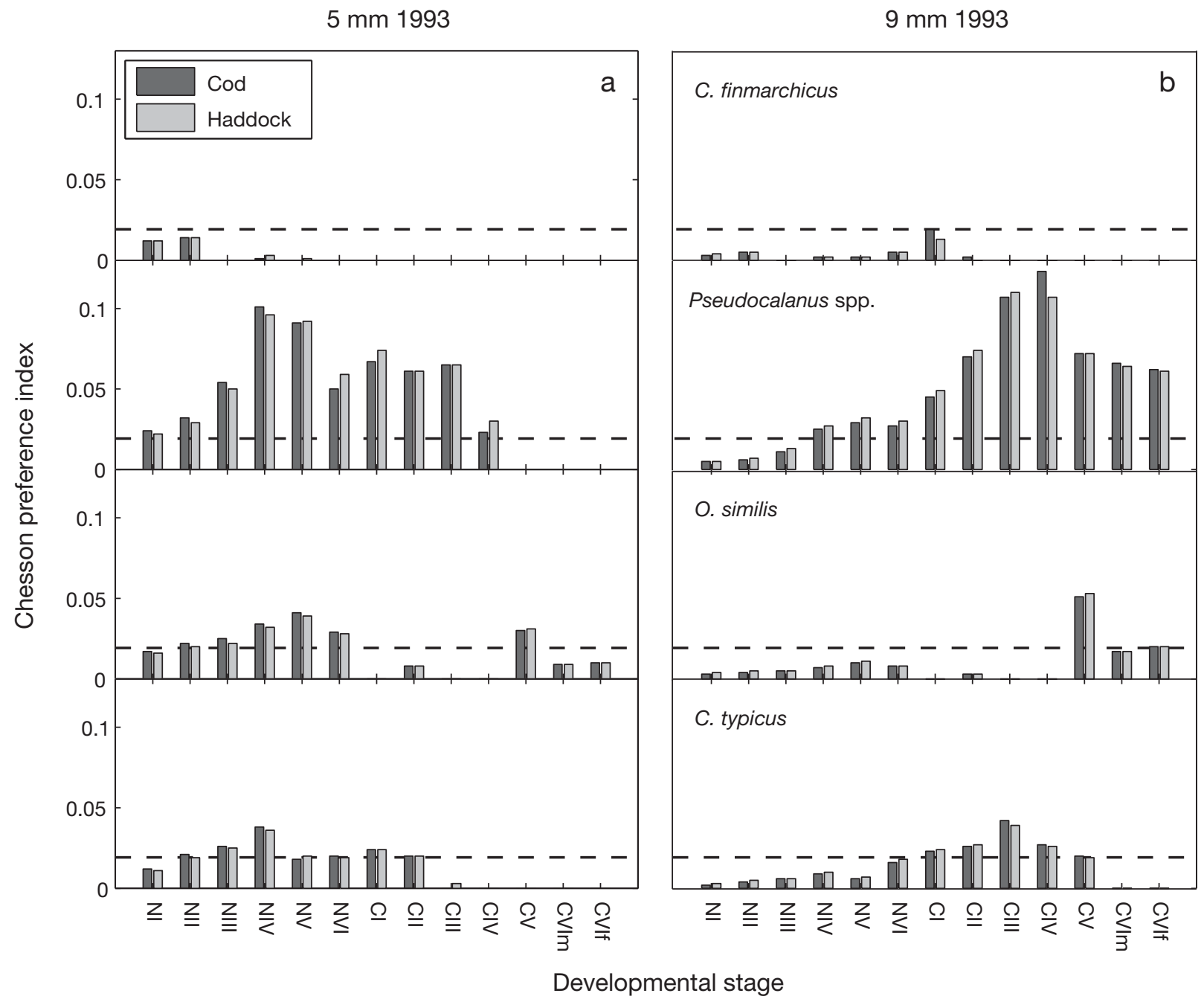

Fig. 7. Melanogrammus aeglefinus (light grey bar) and Gadus morhua (dark grey bar). Simulations of Chesson's preference index of Calanus finmarchicus, Pseudocalanus spp., Oithona similis, and Centropages typicus for (a) $5 \mathrm{~mm}$ and (b) $9 \mathrm{~mm}$ larvae forced by 1993 environmental conditions. The dashed line $(\alpha=0.019)$ indicates neutral selection. NI to NVI: 6 naupliar stages, CI to CV: 5 copepodite stages, CVIf: adult female, CVIm: adult male 
and 1994 Georges Bank study. Mean growth rates of modeled $5 \mathrm{~mm}$ haddock and cod larvae were much less than those observed (Tables $6 \& 7$ ). The $7 \mathrm{~mm}$ cod larvae from both the 1993 and 1994 simulations were within 2 SDs, while $9 \mathrm{~mm}$ cod larvae in simulations of 1994 were within 1 SD of observations (Table 7). Since individual larvae were constrained to $1 \mathrm{~m}$ depth intervals, modeled growth rates were not expected to quantitatively match observed growth rates.

\section{Changes to foraging behavior parameters}

Differences in the average prey length eaten and Chesson's preference index between the haddock simulations with different PF and PD values were minor. There was a 1 to $3 \%$ difference in average length of copepods ingested between models, a difference that was 10 to 20 times smaller than the SD of the observations. The percent error ranged from 0 to 32 , with all simulations being within $1 \mathrm{SD}$ of the observations for 5 to $9 \mathrm{~mm}$ length classes. Chesson's preference index was also similar between simulations with differing PF and PD values. Simulations differed from each other by 0 to $14 \%$ and from observations by 0 to $1300 \%$. When a particular simulation decreased the percent error for one group of stages of a copepod species, it increased in error for another group. The small differences between simulations were also reflected in the Kendall rank correlation analysis with the observed Chesson's preference index, with 0 to $11 \%$ difference between them. An increase in correlation of a small length class often led to a decrease in correlation of a larger length class for the same parameterization.

\section{DISCUSSION}

The ability of a fish and its prey to react to their surroundings by explicit behavior is a key element in understanding the feeding ecology of fish. Behavior of fish has often been neglected, or simply been defined as a static pattern in IBMs; however, several recent papers have pointed to the importance of including behavior in the growth, survival, and drift patterns of ichthyoplankton (Fiksen et al. 2007, Kristiansen et al. 2007, 2009a, Leis 2007, Vikebø et al. 2007). Here, we have shown how differences in behavior among copepod prey species largely determine the feeding preference of both larval haddock and cod, and it is clear that prey selection cannot be predicted by prey length or width alone.

The addition of species-specific copepod escape behavior elucidated the dif- 
ferences in encounter and capture probability of the 4 dominant prey items of larval haddock and cod on Georges Bank. Swimming speed affects the encounter rate between a copepod and a predator, thus fast swimming prey will encounter predators more often. The deformation rate threshold indicates how sensitive a copepod is to disturbances, which helps it detect and escape predators. A lower threshold signifies greater sensitivity. Of the 4 main prey targets the order of sensitivity was exactly the same as for swimming speed, suggesting that those copepods that encounter predators more often must be more sensitive to detecting

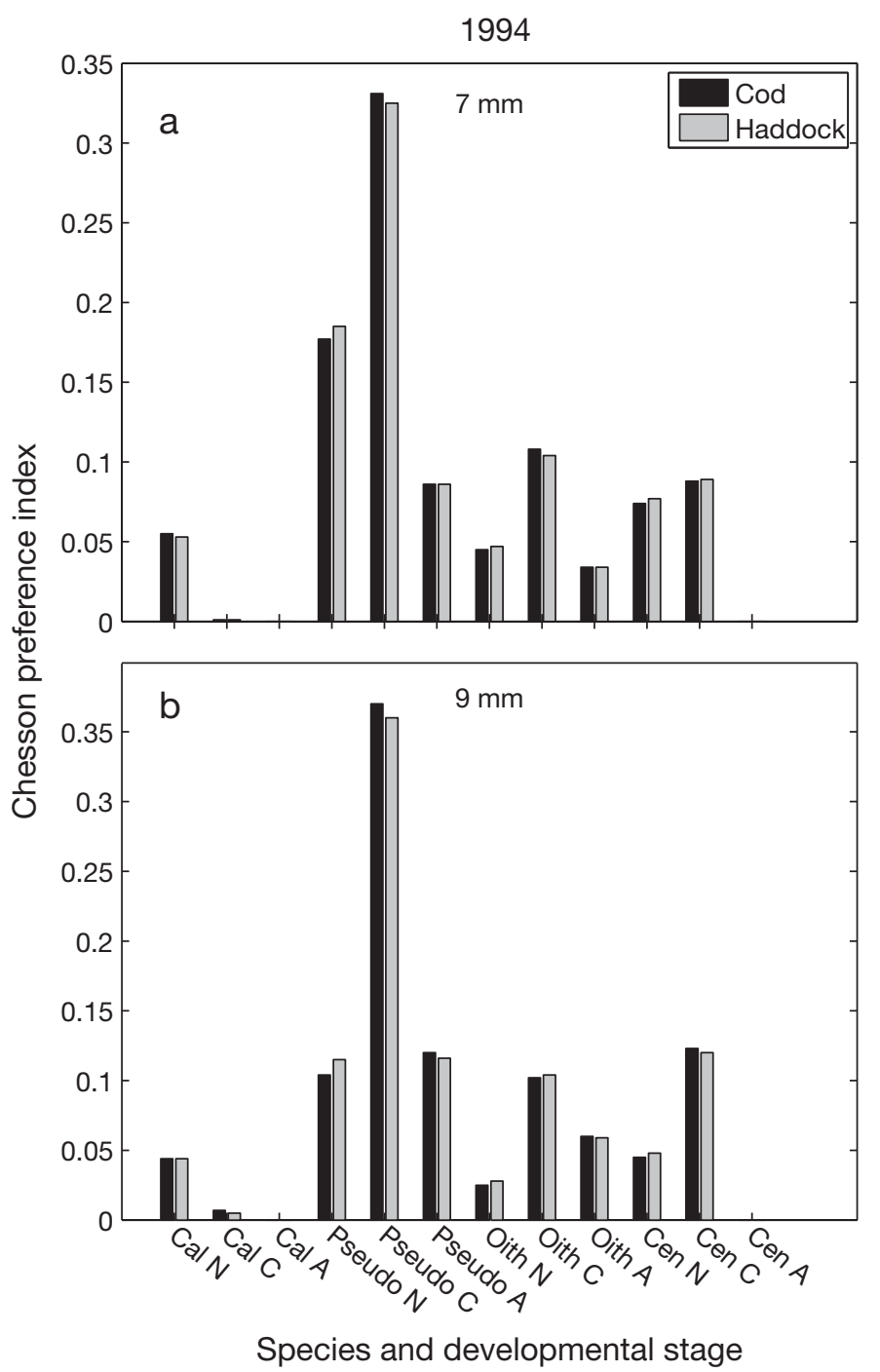

Fig. 9. Melanogrammus aeglefinus (grey bar) and Gadus morhua (black bar). Modeled Chesson's preference index grouped by species (Cal: Calanus finmarchicus, Pseudo: Pseudocalanus spp., Oith: Oithona similis, Cen: Centropages typicus) and stage (N: nauplii, C: copepodites, A: adults) for (a) $7 \mathrm{~mm}$ and (b) $9 \mathrm{~mm}$ larvae simulated under prey conditions from 1994 them. The vulnerability of each copepod species and stage is a function of its visibility and catchability, and can be inferred from its size, its escape behavior, and measures of larval fish gut contents and preference.

With species-specific prey behavior the model was able to reproduce the lower preference for Centropages typicus. The probability of capture results indicate that both infrequent encounter rates from small image area and slow swimming speed, and low probability of capture from a sensitive deformation threshold and fast escape jump speed contribute to the reduced vulnerability and negative selection of C. typicus by larval haddock and cod. Oithona similis and Pseudocalanus spp. are the easiest to catch because of their high deformation rate thresholds, slow escape jump speeds, and, for O. similis, its small size. Though their small size and slow swimming speeds do not lead to frequent encounters, their high abundance and ease of capture results in positive selection for them and thus they make up a large portion of the diet numerically. Calanus finmarchicus is encountered often because of its large image area and fast swimming speed, but it is difficult to capture because it has a very low deformation rate threshold and a fast escape jump speed, and many stages are too wide to be engulfed by the larval fish. For haddock and cod, the small probability of capture outweighed the high encounter rate such that $C$. finmarchicus was negatively selected.

Table 4. Melanogrammus aeglefinus and Gadus morhua. Kendall rank correlation coefficients between observed and depth-weighted modeled Chesson's preference index

\begin{tabular}{|lcccc|}
\hline \multirow{2}{*}{$\begin{array}{l}\text { Species and } \\
\text { year }\end{array}$} & \multicolumn{4}{c|}{ Kendall rank correlation coefficient } \\
\cline { 2 - 5 } & 5 & 7 & 9 & 11 \\
\cline { 2 - 5 } & & & & \\
& & & \\
Haddock 1993 & 0.25 & 0.43 & 0.28 & 0.23 \\
Haddock 1994 & 0.46 & 0.33 & 0.23 & 0.17 \\
Cod 1993 & 0.15 & 0.29 & 0.21 & 0.18 \\
Cod 1994 & 0.26 & 0.11 & 0.32 & 0.32 \\
\hline
\end{tabular}

Table 5. Melanogrammus aeglefinus and Gadus morhua. $\mathrm{p}$-values from the test of independence of the Kendall rank correlation coefficients between observed and depthweighted modeled Chesson's preference index. ${ }^{*}$ Significant

$$
(\mathrm{p}<0.1)
$$

\begin{tabular}{|lcccc|}
\hline \multirow{2}{*}{$\begin{array}{l}\text { Species and } \\
\text { year }\end{array}$} & \multicolumn{5}{c}{ p-value } \\
\cline { 2 - 5 } & 5 & 7 & 9 & 11 \\
\cline { 2 - 5 } & & & \multicolumn{5}{c}{ Larval length $(\mathrm{mm})$} & \\
Haddock 1993 & $0.06^{*}$ & $0.00^{*}$ & $0.04^{*}$ & $0.08^{*}$ \\
Haddock 1994 & $0.00^{*}$ & $0.02^{*}$ & $0.08^{*}$ & 0.14 \\
Cod 1993 & 0.18 & $0.03^{*}$ & $0.10^{*}$ & 0.13 \\
Cod 1994 & $0.06^{*}$ & 0.25 & $0.03^{*}$ & $0.03^{*}$ \\
\hline
\end{tabular}


This finding does not contradict the dominance of $C$. finmarchicus nauplii in the diet of other stocks of larval haddock and cod such as the North Sea and Northeast Arctic populations (Heath \& Lough 2007). In more northern, colder regions, $C$. finmarchicus is the most abundant copepod, whereas the more southern species like Pseudocalanus spp. are low in abundance or absent (Heath \& Lough 2007). The prevalence of C. finmarchicus in these regions will increase its ingestion and thus preference. This pattern was also captured by the model, as the average preference for $C$. finmarchicus and O. similis increased in 1994 in conjunction with their increase in concentration. Similarly, average preference for Pseudocalanus spp. and Centropages typicus decreased in 1994 as their percentage of the total prey available dropped.

The preference of larval haddock and cod for Pseudocalanus spp. and the absence of similarly sized Centropages typicus from their guts is attributable to the superior escape ability (deformation rate threshold, escape speed, escape angle) of C. typicus. A siphon capture success of $86 \%$ supports the weak escape ability of Pseudocalanus spp. (Viitasalo et al. 2001). Though model parameters were taken from observations of escape behavior of Pseudocalanus spp. copepodites and $C$. typicus nauplii, studies of Temora longicornis show that escape speeds in $\mathrm{BL} \mathrm{s}^{-1}$ are equivalent for nauplii and copepodites (Titelman 2001) despite different body morphologies. Model parameters came from observations filmed at 50 frames $\mathrm{s}^{-1}$ (fps). Higherspeed video (1000 fps) observations have found escape speeds in the range of 200 to $400 \mathrm{BL} \mathrm{s}^{-1}$ (Buskey et al. 2002, Waggett \& Buskey 2007, Burdick et al. 2007), though not for the copepod species examined in the present study. Model simulations were repeated with 5 times greater species-specific escape speeds, such that they ranged from 290 to $450 \mathrm{BL} \mathrm{s}^{-1}$. At these speeds, advanced stages of copepods were nearly impossible to capture, resulting in negative growth rates, starvation, and average lengths of copepod eaten and total biomass found in the guts more than 1 SD below the observed mean. Copepodites and adults are found in the guts of larval haddock and cod, suggesting that the copepods are not escaping at their maximum capacity. Further investigation is required to verify that $C$. typicus escapes better than Pseudocalanus spp. under the same conditions and life stages. Yet another caveat of these studies is that most measured escape responses stimulated by a siphon or other near-field mechanical disturbance. Since escape reactions vary with the stimulus (Viitasalo et al. 1998, Burdick et al. 2007, Waggett \& Buskey 2007), a more accurate model would include measurements from attacks by larval cod and haddock.

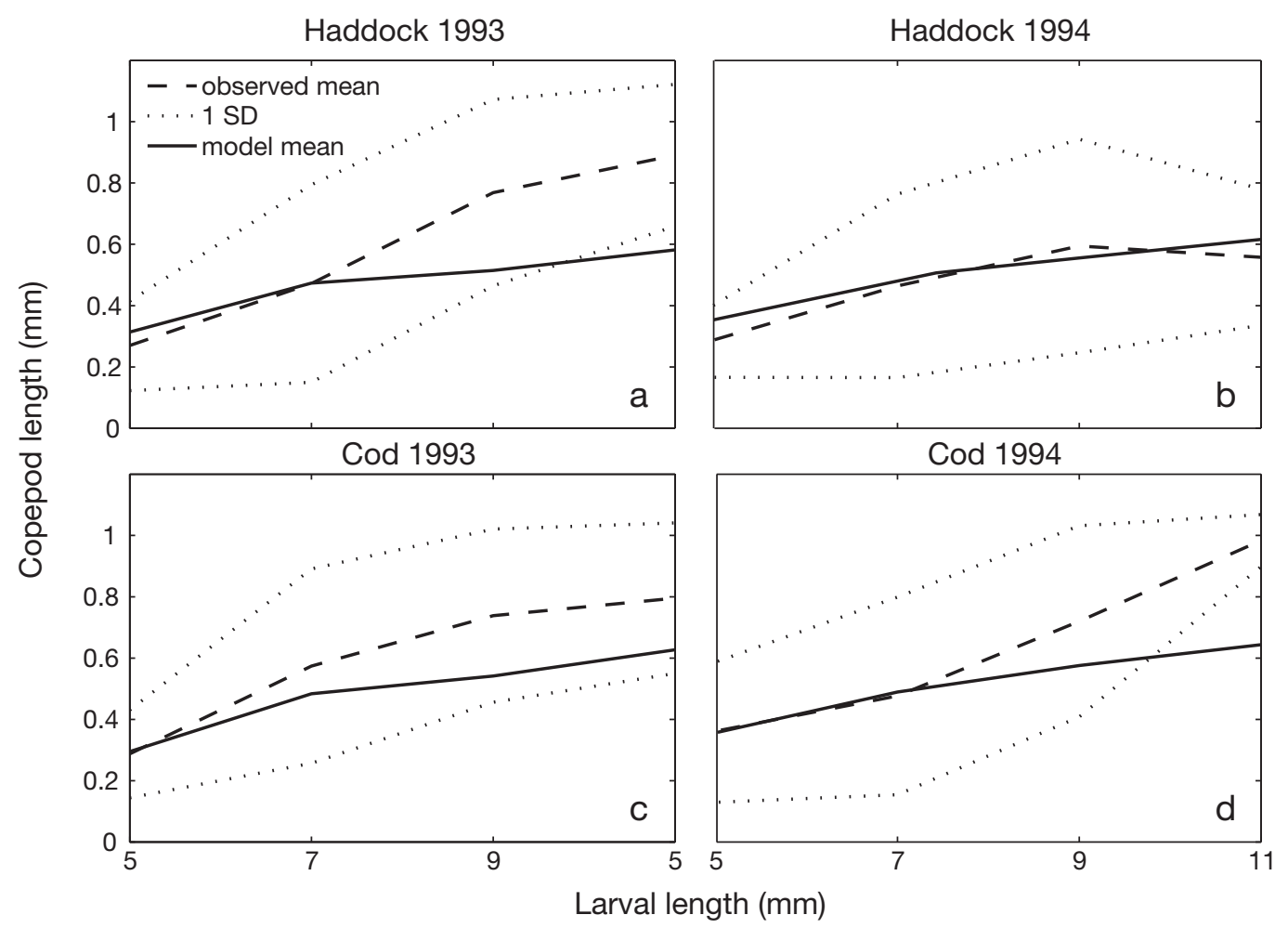

Fig. 10. Melanogrammus aeglefinus and Gadus morhua. Average length of copepod eaten by different sizes of (a,b) haddock and (c,d) cod larvae in 1993 and 1994 
In general, adding species-specific information on mouth size, metabolism, and length-weight relationship to a previously developed model for larval cod resulted in a novel foraging and growth model for larval haddock that agreed well with and helped explain observations on gut contents, prey preference, and growth. Adding detailed information on the feeding behavior of larval haddock to a model of larval cod was not necessary because there was no statistical difference in Chesson's preference index, biomass, or average length of copepods eaten by larval haddock and cod on Georges Bank in May of 1993 and 1994, with the exception of $5 \mathrm{~mm}$ larvae in 1994. The model was not very sensitive to changes in PF and PD behaviors. Doubling or halving $\mathrm{PF}$ and making corresponding changes to the PD produced differences in average observations, and Chesson's preference indices that were up to $100 \times$ more different from observations than from each other. Also, alterations to PF and PD were
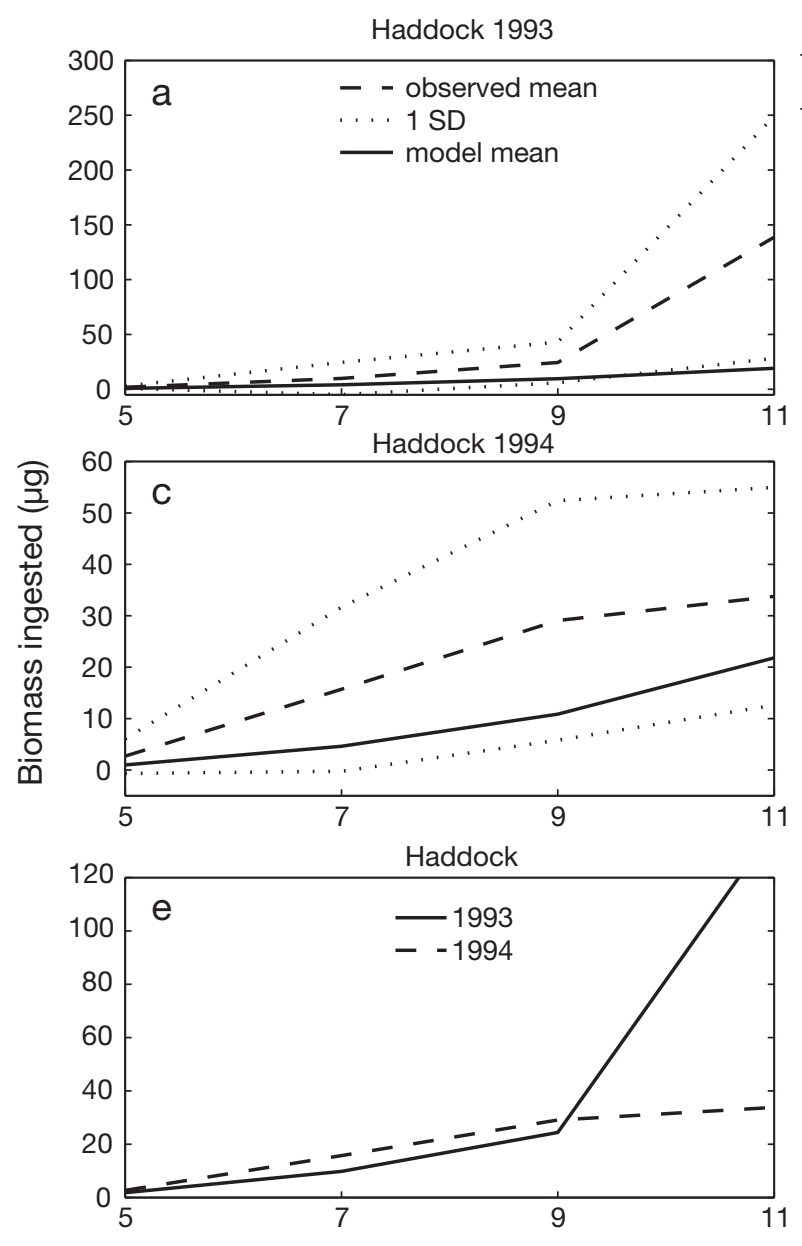

Larval length (mm) length eaten that were 10 to $20 \times$ smaller than the SD of

Table 6. Melanogrammus aeglefinus. Mean growth rates observed (Lough et al. 1997) and modeled

\begin{tabular}{|llccc|}
\hline \multirow{2}{*}{ Year } & & \multicolumn{3}{c|}{ Mean growth rate $\left(\% \mathrm{~d}^{-1}\right)$} \\
\cline { 3 - 5 } & & 5 & 7 & 9 \\
& & 9.5 & 12.1 & 12.5 \\
1993 & Observed & 2.6 & 5.9 & 7.0 \\
1993 & Model & 5.0 & 10.0 & 10.6 \\
1994 & Observed & 3.8 & 7.0 & 8.2 \\
1994 & Model & & \\
\hline
\end{tabular}

Table 7. Gadus morhua. Mean growth rates observed (Lough et al. 2005) and modeled

\begin{tabular}{|llccc|}
\hline \multirow{2}{*}{ Year } & & \multicolumn{4}{c|}{ Mean \pm SD growth rate $\left(\% \mathrm{~d}^{-1}\right)$} \\
\cline { 3 - 5 } & & 5 & Larval length $(\mathrm{mm})$ & $\mathbf{7}$ \\
& & & & 9 \\
\hline 1993 & Observed & $7.6 \pm 2.4$ & $11.3 \pm 3.3$ & $12.9 \pm 1.6$ \\
1993 & Model & 2.1 & 6.0 & 7.5 \\
1994 & Observed & 9.4 & $9.8 \pm 1.9$ & $10.4 \pm 2.0$ \\
1994 & Model & 3.4 & 7.1 & 8.8 \\
\hline
\end{tabular}
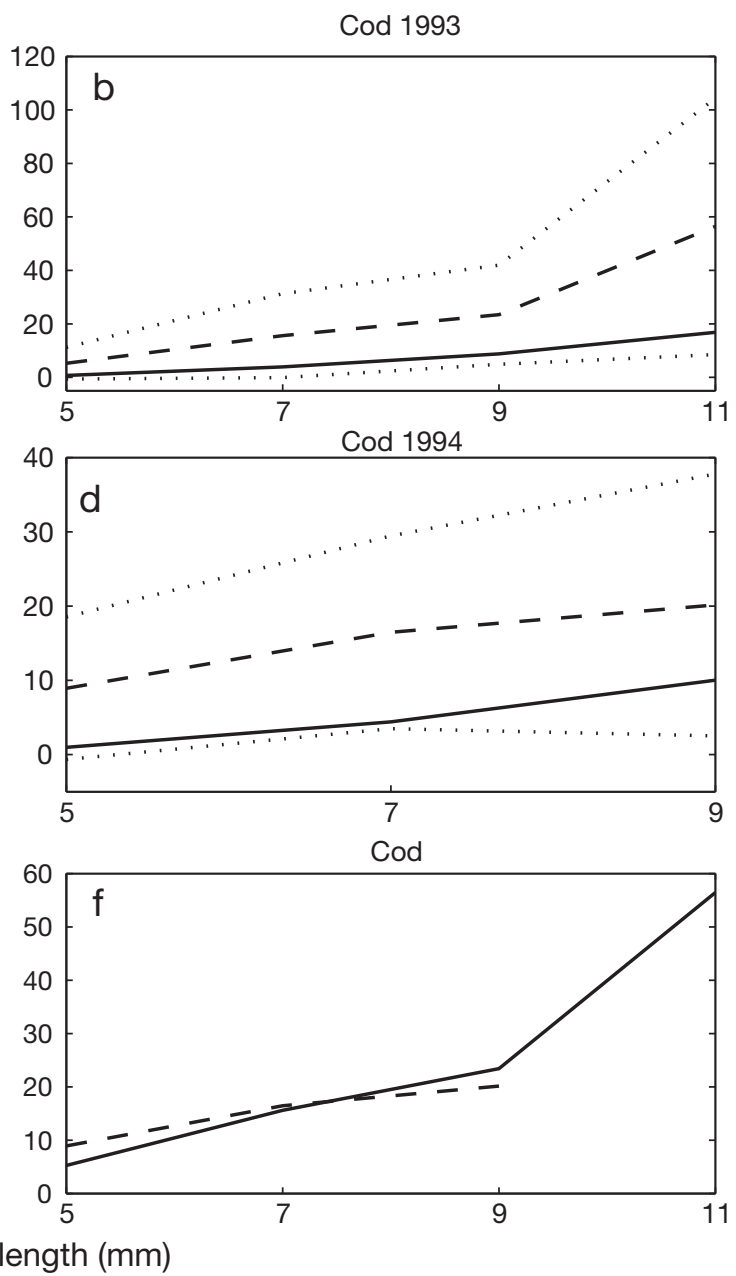

Fig. 11. Melanogrammus aeglefinus and Gadus morhua. Average biomass (dry wt) found in the guts of different sizes of (a,c) haddock and (b,d) cod larvae in (a,b) 1993 and (c,d) 1994. Observed mean biomass (dry wt) ingested by (e) haddock and (f) cod in 1993 (solid line) and 1994 (dashed line) 
not monotonic, such that percent error did not increase or decrease across all developmental stages of a copepod species. These findings suggest that fitting PF and PD parameters for haddock would not lead to improvement of the model in comparison to observations.

The differences in modeled probability of successful capture and average prey length eaten by the 2 species were explained by the mouth sizes of larval haddock and cod. For a given size class, the species with the larger mouth gape had the higher probability of successful capture and ate larger prey. Though there was no statistical difference in average prey length eaten by haddock and cod, modeled 9 to $15 \mathrm{~mm}$ haddock ate smaller prey than cod on average. Modeled Chesson's preference index corroborated that cod preferred later copepod stages more than haddock. In sum, these results suggest that the model can reproduce qualitative observations of cod eating later stages and larger prey than haddock.

The presence of larger prey in 1994 resulted in interannual differences in simulated average length eaten. Average lengths were 0.37 and $0.41 \mathrm{~mm}$ in 1993 and 1994 respectively (Broughton \& Lough in press). Increased average prey size in 1994 was due to fewer numbers of early-stage copepods and greater numbers of late-stage copepods. In 1994 there were more copepodites and adults of all 4 species (Lough et al. 2005).

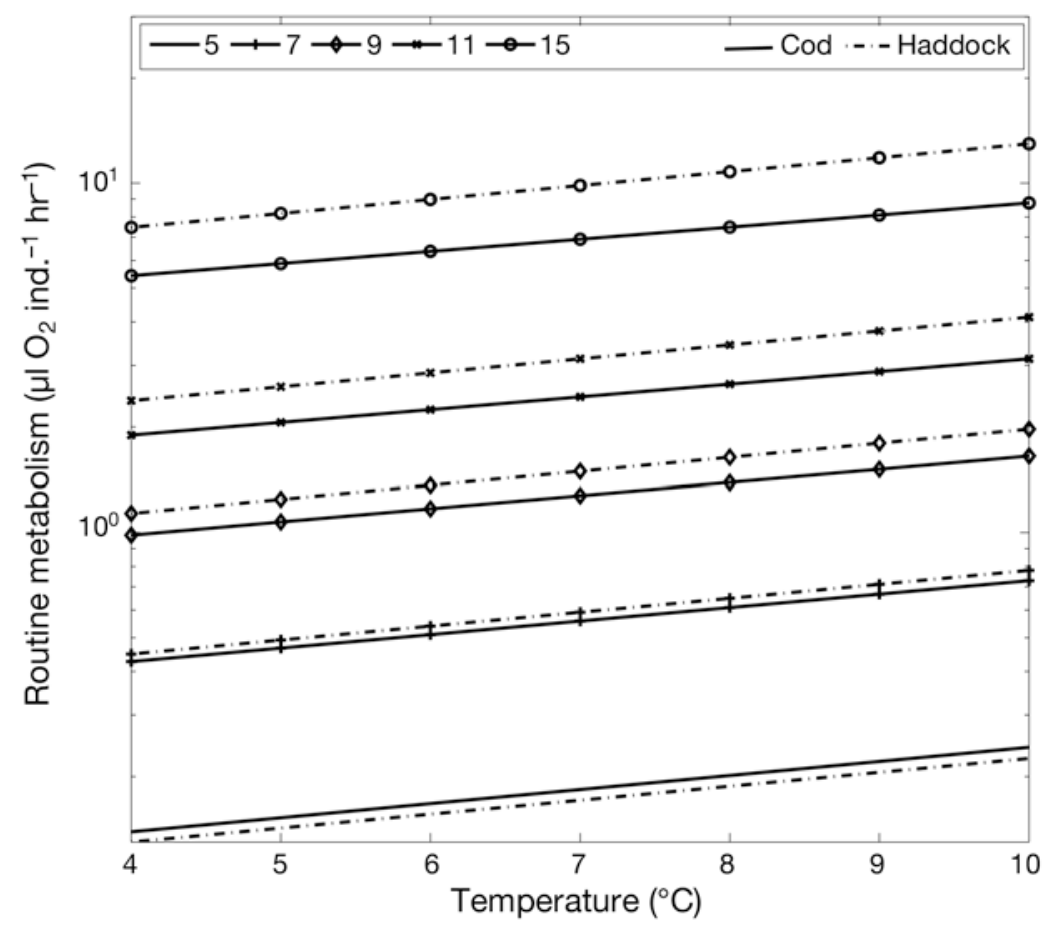

Fig. 12. Melanogrammus aeglefinus and Gadus morhua. Modeled routine respiration rate for haddock (from Lankin et al. 2008) and cod (from Lough et al. 2005) over a range of temperatures for 5, 7, 9, 11, and $15 \mathrm{~mm}$ larvae
Despite these differences, the average length of ingested copepods was not found to be statistically significant.

The model estimated the average prey length eaten by larval haddock and cod to within 1 SD of observations, but with a tendency to underestimate it. There are a few possibilities as to why the model underestimated the average prey length eaten. The first is that the escape abilities of the later stages of copepods were overestimated, leading to lower than accurate probabilities of capture success. Alternatively the foraging abilities of the larval fish (swimming speed, perception area, strike speed) could have been underestimated. A third explanation is that the adult female Pseudocalanus spp., the main prey observed in the guts of larger larvae and juveniles, carry egg sacs that increase their image area. If accounted for in the model, this difference in image area would lead to an increase in encounter and possibly ingestion of the Pseudocalanus spp. females.

The average biomass ingested in model simulations was also within $1 \mathrm{SD}$ of that observed but was underestimated. This could be the result of an underestimation of the average length of copepods eaten. This difference might also be reconciled by allowing larvae to vertically migrate such that they would be able to feed in dense patches of copepods and ingest more biomass at any one time.

Haddock ingested more biomass than cod, but still had lower growth rates (Fig. 8c-h). Differences in modeled growth rates were inversely related to the differences in respiration rates (Fig. 12). For a given size class, the species with the greater respiration rate had the lower growth rate. This was a result of the higher respiration rate incurring more metabolic costs, thereby reducing growth. The greater biomass ingested by haddock was not enough to offset its greater metabolic costs compared to cod. Respiration rate increases exponentially with temperature (Fig. 12), and as temperature increases a higher proportion of ingested energy is allocated to respiration rather than growth. However, in food-satiated conditions, growth also increases with temperature (Buckley et al. 2004). The greater average water temperature in $1994\left(8\right.$ to $\left.9^{\circ} \mathrm{C}\right) \mathrm{com}$ pared to 1993 ( 7 to $8^{\circ} \mathrm{C}$; Lough et al. 2005) explains why the difference in growth rates between haddock and cod was greater in 1994 than in 1993 (Fig. 8e-h). Despite the increase in metabolic costs, the model predicted increased growth in 1994, 
suggesting that there was enough food ingested to support the increase in temperature.

It is likely the result of greater average temperature and prey biomass in 1994 that the simulations were unable to capture the observations of higher growth rates in 1993. The departure of model results from observations may be explained by the lack of vertical movement by the larvae, and will be examined in future work. Lough et al. (2005) found that greater growth rates in 1993 than 1994 for 7 and 9 mm larvae could be achieved by allowing the simulated larvae to follow the observed mean depth of the population and restricting their diet to only Pseudocalanus spp. Another contributing factor could be the difference in mean length of Pseudocalanus spp. adults between 1993 and 1994 (1.1 and $0.9 \mathrm{~mm}$ respectively; Broughton \& Lough in press), which was not represented in the model simulations. Additionally, predation on slower-growing larvae could have resulted in the observed growth rates. It should also be noted that the model-data mismatch is affected to some unknown degree by sampling error, given the inherent variability in plankton sampling. Though the growth rates from the larval haddock and cod simulations were lower than those observed, they were still realistic and would not result in larval death.

Mechanistic models like this one allow us to understand the how and why, rather than just predict what will happen under certain static conditions. Through the foraging model, we have learned that larval haddock and cod select the species and stages of copepods that are physically and behaviorally vulnerable to predation. Parameters and functions of these escape behaviors have been determined for the copepods Calanus finmarchicus, Pseudocalanus spp., Oithona similis, and Centropages typicus, all of which can be used in future studies of prey selection. Additional information on copepod escape behavior and defense morphology (spines, armor, etc.) may help to reconcile the differences between modeled and observed prey selection. Detailed information on prey selection and feeding behavior is necessary to model larval growth. Larval growth then determines survival through its effects on starvation, the ability to encounter and catch prey, and the ability to avoid predation. Ultimately, studies of larval fish survival will provide insights into recruitment dynamics.

The larval haddock and cod foraging models can be used to forecast the effect of climate change on larval haddock survival through associated changes in the size and quantity of food. The foraging model will be necessary for predicting the response of larval fish growth and survival should the copepod community composition be altered by climate change. For example, the mean size of copepods in the North Sea has decreased with increasing temperature since the 1980s, resulting in lower larval and juvenile cod survival (Beaugrand et al. 2003). Alternatively, Pitois \& Fox (2008) found that increased temperature and the correlated increased copepod biomass and decreased mean copepod size resulted in higher growth of first-feeding larval cod when modeled on the UK shelf region. On Georges Bank from 1977 to 2004, the abundance of dominant prey items Calanus finmarchicus, Pseudocalanus spp., Centropages typicus, and Oithona spp. were significantly correlated with temperature and/or salinity (Kane 2007). Though no direct relationship between climate effects and cod recruitment has been found through changes in the zooplankton (Pitois \& Fox 2008), changes in prey size and abundance can easily be incorporated into the cod and haddock foraging models to determine how well larvae will feed and grow under different conditions.

The IBM presented here is the first of its kind for haddock, as more emphasis has usually been placed on cod. Haddock represent a classic case of a recruitment-dominated fish stock, with relatively infrequent large year-classes dominating the population and fishable biomass at any given time (Brodziak et al. 2008). Compared to cod, haddock spawning is more restricted seasonally and spatially (Auditore et al. 1994, Lough et al. 2006), and larval haddock have a lower tolerance to variations in temperature and salinity (Laurence \& Rogers 1976). This combination of restricted spawning, sensitivity to environmental conditions, and dominant year-classes make haddock well suited as a model fish species for unraveling the factors controlling recruitment in fish populations.

In conclusion, our modeling study revealed that both larval haddock and cod demonstrate positive selection of Pseudocalanus spp. and negative selection of Calanus finmarchicus. Adding species-specific copepod behavior to the IBM explained the low selection for Centropages typicus by larval haddock and cod. Morphological and physiological information on larval haddock was sufficient to create a foraging and growth model that reproduced observed patterns of average prey length eaten and preference for the 4 main copepod prey species observed in the gut.

Acknowledgements. We thank A. Solow for help with statistical analysis. C.M.P. was supported by a WHOI Watson Fellowship. Partial support was provided by NOAA GLOBEC grant NA17RJ1223. This is contribution no. 614 of the NW Atlantic US GLOBEC program jointly funded by NOAA and NSF.

\section{LITERATURE CITED}

Auditore PJ, Lough RG, Broughton EA (1994) A review of the comparative development of Atlantic cod (Gadus morhua L.) and haddock (Melanogrammus aeglefinus L.) based on an illustrated series of larvae and juveniles from Georges Bank. NAFO Sci Counc Stud 20:7-18 
Bailey KM, Houde ED (1989) Predation on eggs and larvae of marine fishes and the recruitment problem. Adv Mar Biol 25:1-83

Beaugrand G, Brander KM, Lindley JA, Souissi S, Reid PC (2003) Plankton effect on cod recruitment in the North Sea. Nature 426:661-664

Bolz GR, Lough RG (1988) Growth through the first six months of Atlantic cod, Gadus morhua, and haddock, Melanogrammus aeglefinus, based on daily otolith increments. Fish Bull 86:223-235

Brodziak J, Traver ML, Col LA (2008) The nascent recovery of the Georges Bank haddock stock. Fish Res 94:123-132

Broughton EA, Lough RG (in press) General trends and interannual variability in prey selection by larval cod and haddock from the southern flank of Georges Bank, May 1993-1997. NOAA Tech Memo NMFS/NE

Buckley LJ, Durbin EG (2006) Seasonal and inter-annual trends in the zooplankton prey and growth rate of Atlantic cod (Gadus morhua) and haddock (Melanogrammus aeglefinus) larvae on Georges Bank. Deep-Sea Res II 53: 2758-2770

Buckley LJ, Caldarone EM, Lough RG (2004) Optimum temperature and food-limited growth of larval Atlantic cod (Gadus morhua) and haddock (Melanogrammus aeglefinus) on Georges Bank. Fish Oceanogr 13:134-140

Burdick DS, Hartline DK, Lenz PH (2007) Escape strategies in co-occurring calanoid copepods. Limnol Oceanogr 52: 2373-2385

Buskey EJ, Lenz PH, Hartline DK (2002) Escape behavior of planktonic copepods in response to hydrodynamic disturbances: high speed video analysis. Mar Ecol Prog Ser 235: 135-146

Caparroy P, Thygesen UH, Visser AW (2000) Modelling the attack success of planktonic predators: patterns and mechanisms of prey selectivity. J Plankton Res 22: $1871-1900$

> Chesson J (1978) Measuring preference in selective predation. Ecology 59:211-215

$>$ Davis CS (1984) Predatory control of copepod seasonal cycles on Georges Bank. Mar Biol 82:31-40

Davis CS (1987) Zooplankton life cycles. In: Backus RH, Bourne DW (eds) Georges Bank. MIT Press, London, p 1-593

Evans BI, O'Brien WJ (1988) A reevaluation of the search cycle of planktivorous Arctic grayling, Thamallus arcticus. Can J Fish Aquat Sci 45:187-192

Fields DM (2000) Characteristics of the high frequency escape reactions of Oithona sp. Mar Freshw Behav Physiol 34:21-35

Fields DM, Yen J (1997) The escape behavior of marine copepods in response to a quantifiable fluid mechanical disturbance. J Plankton Res 19:1289-1304

Fiksen $\varnothing$, MacKenzie BR (2002) Process-based models of feeding and prey selection in larval fish. Mar Ecol Prog Ser 243:151-164

Fiksen $\varnothing$, Utne ACW, Aksnes DL, Eiane K, Helvik JV, Sundby S (1998) Modelling the influence of light, turbulence and ontogeny on ingestion rates in larval cod and herring. Fish Oceanogr 7:355-363

Fiksen Ø, Jørgensen C, Kristiansen T, Vikebø F, Huse G (2007) Linking behavioural ecology and oceanography: larval behaviour determines growth, mortality and dispersal. Mar Ecol Prog Ser 347:195-205

- Finn RN, Ronnestad I, van der Meeren T, Fyhn HJ (2002) Fuel and metabolic scaling during the early life stage of Atlantic cod Gadus morhua. Mar Ecol Prog Ser 243: $217-234$
Galbraith PS, Browman HI, Racca RG, Skiftesvik AB, SaintPierre JF (2004) Effect of turbulence on the energetics of foraging in Atlantic cod Gadus morhua larvae. Mar Ecol Prog Ser 281:241-257

Greene CH, Landry MR, Monger BC (1986) Foraging behavior and prey selection by the ambush entangling predator Pleurobrachia bachei. Ecology 67:1493-1501

Grimm V, Railsback SF (2005) Individual based modeling and ecology. Princeton University Press, Princeton, NJ

Grimm V, Berger U, Bastiansen F, Eliassen S and others (2006) A standard protocol for describing individual-based and agent-based models. Ecol Modell 198:115-126

$>$ Hardy AC, Bainbridge R (1954) Experimental observations on the vertical migrations of plankton animals. J Mar Biol Assoc UK 33:409-448

$>$ Haury LR, Kenyon DE, Brooks JR (1980) Experimental evaluation of the avoidance reaction of Calanus finmarchicus. J Plankton Res 2:187-202

Heath MR, Lough RG (2007) A synthesis of large-scale patterns in the planktonic prey of larval and juvenile cod (Gadus morhua). Fish Oceanogr 16:169-185

Houde ED (1987) Fish early life dynamics and recruitment variability. Am Fish Soc Symp 2:17-29

Hunt von Herbing I, Gallager SM (2000) Foraging behavior in early Atlantic cod larvae (Gadus morhua) feeding on a protozoan (Balanion sp.) and a copepod nauplius (Pseudodiaptomus sp.). Mar Biol 136:591-602

Ivlev VS (1961) Experimental ecology of feeding in fishes. Yale University Press, New Haven, CT

$>$ Kane J (1984) The feeding habits of co-occurring cod and haddock larvae from Georges Bank. Mar Ecol Prog Ser 16: 9-20

Kane J (2007) Zooplankton abundance trends on Georges Bank, 1977-2004. ICES J Mar Sci 64:909-919

- Kiørboe T, Visser AW (1999) Predator and prey perception in copepods due to hydromechanical signals. Mar Ecol Prog Ser 179:81-95

> Kiørboe T, Saiz E, Visser A (1999) Hydrodynamic signal perception in the copepod Acartia tonsa. Mar Ecol Prog Ser 179:97-111

Kristiansen T, Fiksen $\varnothing$, Folkvord A (2007) Modelling feeding, growth, and habitat selection in larval Atlantic cod (Gadus morhua): observations and model predictions in a macrocosm environment. Can J Fish Aquat Sci 64: 136-151

> Kristiansen T, Jørgensen C, Lough RG, Vikebø F, Fiksen $\varnothing$ (2009a) Modeling rule-based behavior: habitat selection and the growth-survival trade-off in larval cod. Behav Ecol 20:490-500

Kristiansen T, Lough RG, Werner FE, Broughton EA, Buckley LJ (2009b) Individual-based modeling of feeding ecology and prey selection of larval cod on Georges Bank. Mar Ecol Prog Ser 376:227-243

Landry MR, Fagerness VL (1988) Behavioral and morphological influences on predatory interactions among marine copepods. Bull Mar Sci 43:509-529

Lankin KF, Peck MA, Buckley LJ, Bengtson DA (2008) The effects of temperature, body size and growth rate on energy losses due to metabolism in early life stage of haddock (Melanogrammus aeglefinus). Mar Biol 155:461-472

Laurence GC (1985) A report on the development of stochastic models of food limited growth and survival of cod and haddock larvae on Georges Bank. In: Laurence GC, Lough RG (eds) Growth and survival of larval fishes in relation to the trophodynamics of Georges Bank cod and haddock. NOAA Tech Memo NMFS-F/NEC-36. National Marine Fisheries Service, NOAA, Woods Hole, MA, p 83-150 
Laurence GC, Rogers CA (1976) Effects of temperature and salinity on comparative embryo development and mortality of Atlantic cod (Gadus morhua L.) and haddock (Melanogrammus aeglefinus L.). J Cons Int Explor Mer 36:220-228

Leis JM (2007) Behaviour as input for modelling dispersal of fish larvae: behaviour, biogeography, hydrodynamics, ontogeny, physiology and phylogeny meet hydrography. Mar Ecol Prog Ser 347:185-193

Lough RG, Mountain DG (1996) Effect of small-scale turbulence on feeding rates of larval cod and haddock in stratified water on Georges Bank. Deep-Sea Res II 43: 1745-1772

Lough RG, Caldarone EM, Buckley LJ, Broughton EA, Kiladis ME, Burns BR (1997) A comparative study of feeding, condition, and growth of larval cod and haddock on southern Georges Bank, May 1993 vs. May 1994. ICES CM Doc 1997/T:41. ICES, Copenhagen

> Lough RG, Buckley LJ, Werner FE, Quinlan JA, Pehrson Edwards K (2005) A general biophysical model of larval cod (Gadus morhua) growth applied to populations on Georges Bank. Fish Oceanogr 14:241-262

Lough RG, Hannah CG, Berrien P, Brickman D, Loder JW, Quinlan JA (2006) Spawning pattern variability and its effect on retention, larval growth and recruitment in Georges Bank cod and haddock. Mar Ecol Prog Ser 310: 193-212

MacKenzie BR, Kiørboe T (1995) Encounter rates and swimming behavior of pause-travel and cruise larval fish predators in calm and turbulent laboratory environments. Limnol Oceanogr 40:1278-1289

MacKenzie BR, Kiørboe T (2000) Larval fish feeding and turbulence: a case for the downside. Limnol Oceanogr 45:1-10

MacKenzie BR, Miller TJ, Cyr S, Leggett WC (1994) Evidence for a dome-shaped relationship between turbulence and larval fish ingestion rates. Limnol Oceanogr 39:1790-1799

Mariani P, MacKenzie BR, Visser AW, Botte V (2007) Individual-based simulations of larval fish feeding in turbulent environments. Mar Ecol Prog Ser 347:155-169

Mauchline J (1998) The biology of calanoid copepods. In: Blaxter JHS, Southward AJ, Tyler PA (eds) Advances in marine biology, Vol 33. Academic Press, London, p 400-420

McGillicuddy DJ Jr, Bucklin A (2002) Intermingling of two Pseudocalanus species on Georges Bank. J Mar Res 60: 583-604

Munk P (1995) Foraging behavior of larval cod (Gadus morhua) influenced by prey density and hunger. Mar Biol 122:205-212

> Munk P (1997) Prey size spectra and prey availability of larval and small juvenile cod. J Fish Biol 51:340-351

> Naimie CE (1996) Georges Bank residual circulation during weak and strong stratification periods: prognostic numerical model results. J Geophys Res 101:6469-6486

> Otterå H, Folkvord A (1993) Allometric growth in juvenile cod (Gadus morhua L.) and possible effects on cannibalism. J Fish Biol 43:643-645

Pepin P, Penney R (2000) Feeding by a larval fish community: impact on zooplankton. Mar Ecol Prog Ser 204: 199-212

Pitois SG, Fox CJ (2008) Empirically modelling the potential effects of changes in temperature and prey availability on the growth of cod larvae in UK shelf seas. ICES J Mar Sci 65:1559-1572

Rothschild BJ, Osborn TR (1988) Small-scale turbulence and plankton contact rates. J Plankton Res 10:465-474
Rowlands WL, Dickey-Collas M, Geffen AJ, Nash RDM (2006) Gape morphology of cod Gadus morhua (L.), haddock Melanogrammus aeglefinus (L.) and whiting Merlangius merlangus (L.) through metamorphosis from larvae to juveniles in the western Irish Sea. J Fish Biol 69: 1379-1395

Rowlands WL, Dickey-Collas M, Geffen AJ, Nash RDM (2008) Diet overlap and prey selection through metamorphosis in Irish Sea cod (Gadus morhua), haddock (Melanogrammus aeglefinus), and whiting (Merlangius merlangus). Can J Fish Aquat Sci 65:1297-1306

Ruzicka J (2004) Integrating bioenergetics and foraging behavior: the physiological ecology of larval cod (Gadus morhua). PhD dissertation, Woods Hole Oceanographic Institution

Ruzicka JJ, Gallager SM (2006a) The importance of the cost of swimming to the foraging behavior and ecology of larval cod (Gadus morhua) on Georges Bank. Deep-Sea Res II 53: $2708-2734$

> Ruzicka JJ, Gallager SM (2006b) The saltatory search behavior of larval cod (Gadus morhua). Deep-Sea Res II 53: $2735-2757$

Skartveit A, Olseth JA, Tuft ME (1998) An hourly diffuse fraction model with correction for variability and surface albedo. Sol Energy 63:173-183

Sundby S, Bjørke H, Soldal AV, Olsen S (1989) Mortality rates during the early life stages and year-class strength of the north-east Arctic cod (Gadus morhua L.). Rapp P-V Reun Cons Int Explor Mer 191:351-358

> Svensen C, Kiørboe T (2000) Remote prey detection in Oithona similis: hydromechanical versus chemical cues. J Plankton Res 22:1155-1166

Tiselius P, Jonsson PR (1990) Foraging behavior of six calanoid copepods: observations and hydrodynamic analysis. Mar Ecol Prog Ser 66:23-33

Titelman J (2001) Swimming and escape behavior of copepod nauplii: implications for predator-prey interactions among copepods. Mar Ecol Prog Ser 213:203-213

> Titelman J, Kiørboe T (2003) Predator avoidance by nauplii. Mar Ecol Prog Ser 247:137-149

- Utne-Palm AC (1999) The effect of prey mobility, prey contrast, turbidity and spectral composition on the reaction distance of Gobiusculus flavescens to its planktonic prey. J Fish Biol 54:1244-1258

> Viitasalo M, Kiørboe T, Flinkman J, Pedersen LW, Visser AW (1998) Predation vulnerability of planktonic copepods: consequences of predator foraging strategies and prey sensory abilities. Mar Ecol Prog Ser 175:129-142

Viitasalo M, Flinkman J, Viherluoto M (2001) Zooplanktivory in the Baltic Sea: a comparison of prey selectivity by Clupea harengus and Mysis mixta, with reference to prey escape reactions. Mar Ecol Prog Ser 216: $191-200$

> Vikebø F, Jørgensen C, Kristiansen T, Fiksen Ø (2007) Drift, growth and survival of larval Northeast Arctic cod with simple rules of behaviour. Mar Ecol Prog Ser 347: $207-219$

Waggett RJ, Buskey EJ (2007) Calanoid copepod escape behavior in response to a visual predator. Mar Biol 150: 599-607

> Werner FE, Perry RI, Lough RG, Naimie CE (1996) Trophodynamic and advective influences on Georges Bank larval cod and haddock. Deep-Sea Res II 43:1793-1822

> Yen J, Lenz P, Gassie DV, Hartline DK (1992) Mechanoreception in marine copepods: electrophysiological studies on the first antennae. J Plankton Res 14:495-512 


\title{
Chapter 3
}

\section{Modeling the vertical behavior of larval haddock}

\section{on Georges Bank with respect to starvation and}

\author{
predation mortality
}

Work in this chapter has been submitted to Journal of Marine Systems as a manuscript: Modeling the vertical behavior of larval haddock on Georges Bank with respect to starvation and predation mortality

by Colleen M. Petrik, Cabell S. Davis, and Rubao Ji

\subsection{Introduction}

Individual-based models (IBMs) coupled to three-dimensional (3D) biologicalphysical models are used to study the early life stages of fish. These Lagrangian models have been used to study the timing and placement of spawning (Brickman \& Frank 2000, Hinckley et al. 2001, Mullon et al. 2002, Lough et al. 2006), growth during the larval period (Letcher et al. 1996, Werner et al. 1996, Lough et al. 2005, Kühn et al. 2008, Kristiansen et al. 2009b), contributions of starvation, predation, and advective mortality (Werner et al. 1996, Brickman et al. 2001), arrival at the juvenile habitat (Hinckley et al. 2001, Mullon et al. 2002, Lough et al. 2006), and characteristics of larvae that survive to 
the juvenile transition (Cowan et al. 1997, Mullon et al. 2002). Numerous studies have verified that larvae are not passive particles, but can moderate their vertical position in the water column (Leis 2007). An accurate representation of larval vertical position is important in these models because it affects survival in a number of ways. Differences in light, turbulence, and prey concentration with depth result in different amounts of prey encountered and ingested, which affects growth and starvation. Temperature regulates metabolic processes such that vertical gradients could also influence growth and starvation. Horizontal currents carry larvae toward or away from suitable habitat, and their vertical shear could influence advective loss and retention. Finally, variations in predator abundance and consumption rate with depth cause direct losses of larvae. The losses of larvae through starvation, advection, and predation result in new vertical distributions.

Previous IBMs use either passive particles (e.g. Werner et al. 1996, Mullon et al. 2002) or assign depths to given stages/ages based on observations (e.g. Lough et al. 2005, Kühn et al. 2008). Though assigning depths is a step above passivity, it does not allow larvae to alter their depth with changes to their environment. Observations of larval haddock (Melanogrammus aeglefinus) and cod (Gadus morhua) on Georges Bank indicate that vertical distributions are correlated with the strength of stratification such that the abundance maximum becomes associated with the pycnocline and prey concentration maximum as stratification increases (Lough 1984, Buckley \& Lough 1987, Lough \& Potter 1993). Like many shelf habitats, the water column stratification changes on Georges Bank over the course of the larval duration from seasonal heating, wind 
events, and location (i.e. well-mixed on the crest, stratified on the flanks). Thus, a model of larval fish in shelf areas, such as larval haddock on Georges Bank, should be able to account for these differences in depth position.

To build a 3D model of larval haddock on Georges Bank, first a model of the vertical position of individuals in response to environmental variables is needed. Larvae sense and respond behaviorally to aspects of their environment (e.g., light, gravity, temperature), which results in a nonrandom depth distribution. The dynamic model of Kristiansen et al. (2009a) assumes that larvae can determine their potential ingestion or growth rates and mortality rates at every depth in the water column. Following this model, the larva moves to the depth within swimming distance that maximizes the difference between either ingestion or growth and mortality, weighted by a risk parameter. However, this unrealistic perfect knowledge is not necessary for modeling behaviors that produce observed or optimal vertical distributions. Davis et al. (1991) demonstrated that individuals with swimming behaviors that were randomly oriented could aggregate around resources if the swimming speed was negatively related to resource concentration. In the simplest case, fish larvae are unlikely to sense prey concentrations and gradients because their perception area is too small to encounter more than one prey at a time and such an ability would require a memory. For this same reason larvae probably cannot sense predation risk gradients, but may be able to sense the presence or absence of predators through sight or chemical cues. Regardless, a swimming speed negatively related to resource concentration could arise mechanistically 
from the reduction of time spent swimming by higher ingestion rates and thus handling times in areas of high prey density (Davis et al. 1991).

We constructed a 1D water column similar to the Georges Bank southern flank in the spring with varying conditions of prey and predator concentrations and turbulent mixing rates. Different vertical behavior models using passive, random, and directed swimming were tested to determine (1) how each behavior affects depth distribution, (2) how each behavior affects survival, and (3) which parameterization of each behavior model results in the highest fitness, specifically, how much weight should be placed on avoiding predation or starvation.

\subsection{Model}

An IBM of larval haddock was developed that incorporated key aspects of the environment and biology, including temperature, turbulence, light, prey, predators, feeding, bioenergetics, and swimming behavior. This model was used to examine the effect of passive and active swimming behaviors on vertical distribution as well as survival through the larval stage in a stratified environment at different levels of turbulence, prey, and predators. All constants, variables, and equations are defined in Table 3.1.

\subsubsection{Environment}

The environment was representative of the southern flank of Georges Bank in May. Maximum and mean values of environmental conditions were taken from a study 
tracking a cohort of larval fish in May of 1993 and 1994 (Lough et al. 2005) and used to parameterize the model. The depth of the water column was $70 \mathrm{~m}$.

\section{Light}

Light, $E$, decayed with depth, $z$, following

$$
E(z)=E_{0} \exp (-k z)
$$

with the attenuation coefficient, $k$, equal to $0.18 \mathrm{~m}^{-1}$ and the surface light, $E_{0}$, a sinusoidal function equal to zero for negative values with a maximum of $500 \mu \mathrm{mol} \mathrm{m}^{-2} \mathrm{~s}^{-1}$ (Skartveit et al. 1998).

\section{Turbulence}

The water column was stratified where the vertical distribution of diffusivity, $\kappa$ $\left(\mathrm{m}^{2} \mathrm{~s}^{-1}\right)$, was a sixth degree polynomial function

$$
\kappa=c_{1} z^{6}+c_{2} z^{5}+c_{3} z^{4}+c_{4} z^{3}+c_{5} z^{2}+c_{6} z+c_{7}+10^{-9} \text { (Figure 3.1a). }
$$

This polynomial was fit to the mean output from the Finite Volume Coastal Ocean Model (FVCOM; Chen et al. 2003) for $10 \mathrm{~d}$ in May at a station on the southern flank of Georges Bank near the stations sampled in the Lough et al. (2005) study. The turbulent kinetic energy dissipation rate, $\varepsilon\left(\mathrm{W} \mathrm{kg}^{-1}\right)$, was found from the diffusivity using the relationship from Davis et al. (1991),

$$
\varepsilon=1.65 \cdot 10^{-5} \kappa .
$$

The depth of the turbulence minimum, approximately $18 \mathrm{~m}$, was set as the base of the mixed layer, $z_{m i x}$. The dissipation values generated by the output of FVCOM simulations 
correspond to values observed on Georges Bank $\left(\kappa=10^{-4}-10^{-1} \mathrm{~m}^{2} \mathrm{~s}^{-1}\right.$; Burgett 1997, Burgett et al. 2001, Incze et al. 1996, 2001), however lower rates have also been observed $\left(\kappa=10^{-5}-10^{-2} \mathrm{~m}^{2} \mathrm{~s}^{-1}\right.$; Denman \& Gargett 1984, Yoshida \& Oakey 1996). Since the magnitude of vertical turbulent dissipation rates could affect the ability of a larva to swim vertically, two levels of turbulence were tested, the polynomial given above and the same polynomial reduced by an order of magnitude. The two different turbulent environments will be referred to as high and low turbulence respectively.

\section{Temperature}

To be consistent with a stratified water column representative of the southern flank in late May, temperature, $T$, was also stratified, with a maximum, $T_{\max }$, of $9^{\circ} \mathrm{C}$, minimum, $T_{\min }$, of $7^{\circ} \mathrm{C}$, and thermocline at $z_{m i x}$

$$
T(z)=\left(T_{\max }-T_{\min }\right) *\left(\frac{1}{2}\left(1+\tanh \left(\frac{1}{2}\left(z-z_{\operatorname{mix}}\right)\right)\right)\right)+T_{\min }
$$

\section{Prey}

For simplification, only one type of prey was available for consumption at a given time. The copepod Pseudocalanus spp. was selected because it is the majority of the prey biomass consumed by larval haddock (Kane 1984, Lough et al. 2005, Heath \& Lough 2007) and its biomass is highly correlated to larval haddock growth rate (Buckley \& Durbin 2006). The developmental stage of Pseudocalanus spp. available was set as the dominant naupliar or copepodite stage present in May 1993 and 1994 depending on the 
size of the larvae. For larvae less than $7 \mathrm{~mm}$ it was NIII, and CV for larger larvae. The stratified prey concentration, prey $\left(\mathrm{L}^{-1}\right)$, was represented as a Gaussian

$$
\operatorname{prey}(z)=\left(p_{\max }-p_{\min }\right) *\left(\exp \left(\frac{\left(z-z_{\text {mix }}\right)^{2}}{0.5 * z_{\text {mix }}}\right)\right)+p_{\min }(\text { Figure 3.1b), }
$$

with maximum prey at $z_{m i x}$. Three different levels of prey concentration were simulated, low, mean, and high, each with their own minimum, $p_{\min }$, and maximum, $p_{\max }$ (Table 3.2). The depth averaged prey level was equal to the mean of the combined 1993 and 1994 observations of that prey stage. The depth average of the low prey level was half the mean level, and the high level was double the mean level.

\section{Predation}

Predation by visual predators was examined in the model. On Georges Bank these would include herring, mackerel, krill, mysids, shrimp, and amphipods to name a few. Following visual predation models, predator vision was a function of eye sensitivity, prey contrast, prey size, and light. The perception radius, $R(\mathrm{~m})$, of a predator increased with larval prey size as

$$
R^{2} \exp (c R)=C A_{p} E_{s} \frac{E(z)}{K_{e}+E(z)} \text { (Aksnes \& Giske 1993, Aksnes \& Utne 1997). }
$$

where $c$ is the beam attenuation coefficient, $C$ is prey contrast, $A_{p}\left(\mathrm{~m}^{2}\right)$ is the prey image area, $E_{s}$ is the eye sensitivity of the predator, and $K_{e}$ is the half saturation constant. If $R$ was less than $0.05 \mathrm{~m}$ we used the Fiksen and MacKenzie (2002) approximation

$$
R=\sqrt{C A_{p} E_{s} \frac{E(z)}{K_{e}+E(z)}} .
$$


Predator abundance was related to larval size using size spectrum theory and literature.

Predator size, $M_{\text {pred }}(\mu \mathrm{g})$, was calculated from the size of the haddock larva, $M_{\text {larva }}(\mu \mathrm{g})$,

$$
M_{\text {pred }}=14.7059 M_{\text {larva }}
$$

such that larger predators consumed larger larvae. Predator size was used to calculate predator density, $N_{\text {pred }}\left(\mathrm{m}^{-3}\right)$

$$
N_{\text {pred }}=M_{\text {pred }}^{b}
$$

with a negative power coefficient, $b$, following the theory that larger predators are less abundant. The combination of perception and abundance gave a predation rate, $P\left(\mathrm{~h}^{-1}\right)$

$$
P=\frac{1}{2} \pi R^{2} q N_{\text {pred }}
$$

that decreased with larval size, where $q$ is a proportionality constant. This function is the product of the encounter rate of one predator with one larval fish, the probability of larval capture, and predator density. The encounter rate, Enc, relationship was adapted from MacKenzie \& Kiørboe (1995) for a cruising predator with hemispherical search volume

$$
\text { Enc }=\frac{1}{2} \pi R^{2} N_{\text {larvae }} S \sqrt{u^{2}+v^{2}+2 w^{2}}
$$

with a larval prey concentration, $N_{\text {larvae }}$, equal to one and where $S$ is the proportion of time spent swimming, $u\left(\mathrm{~m} \mathrm{~s}^{-1}\right)$ is larval swimming speed, $v\left(\mathrm{~m} \mathrm{~s}^{-1}\right)$ is predator swimming speed, and $w\left(\mathrm{~m} \mathrm{~s}^{-1}\right)$ is turbulent velocity. The proportionality constant, $q$, (similar to the constant in Fiksen et al. 2002) is obtained by setting $\mathrm{S}=1, u=0, v=0.1$, and $w=0$, and additionally factors in the probability of capture and the proportionality constant of abundance. Three proportionality constants $\left(q_{1}, q_{2}, q_{3}\right)$ were used to give three different predation levels (Figure 3.1c). Predation rates were low, mid, and high with low equal to 
$0.5 \mathrm{x}$ mid, and high equal to $1.5 \mathrm{x}$ mid. The probability of survival for an individual larva at each time step, $p_{\text {surv }}$, was calculated from an exponential probability distribution from the predation rate

$$
p_{\text {surv }}=\exp (-P)
$$

Predation ceased once a larva reached $12 \mathrm{~mm}$ (see Fitness section 2.6 for a discussion).

\subsubsection{Foraging submodel}

The foraging submodel was based on the larval fish feeding models of Caparroy et al. (2000), Fiksen \& MacKenzie (2002) and Kristiansen et al. (2007), and was parameterized for larval haddock and Pseudocalanus spp. by Petrik et al. (2009). The model mechanistically simulated the foraging cycle of encounter, pursuit, capture, and ingestion of copepod prey. In this model ingestion was the product of encounter rate and the probability of successful capture, $p c a$. Encounter rate was a function of the larval fish pause-travel swimming characteristics (pause duration and frequency), the larval perception distance dependent on light and larval size, prey density, prey swimming speed, and turbulent velocity. The probability of successful capture was a function of species-specific prey escape behaviors: the deformation rate threshold, escape jump

speed, and escape jump angle. For computational speed, the probability was parameterized to be a function of prey species (Pseudocalanus spp.) and stage length using the results of Petrik et al. (2009) as

$$
p c a=\frac{\exp \left(d_{1} r^{3}+d_{2} r^{2}+d_{3} r+d_{4}\right)}{1+\exp \left(d_{1} r^{3}+d_{2} r^{2}+d_{3} r+d_{4}\right)}
$$


where $d$ 's are species-specific constants, and $r$ is the copepod prey to larval fish length ratio.

\subsubsection{Bioenergetics submodel}

The bioenergetics submodel was the same as that used in Petrik et al. (2009) for larval haddock, which was based on Kristiansen et al. (2007) for larval cod. The amount of biomass ingested in the foraging submodel was tracked and the energy derived from it was apportioned to metabolism and growth, both of which were temperature- and larval size-dependent. Metabolism was increased a constant amount during light hours to account for the swimming activity of feeding fish.

\subsubsection{Vertical behavior models}

Four different vertical behavior models were tested, which all used the same maximum swimming speed. The routine swimming speed, $u_{R}\left(\mathrm{~m} \mathrm{~s}^{-1}\right)$, was a function of body length, $L(\mathrm{~m})$, derived by Peck et al. (2006) from the closely related species Atlantic cod,

$$
u_{R}=0.261 \cdot 10^{-3} \cdot L^{1.552 L^{-0.08}}-\frac{5.289}{L} .
$$

The imposed maximum swimming speed, $u_{\max }\left(\mathrm{m} \mathrm{s}^{-1}\right)$,

$$
u_{\max }=1.5 u_{R}
$$

resulted in a maximum swimming speed less than $0.8 \mathrm{~L} \mathrm{~s}^{-1}$ for all larval sizes $5-12 \mathrm{~mm}$.

It was outside the range of routine swimming speed $\left(0.3-0.5 \mathrm{~L} \mathrm{~s}^{-1}\right)$ that was calculated as 
the average of bursts and pauses (Peck et al. 2006), but less than the maximum speeds observed during bursts $\left(2.4 \mathrm{~L} \mathrm{~s}^{-1}\right)$, making it within the range of speeds possible to sustain for longer times. To conserve biological diffusivity, the larval swimming speed was also increased proportional to the difference of the swimming speed measurements and the model time step.

\section{Case A - Diffusion}

Under Case A larvae had no swimming behavior $\left(\beta_{I}=0, u_{l}=0\right)$ and moved by passive diffusion only.

\section{Case B - Prey concentration and light with random direction}

With Case B, larvae had no vertically directed swimming behavior, and they swam up or down at random. However, their swimming speed, $u_{2}\left(\mathrm{~m} \mathrm{~s}^{-1}\right)$

$$
u_{2}= \pm 0.5 u_{\max }\left(1-\beta_{2}\right),
$$

(where \pm denotes random direction) was related to a trade-off, $\beta_{2}$

$$
\beta_{2}(z)=\alpha\left(\frac{\operatorname{prey}(z)}{p_{\max }}\right)-(1-\alpha)\left(\frac{E(z)}{E_{0}}\right),
$$

between relative prey concentration and the light conditions. Larvae with this behavior swam at a speed negatively proportional to the difference between relative prey concentration and relative light, for example, slowing down in a region of high prey and low light. This behavior assumed that larvae could sense the amount of light in the water column, but not necessarily the prey concentration. Prey concentration and light were 
proxies for handling time and predation risk, respectively. Regions with high prey concentrations have higher handling times such that larvae would spend more time handling food and less time swimming, thereby reducing their swimming speed. Regions with high light levels have greater visual predation rates, and larvae may be less apt to feed in these regions. Therefore larvae may slow down to feed more in regions of low light than regions of high light, resulting in the above equation for swimming speed.

The weight constant, $\alpha$, determines how much emphasis is placed on feeding or predation in the trade-off. Larvae with $\alpha=1$ will disregard predation risk during feeding, while decreasing values of $\alpha$ increase the importance of light (predation risk) in adjusting time spent feeding (swimming speed). Example swimming speed profiles for different parameterizations of this behavior are given in Figure 3.2.

Since larval fish are visual predators, they only feed during daylight. Given that behavior B is related to feeding, it was assumed that $u_{2}=0$ at night.

\section{Case C - Prey concentration and light with directed swimming}

Like Case B, Case $\mathrm{C}$ also related prey concentration to handling time and swimming speed, and there was a trade-off between prey concentration and light. However, Case $\mathrm{C}$ differed in that swimming was directed specifically up (positive) or down (negative) according to the equations for swimming speed, $u_{3}\left(\mathrm{~m} \mathrm{~s}^{-1}\right)$,

$$
u_{3}=-u_{\max } \beta_{3}
$$

and the trade-off, $\beta_{3}$ 


$$
\beta_{3}=\alpha\left(\tanh \left(z-z_{\text {mix }}\right)\right)+(1-\alpha)\left(\frac{E(z)}{E_{0}}\right)
$$

The first half of the behavior trade-off, $\beta_{3}$, directed larvae towards the prey maximum at the turbulence minimum, $z_{m i x}$, at a speed negatively proportional to the distance from $z_{m i x}$. The second half of the equation directed larvae to swim down at a speed proportional to the amount of light at that depth. This behavior explicitly assumed that larvae could sense the relative abundance of prey or prey gradients. Again, $u_{3}=0$ at night when the larvae could not see their prey. The weight constant, $\alpha$, played the same role in determining how much importance was placed on feeding or predation in the trade-off. Figure 3.2 depicts the swimming speed of all parameterizations of the model tested (in case $\mathrm{C}$, negative values indicate downward swimming).

\subsubsection{Optimal $\alpha$}

Though there are search methods for finding the optimal value of a parameter, we performed a broad search to describe the shape of parameter space $(\alpha=0: 0.1: 1)$ because the behavior of fitness $F(\alpha \mid y)$ as a function of $\alpha$, and not just its maximum, were of interest.

For a given value of the weight $\alpha$, the model provided an outcome for an individual at initial depth $z$ and environment $y$. On the basis of this outcome, the value of the objective function $F(\alpha \mid y, z)$ for this individual was calculated. To remove the dependence on initial depth, define:

$$
F(\alpha \mid y)=\int F(\alpha \mid y, z) f(z) d z
$$


where $f(z)$ is the probability density function (pdf) of initial depth. The quantity $F(\alpha \mid z)$ is the expected value (over the distribution of initial depth) of the fitness for weight $\alpha$ and environment $y$. If $f(z)$ is uniform over the range $\left(z_{\min }, z_{\max }\right)$, then the integral can be approximated as

$$
F(\alpha \mid y) \cong \sum_{j=1}^{n} F\left(\alpha \mid y, z_{j}\right) / n
$$

where $z_{1}, z_{2}, \ldots, z_{n}$ are $n$ depths regularly spaced between $z_{\min }$ and $z_{\max }$.

For a fixed environment $y$, the optimal weight $\alpha^{*}(y)$ maximizes $F(\alpha \mid y)$. This was found by running the model over a range of values, $\alpha=0: 0.1: 1$. The fixed environment, $y_{1}$, used mean prey concentrations and mid level predation rates.

Since larvae experience a wide range of environmental conditions, the optimality of $\alpha$ was also tested under uncertainty. For this round of simulations individuals experienced four environments, one at a time, with the same value of $\alpha$ for each. This assumed that $\alpha$, and thus the behavior, was set before experiencing the environmental conditions. To remove the dependence on the environment, define

$$
F(\alpha)=\int F(\alpha \mid y) g(y) d y
$$

where $g(y)$ is the pdf of the environment. The quantity $F(\alpha)$ is the expected value (over the distribution of the environment) of the objective function for weight $\alpha$. Unlike $z$, the environment $y$ is a complicated quantity. However, $F(\alpha)$ can be approximated as:

$$
F(\alpha) \cong \sum_{j=1}^{m} F\left(\alpha \mid y_{j}\right) / m
$$


where $y_{1}, y_{2}, \ldots, y_{m}$ is a random sample of $m$ observed environments. The optimal weight $\alpha^{*}$ maximizes $F(\alpha)$. The four additional environments tested were $y_{2}$ : low prey and low predation, $y_{3}$ : high prey and low predation, $y_{4}$ : low prey and high predation, and $y_{5}$ : high prey and high predation.

\subsubsection{Fitness}

Fitness, $F$, was the objective function maximized with respect to $\alpha$. Our measure of fitness was the proportion of larvae surviving to $12 \mathrm{~mm}$, which is the approximate length of the transition from larvae to pelagic juveniles, and thus marks the end of the larval period. Grimm and Railsback (2005) define fitness as success in passing genes on to future generations. Only the larval period is studied here and too many processes occur between the end of the larval period and reproduction to make assumptions on how any state at the end of the larval period may relate to reproductive output. However, fish must survive the larval period to reach reproductive maturity, thus surviving the larval period is a target that must be achieved for fitness to be high. This fitness measure is different from many habitat choice behavior studies that use some variation of minimizing mortality over ingestion or growth, or maximizing growth over mortality. One of these growth/ingestion/mortality variations was not used because of the theoretical and practical concerns of their implementation in IBMs addressed in Railsback et al. (1999). 


\subsubsection{Simulations}

Simulations included 1000 individual larvae initialized at $5 \mathrm{~mm}$, the mean length of the first-feeding stage. The model was run for $80 \mathrm{~d}$, which was a long enough time for all individuals to either die or reach $12 \mathrm{~mm}$, with a time step of one hour. A time step of $10 \mathrm{~s}$ was chosen to meet the requirements needed to correctly model a vertical random walk with spatially varying turbulent mixing (Ross \& Sharples 2004). During each time step larvae fed, grew, were exposed to predation, and moved, in that order. Larvae were initially distributed uniformly with depth with $10 \%$ gut fullness. Simulations were repeated 10 times each with a new seed for the random number generator used for the vertical diffusivity random walk component.

\subsection{Results}

\subsubsection{Case A - Diffusion}

The diffusion case assumed no behavior and served as a comparison for Cases B and C. Since there was no behavior, $\alpha^{*}$ was not investigated with these simulations, but the effect of different random seed values on turbulence was. Mean fitness was higher in the runs with high turbulence (Table 3.3). The mean proportion of the initial population that survived to $12 \mathrm{~mm}$ differed by $4-5 \%$ (s.d. $=0.0118-0.0161$; Table 3.3 ) in both the fixed and uncertain environments with high and low turbulence estimates from FVCOM. Following these results, fitness values with standard deviations $\leq 0.0161$ in Cases B and C 
were considered meaningless as the differences were the result of the random variations in turbulence, and not related to the parameterization of $\alpha$.

The depth distribution of all individuals was well-mixed in both high and low turbulence environments, as would be expected from pure diffusion and a uniform random initial distribution (Figure 3.3a,c). When turbulence was high the proportion of larvae that survived to $12 \mathrm{~mm}$ was lower in the top $20 \mathrm{~m}$ until $40 \mathrm{~d}$ (Figure 3.3b). With low turbulence the surviving individuals were between $15-35 \mathrm{~m}$ at $20 \mathrm{~d}$, and spread out over time such that they were between $10-50 \mathrm{~m}$ at $40 \mathrm{~d}$, and then nearly evenly distributed in the water column after $60 \mathrm{~d}$ (Figure 3.3d). The mean depth of the live larvae in comparison with all larvae changed with the turbulence regime. When turbulence was high the live larvae were deeper than all larvae until $50 \mathrm{~d}$, while the live larvae were shallower than all larvae until this time when turbulence was low (Figure 3.4).

\subsubsection{Case $B$ - Prey concentration and light with random direction}

\section{High turbulence}

Under high turbulence and a fixed environment with the mean prey concentration and mid level of predation, $\alpha^{*}=0.4$ resulted in the highest mean fitness of all 10 simulation runs. However, the relationship between $\alpha$ and fitness varied with the random seed value. In some runs there was a positive relationship, others had a negative one, and a few had no clear relationship. In individual runs, the difference in the proportion surviving to $12 \mathrm{~mm}$ was never more than $2 \%$ of the initial population, while the standard 
deviation in mean fitness was $6.72 \times 10^{-4}$ (Table 3.4). The association between fitness and $\alpha$ was weak in relation to the random motion caused by turbulence.

When the environment was uncertain, larvae with the behavior parameterized with $\alpha^{*}=0.9$ had the highest fitness, however it was not much better than $\alpha=1$, or the opposite behavioral strategy of $\alpha=0$. As in the fixed environment, the relationship between $\alpha$ and fitness was not strong across the random variation in turbulence. The lack of a connection between $\alpha$ and fitness was also apparent in the results from the individual environments encountered in the uncertain environment simulations (e.g. $y_{4}=$ high prey and low predation). There were no starvation losses in the high turbulence environment.

The $\alpha^{*}$ values for the fixed and uncertain environments both produced behaviors with swimming speeds greater above the prey maximum than below it. Nevertheless, different parameterizations of $\alpha$ resulted in very small differences in the depth distributions of the larvae during the first $40 \mathrm{~d}$ (Figure 3.5). This pattern was also visible when inspecting the mean depth of all the individuals, and just those that survived to 12 $\mathrm{mm}$ (Figure 3.6). During the first $40 \mathrm{~d}$ the swimming speed of the small larvae was too weak to overcome turbulent diffusion and cause aggregation around the copepod prey. Common to all parameterizations of this behavior was that the larvae that survived to 12 mm were deeper in the water column during the first $40 \mathrm{~d}$ (Figures 3.5, 3.6).

\section{Low turbulence}

Under low turbulence, highest fitness in both the fixed and uncertain environments resulted from $\alpha^{*}=0$. Similar to when this behavior was used under high 
turbulence, the relationship between $\alpha$ and fitness changed with the random seed. The differences across $\alpha$ values in fitness for individual runs and the mean fitness of all runs were small in the fixed and uncertain environments (s.d. $=0.0014$ and $4.73 \times 10^{-4}$, respectively; Table 3.4). It follows that the parameterization of $\alpha$ did not have an effect on fitness. Individuals died of starvation under low turbulence conditions, leading to lower fitness compared to high turbulence.

The optimal value of $\alpha$ resulted in fast swimming at the surface that slowed down to a stop around $30 \mathrm{~m}$ and below. This behavior avoided predation only, and food did not

matter. As a result, larvae were relatively more abundant below the mixed layer, with the exception of the first $20 \mathrm{~d}$ (Figure 3.7a,b). Under low turbulence, stratification of the larvae around their prey occurred earlier in time (40 d Figure 3.7c,d vs. 60 d Figure $3.5 \mathrm{e}, \mathrm{f})$ and was stronger than when turbulence was high. The mean depth of individuals that survived to $12 \mathrm{~mm}$ was shallower than the mean depth of all individuals whether $\alpha$ was 0 or 1 (Figure 3.8). There was no difference in the mean depth of individuals using the behavior with $\alpha=0$ and $\alpha=1$ until $15 \mathrm{~d}$, after which the $\alpha=0$ larvae were deeper (Figure $3.8)$.

\subsubsection{Case $\mathrm{C}$ - Prey concentration and light with directed swimming}

\section{High turbulence}

Larvae in the fixed and uncertain environments behaving with Case $\mathrm{C}$ had $\alpha^{*}=0$ as determined by the mean fitness of all simulations. This result did not depend on random seed value and the differences among $\alpha$ values were 4-5 times greater than in the 
diffusion case (Table 3.5), suggesting that the directed swimming was able to overcome turbulent diffusion and that different fitness values were caused by different parameterizations of the behavior. Mean fitness decreased as $\alpha$ increased in all 5 environments.

The directed swimming behavior with $\alpha^{*}=0$ yielded larvae that swam down out of the well-lit areas of the water column and ceased swimming below this depth. Different parameterizations of $\alpha$ resulted in distinct distributions of larvae at all times. With $\alpha^{*}=0$, the majority of larvae were below $20 \mathrm{~m}$ (Figure 3.9a,b). With $\alpha=1$, larvae concentrated around the prey maximum during the day (Figure $3.9 \mathrm{c}, \mathrm{d}$ ) and were dispersed at night. The distributions of all individuals (Figure 3.9a,c) looked very similar to the distributions of larvae that survived to $12 \mathrm{~mm}$ (Figure 3.9b,d).

\section{Low turbulence}

Directed swimming with low turbulence had $\alpha^{*}=0.1$ in both the fixed and uncertain environments. Unlike in the high turbulence regime, the standard deviations were on the same order as the diffusion case and there was variation in the relationship of $\alpha$ and fitness (Table 3.5). When predation was low, $\alpha^{*}=0.1$ gave the highest fitness, $\alpha=0$ gave the lowest, and all other $\alpha$ values gave fitness values slightly less than the highest. When predation was high, the pattern changed to decreasing fitness with increasing $\alpha$. With intermediate predation, 8 out of 10 runs produced a nonzero value of $\alpha^{*}$. However, none of these relationships was significant with respect to $\alpha$ since the variations were not larger than the ones caused by turbulence alone. 
The larvae were distributed in the water column similarly as when turbulence was high, with $\alpha=0$ larvae below $20 \mathrm{~m}$ and $\alpha=1$ larvae concentrated around the prey maximum (Figure 3.10). In contrast to the high turbulence results, larvae that survived to $12 \mathrm{~mm}$ had greater densities between 20 and $40 \mathrm{~m}$ at $20 \mathrm{~d}$ (Figure 3.10b), and larvae stratified around their prey at an earlier time (Figure 3.10c-f). Also contrary to the high turbulence case, the mean depth of all and just the alive individuals was the same when $\alpha=1$, but not with $\alpha=0$ (Figure 3.11). When $\alpha=0$, the surviving individuals were higher in the water column during the first $40 \mathrm{~d}$ (Figure 3.11).

\subsubsection{All cases}

Using the best parameterization of $\alpha$ for each behavior, Case $\mathrm{C}$ had the highest fitness and Case A the lowest when turbulence was high in either the fixed or uncertain environment and when it was low in the uncertain environment (Figure 3.12). When turbulence was low and the environment fixed, Case B gave the highest fitness and Case A the lowest (Figure 3.12). The highest mean fitness resulted from either $\alpha^{*}=0$ or $\alpha^{*}=0.1$ when comparing all swimming behaviors in every prey, predator, and turbulent environment. For a given behavior, the value of $\alpha^{*}$ changed with predation and turbulence levels, but not prey concentration.

The mean time to reach $12 \mathrm{~mm}$ was calculated for the best parameterization of each case in the fixed environment. Larvae with the Case $\mathrm{C}$ behavior reached $12 \mathrm{~mm}$ the fastest under low turbulence, but the slowest under high (Table 3.6). 


\subsection{Discussion}

Observations of larval haddock show maximum densities that coincide with the depth of highest prey biomass (Lough 1984, Buckley \& Lough 1987, Lough \& Potter 1993). Both behaviors B and C were able to produce similar distributions of haddock, however behavior B could only do this when individuals were approximately greater than $40 \mathrm{~d}$ old and $12 \mathrm{~mm}$ long, classifying them as pelagic juveniles. Since observations following storm-induced mixing events demonstrate that larvae re-stratify around their prey in a few days (Lough 1984, Lough \& Potter 1993), the initial uniform conditions should not be the source of the lack of aggregation in the early days using behavior B. The failure of this behavioral case to reproduce observations must be attributed to the random up or down swimming behavior, and the weak swimming speed with respect to turbulent vertical diffusion. These results suggest that behavior B is not the behavior used by larval haddock since distributions coincident with prey are observed in all sizes (2-13 mm; Lough 1984, Buckley \& Lough 1987, Lough \& Potter 1993).

The present modeling results suggest that haddock larvae use a directed swimming behavior. The distributions of haddock produced by behavior $\mathrm{C}$ (with the exception of $\alpha=0$ ) were very similar to those observed in the field. While this model assumed that larvae direct their swimming by sensing light and knowing the depth with the highest prey concentrations, this is not necessarily the mechanism used by larval haddock in the field. Though fish larvae can probably orient up and down with respect to light and/or gravity, they most likely cannot detect prey concentrations because of their small perception volumes. Nonetheless, larvae may be able to sense environmental 
properties like temperature and turbulent velocity that are associated with the thermo/pycnocline, where copepod prey tends to be most abundant under stratified conditions.

Sclafani et al. (1993) modeled the vertical position of cod larvae with directed swimming towards the prey maximum during the day and buoyancy at night. The swimming ability and ultimately the depth of a larva were related to its condition as determined by ingestion. Two different types of diel vertical migration (DVM) emerged from this behavior model. Larvae in poor condition exhibited nocturnal DVM with buoyancy causing them to rise at night followed by downward swimming towards the prey maximum during the day, whereas good conditioned larvae demonstrated diurnal DVM by swimming up towards the prey during the day after buoyancy caused them to sink at night (Sclafani et al. 1993). In general, larvae in poor condition were higher in the water column than larvae in good condition (Sclafani et al. 1993).

DVM did not emerge from either of the behavior models tested in this study since larvae did not swim at night. Instead, larvae spread vertically with passive turbulent diffusion at night, which is consistent with the Sclafani et al. (1993) buoyancy model of a mixed population of larvae in poor and good condition. If buoyancy were to control the position of larvae at night in our model, poor condition larvae would suffer higher predation losses from being shallower due to their decreased specific gravity. It is difficult to say how this change would impact the fitness results since larvae would not feed or be eaten at night, but their location at the end of the night would affect both the 
prey and turbulence levels experienced and how far larvae had to swim to reach higher concentrations of prey during the day.

There is no consistent evidence of larval haddock DVM or ontogenetic changes in depth. Neither Miller et al. (1963), nor Frank et al. (1989), found significant changes in day-night distributions of larvae spanning lengths of $4 \mathrm{~mm}$ to $19 \mathrm{~mm}$. On the other hand, Lough \& Potter (1993) found 6-8 $\mathrm{mm}$ and 9-13 $\mathrm{mm}$ larvae deeper during the day than night, but the depth difference was only significant for the $9-13 \mathrm{~mm}$ size class. Lough \& Potter (1993) also observed small larvae (2-5 $\mathrm{mm}$ and 6-8 $\mathrm{mm}$ ) either above or in the thermocline and larger larvae $(9-13 \mathrm{~mm})$ in or below the thermocline. Miller et al. (1963) observed the opposite pattern with smaller larvae $(4-8 \mathrm{~mm})$ below the thermocline and larger larvae $(9-19 \mathrm{~mm})$ in the thermocline.

The discrepancies between observations of the vertical distribution of haddock larvae could be explained by differences in condition of the larvae or the density structure of the water column if the Sclafani et al. (1993) model were used. Like our model behavior Case C, the Sclafani et al. (1993) model assumes directed swimming towards the prey maximum. However, it is possible that the vertical position of larvae is controlled by buoyancy and stratification alone until the development of a functioning swim bladder. The buoyancy model is consistent with observations of increased aggregation of eggs and larvae with increases in stratification (Frank et al. 1989, Lough \& Potter 1993), and the depth of maximum abundance coinciding with the thermocline (Miller et al. 1963, Lough 1984, Buckley \& Lough 1987), and warrants more testing. The swim bladder may be functional when larvae reach $9 \mathrm{~mm}$ length, and would explain 
the larger vertical migrations of larvae $>9 \mathrm{~mm}$ in both well-mixed and stratified waters (Lough \& Potter 1993), though the mechanism directing swimming is unknown.

Of the two behaviors tested, only the directed swimming Case $\mathrm{C}$ under high turbulence resulted in changes in fitness with parameterization in the behavioral model greater than those from turbulent diffusion alone. Though a change in survival of 5\% could result in a large difference in the number of larvae surviving to the pelagic juvenile stage when considering the number of larvae that hatch each season (on the order of $10 \mathrm{~s}$ 100s of millions), this difference was the result of the random motion caused by turbulence and could not be attributed to the value of $\alpha$ in Case B under high turbulence and both behaviors $\mathrm{B}$ and $\mathrm{C}$ under low turbulence.

When turbulence was high, the swimming speeds of the larvae during the first $40 \mathrm{~d}$ were weak in comparison. Despite different parameterizations of the Case B swimming behavior, the depth distributions of the larvae were very similar over the first $20 \mathrm{~d}$. It was over this time period that the predation pressure was the strongest, ranging from $0.02-0.04 \mathrm{~d}^{-1}$ while it was less than $0.01 \mathrm{~d}^{-1}$ for the second half of the simulation (Figure 3.13). The fitness was set during this time when predation was high, and, since the larvae had the same depth distributions, they incurred the same predation losses, resulting in similar fitness despite different values of $\alpha$. This explanation could also account for why there was no relationship between $\alpha$ and fitness for Case B under low turbulence conditions, however, it does not hold in low turbulence for Case C. Nonzero values of $\alpha$ produced similar depth distributions during the first $40 \mathrm{~d}$, but the distribution when $\alpha=0$ was markedly different, yet the variation in fitness was not greater than that 
caused by diffusion alone. The number of larvae using Case $\mathrm{C}$ with $\alpha=0$ that died from starvation in the lower water column offset the number of predation losses of larvae in the well-lit upper waters with the nonzero parameterizations, thus resulting in similar fitnesses.

Starvation occurred in the low turbulence simulations from a reduction in encounter rate with prey. The starvation losses were most apparent in deep waters where increased encounter rate compensated for the lack of light when turbulence was high. Starvation in low turbulence shifted the mean depth of individuals that survived to $12 \mathrm{~mm}$ shallower than the mean depth of all individuals, at least during the first $40 \mathrm{~d}$. In contrast, the mean depth of surviving larvae was deeper than that of all larvae when turbulence was high and predation was of greater consequence than starvation.

The conclusions that can be made from these simulation experiments depend on the turbulent environment of larval haddock on Georges Bank and stress the need for accurate turbulence estimates. Turbulence affected both swimming and encounter rate in this model. High turbulence prevented aggregation of larvae around the depth of maximum prey abundance when the random swimming behavior B was used. Though high turbulence in these model simulations prevented starvation, this might not be true in the ocean. One caveat of the model is that the vertical distribution of prey was not allowed to change over time. Prey in the ocean may be more dispersed when turbulence is higher, which was not included in the simulations. Further modeling is needed to examine possible effects of prey levels that dynamically aggregate and diffuse as a function of turbulence level. Additionally, higher turbulence reduces pursuit success of 
prey by larval fish, another aspect missing from the simulations. Larval cod preying on copepods experienced a steep decline in pursuit success in laboratory experiments with turbulent dissipation rates in the range of $1.0 \cdot 10^{-6}-1.3 \cdot 10^{-5} \mathrm{~m}^{2} \mathrm{~s}^{-3}$ (MacKenzie \& Kiørboe 2000). The dissipation rates in both the low and high turbulence environments were below this level, with a range of $1.7 \cdot 10^{-10}-4.6 \cdot 10^{-7} \mathrm{~m}^{2} \mathrm{~s}^{-3}$, thus it is expected that incorporating the effects of turbulence on pursuit success would not markedly alter the model results. The effect of turbulence on swimming in the model is most likely accurate, but the feeding results should be attributed to effective prey density from increased encounter and not to turbulent dissipation rate, such that the same results could be reached by altering either the turbulence level or prey concentration. We did not see this effect with prey concentration because our differences in prey density were not as large as the difference between the turbulent diffusivities.

In conclusion, larval haddock should behave such that they avoid visual predation rather than starvation mortality if conditions are like those in the high turbulence simulations, specifically, encounter rate with prey is high. If turbulence is an order of magnitude lower with a correspondingly lower encounter rate, then predation and starvation should both be factored into vertical swimming behavior decisions with greater emphasis on predation. The high turbulence environment was the only one to produce a behavioral model with significant variations in fitness with its parameterization. The highest fitness resulted when larvae used directed swimming and made behavioral decisions based on light alone. This behavior promoted avoiding light and visual predators while larvae were small and had weak swimming abilities. However, the depth 
distribution produced by this optimal behavior contrasted with the one observed in the field; larvae are found in high abundance in the surface waters contrary to what the model predicts. This discrepancy could mean that actual turbulent dissipation rates on Georges Bank are on the lower end. Alternatively, the visual predation rates may not be an accurate reflection of the predation pressure on haddock larvae. If non-visual predators perform the bulk of predation, then larvae in the upper water column would benefit from increased light to encounter their prey. Furthermore, studies of larvae that survived to the fall reveal that these larvae were spawned ahead of the peak in the spawning curve (Lapolla \& Buckley 2005) during the small window in February-March when growth rates exceed mortality rates, thereby allowing larvae to be bigger in the late spring when predation is higher (Buckley et al. 2010). Their findings in combination with our modeling results imply that larvae may avoid predators in time rather than space. We intend to test this hypothesis using a directed swimming behavior in a $3 \mathrm{D}$ coupled biological-physical model of haddock on Georges Bank. 


\section{References}

Aksnes DL, Giske J (1990) Habitat profitability in pelagic environments. Mar Ecol Prog Ser 64:209-215

Aksnes DL, Giske J (1993) A theoretical model of aquatic visual feeding. Ecol Model $67: 233-250$

Aksnes DL, Utne ACW (1997) A revised model of visual range in fish. Sarsia 82:137147

Banse K, Mosher S (1980) Adult body mass and annual production/biomass relationships of field populations. Ecol Monogr 50:355-379

Brickman D, Frank KT (2000) Modelling the dispersal and mortality of Browns Bank egg and larval haddock (Melanogrammus aeglefinus). Can J Fish Aquat Sci $57: 2519-2535$

Brickman D, Shackell NL, Frank KT (2001) Modelling the retention and survival of Browns Bank haddock larvae using an early life stage model. Fish Oceanogr $10: 284-296$

Buckley LJ, Durbin EG (2006) Seasonal and inter-annual trends in the zooplankton prey and growth rate of Atlantic cod (Gadus morhua) and haddock (Melanogrammus aeglefinus) larvae on Georges Bank. Deep-Sea Res II 53:2758-2770

Buckley LJ, Lough RG (1987) Recent growth, biochemical composition, and prey field of larval haddock (Melanogrammus aeglefinus) and Atlantic cod (Gadus morhua) on Georges Bank. Can J Fish Aquat Sci 44:14-25 
Buckley LJ, Lough RG, Mountain D (2010) Seasonal trends in mortality and growth of cod and haddock larvae result in an optimal window for survival. Mar Ecol Prog Ser 405:57-69

Burgett RL (1997) The structure of tidal mixing on the southern flank of Georges Bank. M.S. Thesis, University of Rhode Island, 142p

Burgett RL, Hebert D, Oakey NS (2001) Vertical structure on the southern flank of Georges Bank. J Geophys Res 106:22545-22558

Caparroy P, Thygesen UH, Visser AW (2000) Modelling the attack success of planktonic predators: patterns and mechanisms of prey selectivity. J Plank Res 22:18711900

Chen C, Liu H, Beardsley RC (2003) An unstructured, finite-volume, three dimensional, primitive equation oceanography model: application to coastal oceanography and estuaries. J Atmos Ocean Tech 20:159-186

Cowan Jr JH, Rose KA, Houde ED (1997) Size-based foraging success and vulnerability to predation: selection of survivors in individual-based models of larval fish populations. In: Chambers RC, Trippel EA (eds) Early life history and recruitment in fish populations. Chapman \& Hall, London, p 357-386

Davis CS, Flierl GR, Wiebe PH, Franks PJS (1991) Micropatchiness, turbulence and recruitment in plankton. J Mar Res 49:109-151

Denman KL, Gargett AE (1984) Time and space scales of vertical mixing and advection of phytoplankton in the upper ocean. Limnol Oceanogr 28:801-815 
Dickie LM, Kerr SR, Boudreau PR (1987) Size-dependent processes underlying regularities in ecosystem structure. Ecol Monogr 57:233-250

Fiksen Ø, Folkvord A (1999) Modelling growth and ingestion processes in herring Clupea harengus larvae. Mar Ecol Prog Ser 184:273-289

Fiksen Ø, MacKenzie BR (2002) Process-based models of feeding and prey selection in larval fish. Mar Ecol Prog Ser 243:151-164

Fiksen Ø, Aksnes DL, Flyum MH, Giske J (2002) The influence of turbidity on growth and survival of fish larvae: a numerical analysis. Hydrobiologia 484:49-59

Frank KT, Page FH, McRuer JK (1989) Hydrographic effects on the vertical distribution of haddock (Melanogrammus aeglefinus) eggs and larvae on the Southwestern Scotian Shelf. Can J Fish Aquat Sci 46:82-92

Grimm V, Railsback SF (eds) (2005) Individual based modeling and ecology. Princeton University Press, Princeton, 428p

Heath MR, Lough RG (2007) A synthesis of large-scale patterns in the planktonic prey of larval and juvenile cod (Gadus morhua). Fish Oceanogr 16:169-185

Hinckley S, Hermann AJ, Mier KL, Megrey BA (2001) Importance of spawning location and timing to nursery areas: simulation study of Gulf of Alaska walleye pollock. ICES J Mar Sci 58:1042-1052

Incze LS, Aas P, Ainaire T (1996) Distributions of copepod nauplii and turbulence on the southern flank of Georges Bank: implications for feeding by larval cod (Gadus morhua). Deep-Sea Res II 43:1855-1873 
Incze LS, Heber D, Wolff N, Oakey N, Dye D (2001) Changes in copepods distributions associated with increased turbulence from wind stress. Mar Ecol Prog Ser 213:229-240

Jennings S, Mackinson S (2003) Abundance-body mass relationships in size-structured food webs. Ecol Lett 6:971-974

Kane J (1984) The feeding habits of co-occurring cod and haddock larvae from Georges Bank. Mar Ecol Prog Ser 16:9-20

Kerr SR, Dickie LM (2001) The Biomass Spectrum: a predator-prey theory of aquatic production. Columbia University Press, New York, 320p

Kristiansen T, Fiksen Ø, Folkvord A (2007) Modelling feeding, growth and habitat selection in larval cod (Gadus morhua): observations and model predictions in a macrocosm environment. Can J Fish Aquat Sci 64:136-151

Kristiansen T, Jørgensen C, Lough RG, Vikebø F, Fiksen Ø (2009a) Modeling rule-based behavior: habitat selection and the growth-survival trade-off in larval cod. Behav Ecol 20:490-500

Kristiansen T, Vikebø F, Sundby S, Huse G, Fiksen Ø (2009b) Modeling growth of larval cod (Gadus morhua) in large-scale seasonal and latitudinal environmental gradients. Deep-Sea Res II 56:2001-20011

Kühn W, Peck MA, Hinrichsen H-H, Daewel U, Moll A, Pohlmann T, Stegert C, Tamm S (2008) Defining habitats suitable for larval fish in the German Bight (southern North Sea): an IBM approach using spatially- and temporally-resolved sizestructured prey fields. J Mar Sys 74:329-342 
Lankin KF, Peck MA, Buckley LJ, Bengtson DA (2008) The effects of temperature, body size and growth rate on energy losses due to metabolism in early life stages of haddock (Melanogrammus aeglefinus). Mar Biol 155:461-472

Lapolla A, Buckley LJ (2005) Hatch date distributions of young-of-year haddock Melanogrammus aeglefinus in the Gulf of Maine/Georges Bank region: implications for recruitment. Mar Ecol Prog Ser 290:239-249

Leis JM (2007) Behaviour as input for modeling dispersal of fish larvae: behaviour, biogeography, hydrodynamics, ontogeny, physiology and phylogeny meet hydrography. Mar Ecol Prog Ser 347:185-193

Letcher BH, Rice JA, Crowder LB, Rose KA (1996) Variability in survival of larval fish: disentangling components with a generalized individual-based model. Can J Fish Aquat Sci 53:787-801

Lough RG (1984) Larval fish trophodynamic studies on Georges Bank: sampling strategy and initial results. In: Dahl E, Danielssen DS, Moskness E, Solemdal P (eds) The propagation of cod Gadus morhua. Flødevigen rapportser I, p 395-434

Lough RG, Potter DC (1993) Vertical distribution patterns and diel migrations of larval and juvenile haddock Melanogrammus aeglefinus and Atlantic cod Gadus morhua on Georges Bank. Fish Bull 91:281-303

Lough RG, Buckley LJ, Werner FE, Quinlan JA, Pehrson Edwards K (2005) A general biophysical model of larval cod (Gadus morhua) growth applied to populations on Georges Bank. Fish Oceanogr 14:241-262 
Lough RG, Hannah CG, Berrien P, Brickman D, Loder JW, Quinlan JA (2006) Spawning pattern variability and its effect on retention, larval growth and recruitment in Georges Bank cod and haddock. Mar Ecol Prog Ser 310:193-212

MacKenzie BR, Kiørboe T (1995) Encounter rates and swimming behavior of pausetravel and cruise larval fish predators in calm and turbulent laboratory environments. Limnol Oceanogr 40:1278-1289

MacKenzie BR, Kiørboe T (2000) Larval fish feeding and turbulence: a case for the downside. Limnol Oceanogr 45:1-10

Miller D, Colton Jr JB, Marak RR (1963) A study of the vertical distribution of larval haddock. J Cons Int Explor Mer 28:37-49

Mullon C, Cury P, Penven P (2002) Evolutionary individual-based model for the recruitment of anchovy (Engraulis capensis) in the southern Benguela. Can J Fish Aquat Sci 59:910-922

Peck MA, Buckley LJ, Bengtson DA (2006) Effects of temperature and body size on the swimming speed of larval and juvenile Atlantic cod (Gadus morhua): implications for individual-based modeling. Env Biol Fish 75:419-429

Peters RH (1986) The ecological implications of body size. Beck E, Birks HJB, Connor EF (eds). Cambridge University Press, Cambridge, 329p.

Petrik CM, Kristiansen T, Lough RG, Davis CS (2009) Prey selection of larval haddock and cod on copepods with species-specific behavior: a model-based analysis. Mar Ecol Prog Ser 396:123-143 
Platt T, Denman K (1978) The structure of pelagic marine ecosystems. Rapp P-v Réun Cons Int Explor Mer 173:60-65

Railsback SF, Lamberson RH, Harvey BC, Duffy WE (1999) Movement rules for individual-based models of stream fish. Ecol Model 123:73-89

Ross ON, Sharples J (2004) Recipe for 1-D Lagrangian particle tracking models in space varying diffusivity. Limnol Oceanogr Methods 2:289-302

Rothschild BJ, Osborn TR (1988) Small-scale turbulence and plankton contact rates. J Plank Res 10:465-474

Schwinghamer P, Hargrave B, Peer D, Hawkins CM (1986) Partitioning of production and respiration among size groups of organisms in an intertidal benthic community. Mar Ecol Prog Ser. 31:131-142

Sclafani M, Taggert CT, Thompson KR (1993) Condition, buoyancy and the distribution of larval fish: implications for vertical migration and retention. J Plank Res $15: 413-435$

Skartveit A, Olseth JA, Tuft ME (1998) An hourly diffuse fraction model with correction for variability and surface albedo. Sol Energy 63:173-183

Utne-Palm AC (1999) The effect of prey mobility, prey contrast, turbidity, and spectral composition on the reaction distance of Gobiusculus flavescens to its planktonic prey. J Fish Biol 54:1244-1258

Werner FE, Perry RI, Lough RG, Naimie CE (1996) Trophodynamic and advective influences on Georges Bank larval cod and haddock. Deep-Sea Res II 43:1793 1822 
White EP, Morgan Ernest SK, Kerkhoff AJ, Enquist BJ (2007) Relationships between body size and abundance in ecology. Trends Ecol Evol 22:323-330

Yoshida J, Oakey NS (1996) Characterization of vertical mixing at a tidal-front on Georges Bank. Deep-Sea Res II 43:1713-1744 


\section{Tables}

Table 3.1. Coefficients, variables, and equations.

\begin{tabular}{|c|c|c|c|c|}
\hline Symbo & Description & Units & Value & Source \\
\hline$\alpha$ & trade-off weight parameter & & & \\
\hline$A_{p}$ & prey image area & $\mathrm{m}^{2}$ & $A_{p}=0.75 \cdot L \cdot$ width & 1 \\
\hline$\beta$ & trade-off behavior & & & \\
\hline$b$ & predator density exponent & & -1 & $2-6$ \\
\hline$C$ & prey contrast & & 0.3 & 7 \\
\hline$c$ & beam attenuation coefficient & $\mathrm{m}^{-1}$ & $c=3 k$ & 8 \\
\hline$c_{1}$ & diffusivity polynomial const. & & $1.31 \cdot 10^{-11}$ & \\
\hline$c_{2}$ & diffusivity polynomial const. & & $3.12 \cdot 10^{-9}$ & \\
\hline$c_{3}$ & diffusivity polynomial const. & & $2.82 \cdot 10^{-7}$ & \\
\hline$c_{4}$ & diffusivity polynomial const. & & $1.30 \cdot 10^{-5}$ & \\
\hline$c_{5}$ & diffusivity polynomial const. & & $3.56 \cdot 10^{-4}$ & \\
\hline$c_{6}$ & diffusivity polynomial const. & & $5.25 \cdot 10^{-3}$ & \\
\hline$c_{7}$ & diffusivity polynomial const. & & $3.11 \cdot 10^{-2}$ & \\
\hline$d_{1}$ & pca function constant & & $-1.06 \cdot 10^{4}$ & \\
\hline$d_{2}$ & pca function constant & & $3.86 \cdot 10^{3}$ & \\
\hline$d_{3}$ & pca function constant & & $-4.96 \cdot 10^{2}$ & \\
\hline$d_{4}$ & pca function constant & & 20.2 & \\
\hline$\varepsilon$ & turbulent kinetic energy & $\mathrm{W} \mathrm{m} \mathrm{m}^{-3}$ & $\varepsilon=1.65 \cdot 10^{-5} \kappa$ & 9 \\
\hline E & irradiance & $\mu \mathrm{mol} \mathrm{m} \mathrm{m}^{-2} \mathrm{~s}^{-1}$ & $E=E_{0} \exp (-k z)$ & \\
\hline$E_{0}$ & surface irradiance & $\mu \mathrm{mol} \mathrm{m} \mathrm{m}^{-2} \mathrm{~s}^{-1}$ & & \\
\hline$E_{s}$ & predator eye sensitivity & & $5 \cdot 10^{4}$ & \\
\hline Enc & encounter rate & Enc & $\frac{1}{2} \pi R^{2} N_{\text {larvae }} S \sqrt{u^{2}+v^{2}+2 w^{2}}$ & 10 \\
\hline$F$ & fitness & & & \\
\hline$f(z)$ & initial depth pdf & & & \\
\hline$g(y)$ & environment pdf & & & \\
\hline$\kappa$ & vertical diffusivity & $\mathrm{m}^{2} \mathrm{~s}^{-1}$ & & \\
\hline$K_{e}$ & half saturation constant & $\mu \mathrm{mol} \mathrm{m} \mathrm{m}^{-2}$ & 1.0 & 11 \\
\hline$k$ & light attenuation coefficient & $\mathrm{m}^{-1}$ & 0.18 & 12 \\
\hline$L$ & larval standard length & $\mathrm{mm}$ & & \\
\hline$M_{\text {larva }}$ & larval fish weight & $\mu g$ & $M_{\text {larva }}=0.194 L^{3.768}$ & 13 \\
\hline$M_{\text {pred }}$ & predator weight & $\mu g$ & $M_{\text {pred }}=14.7059 M_{\text {prey }}$ & $2,6,14,15$ \\
\hline$N_{\text {larvae }}$ & larval prey abundance & $\mathrm{L}^{-1}$ & 1.0 & \\
\hline$N_{\text {pred }}$ & predator density & $\mathrm{m}^{-3}$ & $N_{\text {pred }}=M_{\text {pred }}^{b}$ & 16 \\
\hline
\end{tabular}




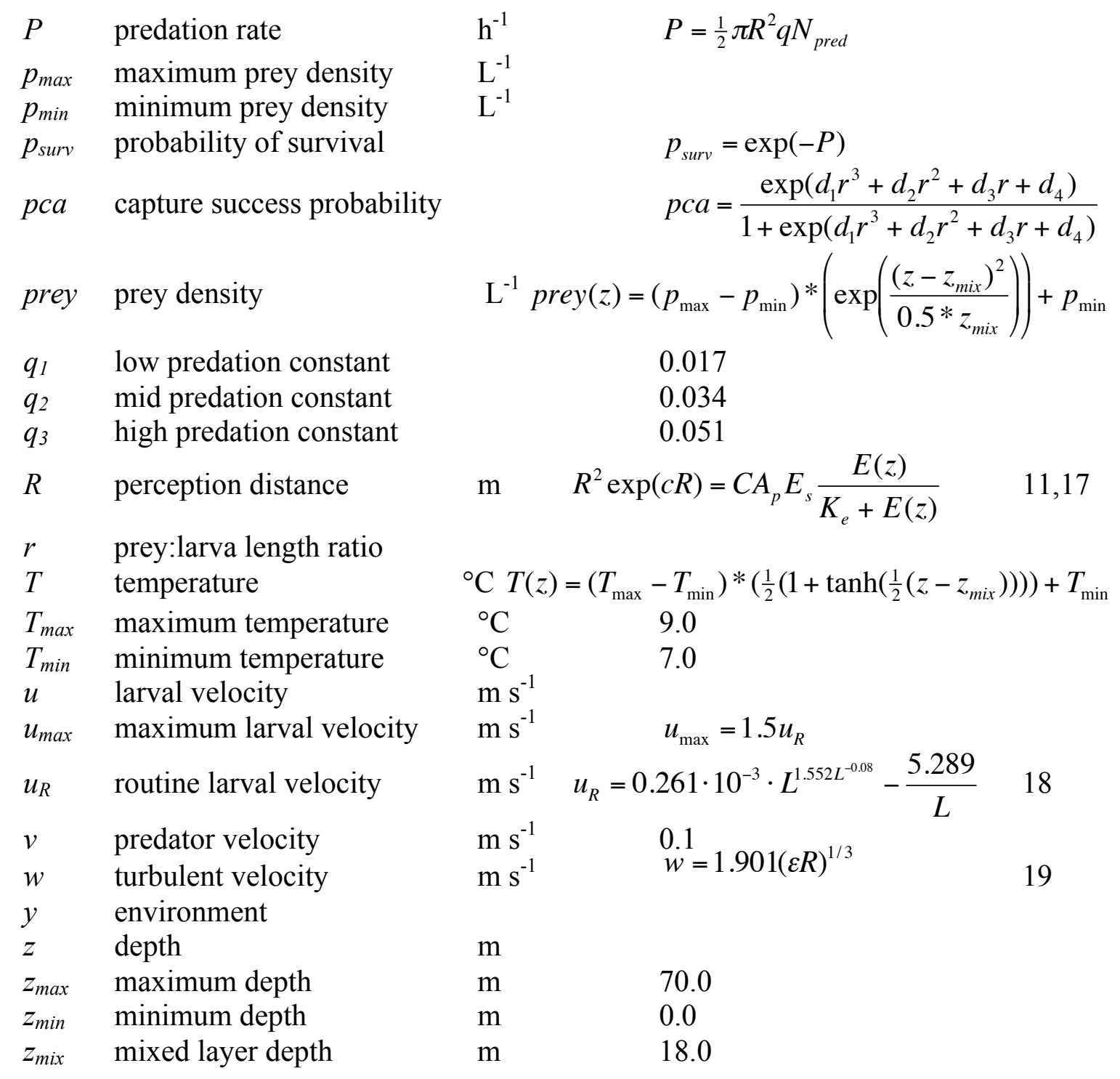

${ }^{1}$ Fiksen \& Folkvord 1999, ${ }^{2}$ Platt \& Denman 1978, ${ }^{3}$ Banse \& Mosher 1980, ${ }^{4}$ Schwinghamer et al. 1986, ${ }^{5}$ Dickie et al. 1987, ${ }^{6}$ Jennings \& Mackinson $2003,{ }^{7}$ UtnePalm 1999, ${ }^{8}$ Fiksen et al. 2002, ${ }^{9}$ Davis et al. 1991, ${ }^{10}$ MacKenzie \& Kiørboe 1995 , ${ }^{11}$ Aksnes \& Utne 1997, ${ }^{12}$ Lough et al. 2005, ${ }^{13}$ Lankin et al. $2008,{ }^{14}$ Peters $1986,{ }^{15}$ Kerr \& Dickie 2001, ${ }^{16}$ White et al. 2007, ${ }^{17}$ Aksnes \& Giske 1993, ${ }^{18}$ Peck et al. 2006, ${ }^{19}$ Rothschild \& Osborn 1988. 
Table 3.2. Minimum and maximum prey concentrations $\left(\mathrm{L}^{-1}\right)$ for low, mean, or high prey levels. $\mathrm{N}=$ NIII for $<7 \mathrm{~mm}$ larvae, $\mathrm{C}=\mathrm{CV}$ for $\geq 7 \mathrm{~mm}$ larvae.

$\begin{array}{lccc} & \text { low } & \text { mean } & \text { high } \\ \mathrm{N}_{\min } & 0.2 & 0.2 & 0.2 \\ \mathrm{~N}_{\max } & 7.6 & 18.0 & 38.4 \\ \mathrm{C}_{\min } & 0.1 & 0.1 & 0.1 \\ \mathrm{C}_{\max } & 3.1 & 7.5 & 16.4\end{array}$

Table 3.3. Case A statistics for all simulations with varying initial seed values in the fixed and uncertain environments with high and low turbulence.

$\begin{array}{lcccc} & \text { mean } & \max & \min & \text { std dev } \\ \text { high fixed } & 0.4284 & 0.457 & 0.4060 & 0.0161 \\ \text { high uncertain } & 0.4675 & 0.494 & 0.4545 & 0.0118 \\ \text { low fixed } & 0.2642 & 0.291 & 0.2460 & 0.0150 \\ \text { low uncertain } & 0.2970 & 0.326 & 0.2843 & 0.0136\end{array}$

Table 3.4. Case B statistics for all simulations with varying initial seed values and all $\alpha$ values in the fixed and uncertain environments with high and low turbulence.

$\begin{array}{lcccc} & \text { mean } & \max & \min & \text { std dev } \\ \text { high fixed } & 0.4334 & 0.4341 & 0.4324 & 6.72 \mathrm{E}-04 \\ \text { high uncertain } & 0.4726 & 0.4736 & 0.4719 & 5.13 \mathrm{E}-04 \\ \text { low fixed } & 0.2841 & 0.2869 & 0.2825 & 0.0014 \\ \text { low uncertain } & 0.3115 & 0.3123 & 0.3106 & 4.73 \mathrm{E}-04\end{array}$


Table 3.5. Case $\mathrm{C}$ statistics for all simulations with varying initial seed values and all $\alpha$ values in the fixed and uncertain environments with high and low turbulence.

$\begin{array}{lcccc} & \text { mean } & \max & \min & \text { std dev } \\ \text { high fixed } & 0.3052 & 0.5342 & 0.2688 & 0.0788 \\ \text { high uncertain } & 0.3599 & 0.563 & 0.3279 & 0.0698 \\ \text { low fixed } & 0.2686 & 0.2737 & 0.2543 & 0.0050 \\ \text { low uncertain } & 0.3207 & 0.3272 & 0.2755 & 0.0150\end{array}$

Table 3.6. Mean time (d) to $12 \mathrm{~mm}$ in the fixed environment with high and low turbulence.

$\begin{array}{llll} & \text { Case A } & \text { Case B } & \text { Case C } \\ \text { High turbulence } & 42.29 & 41.58 & 45.75 \\ \text { Low turbulence } & 45.38 & 45.63 & 34.13\end{array}$




\section{Figures}

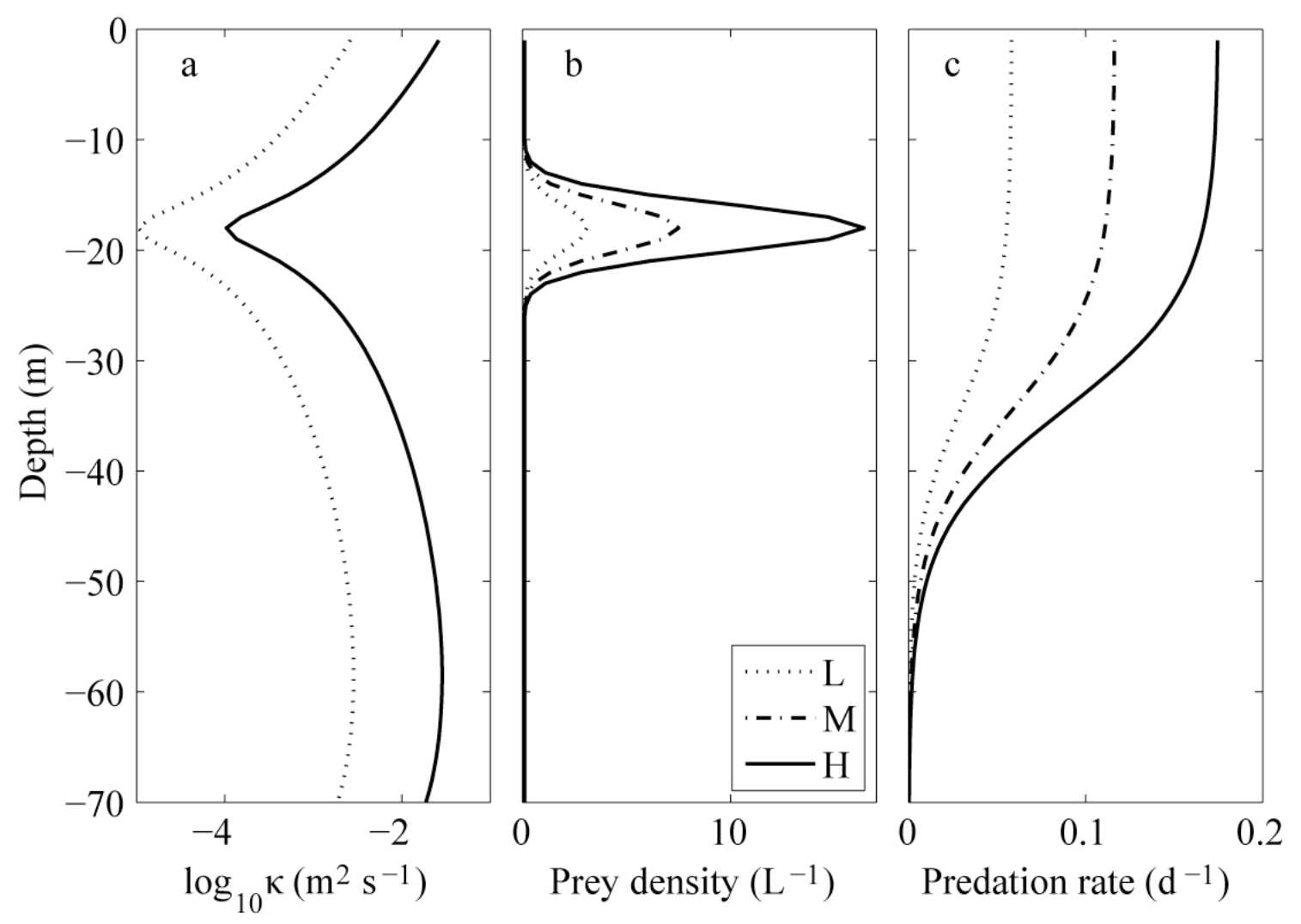

Figure 3.1. Example depth profiles of (a) $\log _{10}$ of the turbulent dissipation rate, $\kappa$ $\left(\mathrm{m}^{2} \mathrm{~s}^{-1}\right),\left(\right.$ b) prey density $\left(\mathrm{L}^{-1}\right)$, and (c) predation rate $\left(\mathrm{d}^{-1}\right)$ for a $7 \mathrm{~mm}$ larva. L: low, $\mathrm{M}$ : mean or mid, H: high. 


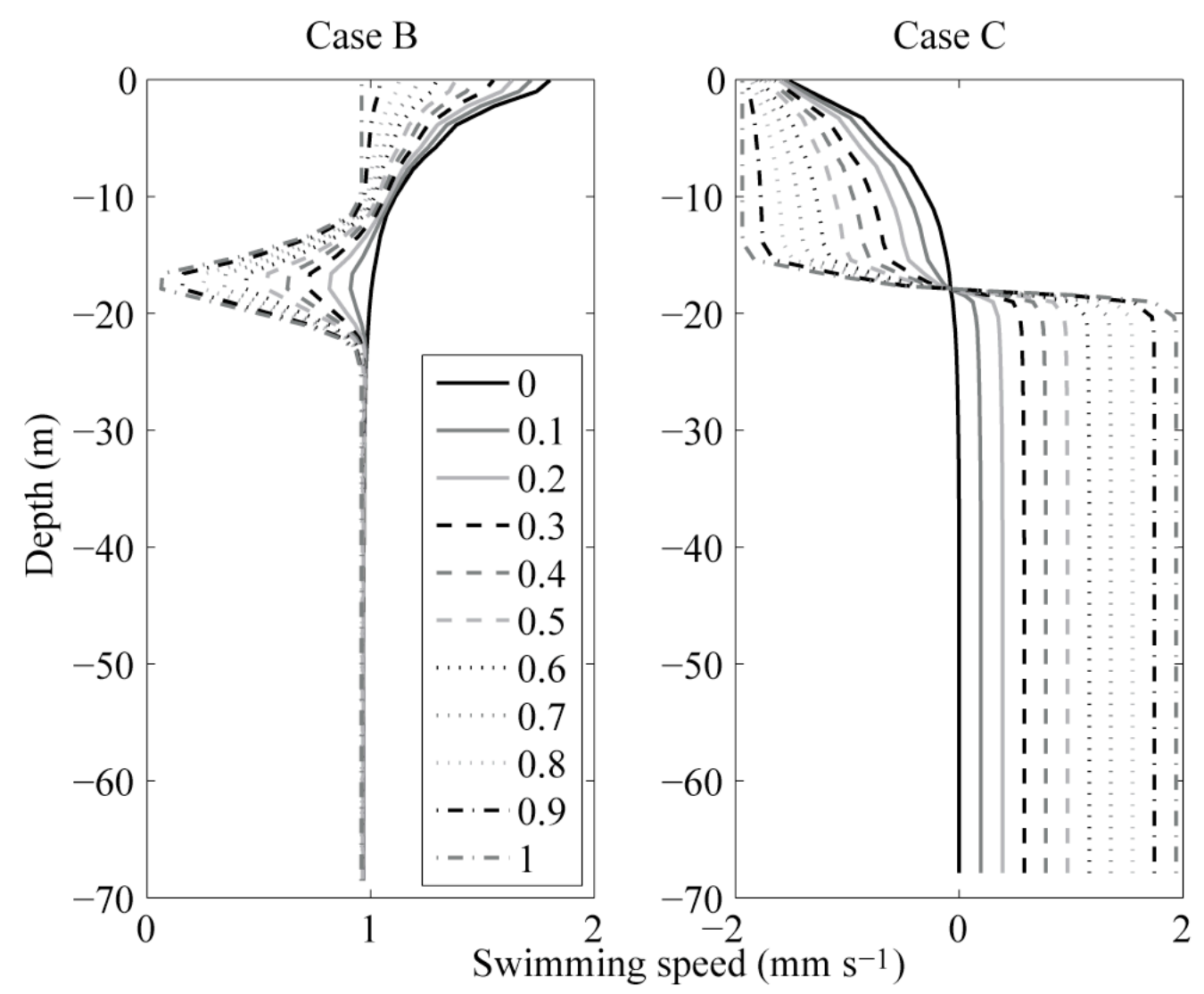

Figure 3.2. Profiles of the magnitude of the swimming speed as determined by Cases B and $\mathrm{C}$ for a $5 \mathrm{~mm}$ larva with different values of $\alpha$ indicated in the legend. For Case $\mathrm{B}$ direction of swimming is random. For Case $\mathrm{C}$ downward swimming is indicated by negative swimming speed values. 


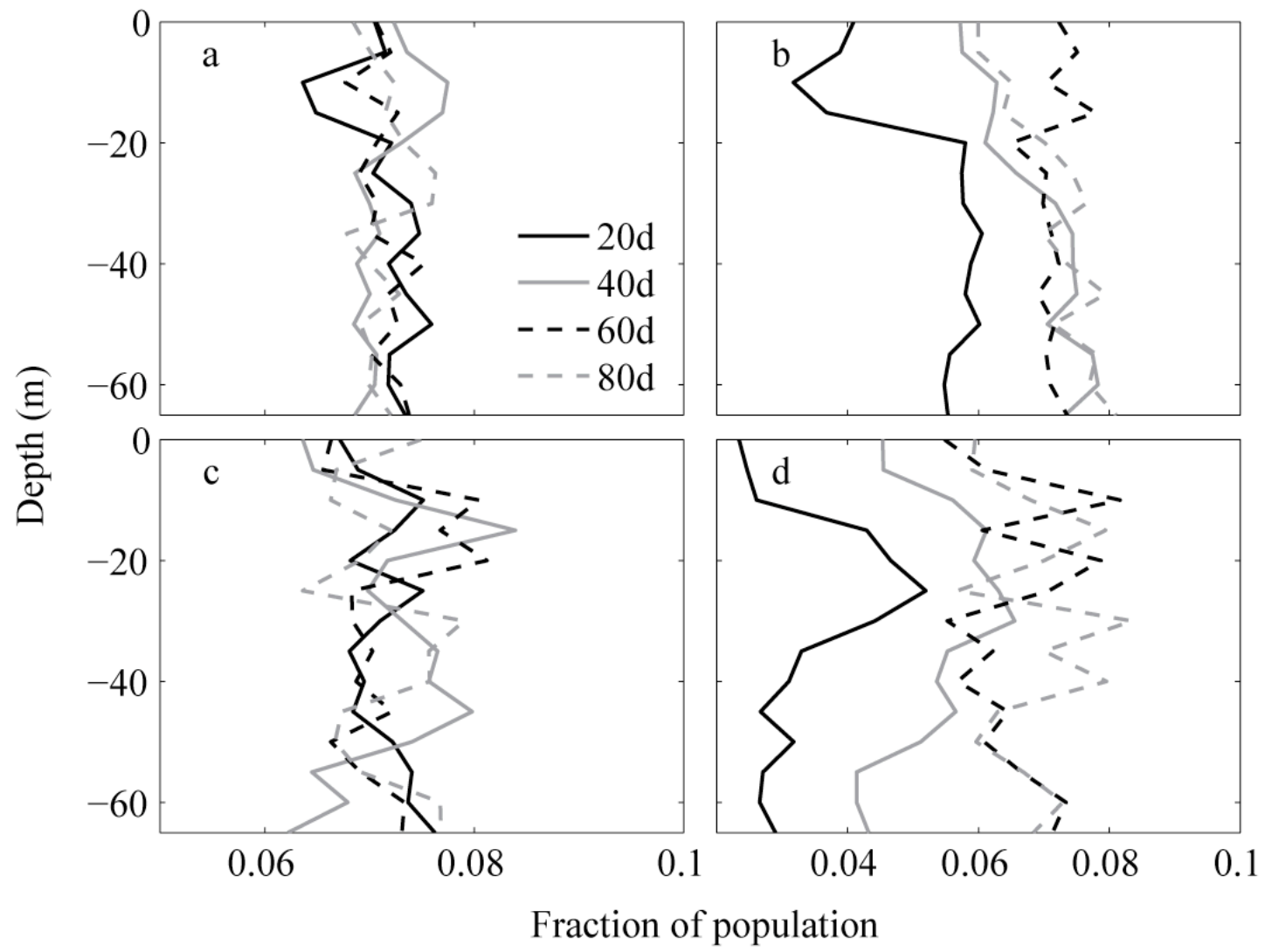

Figure 3.3. Proportion of larval population in $5 \mathrm{~m}$ bins every $20 \mathrm{~d}$ of (a) all individuals and (b) only those that survived to $12 \mathrm{~mm}$ using behavioral Case A under high turbulence, and of (c) all individuals and (d) only those that survived to $12 \mathrm{~mm}$ using behavioral Case A under low turbulence. The proportion is relative to the subpopulation, i.e. the total population for all individuals, and total number of live individuals for those that survived to $12 \mathrm{~mm}$. 


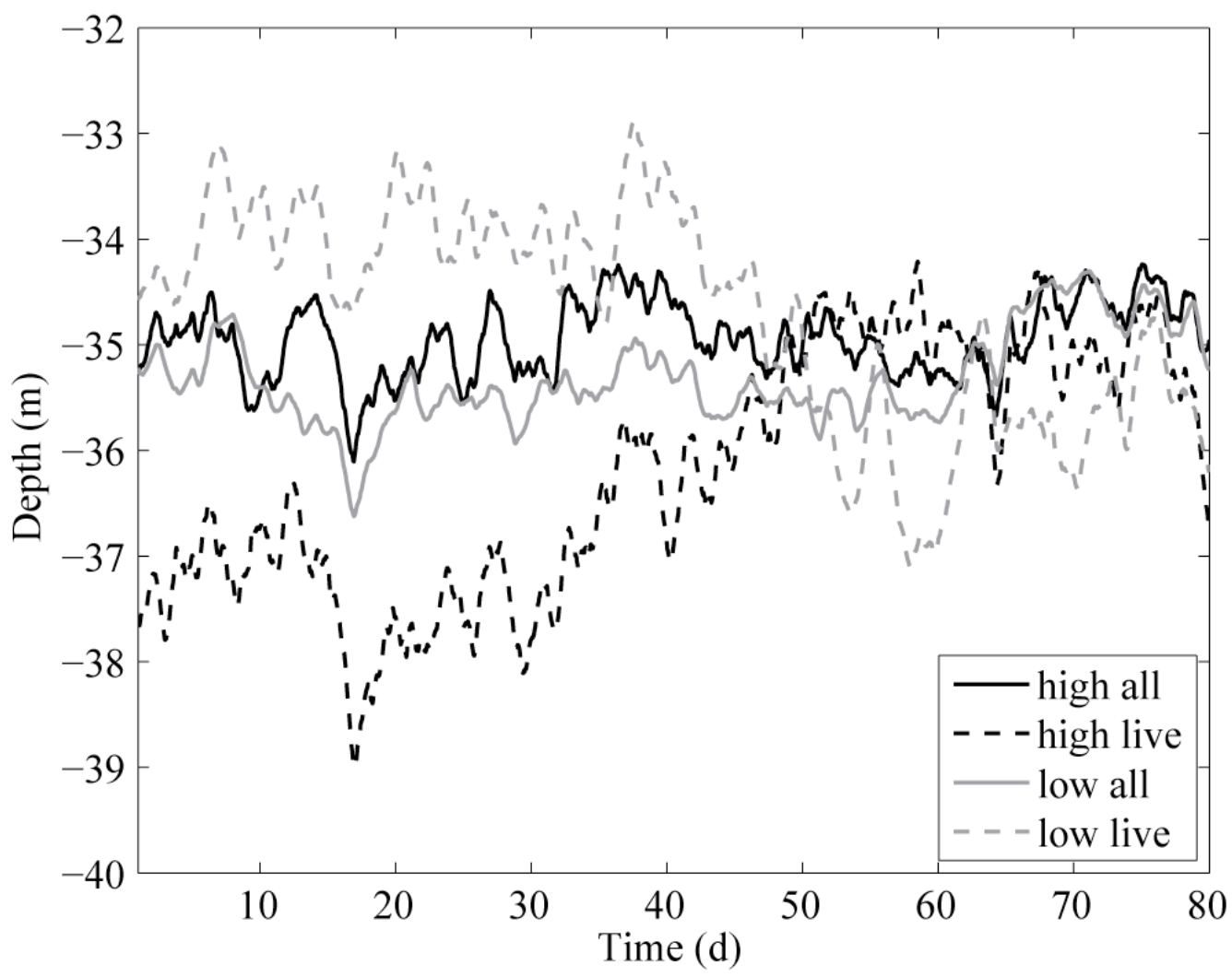

Figure 3.4. Mean depth of larvae using Behavior A in the fixed environment. all: all larvae, live: larvae that survive to $12 \mathrm{~mm}$, high: high turbulence, low: low turbulence. 

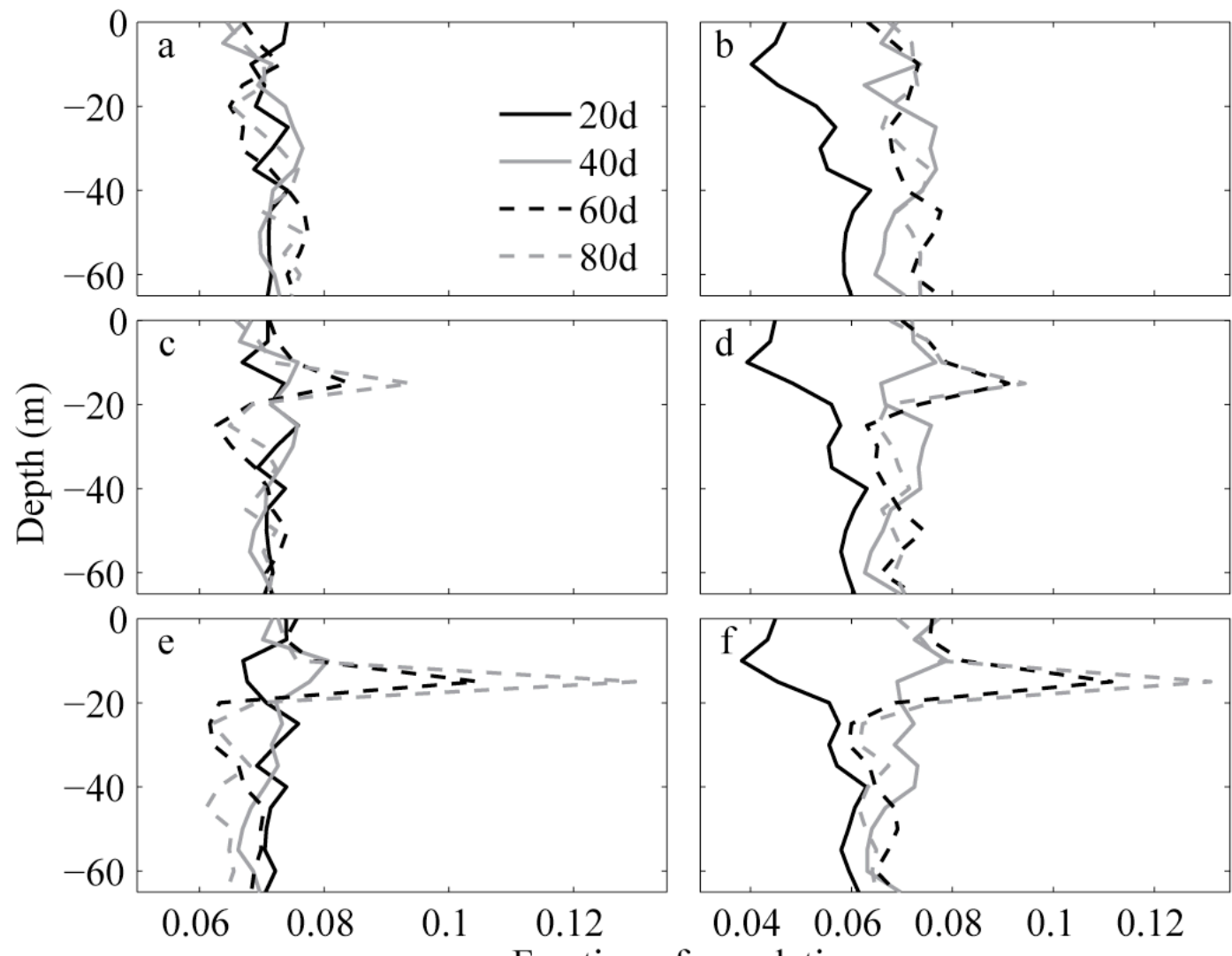

Fraction of population

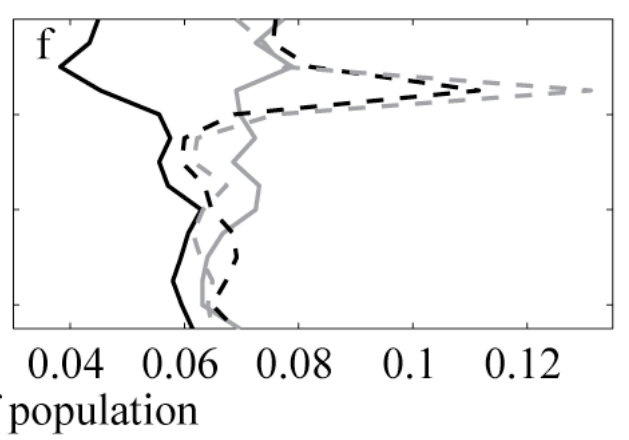

Figure 3.5. Proportion of larval population in $5 \mathrm{~m}$ bins every $20 \mathrm{~d}$ using Behavior B with $\alpha=0$ for (a) all larvae and (b) larvae that survive to $12 \mathrm{~mm}$, with $\alpha^{*}=0.4$ for (c) all larvae and (d) larvae that survive to $12 \mathrm{~mm}$, with $\alpha=1$ for (e) all larvae and (f) larvae that survive to $12 \mathrm{~mm}$ in the fixed environment with high turbulence. The proportion is relative to the subpopulation, i.e. the total population for all individuals, and total number of live individuals for those that survived to $12 \mathrm{~mm}$. 


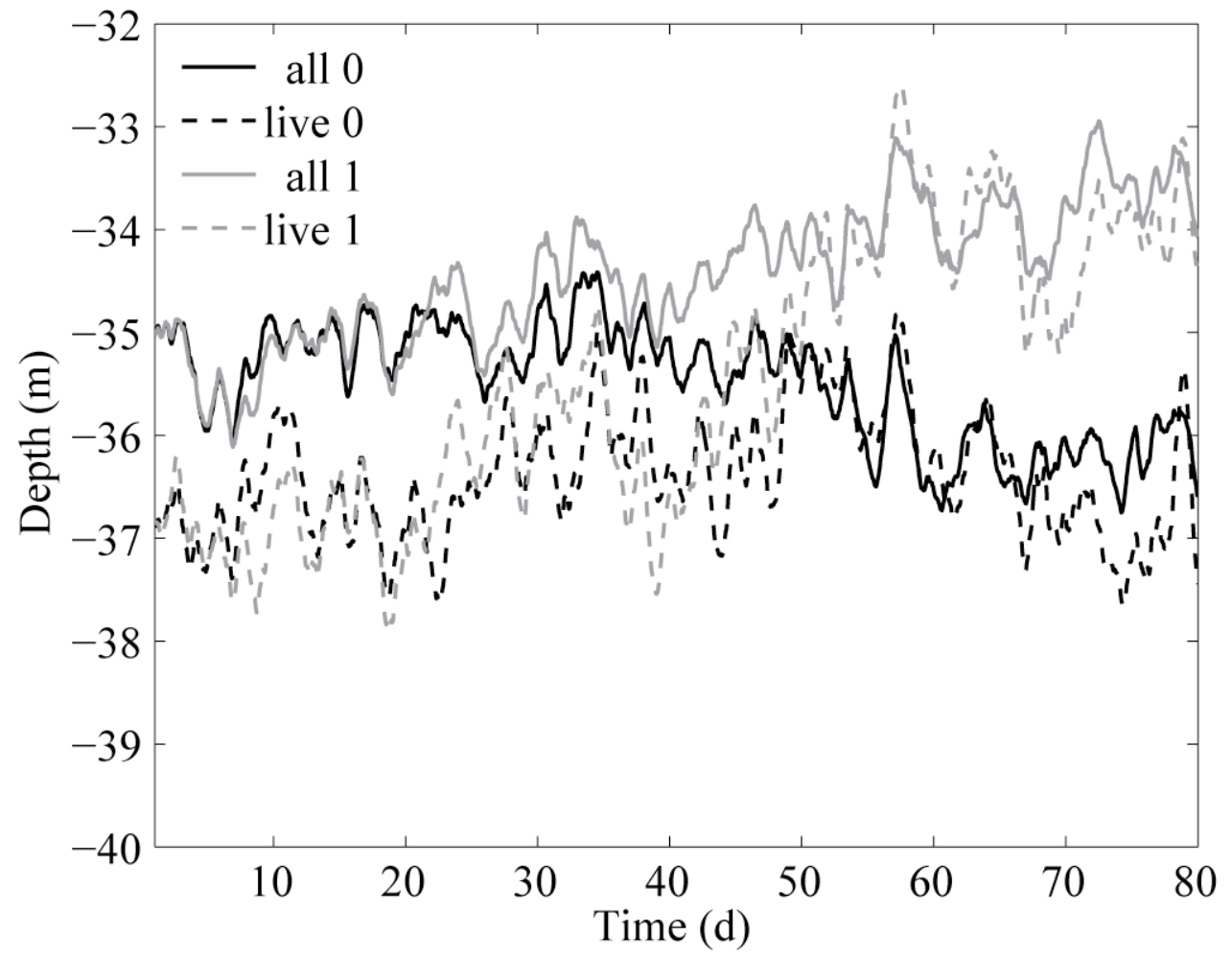

Figure 3.6. Mean depth of larvae using Behavior $B$ in the fixed environment with high turbulence. all: all larvae, live: larvae that survive to $12 \mathrm{~mm}, 0: \alpha=0,1: \alpha=1$. 


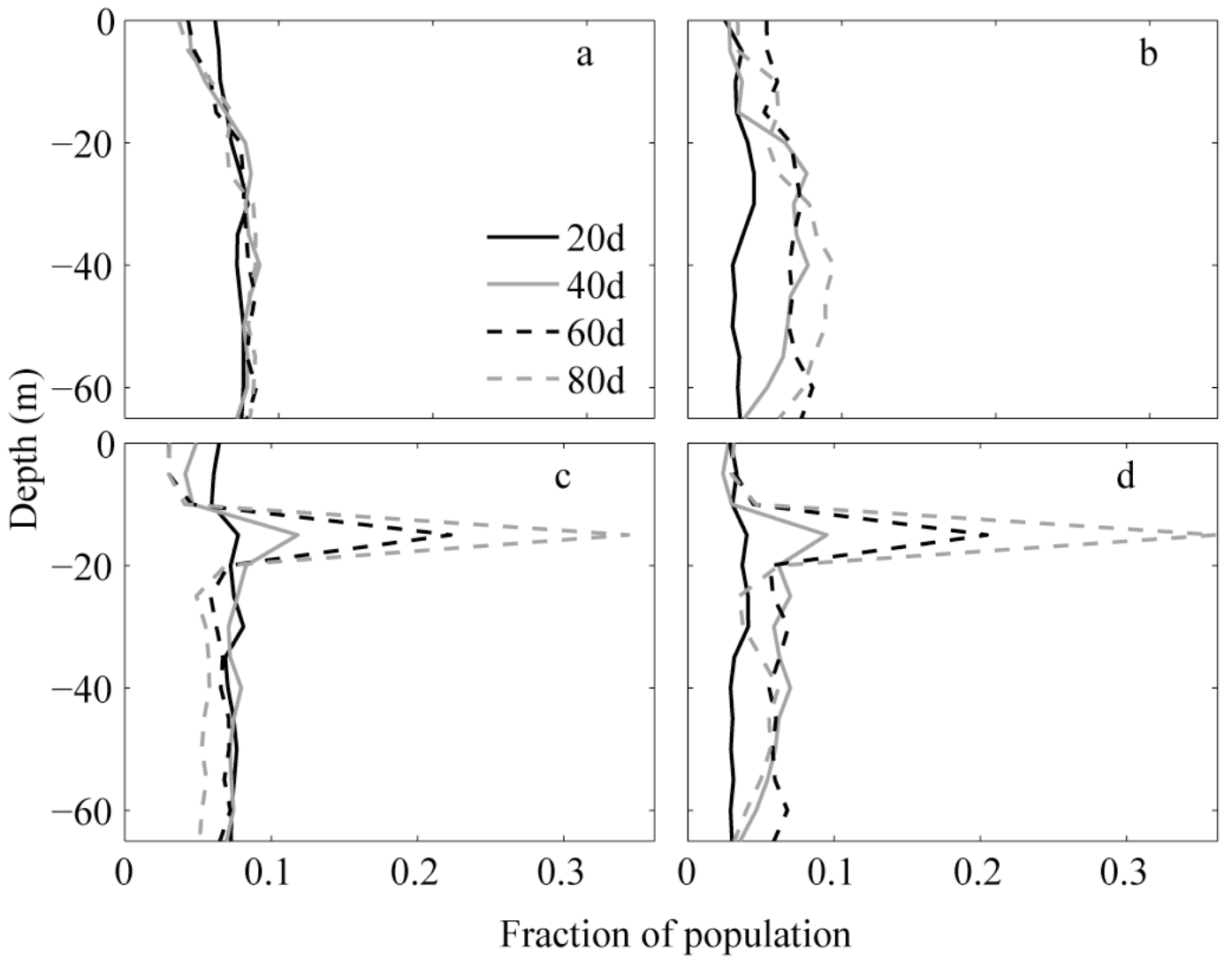

Figure 3.7. Proportion of larval population in $5 \mathrm{~m}$ bins every $20 \mathrm{~d}$ of (a) all larvae and (b) larvae that survive to $12 \mathrm{~mm}$ using Behavior B and $\alpha^{*}=0$, and (c) all larvae and (d) larvae that survive to $12 \mathrm{~mm}$ with $\alpha=1$ in the fixed environment with low turbulence. The proportion is relative to the subpopulation, i.e. the total population for all individuals, and total number of live individuals for those that survived to $12 \mathrm{~mm}$. 


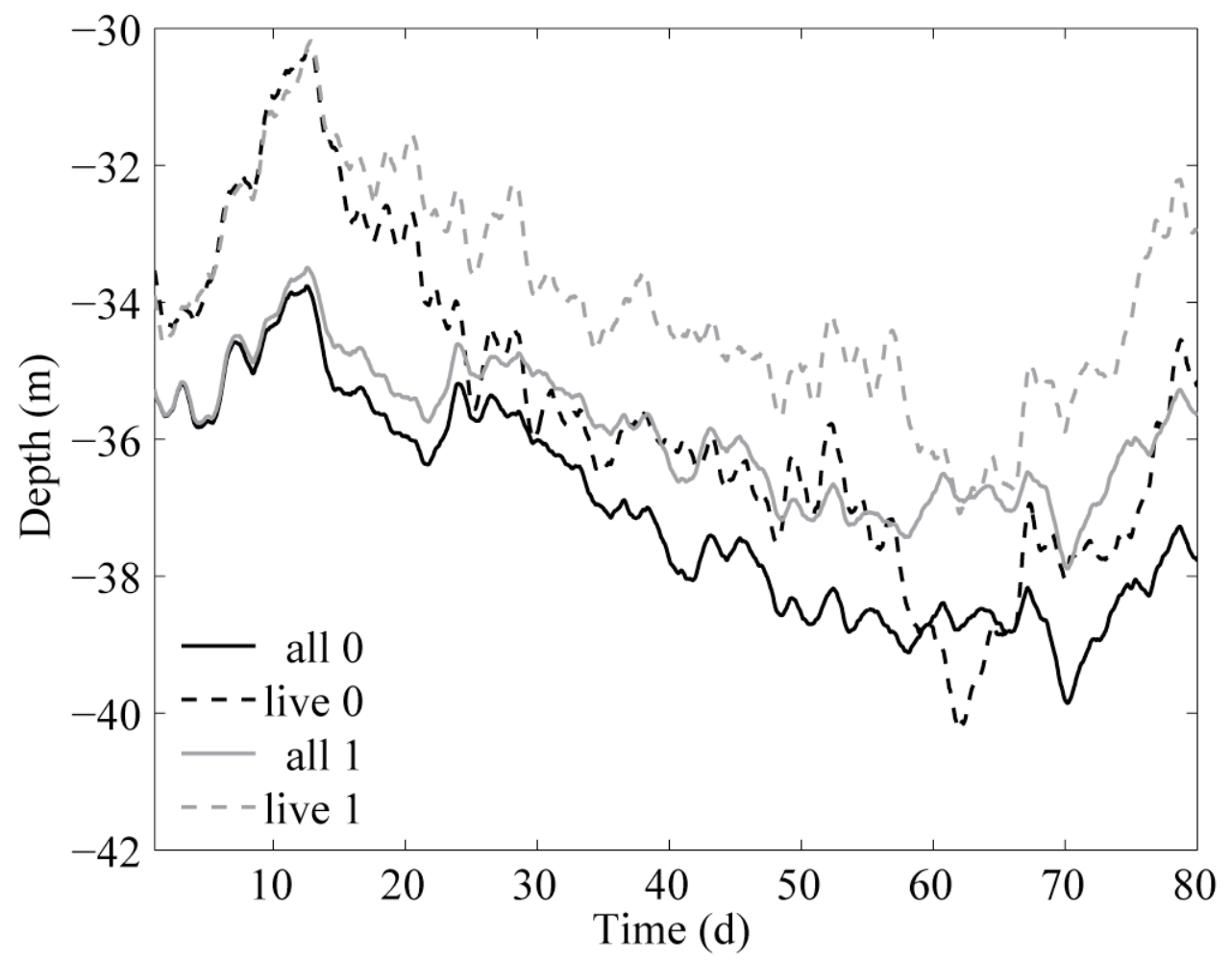

Figure 3.8. Mean depth of larvae using Behavior B in the fixed environment with low turbulence. all: all larvae, alive: larvae that survive to $12 \mathrm{~mm}, 0: \alpha=0,1: \alpha=1$. 

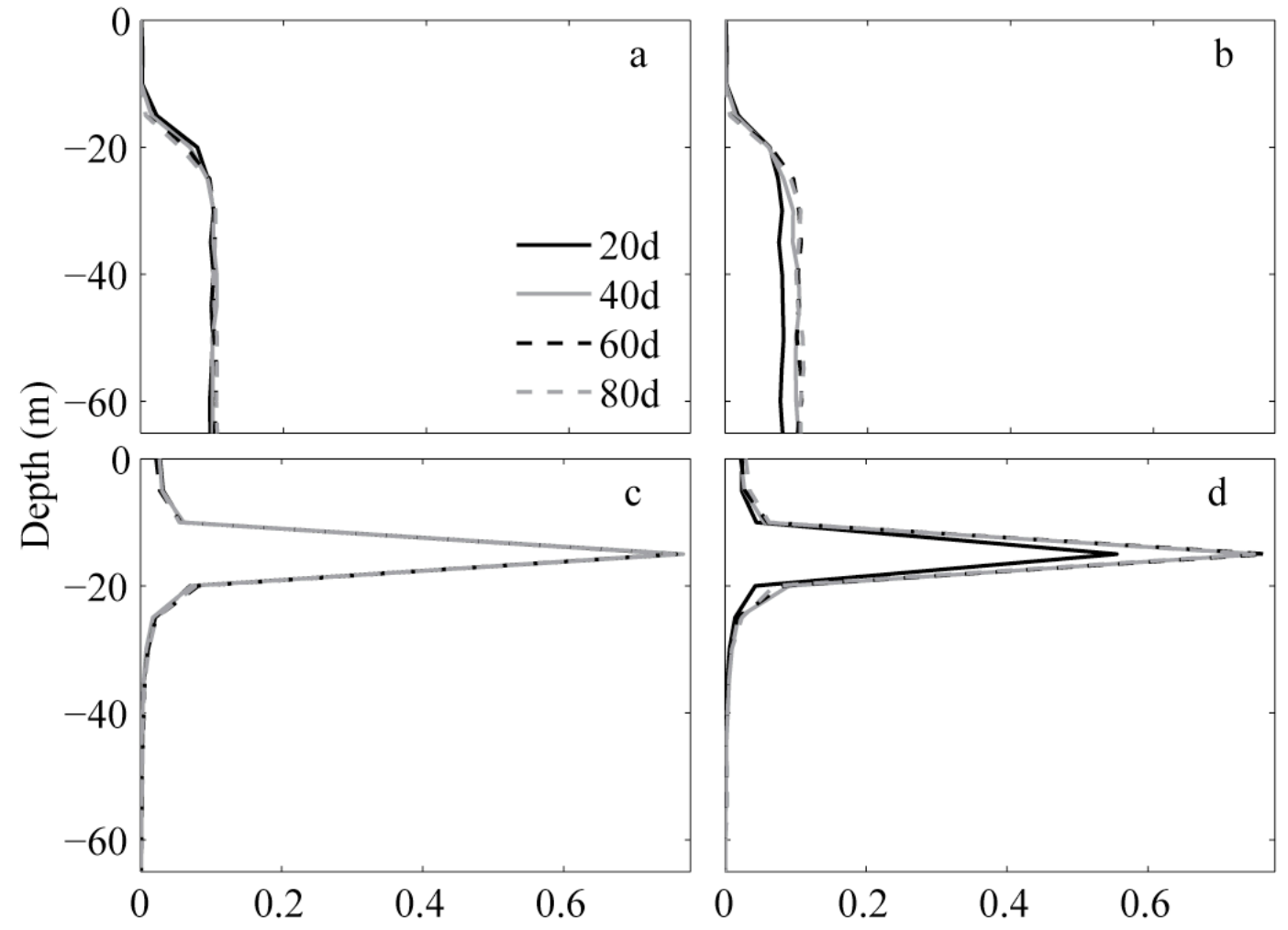

Fraction of population

Figure 3.9. Proportion of larval population in $5 \mathrm{~m}$ bins every $20 \mathrm{~d}$ of (a) all larvae and (b) larvae that survive to $12 \mathrm{~mm}$ using Behavior $\mathrm{C}$ and $\alpha^{*}=0$, and (c) all larvae and (d) larvae that survive to $12 \mathrm{~mm}$ with $\alpha=1$ in the fixed environment with high turbulence. The proportion is relative to the subpopulation, i.e. the total population for all individuals, and total number of live individuals for those that survived to $12 \mathrm{~mm}$. 

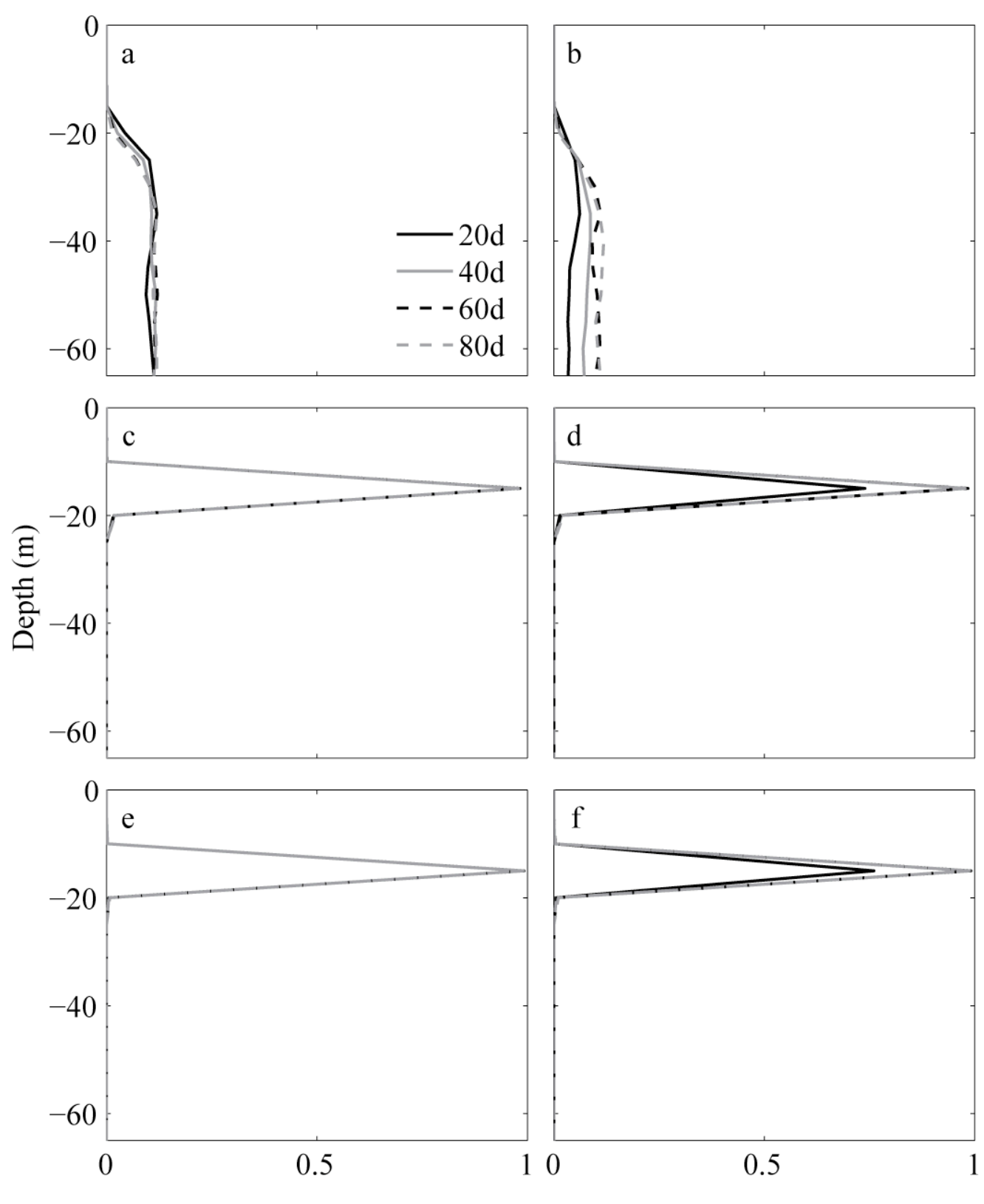

Fraction of population

Figure 3.10. Proportion of larval population in $5 \mathrm{~m}$ bins every $20 \mathrm{~d}$ of (a) all larvae and (b) larvae that survive to $12 \mathrm{~mm}$ using Behavior $\mathrm{C}$ and $\alpha=0$, of (c) all larvae and (d) larvae that survive to $12 \mathrm{~mm}$ using Behavior $\mathrm{C}$ and $\alpha^{*}=0.1$, and of (e) all larvae and (f) larvae that survive to $12 \mathrm{~mm}$ with $\alpha=1$ in the fixed environment with low turbulence. The proportion is relative to the subpopulation, i.e. the total population for all individuals, and total number of live individuals for those that survived to $12 \mathrm{~mm}$. 


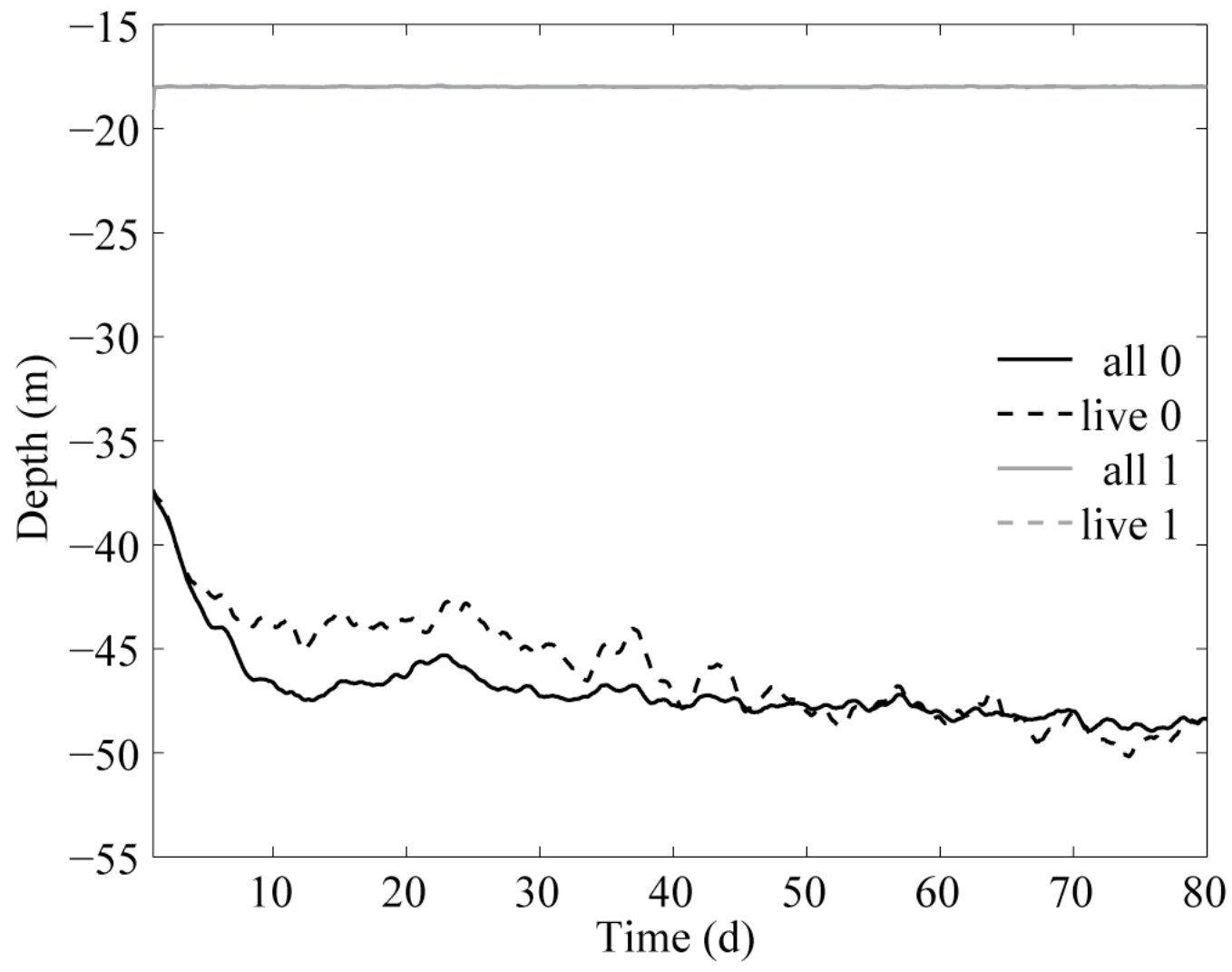

Figure 3.11. Mean depth of larvae using Behavior $\mathrm{C}$ in the fixed environment with low turbulence. all: all larvae, alive: larvae that survive to $12 \mathrm{~mm}, 0: \alpha=0,1: \alpha=1$. 


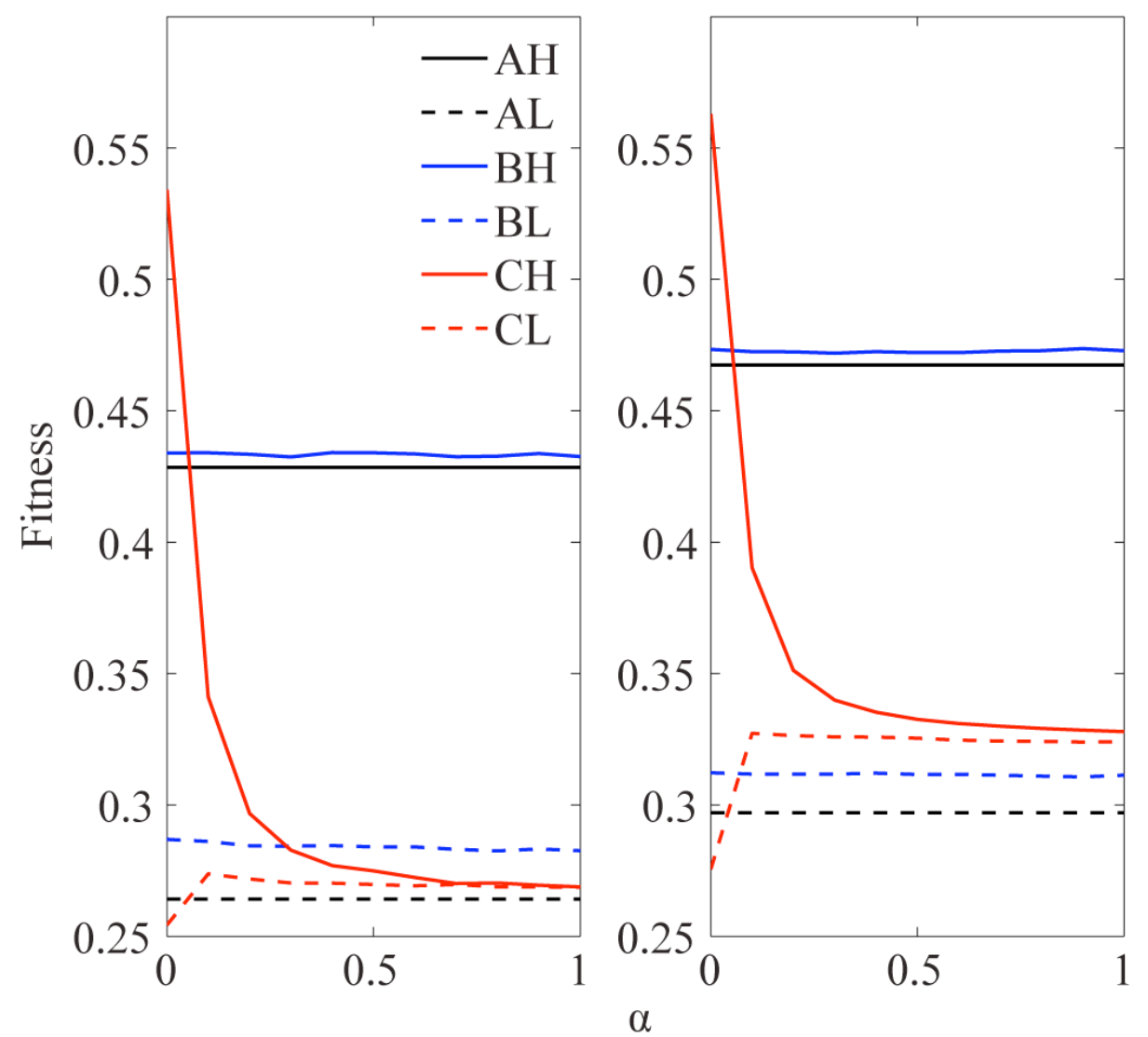

Figure 3.12. Mean fitness of 10 simulations vs. $\alpha$ in the (left) fixed and (right) uncertain environments. AH - Case A, high turbulence, AL - Case A, low turbulence, $\mathrm{BH}-\mathrm{Case}$ $\mathrm{B}$, high turbulence, $\mathrm{BL}$ - Case $\mathrm{B}$, low turbulence, $\mathrm{CH}$ - Case $\mathrm{C}$, high turbulence, $\mathrm{CL}-$ Case $\mathrm{C}$, low turbulence. 


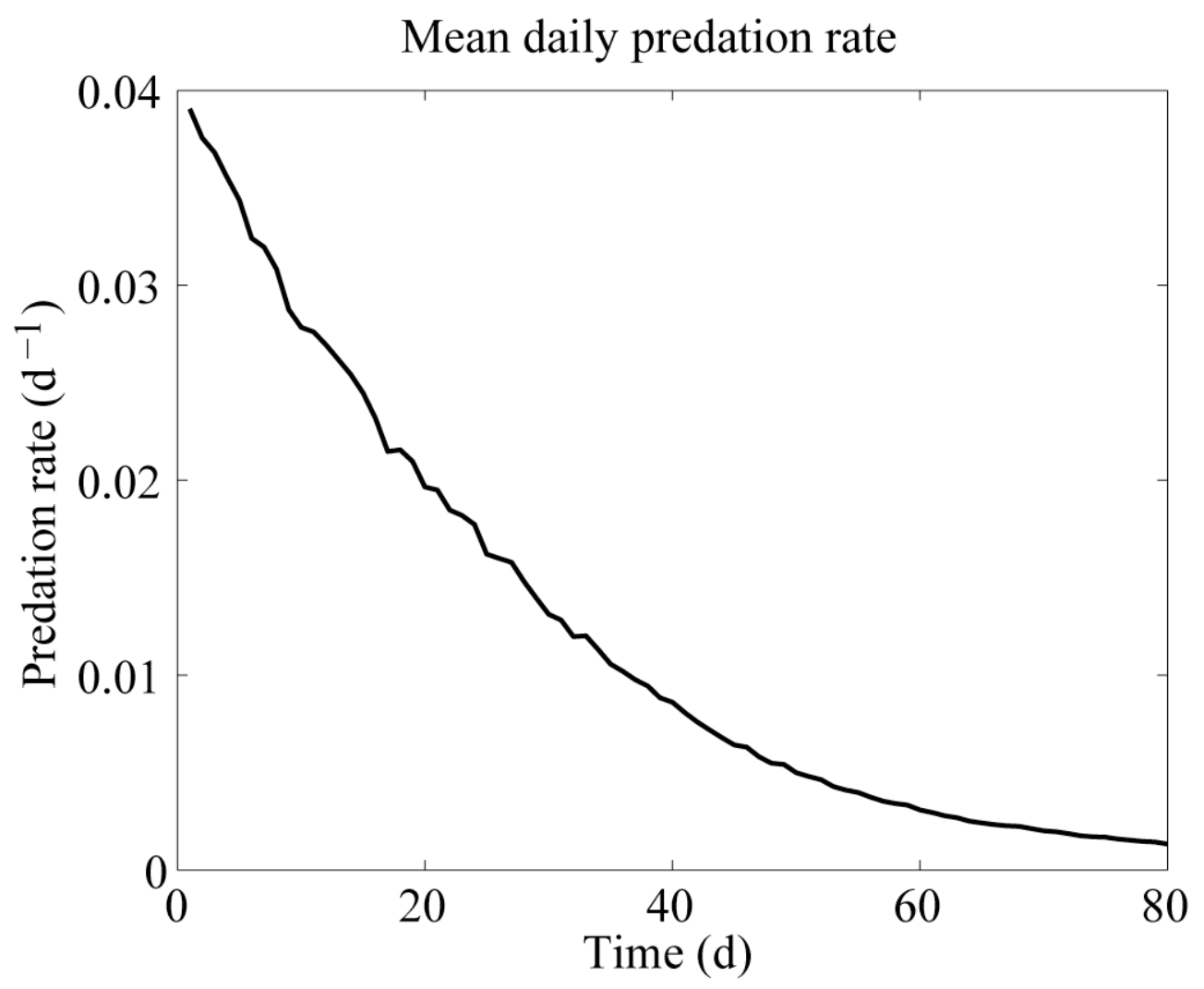

Figure 3.13. Mean predation rate $\left(\mathrm{d}^{-1}\right)$ from passive diffusion with high turbulence. 


\section{Chapter 4}

\section{Interannual differences in larval haddock}

\section{survival: hypothesis testing with a coupled}

\section{biophysical model of Georges Bank}

\subsection{Introduction}

The annual variation in year-class size of a fish population can have a large influence on the biomass of the population that can be fished (Trippel \& Chambers 1997). Despite its importance, the causes of recruitment variability are not clear, and understanding recruitment variability has long been a goal to aid in the management of fisheries. Since Hjort's (1914) hypothesis that the size of a year-class is determined during the early life stage of fish, much emphasis has been placed on the survival from the egg to the early juvenile stage. The haddock population on Georges Bank (Figure 4.1) is one with a strong relationship between recruitment and processes during the larval stage (Mountain et al. 2008).

Larval haddock have greater survival when mismatched (phase-shifted) to the copepod populations (Buckley \& Durbin 2006). By hatching before the spring bloom, 
haddock are maximizing size at time of year rather than size at age (Lapolla \& Buckley 2005, Buckley \& Durbin 2006, Buckley et al. 2010). Hatching early results in slower growth from lower temperatures, less food, and less light available for visual feeding compared to later in the year, but less predation as well (Lapolla \& Buckley 2005, Buckley \& Durbin 2006, Buckley et al. 2010). These findings appear to contradict the larval fish paradigms about size and survival, specifically that individuals with higher growth rates will spend less time as vulnerable larvae, particularly small larvae, with high mortality rates. Nonetheless, higher prey availability earlier in the year could further enhance the survival of early-spawned larvae. In addition to seasonal prey availability and predation risk, advection could be important in regulating the recruitment of haddock. Advective loss of larvae or their planktonic copepod prey could occur early in the spawning period before the gyre has strengthened with seasonal stratification (Butman \& Beardsley 1987), as well as from Gulf Stream rings (Butman et al. 1982, Flierl \& Wroblewski 1985), and strong wind events (Lewis et al. 1994, 2001).

Spatially-explicit coupled biological-physical individual-based models (IBMs) are ideal for studying the processes of feeding, growth, predation, and advection during the larval stage. Such models act as laboratories where simulation experiments can be conducted to disentangle these factors, determine their relative importance, and reveal how they are affected by environmental variability. I seek to gain insights into the recruitment variability of Georges Bank haddock by using a spatially-explicit coupled biological-physical IBM to examine two disparate years sampled during the U.S. GLOBEC Northwest Atlantic/Georges Bank (GLOBEC GB) program from 1995-1999 
(Wiebe et al. 2002). The 1998 haddock year-class was the largest of the study period and the largest since 1978 (but has since been dwarfed by the 2003 year-class; Brodziak \& Traver 2006). It had a broad spawning period, low egg production, and the highest egg and larval survival rates of all the study years (Buckley \& Durbin 2006, Mountain et al. 2008). On the other hand, 1995 was a year of low recruitment with low prey biomasses (Buckley \& Durbin 2006) resulting in food-limited growth and the condition of some first feeding haddock larvae indicative of starvation (Buckley et al. 2006). In addition to recruitment, both recruitment per hatched egg (Mountain \& Kane 2010) and larval abundance at 15 days post hatch (Mountain et al. 2008) were higher in 1998 than 1995. I coupled a hydrodynamics model, a nutrient-phytoplankton-zooplankton-detritus (NPZD) model, a stage-based copepod population model, and a larval haddock IBM to simulate the processes on Georges Bank during the larval period of haddock. The model was used to compare survival over the larval period and the sources of mortality in 1995 and 1998. As stated above, there are generally three hypothesized sources of larval mortality: advection, predation, and starvation. I test these hypotheses to see if any account for the observed differences between 1995 and 1998. Specifically, I test the role of hatch location and abundance, the physical environment, prey density, vertical swimming behavior, seasonal predation, spatial predation, and interannual predation. 


\subsection{Model}

\subsubsection{Physical environment}

The hydrodynamics were provided by the Finite Volume Coastal Ocean Model (FVCOM). FVCOM is a prognostic, unstructured-grid, finite-volume, free-surface, threedimensional, primitive equation coastal ocean circulation model (Chen et al. 2003). FVCOM receives input from an atmospheric mesoscale model (MM5), is driven by realistic surface and boundary forcing, and assimilates satellite and buoy data. There is a Lagrangian particle-tracking routine for FVCOM, which can be used to couple individual-based biological models (Chen et al. 2006).

\subsubsection{Prey}

Many IBMs use size-based feeding models, however it was recently shown that larval fish prey selection is not purely size-based (Petrik et al. 2009). Copepod prey of similar size are ingested in amounts disproportionate to their abundance in the environment (Kane 1984, Heath \& Lough 2007). In addition to its size, the behavioral properties of the copepod Pseudocalanus spp. make it the most preferred prey item of larval haddock (Petrik et al. 2009). It is the majority of the prey biomass consumed (Kane 1984, Lough et al. 2005, Heath \& Lough 2007) and its biomass is highly correlated to larval haddock growth rate (Buckley \& Durbin 2006). As a simplification, Pseudocalanus spp. was used as the sole prey source to larval haddock. The Pseudocalanus spp. density was modeled with a 4-stage (eggs-nauplii-copepodite-adult) 
concentration-based population model (Hu et al. 2008; Ji et al. 2009), excluding the eggs as a prey source. The FVCOM hydrodynamics model was coupled to a NPZD model, with the flow fields, temperature and phytoplankton serving as inputs to the copepod population model (Ji et al. 2009).

\subsubsection{Foraging submodel}

The foraging submodel was based on the larval fish feeding models of Caparroy et al. (2000), Fiksen and MacKenzie (2002) and Kristiansen et al. (2007), and was parameterized for larval haddock and Pseudocalanus spp. by Petrik et al. (2009). Ingestion was the product of encounter rate and the probability of successful capture. Encounter rate was a function of prey density, prey swimming speed, turbulent velocity, the larval fish pause-travel swimming characteristics (pause duration and frequency), and the larval perception distance (dependent on light and larval size). The probability of successful capture was an empirical function of prey species and stage length parameterized from mechanistic simulations of species-specific prey escape behaviors, including the deformation rate threshold, escape jump speed, and escape jump angle (Chapter 3). The species-specific prey characteristics were also size-specific, however size was not a state variable in the copepod population model. As a first approach, I set the length, width, and biomass of a grouped developmental stage (e.g. nauplii) as the mean of all stages within that group (e.g. mean of NI-NVI) using the length, width, and biomass in Davis $(1984,1987)$. 


\subsubsection{Bioenergetics submodel}

The bioenergetics submodel was the same as that used in Petrik et al. (2009) for larval haddock, which was based on Kristiansen et al. (2007) for larval cod. The energy derived from the amount of biomass ingested in the foraging submodel was apportioned to metabolism and growth, both of which were temperature- and larval size-dependent. Metabolism was increased a constant amount during light hours to account for the swimming activity of feeding fish.

\subsubsection{Predation submodel}

Both visual and nonvisual predators were modeled. The same visual predation model from Chapter 3 was used with a different proportionality constant $(\mathrm{c}=0.05)$. The nonvisual predation rate, $\operatorname{pred}_{n v}\left(\mathrm{~d}^{-1}\right)$, representative of contact invertebrate predators, was found using a size-dependent model adapted from Peterson and Wroblewski (1984)

$$
\text { pred }_{n v}=2.63 \cdot 10^{-4} \cdot \text { weight }^{-0.25}
$$

with weight in g. Predation rate decreased with larval size for both types of predators, while the visual predation rate also decreased with depth. The total predation rate was the sum of visual and nonvisual predation and was parameterized to be approximately 0.1 $\mathrm{d}^{-1}$ for a $5 \mathrm{~mm}$ larva (Bailey \& Houde 1989).

\subsubsection{Mortality}

To simulate realistic numbers of individuals and prevent significant variation from being lost from the population, super-individuals (Scheffer et al. 1995) were used to 
represent larvae. The number of individuals, $n$, within each super-individual was determined from estimated egg hatching rates calculated for the years 1995 and 1998 on Georges Bank (Mountain et al. 2003, 2008). Egg hatching rates were available for each month and each grid box within the grid covering the sampling area (Mountain et al. 2003, 2008). Egg hatching rates in units of no. $10 \mathrm{~m}^{-2} \mathrm{~d}^{-1}$ were converted to total number of individuals by multiplying the rate by the area covered by that grid box and the total number of days in that month.

Mortality of larvae resulted from starvation, predation, or advection. A larva was considered to have starved to death if its mass fell below $70 \%$ of the mass that it would have at that length under unlimited food conditions (Kristiansen at al. 2009). Since all individuals within a super-individual were identical biologically, starvation of a superindividual resulted in loss of all its individuals. As argued by Scheffer et al. (1995), losses of individuals within a super-individual via predation were modeled by drawing the number from a binomial distribution. The probability of predation, $p$, for a superindividual was calculated from an exponential probability distribution from the predation rate. This probability was used with an exact binomial probability density function when $n \leq 20$. To reduce computation time, approximations were used when $n>20$. When $n>$ 20 and $n p \leq 50$, the Poisson approximation for a binomial distribution with small $p$ was used. The Poisson distribution was further approximated by a normal distribution when $n$ $>20$ and $n p>50$. Finally, super-individuals were deemed lost by advection when they crossed the $100 \mathrm{~m}$ isobath, representing the edge of Georges Bank (Figure 4.1). Advective loss served as a proxy for the combination of starvation that would occur as 
the larvae left the rich prey environment of the bank, predation by mesopelagic fishes off the slope of the bank, and the inability to find suitable juvenile settlement habitat.

\subsubsection{Simulations}

Two contrasting years in haddock recruitment, 1995 and 1998, as observed during the GLOBEC GB field study, were chosen for this modeling study. Super-individuals were initialized as newly-hatched $5 \mathrm{~mm}$ larvae in the number and location specified from the egg hatching rate estimates of each year. Hatch locations were determined from observations of egg abundance (Sibunka et al. 2006) projected forward using estimated egg mortality rates and spatially integrated using kriging as described in Mountain et al. $(2003,2008)$. Initial depth was random from surface to bottom to approximate the uniform distribution of eggs from wind and tidal mixing (R. G. Lough, personal communication). Three different cohorts were simulated each year that hatched on the midpoint of February, March, and April. Simulations were run until mid-June, the last month sampled by the GLOBEC GB surveys in 1995. Thus, the run time of the April cohort was $55 \mathrm{~d}$. For equality, each cohort was analyzed until 55 days post hatch (dph). Starvation, predation, and advection losses were calculated at $55 \mathrm{dph}$ or at the time when larvae reached $12 \mathrm{~mm}$, the average length at the juvenile transition. It was assumed that the model no longer applied to juveniles because they have different metabolisms, are less vulnerable to predation, and have greater swimming abilities. The time of $55 \mathrm{dph}$ proved to be adequate for most individuals to either die or reach $12 \mathrm{~mm}$. Over $90 \%$ of individuals hatched in February and 100\% of the individuals hatched in March and April 
reached $12 \mathrm{~mm}$ within $55 \mathrm{dph}$ in all but 4 of the 28 total simulations, which had lower percentages for the February cohort.

\section{Reference case}

As a reference case, super-individuals were modeled as passive particles. To test the hypotheses regarding the difference in larval survival between 1995 and 1998, thirteen other cases were simulated for each year.

\section{Cross initialization}

To distinguish the effect of the environment from that of hatch locations and abundance, the locations and numbers of one year were used in conjunction with the physical and biological environment of the other year.

\section{Low prey}

Though the spatial and temporal patterns in Pseudocalanus spp. abundance from the population model match observations (Ji et al. 2007), the absolute prey concentrations do not. In the reference case and all other cases, the 1998 copepod model concentration was increased by a factor of 5 to result in mean abundances 2-3 times higher (E. Durbin, unpublished data) than the 1995 output from the copepod model (Table 4.1). There were two "low-prey" simulations where the 1995 prey density was decreased to be $1 / 5^{\text {th }}$ ("low prey 5") and $1 / 10^{\text {th }}$ ("low prey 10") of the copepod model prey density for 1995 (Table 
4.1). In both cases, the 1998 copepod model prey density output was adjusted to be $2-3$ times higher than the resulting density for 1995 (Table 4.1).

\section{Swimming behavior}

High turbulence avoidance behavior

Observations of the vertical distribution of larval haddock and their prey (Lough 1984, Buckley \& Lough 1987, Lough \& Potter 1993) suggest that the larvae have a preyseeking vertical migration behavior. The results of Chapter 3 determined that this swimming behavior needed to be directed to overcome turbulent diffusion. Given the unlikelihood of sensing gradients, the swimming behavior was related to local conditions as a first attempt. In stratified water columns the prey maximum is often associated with the pycnocline (Lough 1984, Buckley \& Lough 1987, Lough \& Potter 1993), a region of low turbulent mixing. Directional swimming to avoid high turbulence cannot be used as the sole proxy for the swimming behavior, because both surface and bottom waters experience high turbulence from wind and tidal forcing respectively. However, this behavior can be used together with light information. If a larva is in the surface waters where both light and turbulence are high, it swam down. Conversely, if a larva is in the bottom waters where light is low and turbulence is high, then it swam up. The magnitude

of the swimming velocity was proportional to the strength of the turbulence and light, and scaled to the size of the larva. The threshold that determined high light versus low light (downward versus upward swimming) was dependent on the visual system of the larva, which has a saturating relationship with light. This saturating relationship in combination 
with the exponential decay of light results in perception having a hyperbolic tangential shape with depth. The inflection point of this perception curve delineated high and low light. Since larval haddock are visual feeders, they only search for prey when there is light. Thus to avoid predation and save energy the larvae remain motionless in the dark. In lit waters the swimming speed, $w\left(\mathrm{~m} \mathrm{~s}^{-1}\right)$, was

$$
w=\left\{\begin{array}{cc}
w_{\max }\left(2\left(\frac{1}{2}-\frac{E}{E+1}\right)\right)\left(\log _{10}(\kappa)>0\right. \\
\left.w_{\max }\left(\frac{\kappa}{13}\right)+1\right) & \text { for }-13 \leq \log _{10}(\kappa) \leq 0 \\
\log _{10}(\kappa) \leq-13
\end{array}\right.
$$

where $E$ is the light intensity $\left(\mu \mathrm{mol} \mathrm{m} \mathrm{m}^{-2} \mathrm{~s}^{-1}\right), \kappa$ is the turbulent diffusivity $\left(\mathrm{m}^{2} \mathrm{~s}^{-1}\right)$, and the maximum swimming speed, $w_{\max }\left(\mathrm{m} \mathrm{s}^{-1}\right)$, is a $50 \%$ increase of the routine swimming speed of Peck et al. (2006) for the closely related species Atlantic cod.

$$
w_{\max }=1.5 \cdot 10^{-3} \cdot\left(0.261 L^{1.552 L^{-0.08}}-5.289 / L\right)
$$

with length, $L$, in $\mathrm{mm}$.

\section{Swim to turbulence minimum behavior}

A similar behavior was tested that assumed that larvae could detect gradients to find the depth of the turbulence minimum, $z_{\min }(\mathrm{m})$, and swim towards it. Swimming was downwards when above $z_{\min }$, and upwards when below it, while the speed of swimming was inversely proportional to distance from the depth following

$$
w=w_{\max } \cdot \tanh \left(z-z_{\min }\right)
$$

where $w_{\max }$ is the same as above and $z(\mathrm{~m})$ is the depth of the larvae. 
Swim to specified depth behavior

One other behavior was tested, which imposed a depth towards which larvae swam. I tested both $-10 \mathrm{~m}$ and $-30 \mathrm{~m}$ based on the modeling results of Werner et al. (1993, 1996) that suggest larvae must stay below $-30 \mathrm{~m}$ to remain on the bank, despite observations of larvae above this depth.

\section{Predation}

\section{Temperature-dependent predation}

Following Houde (1989), the temperature-dependent predation rate, $\operatorname{pred}_{t e m p}\left(\mathrm{~d}^{-1}\right)$, increased $0.01 \mathrm{~d}^{-1}$ per $1^{\circ} \mathrm{C}$ increase in temperature, $T\left({ }^{\circ} \mathrm{C}\right)$. The base temperature, $T_{\text {base }}$ $\left({ }^{\circ} \mathrm{C}\right)$, was set as $6.5^{\circ} \mathrm{C}$, the temperature associated with the predation rate of $0.1 \mathrm{~d}^{-1}$ for a 5 mm larva (Jones 1973, Bailey \& Houde 1989, Houde 1989). The base predation rate, $\operatorname{pred}_{\text {base }}\left(\mathrm{d}^{-1}\right)$, was the constant rate used in the passive simulations.

$$
\text { pred }_{\text {temp }}=\text { pred }_{\text {base }}+0.01\left(T-T_{\text {base }}\right)
$$

\section{Spatially-dependent predation}

The distribution of potential predators of larval haddock on Georges Bank (chaetognaths, predatory copepods, amphipods, mysid shrimps, decapod shrimps, euphausiids, hydroids, hydromedusae, siphonophores, scyphomedusae, herring, mackerel) falls into two groups, those that are more abundant on the shallow, well-mixed crest region (shoalward of the $60 \mathrm{~m}$ isobath), and those that are more abundant on the seasonally stratified flanks that are in waters deeper than $60 \mathrm{~m}$ (Sullivan \& Meise 1996). 
The predators are more diverse and abundant on the crest (Sullivan \& Meise 1996), however this does not necessarily equate to higher predation rates because of possible differences in consumption rates. Two different simulations were run to test the effect of spatially-dependent predation, one where predation was three times as high on the crest compared to the flanks,

$$
\begin{aligned}
& \text { pred }_{\text {crest }}=1.5 \cdot \operatorname{pred}_{\text {base }} \\
& \text { pred }_{\text {flanks }}=0.5 \cdot \text { pred }_{\text {base }}
\end{aligned}
$$

and a second where predation was higher on the flanks

$$
\begin{aligned}
& \text { pred }_{\text {crest }}=0.5 \cdot \text { pred }_{\text {base }} \\
& \text { pred }_{\text {flanks }}=1.5 \cdot \operatorname{pred}_{\text {base }}
\end{aligned} .
$$

Predation rates were offset from the base predation rate by $50 \%$ to try to keep the numbers of individuals eaten similar.

\section{Interannually varying predation}

To investigate the hypothesis of differing predator communities in 1995 and 1998 the predation rate was increased in 1995 and decreased in 1998 in relation to the base predation rate. Differences of $\pm 10 \%, 25 \%$, and $50 \%$ of the base rate were tested. 


\subsection{Results}

\subsubsection{Reference case}

\section{Trajectories}

There are some noticeable similarities and differences in the trajectories of modeled passive larvae between 1995 and 1998. The trajectories from hatch until the time each super-individual reaches $12 \mathrm{~mm}$ show similar major advective pathways between months and years such as clockwise around the bank (Figure 4.2). In 1995 (Figure 4.2a-c), some individuals that hatched in the Northeast Channel were advected northward into the Gulf of Maine (GOM), whereas in 1998 they made it onto the bank (Figure 4.2d-f). In 1995, some of the larvae that exited the bank were carried back up to the northeast (Figure 4.2a-c). The number that were advected in this direction decreased as hatch date increased, whereas the number advected to the southwest out the Great South Channel (GSC) and towards the Mid-Atlantic Bight increased. In 1998, most larvae were lost out the GSC to the Mid-Atlantic Bight (Figure 4.2d-f).

\section{Hatch distributions}

Both the hatching rates and locations differed between 1995 and 1998. Hatching occurred in two places in February of 1995, the Northeast Peak (NEP) and the western side of Georges Bank (Figure 4.2a), while February hatching was concentrated around the NEP in 1998 (Figure 4.2d). The hatch distributions of the March cohorts were similar in 1995 and 1998 (Figures 4.2b,e), with 1995 having more larvae hatch on the center of the bank and 1998 having more hatch on the Southern Flank (SF). The April hatch 
distributions were markedly different with larvae hatching on the NEP in 1995 (Figure 4.2c), and larvae hatching all over the bank in 1998 (Figure 4.2f). More larvae hatched in all months of 1998 compared to 1995 (Table 4.2). In 1998, the April cohort made up the largest proportion of larvae hatching and surviving, and the February cohort the least (Figure 4.3). Conversely, the majority of larvae hatching in 1995 came from the March cohort, but the proportion of survivors that originated in the April cohort was greater than the proportion of all hatched larvae derived from that cohort (Figure 4.3).

\section{Growth rates}

Mean time to $12 \mathrm{~mm}(\mathrm{~d})$ was calculated and used to find the mean specific growth rate $\left(\% \mathrm{~d}^{-1}\right)$ from hatch until that time. The mean time to $12 \mathrm{~mm}$ decreased and growth rate increased with increasing cohort hatch date for both years (Table 4.3). The mean time was shorter, corresponding to faster growth, for all cohorts in 1998 compared to 1995 (Table 4.3). Since the larvae experienced lower mean temperatures in 1998 (Table 4.4), the faster growth rates in this year can be attributed to higher prey concentrations (Table 4.5).

\subsubsection{Hatch distribution effect on survival and sources of mortality}

Percent survival, calculated as the percentage of individuals hatched that were alive at $55 \mathrm{dph}$ or upon reaching $12 \mathrm{~mm}$, increased with cohort hatch date in both 1995 and 1998 (Figure 4.4). Percent survival of all cohorts hatched in 1998 was lower than in 1995. The 1995 April cohort had the highest percent survival (Figure 4.4), however, the 
1998 April cohort had the greatest number of surviving individuals (Table 4.7).

Predation loss decreased as advection increased with hatch date in both years (Figure

4.4). Starvation losses were negligible and represented $<1 \%$ of all loses in the February and March cohorts in the 1995 environment (Figure 4.4 left).

Both the hatch locations and the environment affected survival, with the dominant source of mortality depending more strongly on hatch location. A greater percentage of a cohort hatched in the 1995 locations was lost to predation in both the 1995 and 1998 environments, with the exception of the April cohort that suffered greater advective losses in the 1998 environment (Figure 4.4 top). By contrast, all cohorts hatched in the 1998 locations experienced greater percent losses from advection (Figure 4.4 bottom). Larvae hatched in the 1995 locations had equal or greater percent survival than those hatched in the 1998 locations under both environments (Figure 4.4). Cohorts in the 1995 environment had equal or greater survival than those in the 1998 environment with the exception of the March cohort hatched in 1995 (Figure 4.4).

\subsubsection{Mean depth of cases with behavior}

The mean depth of passive super-individuals as well as those avoiding high turbulence and those swimming to the turbulence minimum had a maximum in the surface waters in both years (Figure 4.5a-c,f-h). The binned mean depth distributions of the passive larvae and those swimming to the turbulence minimum were very similar to each other, but years differed (Figure 4.5a,c,f,h). In the 1998 environment, there was a local maximum between 10-15 $\mathrm{m}$ (Figure 4.5f,h). This maximum extended deeper in the 
passive case (Figure 4.5f). The 1995 and 1998 depth distribution of the high turbulence avoidance behavior was more spread out than the passive and swim to turbulence minimum cases, with a small local maximum at $75-80 \mathrm{~m}$ (Figure $4.5 \mathrm{~b}, \mathrm{~g}$ ). With this behavior, the 1998 local maximum at 10-15 m (Figure 4.5g) was less pronounced than in the passive and swim to turbulence minimum cases. In both years, the swim to $10 \mathrm{~m}$ and $30 \mathrm{~m}$ behaviors had maximum concentrations at those depths as expected (Figure $4.5 \mathrm{~d}-$ e,i-j). The mean depth of over half of the super-individuals was $10 \mathrm{~m}$ with the behavior of swimming to this depth (Figure $4.5 \mathrm{~d}$,i), but less than $50 \%$ of the super-individuals had a mean depth of $30 \mathrm{~m}$ when swimming to it (Figure 4.5e,j). The fraction of superindividuals was greater above the specified depth than the fraction below in both cases (Figure 4.5d-e,i-j).

Copepod prey concentrations were highest in the surface layer with maximum concentrations generally between 0 to $35 \mathrm{~m}$ in 1995 and 0 to $65 \mathrm{~m}$ in 1998 . There was a sharp decline in prey density between 50 and $100 \mathrm{~m}$. Thus the majority of larvae in all cases were in regions with high prey availability. However, a greater proportion of larvae using the high turbulence avoidance behavior were distributed below $50 \mathrm{~m}$ (Figure $4.5 \mathrm{~b}, \mathrm{~g})$ and experienced much lower prey densities.

\subsubsection{Alternate hypotheses}

\section{Survival}

The total number of individuals that survived was greater in 1998 than 1995 for all cases (Figure 4.6). Interannually different predation $50 \%$ more or less than the 
reference passive case resulted in the lowest survival in 1995 and highest survival in 1998. Ignoring the interannual changes to predation, spatially-dependent predation with increased rates on the crest and decreased rates on the flanks resulted in the highest survival, whilst lowest survival occurred with increased predation on the flanks relative to the crest in both years (Figure 4.6). The high turbulence avoidance behavior also resulted in low survival in 1998 (Figure 4.6).

The number of survivors per hatched larva was greater in 1995 than 1998 for all cases except for interannual differences in predation of $25 \%$ and $50 \%$, resulting in a ratio of survivors per hatch in 1998 to 1995 less than one (Figure 4.7). The predation difference of $25 \%$ had the ratio of survivors per hatch closest to the 1.17 ratio of recruits per hatched larva in 1998 to 1995 calculated from GLOBEC GB data by Mountain and Kane (2010). The ratio was higher than the reference case in simulations of the opposite

environment, swimming to the turbulence minimum or $10 \mathrm{~m}$ or $30 \mathrm{~m}$, higher predation on the flanks, and an interannual difference in predation of $\pm 10 \%$ of reference. Survival per hatch was least similar to observations of recruits per hatch when larvae used the high turbulence avoidance behavior or when predation was higher on the crest.

\section{Sources of mortality}

The percentage of larvae lost to advection was greater in 1998 than 1995 for all cases (Figure 4.8a). Higher predation on the flanks resulted in the least advective loss in 1995, while higher predation on the crest resulted in the most (Figure 4.8a). In 1998, 
swimming to $30 \mathrm{~m}$ was the simulation with the lowest advection and the simulation with decreased predation by $50 \%$ had the highest (Figure $4.8 \mathrm{a}$ ).

Conversely, percentages of hatched larvae lost to predation were greater in 1995 than 1998 for all cases (Figure 4.8b). Changing the baseline predation by $\pm 50 \%$ caused the greatest predation losses in 1995 and the least in 1998. Excluding this case, increased

predation on the flanks resulted in the greatest losses and higher predation on the crest the least for both years (Figure 4.8b). The fraction of advection and predation losses was similar across cases.

Starvation occurred more often in 1995 than 1998, and only occurred with 1998 prey fields in the high turbulence avoidance behavior case and when prey was $1 / 10^{\text {th }}$ the copepod model concentrations (Figure 4.8c). The greatest amount of starvation happened in the swim to turbulence minimum behavior case. The low prey 10, high turbulence avoidance behavior, and high crest predation cases had relatively moderate amounts of starvation compared to other cases, while lower amounts occurred in the passive, low prey 5 , temperature-dependent predation, higher flank predation, and interannually altered predation cases of 1995 . All starvation losses were less than $1 \%$ of the larvae hatched (Figure 4.8c).

\section{Cohort contribution}

In 1995, the percent of total survivors from the February cohort was low across all simulations. The contribution of this cohort was increased from the reference case by swimming to $30 \mathrm{~m}$, temperature-dependent predation, and higher predation on the flanks, 
remained the same with high crest predation, and decreased by all other cases (Figure 4.9a). The percent of total survivors from the 1995 February cohort was always less than the percent of total larvae that hatched in that month (Figure 4.9a). The contributions of the March and April cohorts to the surviving larvae in 1995 tended to vary reciprocally. The opposite environment, swim to $30 \mathrm{~m}$, temperature-dependent predation, and higher predation on the crest all increased the contribution of the March cohort, while both low prey 5 and 10, the high turbulence avoidance behavior, the swim to $10 \mathrm{~m}$ behavior, and $25 \%$ increased interannual predation decreased it (Figure 4.9b). Only in the opposite environment was the percent of survivors from March greater than the percent that hatched and the percent of survivors from April less. The contribution of the 1995 April cohort was decreased in the simulations that increased the contributions of February and March: opposite environment, swim to $30 \mathrm{~m}$, temperature-dependent predation, and spatially-dependent predation on both the crest and flanks (Figure 4.9c).

The contribution of the February cohort to survivors experienced greater changes in 1998. Both February and March 1998 cohort contributions were increased by temperature-dependent predation, high crest predation, and all interannually lower predation rates, which in turn decreased the contribution of April (Figure 4.9d-f). Both low prey cases and all four behaviors decreased the February contribution in 1998 (Figure 4.9d). Decreases in the 1998 March contribution resulted from the opposite environment, low prey 5 and 10, high turbulence avoidance behavior, swim to $10 \mathrm{~m}$ and $30 \mathrm{~m}$ behaviors, and high flank predation (Figure 4.9e). These were the same cases that resulted in increases in the fraction of survivors from the 1998 April cohort (Figure 4.9f). 
In all simulations, the percent of survivors from the February cohort was less than the percent hatched, whereas that of the April cohort was always greater than the percent hatched from that month (Figure 4.9d,f). The 1998 March cohort contributed less to survivors than it did to hatched larvae except when predation was temperature-dependent (Figure 4.9e).

\section{Growth rate}

In comparison to 1995, larvae hatched in 1998 had faster mean specific growth rates $\left(\% \mathrm{~d}^{-1}\right)$ from hatch until the mean time to $12 \mathrm{~mm}$ for that cohort in all but three cases (Figure 4.10). Growth was greater for larvae hatched at 1995 locations in the 1998 environment than larvae hatched in the 1998 locations exposed to the 1995 environment. Growth was also slightly higher in 1995 when larvae used the high turbulence avoidance behavior and the swim to $10 \mathrm{~m}$ behavior, which resulted in the lowest and highest growth rates respectively. Growth rates were very consistent across all different predation runs.

\subsection{Discussion}

Coupled biological-physical modeling simulations revealed disparities in the processes occurring during the larval period of haddock on Georges Bank between the years of differing recruitment, 1995 and 1998. 


\subsubsection{Advection}

Larvae followed the general clockwise circulation pattern of Georges Bank. Though the majority of advective loss from the bank was out the GSC towards the MidAtlantic Bight, the lesser proportion of losses was northeastward along the shelf break or into the GOM in 1995 and out towards the Atlantic Ocean along the shelf break in 1998 (Figure 4.2). The February and March egg hatching patterns of 1995 resulted in larvae developing all over the bank in 1995, while development was restricted to the SF in 1998. This pattern was reversed for the April cohort where larvae developed along the SF in 1995 and all over the bank in 1998. Advective losses were greater in 1998 despite this year having lower wind stress (Mountain et al. 2008). In general, 1998 had lower percent survival in the model runs because the hatch locations made larvae more susceptible to advective loss, and was not the result of between-year differences in the physical circulation (Figure 4.4). Percent advective loss had a reciprocal relationship with predation, suggesting that an increase in one resulted in the decrease of the other (Figures 4 and 8a,b). Predation losses decreased with hatch date (Figure 4.4), which was consistent with the hypothesis that larvae were exposed to predation for less time as growth rate increased with hatch date (Table 4.4). Advective loss increased with hatch date simply because fewer larvae had been eaten, thus more live larvae were left to be advected off Georges Bank.

As mentioned in the methods, advection past the $100 \mathrm{~m}$ isobath was a proxy for starvation from leaving the rich prey environment of Georges Bank, heavy predation off the slope of the bank, and the inability to find suitable juvenile settlement habitat. 
Alternatively, each of these processes could be modeled. Super-individuals and individuals are followed for the entire duration of the simulation, such that information on starvation, predation, and location are available after a larva leaves the region denoted by the $100 \mathrm{~m}$ isobath as long as it remains in the model domain. Many of these individuals starved and were eaten after advective loss in the model simulations. Though potential prey are advected off the bank in the same mass of water that contains the larvae being advected, starvation will occur from spatial and temporal mismatch of the larvae and prey. If larvae swim out of the layer of water that was advected, they will immediately experience the lower prey densities off the continental slope. Also, prey concentration will decrease as both the prey and their resources are diluted in the deepocean environment and as the prey are eaten by many of the same slope-water predators that will consume the larval fish. As with all predation, it is difficult to determine how to parameterize the off-bank predation rates to simulate the losses to mesopelagic fish and other predators. Finally, it is possible for larvae to be advected back onto the bank before experiencing either starvation or predation, thus true advective loss should be determined from individuals that are not near the favorable pebble-gravel settlement habitats (Lough et al. 1989) on Georges Bank at the time of the demersal transition. As this transition from a pelagic to demersal lifestyle happens during the juvenile stage, it could not be simulated in the present study because the biological models do not hold for juvenile haddock. 


\subsubsection{Starvation and growth}

The model result that starvation was not an important source of mortality (Figure 4.8c) supports the findings of Buckley et al. (2006) who observed very low incidence of starvation in 5-12 mm larvae of haddock. Though direct starvation of larvae was not a large source of mortality, it most likely contributed to predation losses since malnourished larvae would be smaller and have higher predation rates. Starvation decreased with hatch date (Figure 4.4) because as the season progressed photoperiod and copepod prey concentrations (Table 4.5) increased, both of which allowed for the consumption of more biomass. These seasonal increases, in addition to the seasonal rise in temperature (Table 4.4), were reflected in the growth rates and mean times to $12 \mathrm{~mm}$. Mean times decreased with hatch date due to faster growth rates from increased photoperiod, higher prey densities, and higher temperatures. The growth rates of the April cohorts were consistently high from dramatic increases in the copepod population during this time such that food was not limiting despite reductions to prey concentration. These high growth rates may have skewed the mean growth rates and mitigated the effect of prey availability on total survivorship.

The growth rate of haddock larvae is strongly correlated with the Pseudocalanus spp. biomass with a Michaelis-Menten type response (Buckley \& Durbin 2006). The low prey cases were run to test the effect of interannual differences in prey concentration at concentrations below those producing saturated growth rates. The model results agree well with the curves calculated by Buckley and Durbin (2006) for 7-12 mm larvae,

particularly the reference case (Figure 4.11). The discrepancy between the 5-7 mm 
model results and the curve derived from RNA:DNA measurements (Figure 4.11a) can be explained by the developmental stages of Pseudocalanus spp. used to estimate biomass. For the 5-7 mm curve, Buckley and Durbin (2006) used the biomass of the developmental stages available to a $7 \mathrm{~mm}$ cod larvae following Lough et al. (2005), which was all of the stages. Though all stages may be found in observations of gut contents, they are not ingested with the same frequency, even when present in equal abundance, because of differences in capture success (Petrik et al. 2009). The modeled capture success of the naupliar stages of Pseudocalanus spp. is greater than $90 \%$, however there is a steep decrease for the copepodite and adult stages from $90 \%$ for CI to $<10 \%$ for CVI (Petrik et al. 2009). The low capture success of these stages suggests that the biomass used by Buckley and Durbin (2006) is an overestimate. Additionally, cod larvae eat larger prey than haddock (Kane 1984), and use of these prey items further overestimates the biomass available to larval haddock. Adjustments to the biomass available to 5-7 $\mathrm{mm}$ larvae would result in a lower half saturation constant in the fitted Michaelis-Menten function and shift the curve to the left, which would better fit the model results.

\subsubsection{Swimming behavior}

The different depth distributions resulting from the four different vertical swimming behaviors tested affected larval survival and sources of mortality. The differences in the number of surviving individuals were three-fold in 1998, with the high turbulence avoidance behavior causing the lowest survival, and the swim to $30 \mathrm{~m}$ 
behavior the highest (Figure 4.6). Differences in the number surviving across these simulations were not as great in 1995 , but the swim to $30 \mathrm{~m}$ behavior still resulted in the highest amount. Larvae with the swim to $30 \mathrm{~m}$ behavior benefitted from lower advection and predation losses by residing below the surface layer, but at a depth with high prey abundance and enough light for visual foraging. The starvation losses in the high turbulence avoidance and swim to turbulence minimum cases can be attributed to their greater proportions of larvae deeper in the water column where both prey density and light were low. All behaviors except high turbulence avoidance raised the 98:95 survival per hatch ratio from the reference level (Figure 4.7). These results of vertical swimming behavior helping to rectify model results with observations of interannual variability in survival, in combination with observations that the depth distribution of larval haddock is nonrandom (Lough 1984, Buckley \& Lough 1987, Lough \& Potter 1993) suggest that the larvae are not passive. The mechanism governing their vertical behavior has not been determined and is an important area for future research.

The uneven vertical distribution of passive larvae (Figure 4.5a,f) and its similarity to that of larvae using the swim to turbulence minimum behavior (Figure $4.5 \mathrm{c}, \mathrm{h}$ ) suggest there is a problem with the vertical random walk model. When turbulent diffusivity is spatially nonuniform, particles can aggregate in the turbulence minimum region if a random walk model is implemented incorrectly (Visser 1997). The Lagrangian particletracking model applies the Visser (1997) correction to prevent this, however the time-step may not have been small enough to meet his criteria and is being investigated. Though the super-individuals had a mean depth near the surface rather than being randomly 
distributed throughout the water column in all non-behavior cases, I believe that these results are still meaningful. For one, changes in the vertical distribution of larvae with behavior did not drastically alter the survival per hatch ratio (Figure 4.7), nor the fraction of larvae lost to advection, predation, and starvation (Figure 4.8). Secondly, this distribution is more similar to the distributions of larvae observed in the field (Lough 1984, Buckley \& Lough 1987, Lough \& Potter 1993) than an even or random distribution, making it an adequate reference case.

\subsubsection{Hatch date of survivors}

Lapolla and Buckley (2005) back-calculated the hatch date of young-of-year juvenile haddock and found that the hatch date frequency of the surviving juveniles peaked between February and mid-March, with 1998 having a significantly later peak hatch date than 1995. More larvae hatched in April and May of 1998 survived than the 1995-1999 average, but the highest survival was still from the early hatch dates (Lapolla \& Buckley 2005). Mountain et al. (2008) also found that the peak contribution of each cohort occurred in March of 1995 and 1998 by back-calculated hatch dates from larval abundances and estimated mortality rates. The passive reference case simulation had lower percent survival from the February and March cohorts, but the cases with swim to $10 \mathrm{~m}$ behavior, temperature-dependent predation, higher predation on the crest, and higher predation on the flanks increased their contributions (Figure 4.9). The proportion of survivors from the February cohort was never greater than the proportion of larvae hatched from this month, but the proportion of survivors from the March cohort was 
greater than the proportion hatched under the simulation of temperature-dependent predation in 1998 (Figure 4.9).

The temperature-dependent predation rate was used to test the hypothesis that early-hatched haddock are the dominant survivors because they reach an invulnerable size before their predators become abundant (Lapolla \& Buckley 2005, Buckley \& Durbin 2006, Buckley et al. 2010). Even though temperature-dependent predation failed to increase the fraction of survivors from February and March above the fraction that hatched, it was able to increase their contributions while decreasing that of the April cohort. Part of the discrepancy between my results and theirs could be that I measured survival at the end of the larval period rather than during the juvenile stage.

Nevertheless, a different parameterization of temperature-dependent predation may result in cohort contributions that agree better with observations of the mean hatch date of survivors.

Observations from 1976-1987 (Lough et al. 2006) and 1995-1999 (Mountain et al. 2008) show peak haddock spawning between March and April. Evolutionarily, the peak in spawning and subsequent hatching should be timed to result in the highest survival of eggs and larvae. During the MARMAP (Marine Resources Monitoring, Assessment and Prediction) study period of 1976-1987, the large and moderate year-classes of haddock were spawned in April and benefitted from high hatching rates, high physical retention, high prey concentrations in May, and a late seasonal temperature-dependent growth optimum (Lough et al. 2006). In contrast, observations from the 1995-1999 GLOBEC GB study period demonstrate a mismatch between the time of peak hatching and time 
when most survivors hatched (Lapolla \& Buckley 2005, Mountain et al. 2008). For example, 1998 peak spawning occurred between February and March (days 45-85) followed by peak hatching in April (day 115), but the peak hatch time of survivors was in early March (day 65; Mountain et al. 2008).

Following the seasonal predation hypothesis (Lapolla \& Buckley 2005, Buckley \& Durbin 2006, Buckley et al. 2010), there could have been a decadal shift in the predator community on Georges Bank that resulted in higher predation rates earlier in the year for 1995-1999 than 1977-1987 and the earlier hatch dates of survivors. Conversely, the predation rates may have been constant, but the physical environment in 1995-1999 could have become more retentive earlier in the year and/or more advective later in the spring. Similarly, bottom-up biological processes in 1995-1999 could have resulted in prey concentrations in February and March that were high enough to support growth to a size invulnerable to predators. A potential mechanism responsible for this hypothesis is increased stratification from the input of low salinity water into the Gulf of Maine and Georges Bank from the Arctic, which could result in an earlier spring bloom and earlier development of larval haddock prey populations (Ji et al. 2008). Regardless of the cause of the mismatch in peak hatching time of all eggs and just those that survived, if this state persists, the adult haddock population may shift its peak spawning time to coincide with the ideal conditions.

Alternatively, the time of peak spawning may be controlled by the age structure of the adult population. Age 2 females of the North Sea haddock population spawned 27-36 days later than older females in 1994, 1996, and 1999 (Wright \& Gibb 2005). Similar to 
the 1995-1999 observations from Georges Bank population, the timing of peak spawn date of surviving North Sea juveniles was earlier than the peak in egg production in 1996 and 1999 (Wright \& Gibb 2005). Wright and Gibb (2005) suggested that the negative selection on late spawning dates was the result of less viable eggs and larvae produced by the age 2 females. This hypothesis is supported by the fact that older haddock females produce larger eggs (Hislop 1988) from which larger larvae hatch (Rideout et al. 2005). Larger larvae have more advanced morphological characteristics that could confer survival advantages during the first few days after hatch (Rideout et al. 2005). In addition, haddock are batch spawners and egg size decreases with each batch spawned (Rideout et al. 2005). Thus, the early hatch date of surviving haddock in the Georges Bank population could be the product of small eggs spawned late in the year as last batches and/or from young females resulting in higher mortality rates and merits further study.

\subsubsection{Survival}

Higher total numbers of surviving larvae in the reference simulations of 1998 than 1995 (Figure 4.6) appear to be related to the greater number of larvae hatched in 1998 (Table 4.2). Since the number surviving was only a small percentage of the initial number of larvae, changes in predation, advection, and growth were expected to be important causes of changes in numbers of surviving larvae between years. However, in all but the high-predation runs, the initial abundance and distribution of hatched larvae was critically important, as can clearly be seen in the run with opposite environment, i.e., 
the larvae hatched in 1998 but subjected to the 1995 environmental conditions still had a greater number of survivors (Figure 4.6).

The number of eggs spawned is not a good predictor of hatching success, which is instead correlated to southeastern wind stress off Georges Bank (Mountain et al. 2008). Though spawning predominantly occurs on the NEP, spawning on western Georges Bank can contribute survivors in the winter when advective loss from the surface waters of the NEP is highest (Lough et al. 2006). The interannual variability in hatching success may also be related to the percentage of eggs spawned west of $67.5^{\circ} \mathrm{W}$ (Mountain et al. 2008). Despite the result of higher total survival in 1998 than 1995, the percent of hatched larvae that survived was greater in 1995 (Figure 4.7), opposite to estimates of percent of hatched larvae that recruited (Mountain \& Kane 2010) or that survived to $15 \mathrm{dph}$ (Mountain et al. 2008). The only way to match the observed ratio reported by Mountain and Kane (2010) was to increase the predation mortality by $25 \%$ in 1995 and decrease it by the same amount in 1998. It was under these interannually varying predation runs that the influence of predation on the total number surviving surpassed that of the number of eggs hatched. These results suggest that predation is the dominant factor controlling the difference in larval survival between these two years.

\subsubsection{Predation}

Making changes to the predation rate was the only way to reconcile the differences in survival per hatch between 1995 and 1998, as well as reproduce observations of early hatch dates contributing more to the surviving juveniles. All 
simulations with interannually varying predation rates and the simulation with high predation on the flanks increased the survival per hatch ratio above the reference case (Figure 4.7). Each predation case both increased and decreased the contributions of the February and March cohorts depending on cohort and year, with the exception of temperature-dependent predation, which always increased the contributions of the early hatch dates while decreasing that of April (Figure 4.9). In order to have higher survival per hatch in 1998 compared to 1995 and to have early hatched larvae contribute more to the survivors, it can be inferred that predation rates were higher in 1995 than 1998 and that predation rate increased with increasing temperature. In addition, higher predation on the flanks in 1995 would also improve interannual differences in survival rate and the contribution of the March cohort.

There are many types of potential invertebrate predators of fish larvae such as chaetognaths (Kuhlmann 1977), copepods (e.g. Euchaeta norvegica; Bailey 1984, Yen 1987), amphipods (e.g. Parathemisto; Sheader \& Evans 1975, Yamashita et al. 1985), mysids (Bailey 1984), decapod shrimps (e.g. Crangon septemspinosa; Wilcox \& Jeffries 1974), euphausiids (Bailey 1984), hydroids (Madin et al. 1996), medusae (Bailey 1984, Purcell 1985), siphonophores (Purcell 1985), as well as vertebrate predators like Atlantic herring (Clupea harengus) and mackerel (Scomber scombrus; Garrison et al. 2000). Most of these predators are opportunistic such that the prey items found in their guts reflect the natural abundances of the plankton. Since fish larvae are rather dilute (0-2.5 $\mathrm{m}^{-3}$; Lough 1984), it is doubtful that any predator specifically targets them or that they make up a significant portion of any predator's diet. Even though predation of fish larvae 
may be incidental, there may be considerable loss of larvae if predator abundances and consumption rates are high.

Chaetognaths are probably not significant predators on larval haddock since they can only eat larvae within a narrow time period after hatch (4 dph; Kuhlmann 1977). Similarly, the copepod E. norvegica cannot consume larvae greater than $7 \mathrm{~mm}$ (Bailey 1984). In addition, its consumption rate of larval fish is low in comparison to medusae and euphausiids (Bailey 1984) and it is the least abundant of all potential invertebrate predators on Georges Bank (Sullivan \& Meise 1996), thus negating it as a dominant predator. Though the filtering rates of mackerel could lead to high predation losses, their lack of spatial and temporal overlap on Georges Bank with haddock larvae discounts them as important predators (Garrison et al. 2000).

Consequently, I examined the remaining potential predators (amphipods, mysids, C. septemspinosa, euphausiids, siphonophores, and herring) for interannual differences to support the model conclusions of greater predation rates in 1995. Herring stock estimates indicate that the population was greater in 1998 (DFO 2003), contradicting model results. Many of the invertebrate predators were sampled during the GLOBEC GB study with a $10 \mathrm{~m}^{2}$ MOCNESS (Brown et al. 2005). First, the fraction of tows found containing each predatory taxon was used to test if there was a significant difference in the presence of each taxon between years. Then the measured abundances were used to compute 2-way ANOVAs with year and month as factors. Neither the presence of euphausiids $(p=0.71)$, mysids $(\mathrm{p}=0.50)$ and $C$. septemspinosa $(\mathrm{p}=1.00)$, nor their abundance when found $(\mathrm{p}=0.13, \mathrm{p}=0.38, \mathrm{p}=0.81$ respectively) were significantly greater in 1995 compared to 
1998, though mean log abundance of mysids was greater in April and May of 1995 (Figure 4.12a). There was a greater chance of collecting siphonophores $(\mathrm{p}<0.01)$ and hyperiid amphipods ( $\mathrm{p}=0.02$ ) in 1995, and the abundances of both predators had highly significant year effects $(\mathrm{p}<0.01$ and $\mathrm{p}=0$, respectively), with mean log abundances showing increased concentrations in 1995 (Figure 4.12b,c).

It is very possible that the greater abundances of siphonophores and hyperiid amphipods in 1995 compared to 1998 resulted in greater predation rates in 1995 and the observed differences in survival rate. Unlike the other invertebrate predators that eat fish larvae incidentally, fish larvae can comprise $90-100 \%$ of the diets of cystonect siphonophores and are frequently consumed by physonect siphonores (Purcell 1981, 1985). The many gastrozooids of siphonophores allow them to ingest more than one larva at a time (Purcell 1985). Hyperiid amphipods can have a detrimental effect on larval fish populations depending on densities of predator and prey, and on their spatial and temporal overlap. For example, predation by the hyperiid amphipod Parathemisto japonica resulted in daily predation losses up to $45.2 \%$ of sand-eel larvae (Yamashita et al. 1985). The importance of siphonophores and hyperiid amphipods as predators on haddock larvae is further supported by their lowest abundances occurring in March (Figure 4.12), which could lead to an increase in the contribution of larvae hatched during this month as observed (Lapolla \& Buckley 2005, Mountain et al. 2008). The climatological distributions of siphonophores and hyperiids indicate greater abundances outside the $60 \mathrm{~m}$ isobath (Sullivan \& Meise 1996), which lends credence to model predictions of higher predation on the flanks in 1995 to help reconcile the survival per 
hatch ratios and contribution of the March cohort. Conversely, mysids and $C$. septemspinosa are more abundant on the crest region inside 60m (Sullivan \& Meise 1996), thus the fact that these taxa were not significantly more abundant in 1995 might be irrelevant if predation in this region is not important in driving interannual variability in larval survival. Additionally, the warm water intrusions in 1995 could have advected slope water predators onto Georges Bank (Brown et al. 2005), thereby increasing overall predation rates, as well as rates on the flank.

This analysis was a small effort to understand the interannual predation rates on Georges Bank. Further work is required in the form of horizontal and vertical distributions of predators and consumption rates on larval fish.

\subsubsection{Conclusions}

From the model results, I conclude that the survival of larval haddock on Georges Bank is dominated by predation. Model results from changes to the predation rate were the only ones that agreed with observations of higher survival per hatch of larvae in 1998 compared to 1995 (Mountain et al. 2008, Mountain \& Kane 2010), and of observations of the mean hatch date of survivors (Lapolla \& Buckley 2005, Mountain et al. 2008). The role of advection during the larval period was negated by the fact that modeled advective losses were higher in 1998 due to hatch location, despite lower wind stress that year. This conclusion is supported by Mountain et al. (2008), who did not find a relationship between modeled wind-driven transport and early larval mortality rates. Furthermore, the hypothesis that interannual variation in larval survival is the result of bottom-up 
effects was rejected by the cases with low prey concentrations, which did not agree with observations of survival per hatch and the hatch date of survivors.

The higher total number of survivors in 1998 was related to the greater number of larvae hatched in that year and to a hypothesized lower predation rate. The greater hatching success in 1998 seems related to lower southeastern wind stress and a greater proportion of eggs spawned on the western part of Georges Bank (Mountain et al. 2008), while the lower predation rate could stem from the lower abundances of hyperiid amphipods and siphonophores in that year relative to 1995. The number of haddock eggs spawned is not significantly correlated to recruitment, whereas egg hatching and larval survival are (Mountain et al. 2008). Mountain et al. (2008) found that the contributions of egg and larval mortalities to overall haddock survivorship were comparable. In light of their results and the modeling work presented here, I conclude that interannual differences in haddock recruitment during the 1995-1999 GLOBEC GB study period are dominated by advection during the embryonic period and predation during the larval stage. Further research is needed to assess whether these patterns hold for other years. 


\section{References}

Aksnes DL, Giske J (1993) A theoretical model of aquatic visual feeding. Ecol Model $67: 233-250$

Aksnes DL, Utne ACW (1997) A revised model of visual range in fish. Sarsia 82:137147

Bailey KM (1984) Comparison of laboratory rates of predation on five species of marine fish larvae by three planktonic invertebrates: effects of larval size on vulnerability. Mar Biol 79:303-309

Bailey KM, Houde ED (1989) Predation on eggs and larvae of marine fishes and the recruitment problem. Adv Mar Biol 25:1-83

Brodziak J, Traver M (2006) Status of fishery resources off the Northeastern US: haddock. http://www.nefsc.noaa.gov/sos/spsyn/pg/haddock/. 8/20/10

Brown H, Bollens SM, Madin LP, Horgan EF (2005) Effects of warm water intrusions on populations of macrozooplankton on Georges Bank, Northwest Atlantic. Cont Shelf Res 25:143-156

Buckley LJ, Durbin EG (2006) Seasonal and inter-annual trends in the zooplankton prey and growth rate of Atlantic cod (Gadus morhua) and haddock (Melanogrammus aeglefinus) larvae on Georges Bank. Deep-Sea Res II 53:2758-2770

Buckley LJ, Lough RG (1987) Recent growth, biochemical composition, and prey field of larval haddock (Melanogrammus aeglefinus) and Atlantic cod (Gadus morhua) on Georges Bank. Can J Fish Aquat Sci 44:14-25 
Buckley LJ, Caldarone EM, Lough RG, St. Onge-Burns JM (2006) Ontogenetic and seasonal trends in recent growth rates of Atlantic cod and haddock larvae on Georges Bank: effects of photoperiod and temperature. Mar Ecol Prog Ser 325: $205-226$

Buckley LJ, Lough RG, Mountain D (2010) Seasonal trends in mortality and growth of cod and haddock larvae result in an optimal window for survival. Mar Ecol Prog Ser 405:57-69

Butman B, Beardsley RC (1987) Long-term observations on the southern flank of Georges Bank. Part I: A description of the seasonal cycle of currents, temperature, stratification, and winds stress. J Phys Oceanogr 17:367-384

Butman B, Beardsley RC, Magnell B, Frye D, Vermersch JA, Schlitz R, Limeburner R, Wright WR, Noble MA (1982) Recent observations of the mean circulation on Georges Bank. J Phys Oceanogr 12:569-591

Caparroy P, Thygesen UH, Visser AW (2000) Modelling the attack success of planktonic predators: patterns and mechanisms of prey selectivity. J Plank Res 22:18711900

Chen C, Liu H, Beardsley RC (2003) An unstructured, finite-volume, three dimensional, primitive equation oceanography model: application to coastal oceanography and estuaries. J Atmos Ocean Tech 20:159-186

Chen C, Cowles G, Beardsley RC (2006) An unstructured grid, finite-volume coastal ocean model: FVCOM User Manual. Second edition, SMAST/UMASSD Technical Report-06-0602, 315p 
Davis CS (1984) Predatory control of copepod seasonal cycles on Georges Bank. Mar Biol 82:31-40

Davis CS (1987) Zooplankton life cycles. In: Backus RH, Bourne DW (eds) Georges Bank. MIT Press, London, p 1-593

DFO (2003) Atlantic herring: Georges Bank, Nantucket Shoals, Gulf of Maine stock complex. DFO Science Stock Status Report 2003/028, 7p

Fiksen Ø, MacKenzie, BR (2002) Process-based models of feeding and prey selection in larval fish. Mar Ecol Prog Ser 243:151-164

Flierl GR, Wroblewski, JS (1985) The possible influence of warm core Gulf Stream rings upon shelf water larval fish distributions. Fish Bull 83:313-330

Fogarty MJ, Myers RA, Bowen KG (2001) Recruitment of cod and haddock in the North Atlantic: a comparative analysis. ICES J Mar Sci 58:952-961

Garrison LP, Michaels W, Link JS, Fogarty M (2000) Predation risk on larval gadids by pelagic fish in the Georges Bank ecosystem. I. Spatial overlap associated with hydrographic features. Can J Fish Aquat Sci 57:2455-2469

Heath MR, Lough RG (2007) A synthesis of large-scale patterns in the planktonic prey of larval and juvenile cod (Gadus morhua). Fish Oceanogr 16:169-185

Hislop JRG (1988) The influence of maternal length and age on the size and weight of the eggs and the relative fecundity of the haddock, Melanogrammus aeglefinus, in British waters. J Fish Biol 32:923-930

Hjort J (1914) Fluctuations in the great fisheries of Northern Europe viewed in the light of biological research. Rapp P-v Réun Cons Int Explor Mer 20:1-228 
Houde ED (1989) Comparative growth, mortality, and energetics of marine fish larvae: temperature and implied latitudinal effects. Fish Bull 87:471-495

Hu Q, Davis CS, Petrik CM (2008) A simplified age-stage model for copepod population dynamics. Mar Ecol Prog Ser 360:179-187.

Ji R, Davis CS, Chen C, Townsend DW, Mountain DG, Beardsley RC (2008) Modeling the influence of low-salinity water inflow on winter-spring phytoplankton dynamics in the Nova Scotian Shelf-Gulf of Maine region. J Plank Res 30:13991416

Ji R, Davis CS, Chen C, Beardsley RC (2009) Life history traits and spatiotemporal distributional patterns of copepod populations in the Gulf of Maine-Georges Bank region. Mar Ecol Prog Ser 384:187-205

Jones R (1973) Density-dependent regulation of the numbers of cod and haddock. Rapp P-v Rèun Cons Int Explor Mer 164:119-127

Kane J (1984) The feeding habits of co-occurring cod and haddock larvae from Georges Bank. Mar Ecol Prog Ser 16:9-20

Kristiansen T, Fiksen Ø, Folkvord A (2007) Modelling feeding, growth and habitat selection in larval cod (Gadus morhua): observations and model predictions in a macrocosm environment. Can J Fish Aquat Sci 64:136-151

Kristiansen T, Jørgensen C, Lough RG, Vikebø F, Fiksen Ø (2009) Modeling rule-based behavior: habitat selection and the growth-survival trade-off in larval cod. Behav Ecol 20:490-500 
Kuhlmann D (1977) Laboratory studies on the feeding behavior of the chaetognaths Sagitta setosa J. Müller and S. elegans Verril with special reference to fish eggs and larvae as food organisms. Meeresforsch 25:163-171

Lapolla A, Buckley LJ (2005) Hatch date distributions of young-of-year haddock Melanogrammus aeglefinus in the Gulf of Maine/Georges Bank region: implications for recruitment. Mar Ecol Prog Ser 290:239-249

Laurence GC, Rogers CA (1976) Effects of temperature and salinity on comparative embryo development and mortality of Atlantic cod (Gadus morhua L.) and haddock (Melanogrammus aeglefinus L.). J Cons Int Explor Mer 36:220-228

Lewis CVW, Davis CS, Gawarkiewcz G (1994) Wind-forced biological-physical dynamics on an isolated off-shore bank. Deep-Sea Res II 41:51-73

Lewis CVW, Chen C, Davis CS (2001) Variability in wind forcing and its effect on circulation and plankton transport over Georges Bank. Deep-Sea Res II 48:137158

Lough RG (1984) Larval fish trophodynamic studies on Georges Bank: sampling strategy and initial results. In: Dahl E, Danielssen DS, Moskness E, Solemdal P (eds) The propagation of cod Gadus morhua. Flødevigen rapportser I, p 395-434

Lough RG, Potter DC (1993) Vertical distribution patterns and diel migrations of larval and juvenile haddock Melanogrammus aeglefinus and Atlantic cod Gadus morhua on Georges Bank. Fish Bull 91:281-303 
Lough RG, Buckley LJ, Werner FE, Quinlan JA, Pehrson Edwards K (2005) A general biophysical model of larval cod (Gadus morhua) growth applied to populations on Georges Bank. Fish Oceanogr 14:241-262

Lough RG, Hannah CG, Berrien P, Brickman D, Loder JW, Quinlan JA (2006) Spawning pattern variability and its effect on retention, larval growth and recruitment in Georges Bank cod and haddock. Mar Ecol Prog Ser 310:193-212

Lough RG, Valentine PC, Potter DC, Auditore PJ, Bolz GR, Neilson JD, Perry RI (1989) Ecology and distribution of juvenile cod and haddock in relation to sediment type and bottom currents on eastern Georges Bank. Mar Ecol Prog Ser 56:1-12

MacKenzie BR, Kiørboe T (2000) Larval fish feeding and turbulence: a case for the downside. Limnol Oceanogr 45:1-10

Madin LP, Bollens SM, Horgan E, Butler M, Runge J, Sullivan BK, Klein-MacPhee G, Durbin E, Durbin AG, Van Keuren D, Plourde S, Bucklin A, Clarke ME (1996) Voracious planktonic hydroids: unexpected predatory impact on a coastal marine ecosystem. Deep-Sea Res II 43:1823-1829

Mountain DG, Kane J (2010) Major changes in the Georges Bank ecosystem, 1980s to the 1990s. Mar Ecol Prog Ser 398:81-91

Mountain DG, Berrien P, Sibunka J (2003) Distribution, abundance and mortality of cod and haddock eggs and larvae on Georges Bank in 1995 and 1996. Mar Ecol Prog Ser 263:247-260 
Mountain D, Green J, Sibunka J, Johnson D (2008) Growth and mortality of Atlantic cod Gadus morhua and haddock Melanogrammus aeglefinus eggs and larvae on Georges Bank, 1995 to 1999. Mar Ecol Prog Ser 353:225-242

Peck MA, Buckley LJ, Bengtson DA (2006) Effects of temperature and body size on the swimming speed of larval and juvenile Atlantic cod (Gadus morhua): implications for individual-based modeling. Env Biol Fish 75:419-429

Peterson I, Wroblewski JS (1984) Mortality rate of fishes in the pelagic ecosystem. Can J Fish Aquat Sci 41:1117-1120

Petrik CM, Kristiansen T, Lough RG, Davis CS (2009) Prey selection of larval haddock and cod on copepods with species-specific behavior: a model-based analysis. Mar Ecol Prog Ser 396:123-143

Purcell J (1981) Feeding ecology of Rhyzophysa eysenhardti, a siphonophore predator of fish larvae. Limnol Oceanogr 26:424-432

Purcell J (1985) Predation on fish eggs and larvae by pelagic cnidarians and ctenophores. Bull Mar Sci 37:739-755

Rideout RM, Trippel EA, Litvak MK (2005) Effects of egg size, food supply and spawning time on early life history success of haddock Melanogrammus aeglefinus. Mar Ecol Prog Ser 285:169-180

Scheffer M, Baveco JM, DeAngelis DL, Rose KA, van Nes EH (1995) Super-individuals a simple solution for modeling large populations on an individual basis. Ecol Model 80:161-170 
Sheader M, Evans F (1975) Feeding and gut structure of Parathemisto gaudichaudi (Guerin) (Amphipoda, Hyperiidea). J Mar Biol Assoc UK 55:641-656

Sibunka JD, Johnson DL, Berriein PL (2006) Distribution and abundance of fish eggs collected during the GLOBEC broad-scale Georges Bank surveys, 1995-1999. NOAA Tech Memo NMFS-NE-199, 72p

Sullivan BK, Meise CJ (1996) Invertebrate predators of zooplankton on Georges Bank, 1977-1987. Deep-Sea Res II 43:1503-1519

Trippel EA, Chambers RC (1997) Introduction. In: Chambers RC, Trippel EA (eds) Early life history and recruitment in fish populations. Chapman and Hall, London, p xxi-xxxii

Visser AW (1997) Using random walk models to simulate the vertical distribution of particles in a turbulent water column. Mar Ecol Prog Ser 158:275-281

Werner FE, Page FH, Lynch DR, Loder JW, Lough RG, Perry RI, Greenberg DA, Sinclair M (1993) Influences of mean advection and simples behavior on the distribution of cod and haddock early life stages on Georges Bank. Fish Oceanogr 2:43-64

Werner FE, Perry RI, Lough RG, Naimie CE (1996) Trophodynamic and advective influences on Georges Bank larval cod and haddock. Deep-Sea Res II 43:1793 1822

Wiebe P, Beardsley R, Mountain D, Bucklin A (2002) U.S. GLOBEC Northwest Atlantic/Georges Bank Program. Oceanogr 15:13-29 
Wilcox JR, Jeffries HP (1974) Feeding habits of the sand shrimp Crangon septemspinosa. Bio Bull 146:424-434

Wright PJ, Gibb FM (2005) Selection for birth date in North Sea haddock and its relation to maternal age. J Anim Ecol 74:303-312

Yamashita Y, Aoyama T, Kitagawa D (1985) Laboratory studies of predation by the hyperiid amphipod Parathemisto japonica on larvae of the Japanese sand-eel Ammodytes personatus. Bull Jap Soc Sci Fish 50:1089-1093

Yen J (1987) Predation by a carnivorous marine copepod, Euchaeta norvegica Boeck, on eggs and larvae of the North Atlantic cod Gadus morhua L. J Exp Mar Biol Ecol $112: 283-296$ 


\section{Tables}

Table 4.1. Multiplication factor used to adjust copepod population model concentrations

$\begin{array}{cccc} & \text { Reference } & \text { Low Prey } 5 & \text { Low Prey } 10 \\ 1995 & 1.0 & 0.2 & 0.1 \\ 1998 & 5.0 & 1.0 & 0.5\end{array}$

Table 4.2. Total number of larvae hatched $\left(\times 10^{12}\right)$ by cohort.

$\begin{array}{ccccc} & \text { Feb } & \text { Mar } & \text { Apr } & \text { Total } \\ 1995 & 0.16 & 1.58 & 0.74 & 2.47 \\ 1998 & 1.46 & 4.15 & 5.98 & 11.58\end{array}$

Table 4.3. Mean time (d) to $12 \mathrm{~mm}$ and mean specific growth rate $\left(\% \mathrm{~d}^{-1}\right)$ from hatch until mean time to $12 \mathrm{~mm}$ in the reference case.

\begin{tabular}{ccccccc} 
& \multicolumn{2}{c}{ Feb } & \multicolumn{2}{c}{ Mar } & \multicolumn{2}{c}{ Apr } \\
1995 & 56 & 0.051 & 47 & 0.061 & 36 & 0.074 \\
1998 & 50 & 0.054 & 43 & 0.064 & 35 & 0.083
\end{tabular}

Table 4.4. Mean temperature $\left({ }^{\circ} \mathrm{C}\right)$ experienced by larvae from hatch until mean time to $12 \mathrm{~mm}$ in the reference case.

$\begin{array}{cccc} & \text { Feb } & \text { Mar } & \text { Apr } \\ 1995 & 7.8 & 7.9 & 8.5 \\ 1998 & 6.5 & 7.1 & 8.1\end{array}$


Table 4.5. Mean Pseudocalanus spp. concentration (no. $\mathrm{m}^{-3}$ ) of the grouped developmental stages experienced by larvae from hatch until mean time to $12 \mathrm{~mm}$ for each cohort and year in the reference case.

\begin{tabular}{lccccccc} 
& \multicolumn{3}{c}{1995} & & \multicolumn{3}{c}{1998} \\
\cline { 2 - 4 } \cline { 6 - 8 } Nauplii & Feb & Mar & Apr & & Feb & Mar & Apr \\
Copepodites & 210 & 704 & 806 & & 593 & 2003 & 2427 \\
Adults & 82 & 79 & 485 & & 220 & 349 & 1860 \\
Total & 15 & 32 & 24 & & 52 & 86 & 94 \\
& 307 & 815 & 1315 & & 865 & 2439 & 4380
\end{tabular}

Table 4.6. Total number of surviving larvae $\left(\times 10^{10}\right)$ by cohort in the reference case.

$\begin{array}{lllcl} & \text { Feb } & \text { Mar } & \text { Apr } & \text { Total } \\ 1995 & 0.56 & 7.00 & 6.03 & 13.59 \\ 1998 & 2.05 & 8.50 & 19.69 & 30.25\end{array}$




\section{Figures}

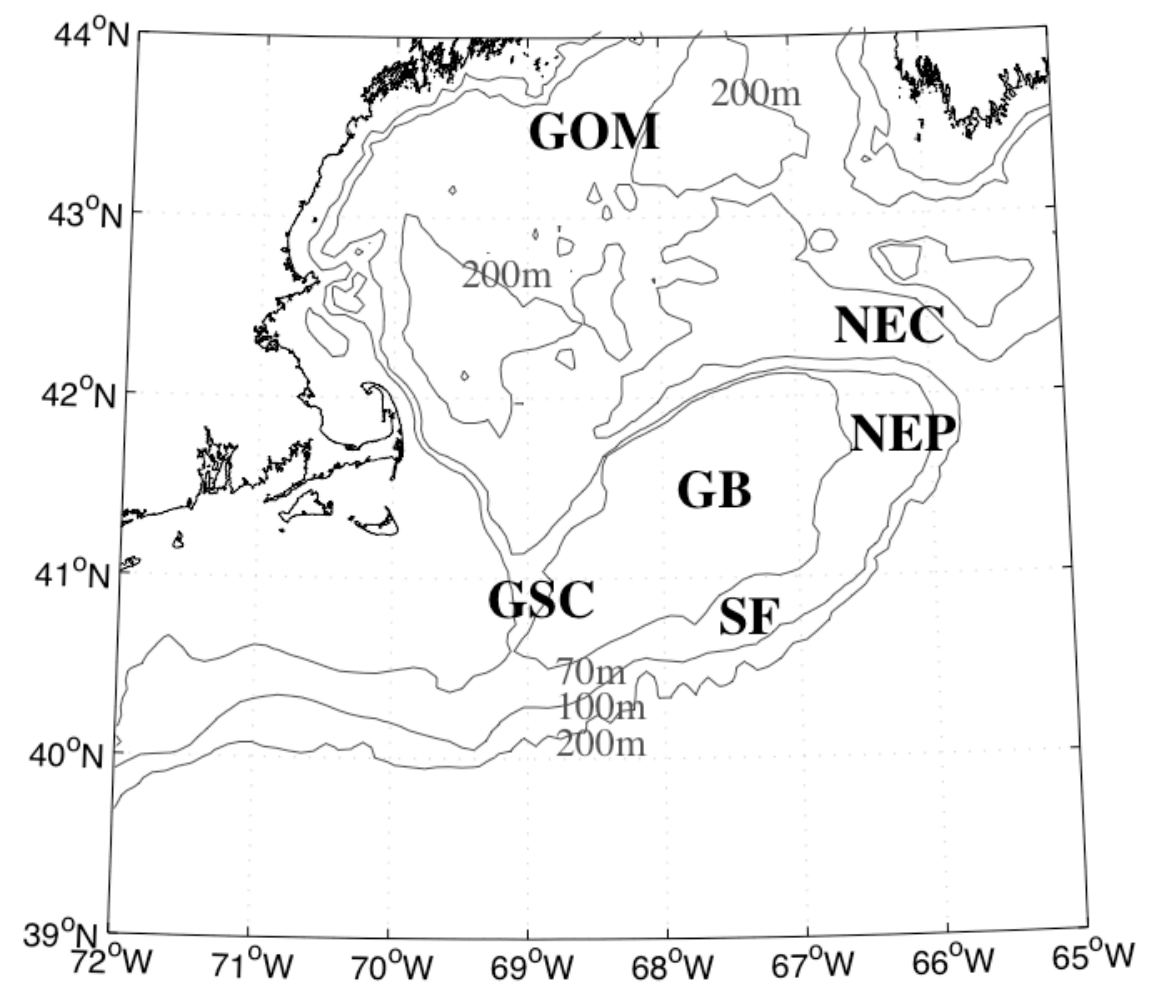

Figure 4.1. Map of the Gulf of Maine (GOM) and Georges Bank (GB) with the subregions: Northeast Channel (NEC), Northeast Peak (NEP), Southern Flank (SF), Great South Channel (GSC). 

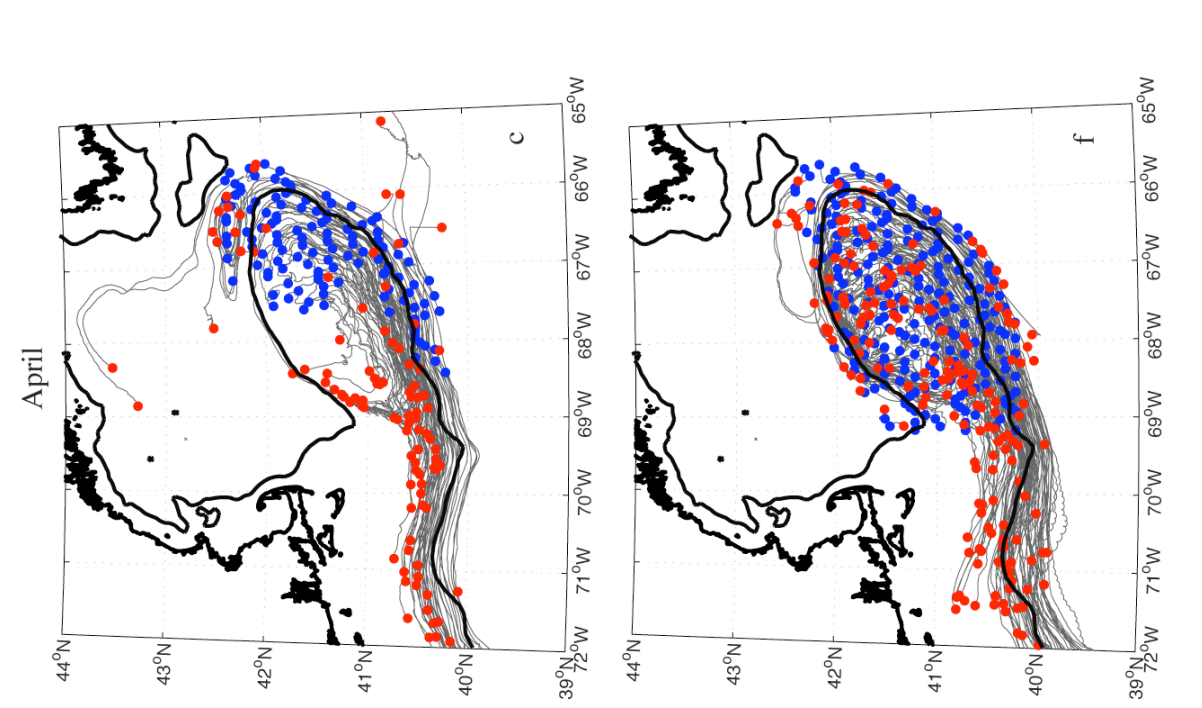

苾

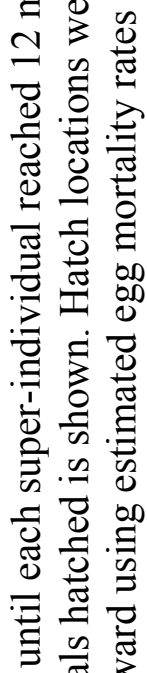
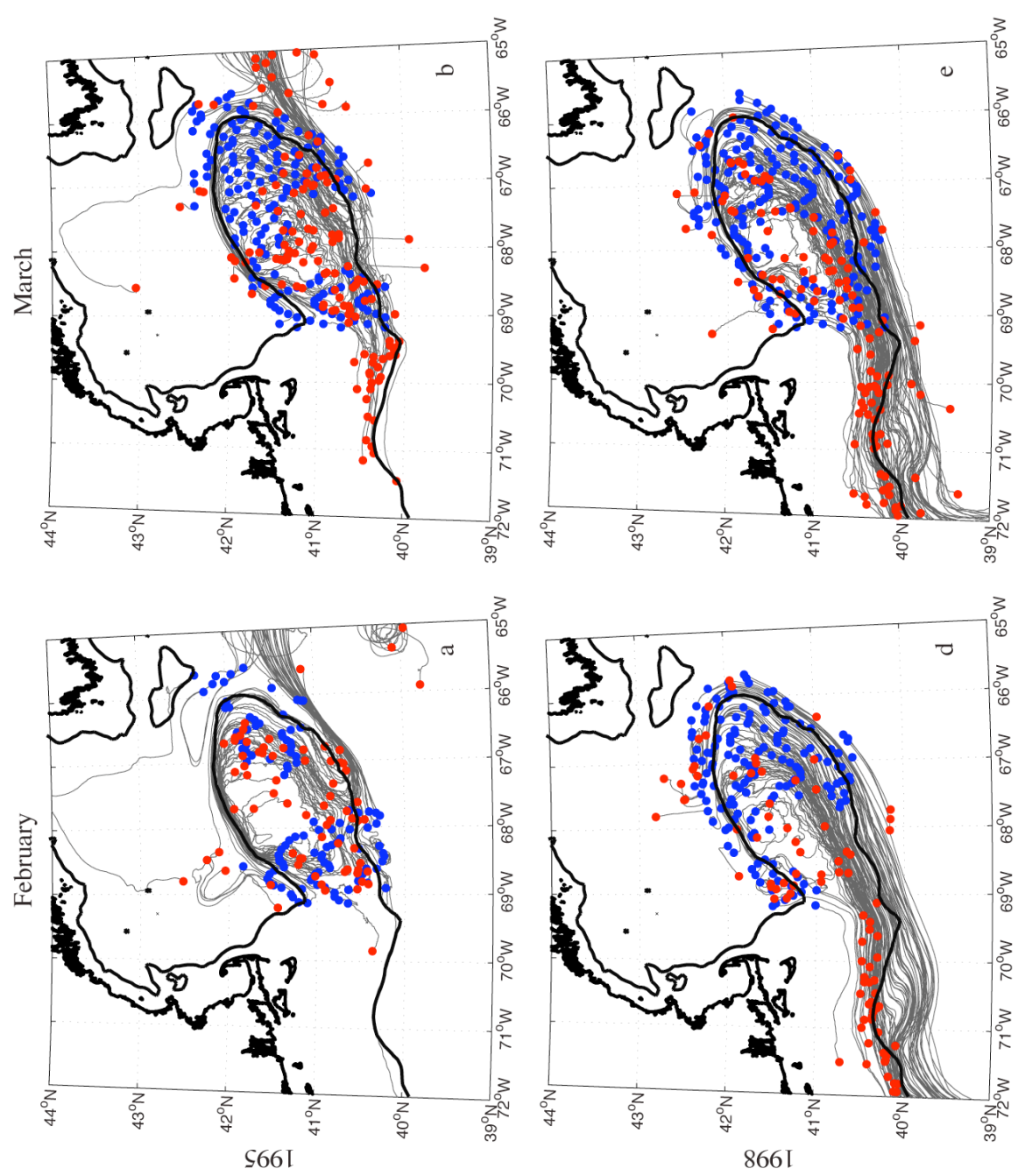

(ิ) 롤

윰 흥

응 웡

리용

융 을 잉

胥 0 ᄋ

प্

휴 ग

ลิษ

등 光主

ชิ

ฮั)

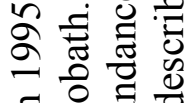

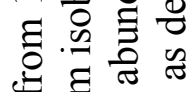

เి 8 잉

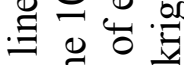

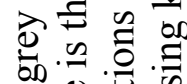

ब

包

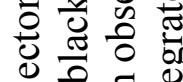

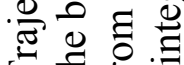

E曰

ํ.

음

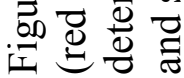



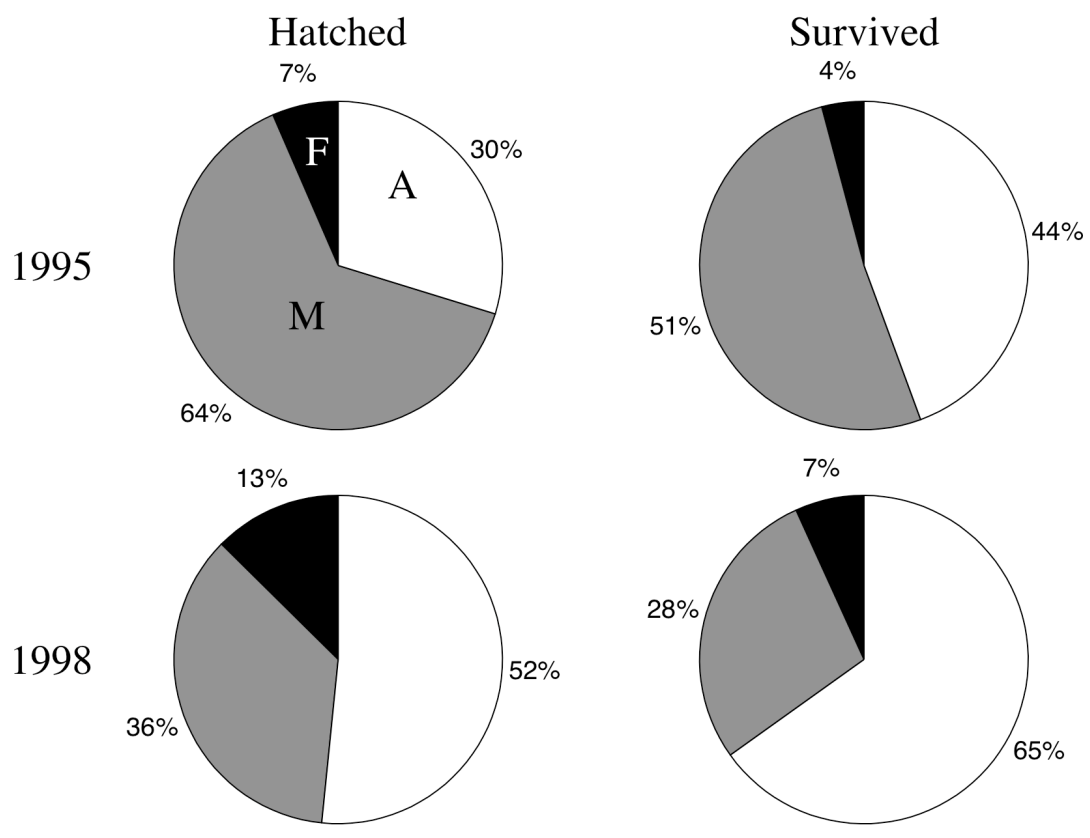

Figure 4.3. Percent contributed by each cohort to the total number of individuals hatched (left) or survived (right). F - February (black), M - March (gray), A - April (white). 


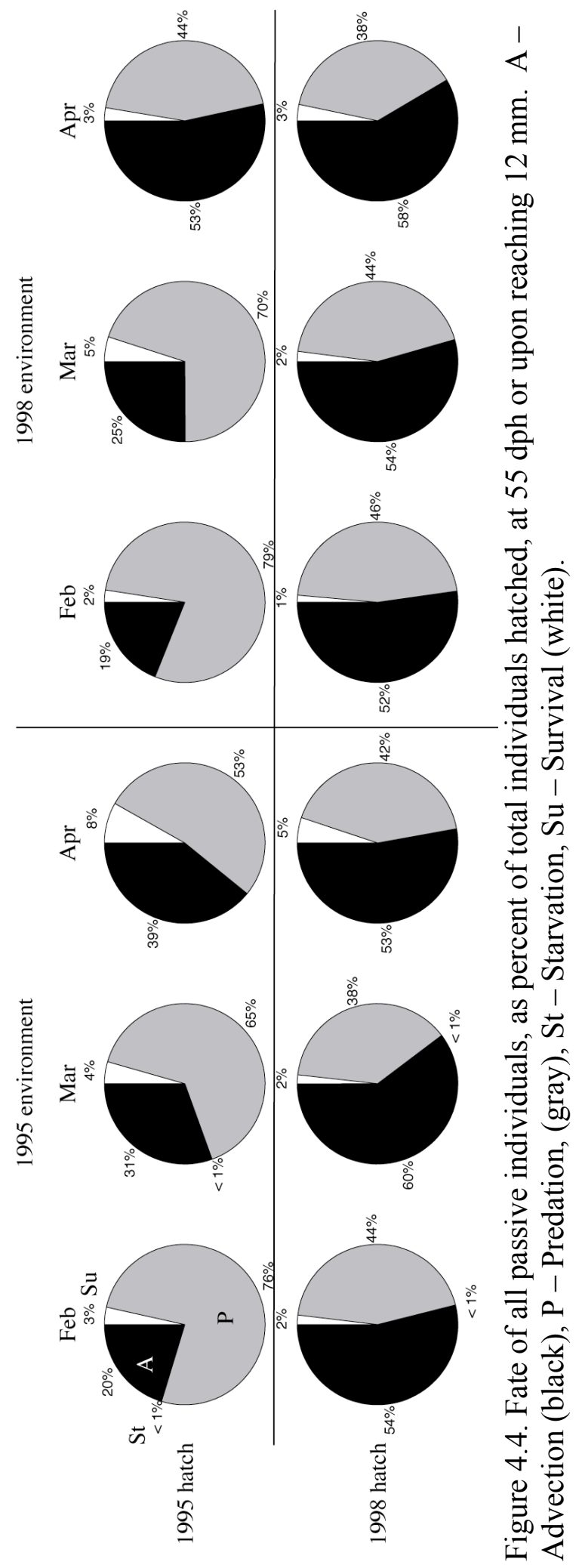



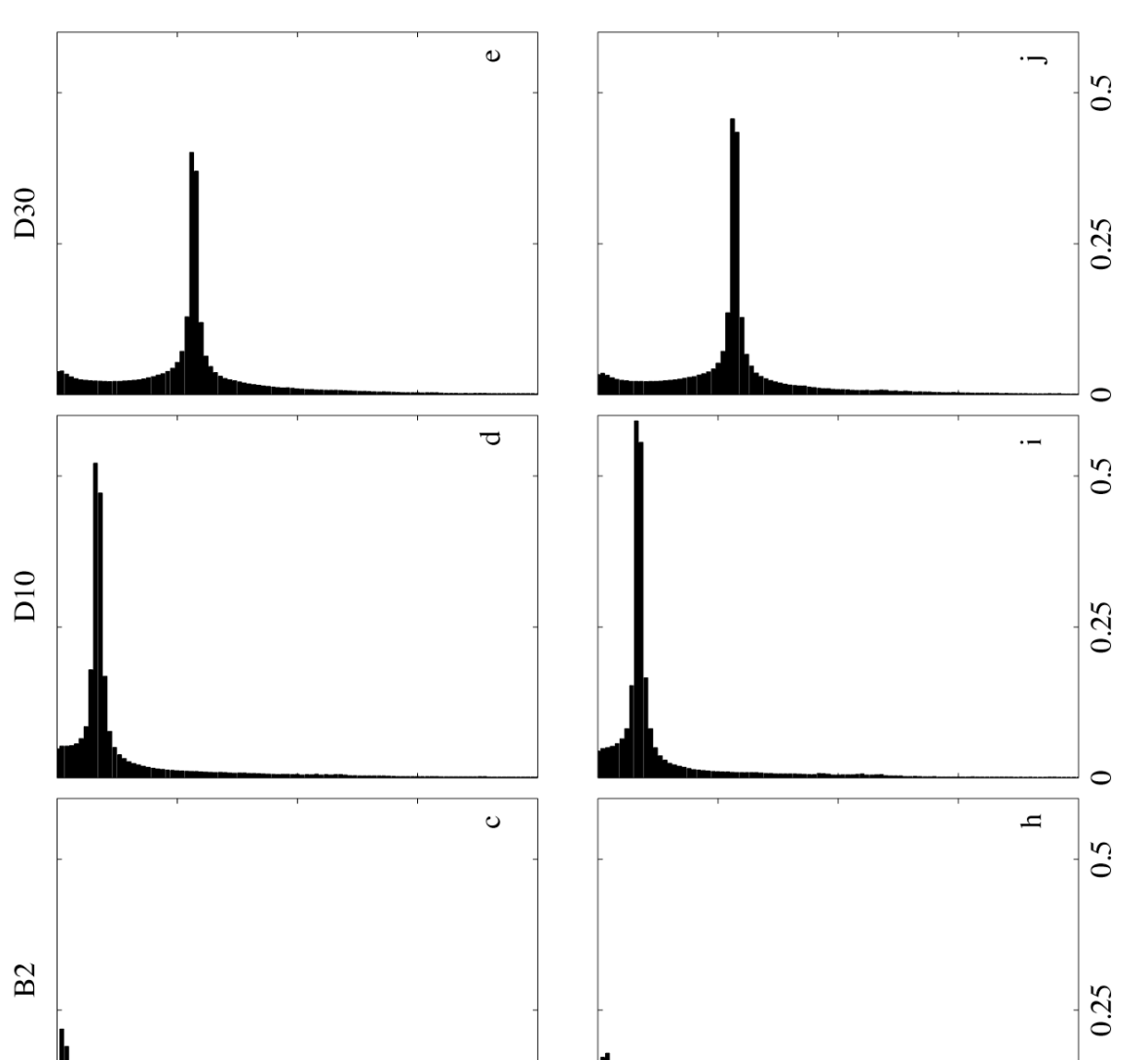

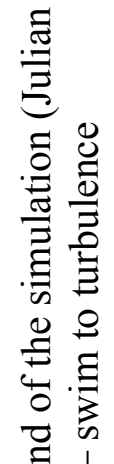
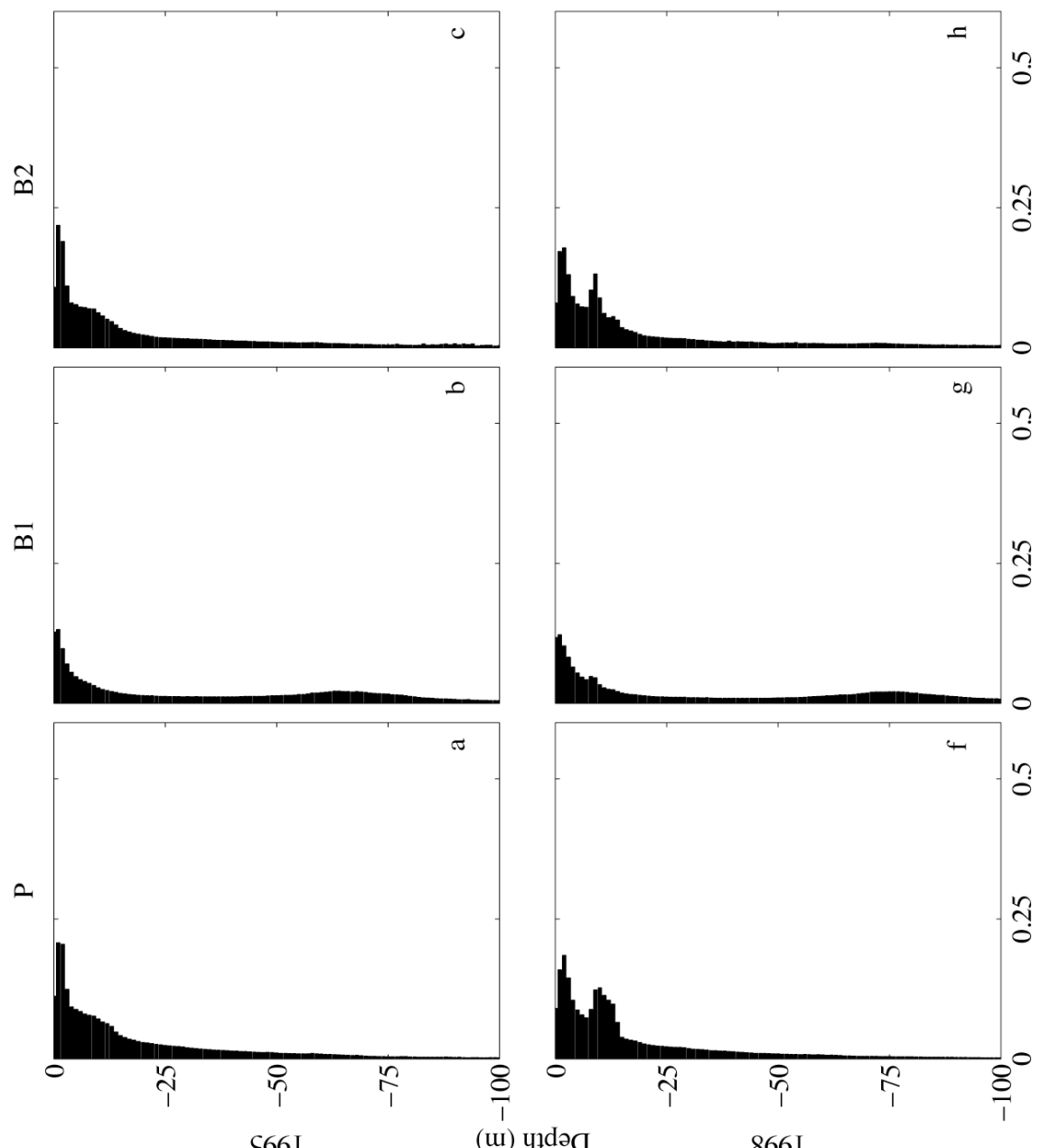

व ।

$\cong \approx$

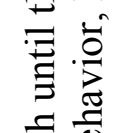

ग्ञ

콩

(을

눙

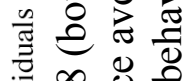

- 0

न बे छ

궁ㅇ

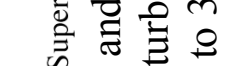

पे 2 I

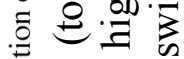

造

बूे

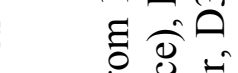

过

氬

记

.尹口

เป็

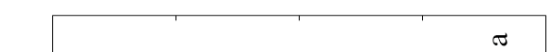

일

क 2 .

4.

든

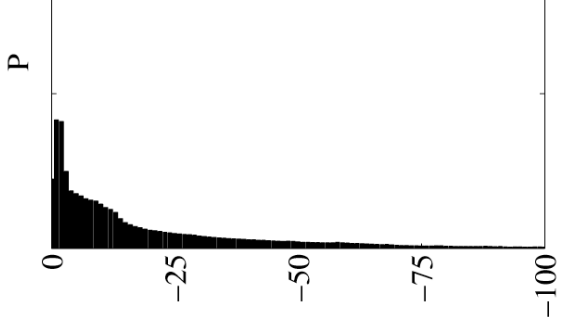

S66I

(แ) पıdəવ

$866 \mathrm{I}$

항 훙

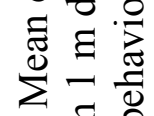

棺 $\Xi$

ๆชู ฏ

을

的令. 


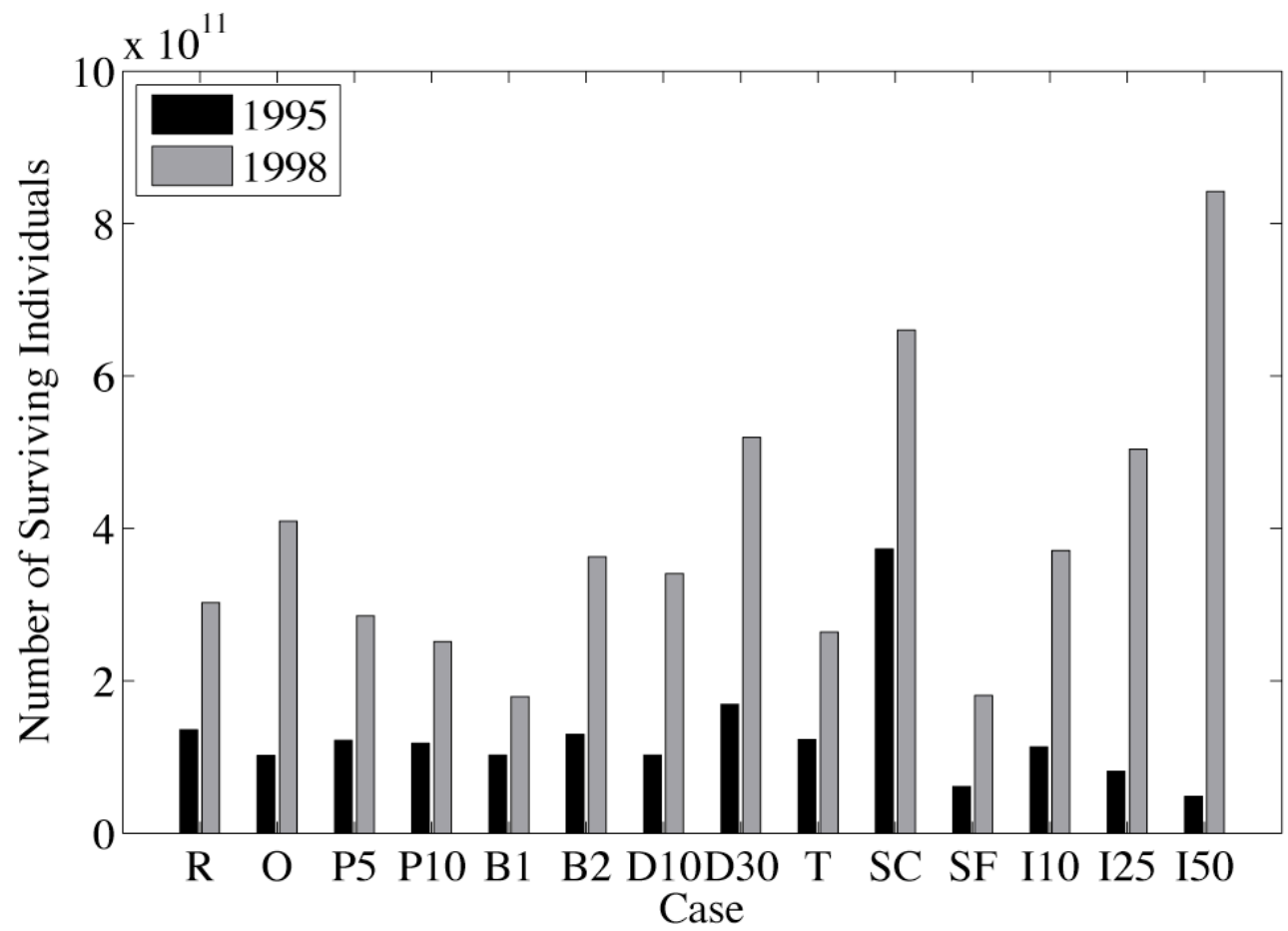

Figure 4.6. The total number of surviving individuals hatched in 1995 and 1998 for all fourteen cases. $\mathrm{R}$ - reference, $\mathrm{O}$ - opposite environment, P5 - low prey 5, P10 - low prey 10, B1 - high turbulence avoidance behavior, B2 - swim to low turbulence minimum behavior, D10 - swim to $10 \mathrm{~m}$ behavior, D30 - swim to $30 \mathrm{~m}$ behavior, T - temperaturedependent predation, SC - spatially-dependent high crest predation, SF - spatiallydependent high flank predation, I10 - interannually varying predation $\pm 10 \%, \mathrm{I} 25-$ interannually varying predation $\pm 25 \%$, I50 - interannually varying predation $\pm 50 \%$. 


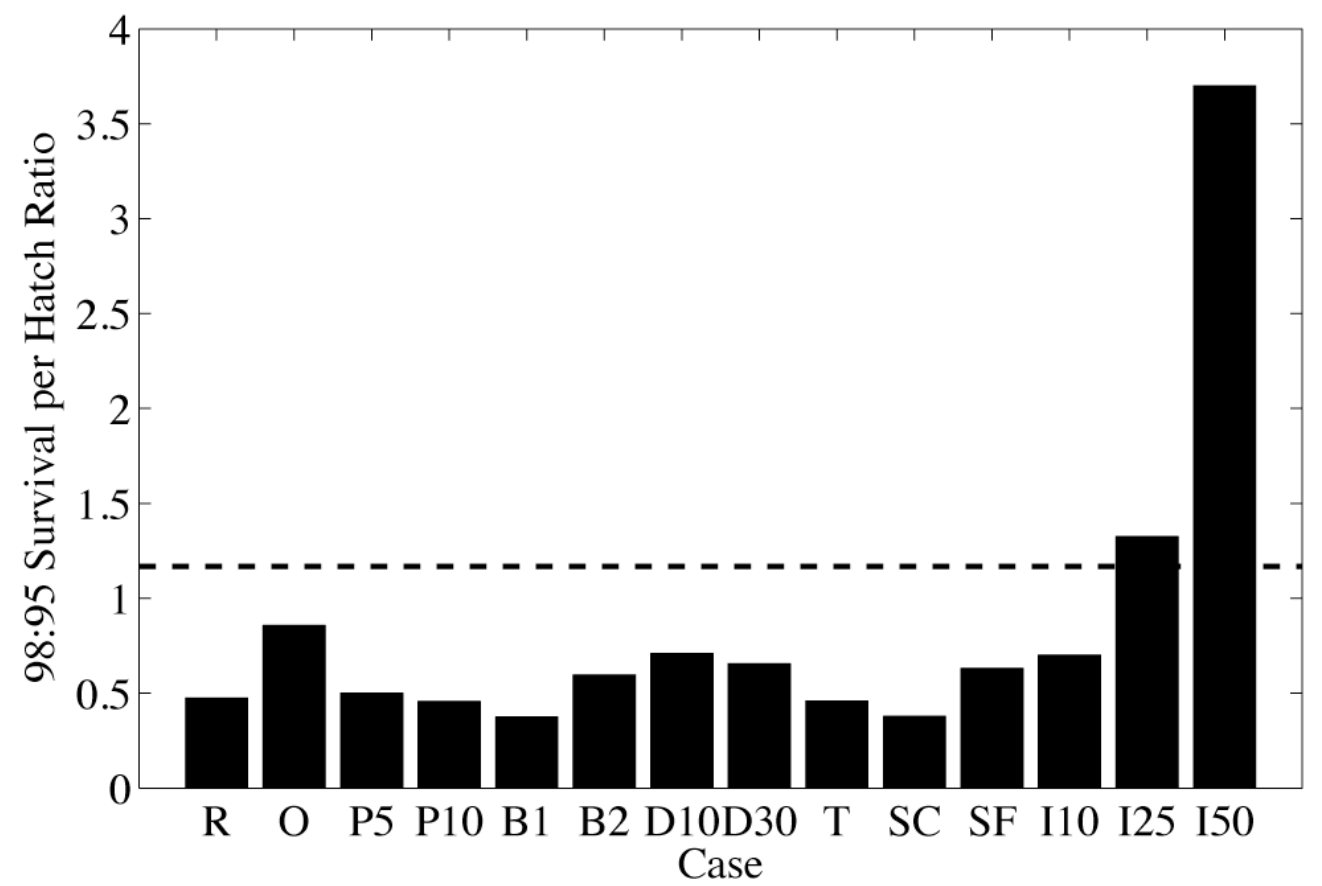

Figure 4.7. 1998:1995 ratio of the number of survivors per hatched larva. The dashed line at 1.17 represents the calculated 1998:1995 ratio of the number of recruits per hatch from Mountain and Kane (2010). R - reference, O - opposite environment, P5 - low prey 5 , P10 - low prey 10, B1 - high turbulence avoidance behavior, B2 - swim to low turbulence minimum behavior, D10 - swim to $10 \mathrm{~m}$ behavior, D30 - swim to $30 \mathrm{~m}$ behavior, $\mathrm{T}$ - temperature-dependent predation, $\mathrm{SC}$ - spatially-dependent high crest predation, $\mathrm{SF}$ - spatially-dependent high flank predation, I10 - interannually varying predation $\pm 10 \%$, I 25 - interannually varying predation $\pm 25 \%$, I50 - interannually varying predation $\pm 50 \%$. 

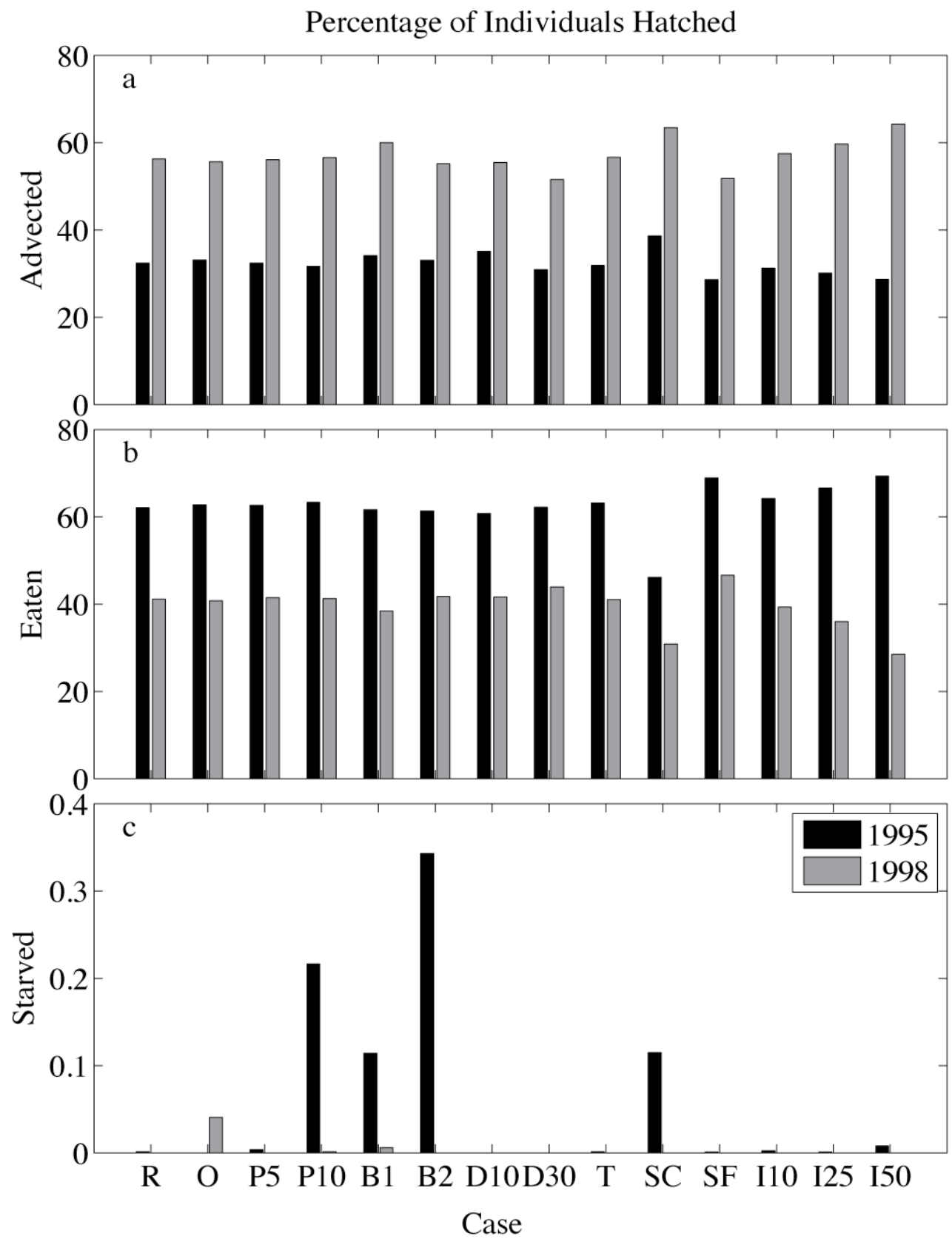

Figure 4.8. The percentage of individuals hatched that were lost to (a) advection, (b) predation, and (c) starvation in 1995 and 1998. Note difference in y-axis scale for starved. $\mathrm{R}$ - reference, $\mathrm{O}$ - opposite environment, P5 - low prey 5, P10 - low prey 10, B1 - high turbulence avoidance behavior, B2 - swim to low turbulence minimum behavior, D10 - swim to $10 \mathrm{~m}$ behavior, D30 - swim to $30 \mathrm{~m}$ behavior, T - temperaturedependent predation, SC - spatially-dependent high crest predation, SF - spatiallydependent high flank predation, I10 - interannually varying predation $\pm 10 \%, \mathrm{I} 25-$ interannually varying predation $\pm 25 \%$, I50 - interannually varying predation $\pm 50 \%$. 

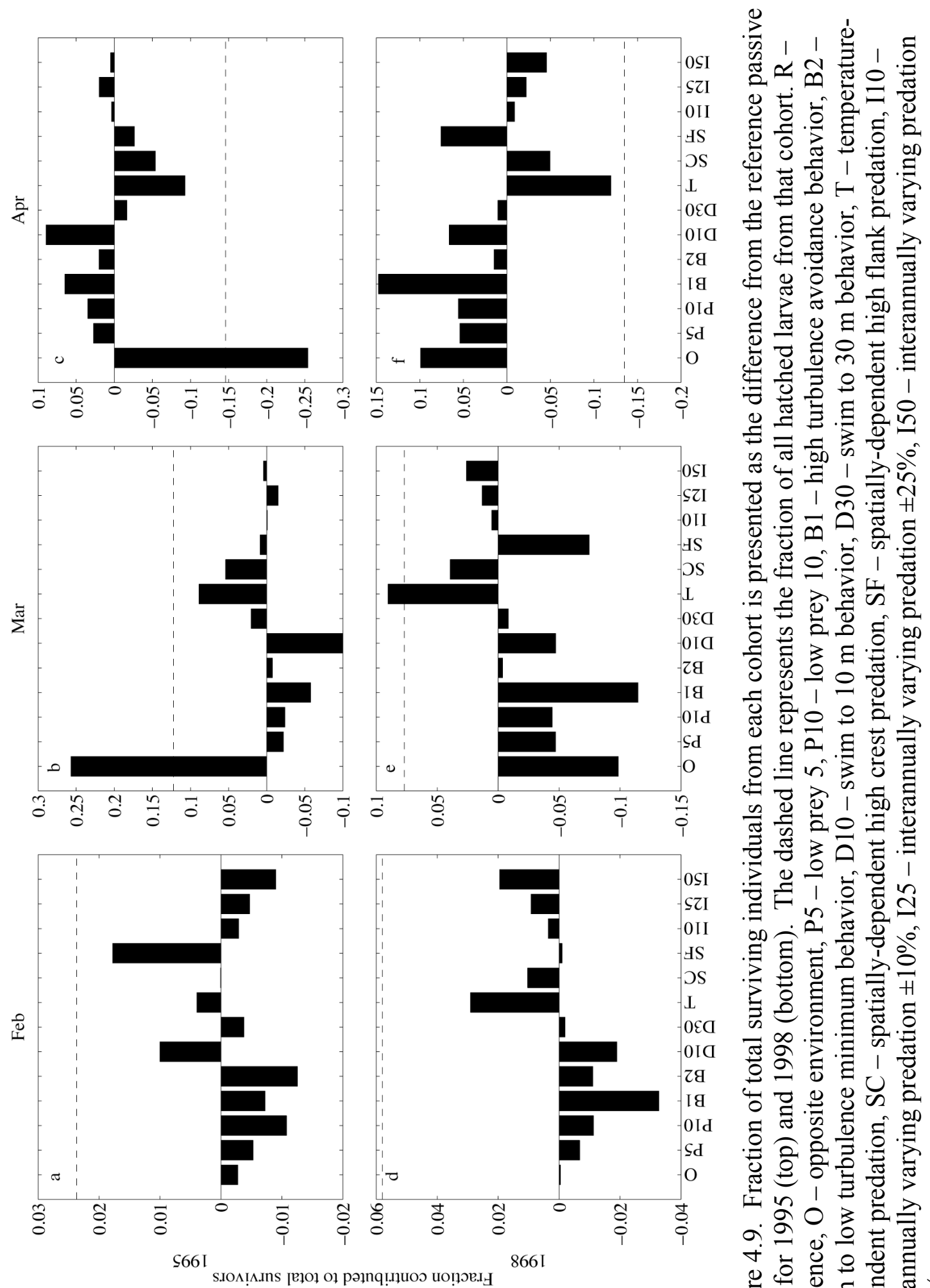

万ृ $>$ 으미

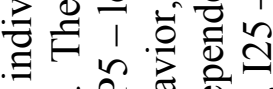

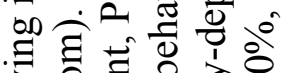

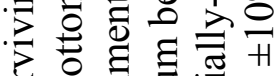

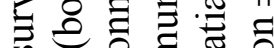
क

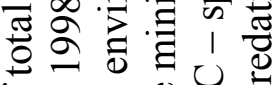
t) 00

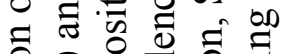

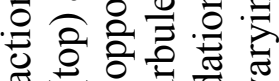
Tं ๙ 200 을 +े 원

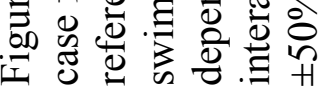




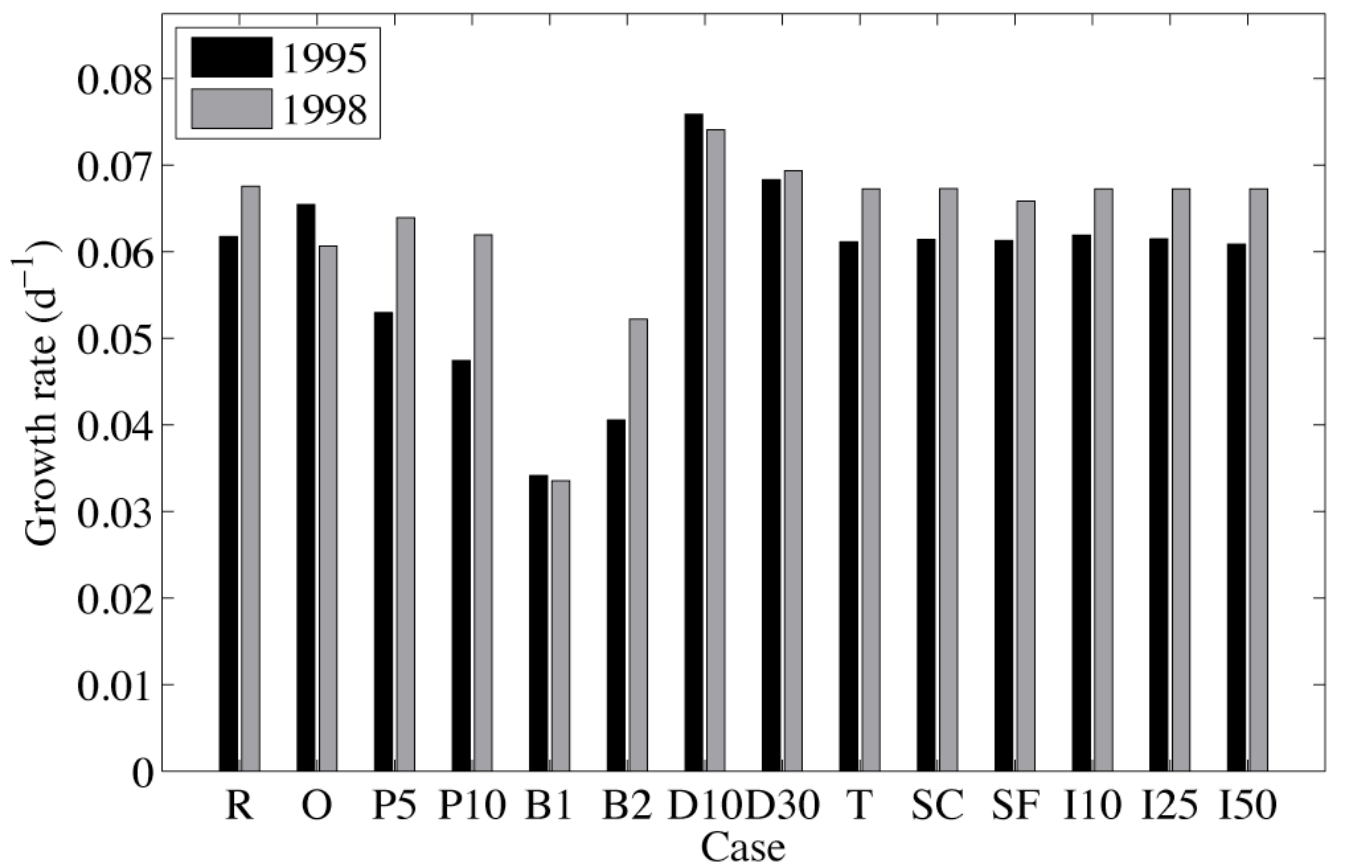

Figure 4.10. Mean specific growth rate $\left(\% \mathrm{~d}^{-1}\right)$ of larvae from hatch in 1995 and 1998 until mean time to $12 \mathrm{~mm}$. $\mathrm{R}$ - reference, $\mathrm{O}$ - opposite environment, $\mathrm{P} 5$ - low prey 5 , P10 - low prey 10, B1 - high turbulence avoidance behavior, B2 - swim to low turbulence minimum behavior, D10 - swim to $10 \mathrm{~m}$ behavior, D30 - swim to $30 \mathrm{~m}$ behavior, $\mathrm{T}$ - temperature-dependent predation, $\mathrm{SC}$ - spatially-dependent high crest predation, $\mathrm{SF}$ - spatially-dependent high flank predation, I10 - interannually varying predation $\pm 10 \%$, I 25 - interannually varying predation $\pm 25 \%$, I50 - interannually varying predation $\pm 50 \%$. 


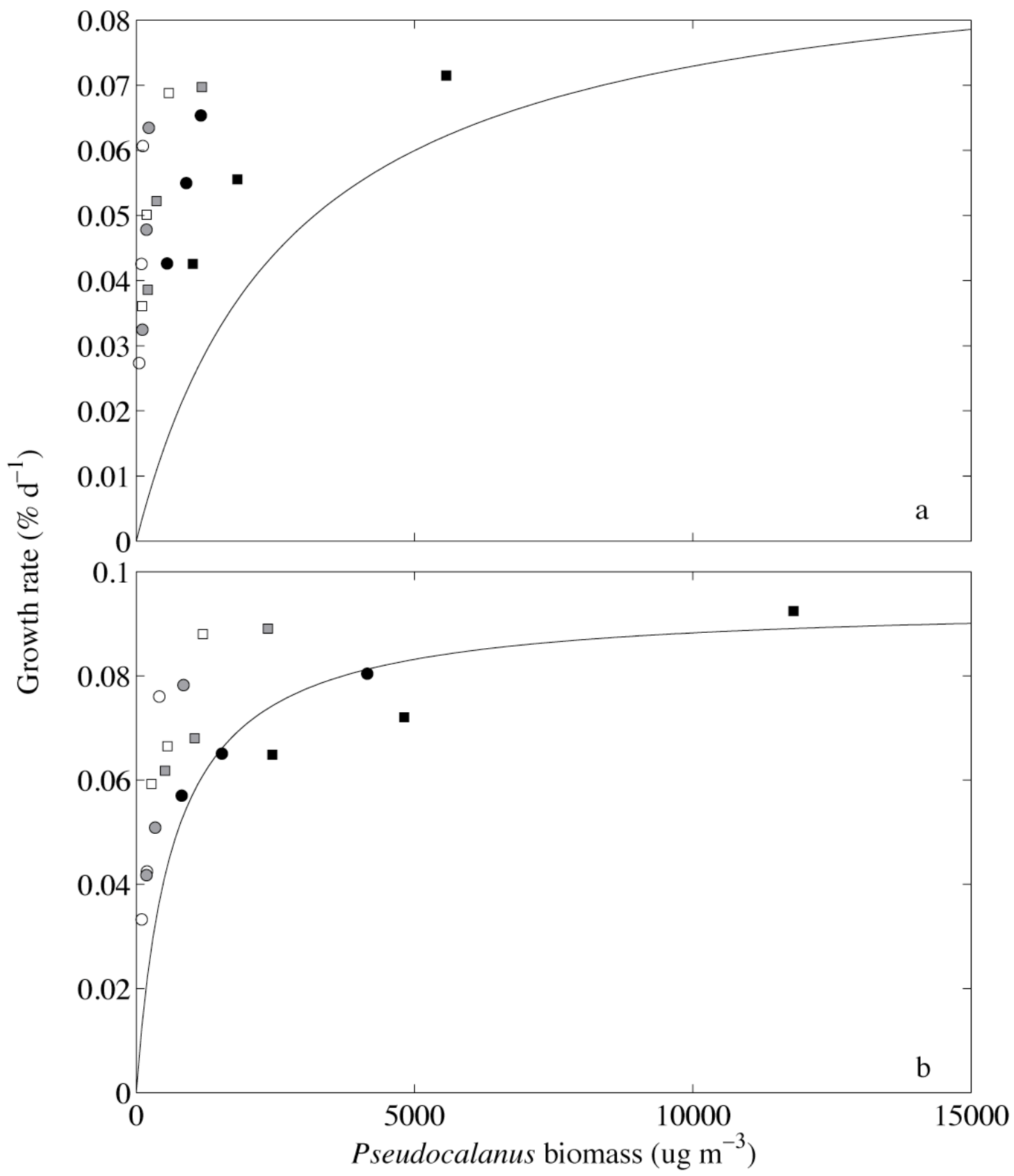

Figure 4.11. Comparison of model growth rates and prey concentrations to Buckley \& Durbin (2006) derived curves for (a) 5-7 mm and (b) 7-12 mm larvae. (•)1995 reference,

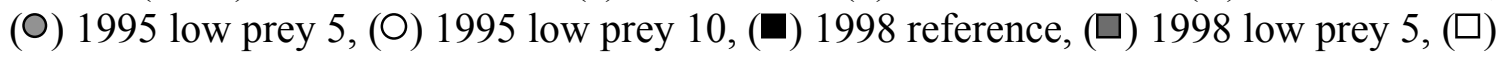
1998 low prey 10. 


\section{Mysids}

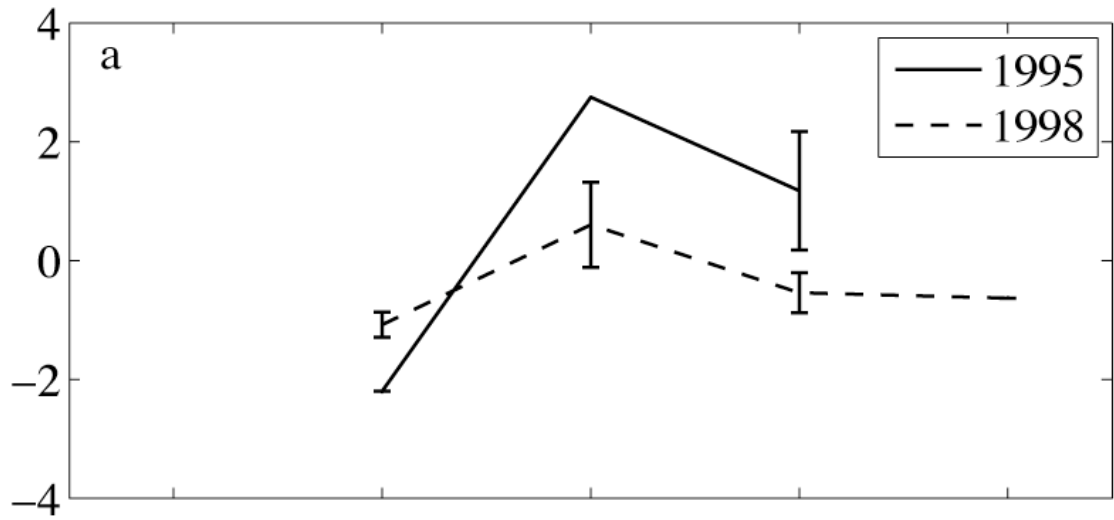

Siphonophores
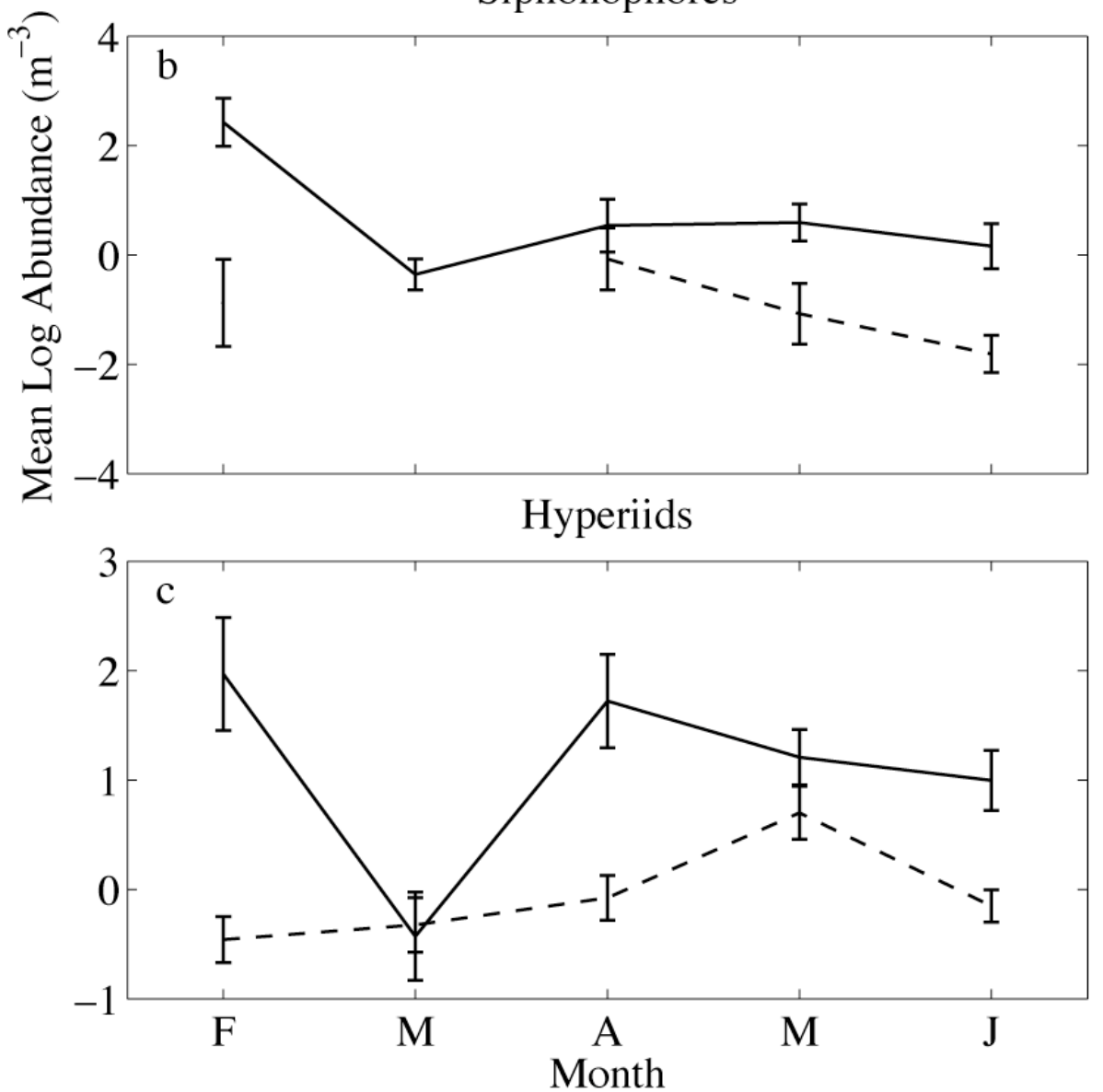

Figure 4.12. Mean log abundance and standard errors $\left(\mathrm{m}^{-3}\right)$ of the potential predators (a) mysid shrimp, (b) siphonophores, and (c) hyperiid amphipods on Georges Bank in 1995 and 1998. 


\section{Chapter 5}

\section{Conclusions from individual-based modeling of}

\section{larval haddock on Georges Bank}

\subsection{Thesis Summary}

The goal of this thesis was to investigate the processes affecting larval survival and thus recruitment success of the haddock population on Georges Bank. Focus was placed on the feeding and vertical behavior of larval haddock, which affect starvation, growth, predation, and physical transport.

\subsubsection{Foraging model}

The feeding model of Chapter 2 revealed that differences between larval haddock and cod prey selection are not large. Similar to observations of gut contents from fieldcollected larvae (Kane 1984, Lough \& Mountain 1996), modeled cod larvae ate larger and later developmental stages of copepod prey than haddock of the same length as a result of their bigger mouths. Additionally, the metabolic requirements of haddock are higher than those of cod, resulting in slower modeled growth rates when the same amount 
of food was available. Prey selection proved rather insensitive to changes in the pausetravel foraging behavior, suggesting that the parameters measured for larval cod are sufficient in models for haddock.

The modeling results of Chapter 2 support observations that prey preference of larval fish varies by copepod species, and is not solely dependent on the predator-prey size relationship (Munk 1997). By adding species-specific behavioral characteristics of the four main copepod prey species Calanus finmarchicus, Pseudocalanus spp., Oithona similis., and Centropages typicus, the mechanistic feeding model was able to resolve the discrepancies between previous prey selection models (Kristiansen et al. 2009a) and observations, particularly that $C$. typicus is found less often in the guts of larval haddock and cod than its abundance and length would predict (Kane 1984, Heath \& Lough 2007). Though encounter rate is important, the results of the mechanistic foraging model imply that the species and stages of copepods available to larval fish are determined by the escape abilities of the copepods. The prey that will be highly preferred, for example Pseudocalanus spp. by larval haddock, is one that has weak escape abilities, a size smaller than the mouth gape of the fish, and high population densities.

\subsubsection{Vertical behavior model}

Chapter 3 revealed that haddock larvae have rather weak swimming abilities compared to the turbulent velocities on Georges Bank. As a result, larvae that directed their vertical swimming at random, with a speed inversely related to prey concentration, had very similar depth distributions, at least during the first 20 days post hatch in model 
simulations. It was during this time that predation rates were highest, setting the survival rate of the population. For these reasons, no parameterization of this swimming behavior was clearly better than the others. In contrast, when larvae used a directed vertical swimming behavior, they were able to overcome turbulence and different behavioral parameterizations resulted in changes in fitness. More individuals survived to the juvenile stage when they put more emphasis on avoiding visual predation than finding food.

Despite the fact that the individuals using the predation-avoidance directed swimming behavior had the highest fitness, the depth distribution produced by this behavior was not consistent with observations of larvae in the field. The disparity between observations and model results suggests that visual predation does not strongly influence the vertical behavior of larval haddock on Georges Bank. The observed nonrandom vertical distribution of haddock larvae (Lough 1984, Buckley \& Lough 1987, Lough \& Potter 1993) indicates that they have vertical behavior, while results from this modeling study imply that it must be directed in some way since the mechanism of spending more time handling food in regions of high prey was not able to reproduce the observed distributions.

\subsubsection{Three-dimensional coupled biological-physical model}

In Chapter 4, I created the first three-dimensional (3D) biophysical individualbased model (IBM) of larval haddock for Georges Bank to test why levels of larval haddock survival on Georges Bank were different in the years 1995 and 1998, thereby 
gaining insights into mechanisms controlling recruitment in fish populations. Advection, prey availability, hatch location, and vertical behavior were rejected as causes of the interannual variability. Changes to the predation rate produced the only model results that agreed with observations of higher survival per hatch of larvae in 1998, and with observations of the mean hatch date of survivors. These findings suggest that predation on larval haddock was greater in 1995 than 1998, possibly from the increased abundance of siphonophores and hyperiid amphipods, and that predation intensifies seasonally from both the increase in predator abundances and their metabolic demands. If these two years are representative of the Georges Bank haddock population, then model results can be extrapolated to conclude that interannual variability in haddock recruitment is dominated by predation during the larval stage.

\subsection{Significance}

This thesis is the culmination of much of the work proposed by the U.S. GLOBEC Northwest Atlantic/Georges Bank (GLOBEC GB) program (Wiebe et al. 2002). In it, I used data on copepod abundances, larval fish gut contents, larval fish vertical distributions, and predator abundances collected during the 1995-1999 GLOBEC GB field sampling. Additionally, I utilized the FVCOM Eulerian and Lagrangian particle-tracking models (Chen et al. 2006), and a Pseudocalanus spp. population model (Ji et al. 2009), all of which were developed at least in part to study the population dynamics of the dominant copepod species and fishes Atlantic cod and haddock, with respect to physical and biological changes of their habitat. My thesis specifically 
addressed the aim of GLOBEC GB Phase $4 \mathrm{~b}$ to better understand the recruitment of haddock with the creation of biophysical models of fish larvae.

The foraging model identified that species-specific differences in swimming and escape behaviors of copepod prey are important in determining prey selection. Current models of larval fish have moved beyond temperature-dependent growth rates and include more realistic growth models that incorporate ingestion (e.g. Kühn et al. 2008, Kristiansen et al. 2009b). Size-structured prey selection has been recommended for these models (Daewel et al. 2008), however, the results of my thesis suggest that size alone cannot predict the availability of prey to larval fish. The appeal of using size-structured prey fields is that they are simpler in complex 3D biophysical models. This approach will lead to inaccurate estimates of prey availability. Models that include the composition of species in the prey community are needed to account for species-specific encounter rates and capture probabilities.

Incorporating differences in prey selection will be crucial for studying climate variability. Copepod communities have changed with temperature and salinity in the North Sea (Beaugrand et al. 2003, Pitois \& Fox 2008) and on Georges Bank (Kane et al. 2007, Mountain \& Kane 2010). The inclusion of species composition and their ability to be encountered and captured by larval fish should forecast how larval fish survival will be affected by varying copepod community structure better than studying the changes in size and abundance alone. This may be of particular importance to the Georges Bank haddock population, as it is predicted that increasing temperatures with climate change will lead to a northward shift of $C$. typicus, causing it to be the dominant copepod in the 
Gulf of Maine region (Stegert et al. 2010). The dominance of C. typicus could be detrimental to larval haddock because they are more evasive than the preferred prey Pseudocalanus spp., which is projected to experience declines in both abundance and temporal overlap with feeding haddock larvae. This species-specific predator-prey interaction together with climate-induced shifts in prey species composition could lead to a collapse of the haddock fishery on Georges Bank, regardless of management strategy. This result provides an excellent example of why the GLOBEC species-level approach is critical for understanding marine ecosystems and fisheries ecology.

Observations of the vertical distribution of haddock larvae suggest that feeding is of greater consequence than avoiding visual predation, thus the haddock larvae are centered around the depths with highest prey biomass (Lough 1984, Buckley \& Lough 1987, Lough \& Potter 1993). Modeling results indicated the opposite, that avoiding visual predation produced greater fitness than seeking food. However, in these model simulations the effective prey densities were high due to high turbulent velocities that increased encounter rates, yet did not act to disperse the prey as they would in the field. Thus it would seem that avoiding visual predation is only important when larvae are not food-limited. There is some evidence that older larvae $(>9-13 \mathrm{~mm})$ avoid visual predators with diel vertical migrations such that they reside below the pycnocline during the day and move up into it at night (Lough \& Potter 1993).

The lack of visual predation pressure as a selection force on the vertical behavior of haddock larvae is consistent with the hypothesized significant predators on Georges Bank in 1995. Predation by the piscivorous fishes herring and mackerel is not regularly 
present and the stochastic overlap of these fish populations with larval haddock probably prevents the haddock population from adapting to it. On the other hand, invertebrate predation is a constant threat on Georges Bank. Cnidarians, such as siphonophores, are non-visual predators (Purcell 1985), and though hyperiid amphipods do use vision, they also feed in the dark (Yamashita et al. 1984).

Since invertebrate predators are present throughout the water column, there is no vertical refuge for the fish larvae and consequently their vertical behavior orients them towards finding prey instead. The inability of larval haddock to avoid their predators spatially further supports the hypothesis that they avoid them in time (Lapolla \& Buckley 2005, Buckley \& Durbin 2006, Buckley et al. 2010). The larvae spawned early in the season are able to grow to an invulnerable size by the time predation rates reach their peak, thereby contributing more to the surviving year-class than larvae hatched later in the year. This hypothesis was verified by using temperature-dependent predation rates in the 3D model of larval haddock.

Predation has long been hypothesized as one of the drivers of fish recruitment variability (Bailey \& Houde 1989). Direct predation is difficult to study, but it is supported by mesocosm studies that show lower mortality rates of larvae when predators were excluded in comparison with the mortality rates calculated for larvae in the field (Bailey \& Houde 1989). Another line of supporting evidence is that the non-feeding stages of fish (eggs and yolk-sac larvae) are the ones with the highest mortality rates, which negates starvation as the cause (Bailey \& Houde 1989). Neither type of these studies is able to reject advection as the dominant source of mortality, which is where 
hydrodynamic models are useful. The coupled biophysical model of larval haddock on Georges Bank eliminated both advection and starvation in favor of predation as the main cause of larval survival differences between 1995 and 1998.

\subsection{Future Directions}

This thesis has identified two large gaps in our knowledge of larval fish and points towards areas of future research.

\subsubsection{Larval fish vertical behavior}

The first knowledge gap is on the vertical swimming behavior of larvae and the mechanism behind it. In stratified conditions the maximum abundance of haddock larvae often coincides with the depth of maximum prey density and the pycnocline (Lough 1984, Buckley \& Lough 1987, Lough \& Potter 1993), though it is not known how the larvae find this depth. It has been postulated from the small perception volume of the larvae that they rarely encounter more than one prey item at a time, thus they do not experience prey gradients for making decisions. Davis et al. (1991) demonstrated that the use of gradients is not necessary for concentrating individuals around a resource.

Individuals can aggregate around a resource simply by spending more time in the regions with higher prey density. This mechanism would arise naturally by larvae spending less time swimming and more time handling prey in areas of high prey abundance. However, this mechanism was unable to concentrate haddock larvae around a layer of prey because random orientation combined with their low swimming speeds was not enough to 
overcome the turbulent dissipation rates estimated for Georges Bank. Then again, this mechanism cannot be rejected completely since it may succeed if dissipation rates are one to two orders of magnitude lower as some field observations suggest.

Assuming that the higher turbulent dissipation rates are accurate, larval haddock must be using a directed vertical swimming behavior to orient towards prey. Continuing with the supposition that larvae cannot detect gradients, larvae could direct their swimming by using local information on light and turbulence. Light decreases with depth, while turbulent dissipation rates are highest at the surface and bottom of the water column on Georges Bank. By swimming down under high turbulence and high light conditions, and up under high turbulence and low light conditions, larvae should reach a subsurface location with low turbulence corresponding with the pycnocline, the region associated with high prey abundance. Such a mechanism was tested in the $3 \mathrm{D}$ simulations, but did not prove very successful as it led to some larvae starving at depths where either prey concentrations or light levels were too low, or both. This mechanism still has potential, possibly with different parameterizations, and requires further study.

It is not implausible for larval haddock to detect gradients in prey, temperature, or turbulence, which would lead them to the thermo/pycnocline and depth of high prey density. Conversely, larval vertical position may be controlled by their buoyancy and not active behavior (Sclafani et al. 1993). Alternatively, larvae may be inhabiting certain depths not because of high prey availability, but because they lead to greater retention on Georges Bank. For example, larvae that swam to $30 \mathrm{~m}$ in the 3D simulations had lower advective losses. It would be valuable to determine which selection pressure is 
responsible for the vertical distribution of larvae, and to identify how larvae are detecting these depths. Work with vertical models of behavior needs to be continued with different behaviors and alternate parameterizations of those behaviors, as well as with temporally varying prey fields and environmental conditions. Additionally, laboratory studies should be conducted to test which biological and environmental variables larvae can sense, and how their vertical position responds to them. Though prescribing depths for particles in coupled biophysical models is better than assuming passivity, we should strive to use mechanistic models of vertical position since only these will be able predict consequences should the system change from the state under which vertical position was originally studied.

\subsubsection{Predation mortality}

The second knowledge gap uncovered by this thesis is information about predation mortality. Much focus has been placed on bottom-up studies of zooplankton and fish larvae, whereas the GLOBEC GB program was designed to study both bottomup and top-down processes. The results of the 3D model stress the importance of predation and necessitate more top-down investigations. For one, we require more information on the spatial (horizontal and vertical) distributions of predators both seasonally and interannually to determine how they overlap with larval fish in both space and time. Further analysis of the GLOBEC GB net tow data will be helpful in this regard. Secondly, we need supplementary data on consumption rates and how they are affected by temperature. Further analysis of predator feeding studies carried out during 
GLOBEC GB is also recommended. Predation studies are difficult because of the low abundances of larval fish, patchiness of both larvae and their predators, rapid digestion of larvae, undersampling of large and fragile predators, potential for net feeding in field samples, and container effects in laboratory studies (Hunter 1984). Since fish larvae are often eaten incidentally, laboratory studies of consumption rates will not accurately reflect those of the ocean unless larvae are present in field concentrations and alternate prey types are available. Additional mesocosm studies may provide new insights into these processes.

This thesis, in conjunction with work by Mountain et al. (2008), has identified the sources of mortality responsible for the different recruitment levels of haddock on Georges Bank in 1995 and 1998: advection of the egg stages and predation of the larval stages. Future research should assess if these sources hold for other years, such as 1963, 1975, and 2003, which had very large year-classes of Georges Bank haddock. 


\section{References}

Bailey KM, Houde ED (1989) Predation on eggs and larvae of marine fishes and the recruitment problem. Adv Mar Biol 25:1-83

Beaugrand G, Brander KM, Lindley JA, Souissi S, Reid PC (2003) Plankton effect on cod recruitment in the North Sea. Nature 426:661-664

Buckley LJ, Durbin EG (2006) Seasonal and inter-annual trends in the zooplankton prey and growth rate of Atlantic cod (Gadus morhua) and haddock (Melanogrammus aeglefinus) larvae on Georges Bank. Deep-Sea Res II 53:2758-2770

Buckley LJ, Lough RG (1987) Recent growth, biochemical composition, and prey field of larval haddock (Melanogrammus aeglefinus) and Atlantic cod (Gadus morhua) on Georges Bank. Can J Fish Aquat Sci 44:14-25

Buckley LJ, Lough RG, Mountain D (2010) Seasonal trends in mortality and growth of cod and haddock larvae result in an optimal window for survival. Mar Ecol Prog Ser 405:57-69

Chen C, Cowles G, Beardsley RC (2006) An unstructured grid, finite-volume coastal ocean model: FVCOM User Manual. Second edition, SMAST/UMASSD Technical Report-06-0602, 315p

Davis CS, Flierl GR, Wiebe PH, Franks PJS (1991) Micropatchiness, turbulence and recruitment in plankton. J Mar Res 49:109-151

Daewel U, Peck MA, Schrum C, St. John MA (2008) How best to include the effects of climate-driven forcing on prey fields in larval fish individual-based models. J Plank Res 30:1-5 
Heath MR, Lough RG (2007) A synthesis of large-scale patterns in the planktonic prey of larval and juvenile cod (Gadus morhua). Fish Oceanogr 16:169-185

Hunter JR (1984) Inferences regarding predators on the early life stages of cod and other fishes. In: Dahl E, Danielssen DS, Moskness E, Solemdal P (eds) The propagation of cod Gadus morhua. Flødevigen rapportser I, p 533-562

Kane J (1984) The feeding habits of co-occurring cod and haddock larvae from Georges Bank. Mar Ecol Prog Ser 16:9-20

Kane J (2007) Zooplankton abundance trends on Georges Bank, 1977-2004. ICES J Mar Sci 64:909-919

Kristiansen T, Lough RG, Werner FE, Broughton E, Buckley LJ (2009a) Individualbased modeling of feeding ecology and prey selection of larval cod on Georges Bank. Mar Ecol Prog Ser 376:227-243

Kristiansen T, Vikebø F, Sundby S, Huse G, Fiksen Ø (2009b) Modeling growth of larval cod (Gadus morhua) in large-scale seasonal and latitudinal environmental gradients. Deep-Sea Res II 56:2001-20011

Kühn W, Peck MA, Hinrichsen H-H, Daewel U, Moll A, Pohlmann T, Stegert C, Tamm S (2008) Defining habitats suitable for larval fish in the German Bight (southern North Sea): an IBM approach using spatially- and temporally-resolved sizestructured prey fields. J Mar Sys 74:329-342

Lapolla A, Buckley LJ (2005) Hatch date distributions of young-of-year haddock Melanogrammus aeglefinus in the Gulf of Maine/Georges Bank region: implications for recruitment. Mar Ecol Prog Ser 290:239-249 
Lough RG (1984) Larval fish trophodynamic studies on Georges Bank: sampling strategy and initial results. In: Dahl E, Danielssen DS, Moskness E, Solemdal P (eds) The propagation of cod Gadus morhua. Flødevigen rapportser I, p 395-434

Lough RG, Mountain DG (1996) Effect of small-scale turbulence on feeding rates of larval cod and haddock in stratified water on Georges Bank. Deep-Sea Res II $43: 1745-1772$

Lough RG, Potter DC (1993) Vertical distribution patterns and diel migrations of larval and juvenile haddock Melanogrammus aeglefinus and Atlantic cod Gadus morhua on Georges Bank. Fish Bull 91:281-303

Mountain DG, Kane J (2010) Major changes in the Georges Bank ecosystem, 1980s to the 1990s. Mar Ecol Prog Ser 398:81-91

Mountain D, Green J, Sibunka J, Johnson D (2008) Growth and mortality of Atlantic cod Gadus morhua and haddock Melanogrammus aeglefinus eggs and larvae on Georges Bank, 1995 to 1999. Mar Ecol Prog Ser 353:225-242

Munk P (1997) Prey size spectra and prey availability of larval and small juvenile cod. J Fish Biol 51:340-351

Pitois SG, Fox CJ (2008) Empirically modeling the potential effects of changes in temperature and prey availability on the growth of cod larvae in UK shelf seas. ICES J Mar Sci 65:1559-1572

Purcell J (1985) Predation on fish eggs and larvae by pelagic cnidarians and ctenophores. Bull Mar Sci 37:739-755 
Sclafani M, Taggert CT, Thompson KR (1993) Condition, buoyancy and the distribution of larval fish: implications for vertical migration and retention. J Plank Res $15: 413-435$

Stegert C, Ji R, Davis C (2010) Influence of ocean warming on population growth rates in North Atlantic copepod species. Prog Oceanogr doi:10.1016/j.pocean.2010.09.013

Wiebe P, Beardsley R, Mountain D, Bucklin A (2002) U.S. GLOBEC Northwest Atlantic/Georges Bank Program. Oceanogr 15:13-29

Yamashita Y, Aoyama T, Kitagawa D (1985) Laboratory studies of predation by the hyperiid amphipod Parathemisto japonica on larvae of the Japanese sand-eel Ammodytes personatus. Bull Jap Soc Sci Fish 50:1089-1093 